1 
LIBRARY UNIVERSITY of CALFONMA

SAN DIEGO 
Catim Dober 
Digitized by the Internet Archive in 2007 with funding from Microsoft Corporation 
EVOLUTION AND THE

DOCTRINE OF THE

TRINITY 
CAMBRIDGE UNIVERSITY PRESS

C. F. Clay, Manager

LONDON : FETTER LANE, E.C. 4 NEW YORK \& G. P. PUTNAM'S SONS BOMBAY

CALCUTTA $\}$ MACMILLAN AND CO. LTD. TORONTO : J. M. DENT AND SONS, LTD. TOKYO : MARUZEN-KABUSHIKI-KAISHA

ALL RIGHTS KESERVED 


\section{EVOLUTION AND THE DOCTRINE OF THE TRINITY}

BY

STEWAR'T A. McDOWALL, B.D.

TRINITY COLLEGR, CAMBRIDGE

CHAPLAIN AND ASSISTANT MASTER AT WINCHESTER COLLEgB Author of Evolution and the Need of Atonement

Evolution and Spiritual Life

CAMBRIDGE

AT THE UNIVERSITY PRESS

1918 


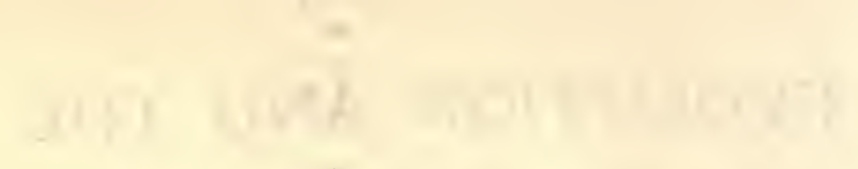

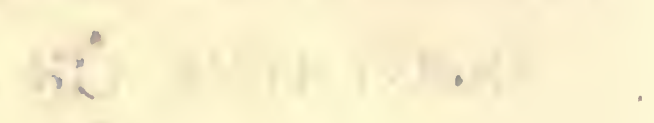


TO MY WIFE 



\section{PREFACE}

Ir is occasionally possible to disarm a critic by anticipating his criticisms. There is a frank ingenuousness about the proceeding that is somewhat disconcerting. That fact, however, is not my main reason for using this Preface to draw attention to two characteristics of the pages that follow, which may very likely, and perhaps justly, be selected for adverse comment. Anyone who tries to think honestly can only be grateful when his theories are subjected to criticism. There comes a stage when he can no longer act as his own critic. Then he must get the help he needs from others. In those conditions he is justly entitled, as it seems to me, to explain why he has set out his theories in the particular form in which they are submitted to the critics; and it is only this liberty I claim.

There is, unquestionably, full room at present for a restatement of the Doctrine of the Holy Trinity in terms that are consonant with modern thought. Indeed, it is not too much to say that there is urgent need of such a restatement. A vague pantheism is the characteristic product of the religious speculation of to-day, and Christian doctrine, if not Christian ethics, is in danger of losing its hold on the minds of the most able among the younger men and women of England. Pantheism, with its emphasis on ultimate Unity, is not impressed by the tritheistic expression of Christian belief which passes popularly for Trinitarian doctrine.

It seemed to me that an attempt to formulate the doctrine anew from the standpoint of evolution, however inadequately carried out, might prove useful as a 
preliminary step, and might further serve an end in showing that the truth of a doctrine does not stand or fall by the terminology in which it is expressed. Terminology may become archaic, words may change their meaning, but the deposit of truth is unaffected if we would only realise it.

The best way to start such a restatement of the Doctrine of the Holy Trinity seemed to be by examining anew the conception of personality, both in its manward and Godward aspects. When this had been done, a fresh start was made in the examination of Christhoodthe link between Godhead and manhood. Yet another starting point presented itself in the almost universal belief in human immortality. Lastly, the evolution of personality itself demanded consideration.

As in each and all of these matters one was almost immediately faced with the double problem of immanence and transcendence, it quickly became clear that little progress could be made until these had been carefully considered. Therefore a preliminary chapter on this subject was worked out. Although logically this chapter had to stand first, it is recommended that the reading of it be postponed until the first five chapters, at least, if not the whole of the rest of the book, have been studied. The subject matter is peculiarly difficult and technical, and its importance may escape notice until the reader has actually been brought face to face with the problems as they occur in the general discussion.

It will be seen that the bulk of the book, therefore, consists of a series of separate essays which converge upon the different aspects of personality. As such they are necessarily not very closely articulated with one another, and it is only in the final chapter that they are linked so that a judgment of the evidence as a whole becomes possible.

Moreover a certain amount of material is common to 
the subject matter of all the essays, and consequently there must be a measure of repetition, and still more of discussion of the samequestions from somewhat different stand-points. It seemed preferable, for many reasons, to retain the original structure instead of recasting the whole in such a way as to give a greater sense of unity. I could see no near prospect of finding time to re-write the book. Some years' delay at least would have been inevitable; and the need of restatement of fundamentals is so urgent, in view of the awakened interest of all classes in matters of religion and the widespread vagueness of religious thought, that it seemed undesirable to hold back anything, however unworthy of its subject, that might hasten the appearance of fuller and more competent treatises. Being, professedly, no more than a preliminary study, there seemed to be a certain advantage in issuing it in a form which left the framework visible. A builder's plan is less satisfying than a picture of a completed building, but it has its uses.

Again, the original form of any thought on ultimate things must necessarily be technical, if it is to give a true idea of the foundation of the arguments on which the theory is based. When, and if, the theory has been approved, it can be put out in more general form, but not before. Since, then, the present volume was bound to be technical in parts, it seemed best to omit all more general discussion, including such vitally important questions as the relation of Trinitarian doctrine to the Christian life and experience, reserving them, possibly, for treatment in a more general book, if such a book should later seem to be desirable as meeting a need. Finally, the fact that one had come to a standstill on the side of pure reasoning seemed to indicate the need of criticism. For all these reasons I decided to let my essay stand or fall in its present guise. 
The objection to form may come from any critic. A different one will surely come also from the evolutionist. The book is written backwards. To find any but incidental discussion of the lower stages of life you must turn to the end. The explanation of this is simple.

In Evolution and the Need of Atonement we started from the beginning, the simplest organism, and we found the necessity for a teleological interpretation of the evolutionary process.

In this book, therefore, following a sound metaphysical principle, we start from the end, and, after a preliminary discussion of the problem of Being and Becoming, consider first of all the Being of God, as the Ground of Reality (Chapter I). I cannot think that this will seem an unreasonable proceeding either to the philosopher or to the religious-minded man. From our study we conclude that the thought, and the very nature, of man must mirror God truly, if incompletely (Chapter II). Then we proceed to discuss the personality of man, and to argue from that to the personality of God; and we find in man just that triunity that seems to be demanded in the Being of God (Chapter III). Turning to the problem of Christhood we then discuss the necessity of God becoming Man, apart from the questions of sin and atonement, in order to make the Divine Experience completely coincident with the human, so that human experience in its turn may be completely coincident with the Divine, rendering perfect union possible between God and man. Some consequences and implications of Christhood are discussed at considerable length (Chapters IV and V).

Next, we argue the identity between the nature of man and that of God, finding in this identity the only sure intellectual ground of belief in human immortality (Chapter VI). In the consideration of the awakening of personality in man we next link up the preconscious 
stages with the conscious, and find the unity of process that we need. This we had already found foreshadowed in Christhood. In passing through the recapitulatory stages that are characteristic of a child's development, and in the continuity of the germ-plasm involved in His birth from the Virgin Mary, we find evidence of the solidarity and oneness of the life and process from first to last (Chapter VII). Finally we gather up the threads by means of a discussion of what is meant by the evolution of transcendence (Chapter VIII).

A change of attitude in regard to one or two matters will be noticed if the book is compared with my previous ones. That is inevitable. Thought is bound to correct and amplify earlier thought in matters which had received inadequate consideration. But I dare to hope that what change there is represents an advance. Moreover, I am not conscious of any radical disagreement between my earlier and later reasonings. In a few minor points there is disagreement, but as far as I am aware, the bigger changes are rather in the direction of amplification than of any real difference of view.

In this book, as in its predecessors, the existence of spiritual phenomena and of a spiritual environment has been assumed. One or two correspondents have raised objection to the use of the word spiritual without definition of its exact meaning. It has been suggested that the word conveys simply the same idea as personal; or that it connotes mind, ideas being spiritual phenomena. Considering the vagueness with which the terms spirit and spiritual are generally used, it may not be out of place to attempt here a definition that will make clear the meaning we attribute to them in our discussions. One definition that has been suggested to me is "Personality minus matter." This comes near the truth; but if we use matter in its strict connotation, the words would imply that any non-material body, such as is desider- 
ated by spiritualists and theosophists, would be spirit, which I am not disposed to grant. (I do not say that there is real evidence that such bodies exist, but one must at least admit that their existence is possible.) If we widen the mode of expression into "Personality minus any limiting factor" we have to admit that by self-limitation spirit lessens its spirituality, whereas self-limitation is characteristic of perfect spirit. On the whole I am inclined to think that we cannot get much nearer to the truth than by saying that "Spirit is the originative Reality that lies behind the power of selfexpression."

The word originative points to the creative activity of spirit, and involves a judgment of values. Moreover, in man the existence of judgments of value constitutes a response to the spiritual environment, and substantiates his appreciation of it as in the category of absolute Reality.

Further, this definition draws attention to the selfexistence of the spiritual and to the implication of self-expression as a necessary consequence of self-existence. It indicates the important truth that spirit must be at least personal, without committing us to any premature statement that spirit is itself actually personal. Finally, since objectless self-expression is an impossible conception, the definition foreshadows the need for interpenetration and sharing of the self-experience which we find to be an integral quality of spiritual Being.

Among all sorts and conditions of the younger generation a great search is in progress. Young men and women are caring for truth more than for anything else, and it is a truly religious fervour which repels so many from a Church whose doctrines are cast in an antiquated and misleading phraseology. They do not understand formulae which recall long-dead issues. They know nothing of the difficulties of the early Church; they 
know nothing of mediaeval speculations. They do know the difficulties and speculations of to-day, and on these official Christian formulae cast little light. Truth that slew an ancient heresy is quite competent to deal with a modern one, but it cannot do so by persistently aiming at the spot where the old one stood and discharging a stream of missiles at a mouldering heap of dust. Let Truth turn round and face the new adversaries, let her discard the cross-bow for the rifle, and she will find them as little invincible as the old. She herself is clad in armour of proof, like that of magic gift in fairy-lore, and nothing can harm her. Of course, as long as we persist in putting a glass shade over Truth, to change our metaphor, so long will our nerves be shaken by the crash when it is shivered to atoms, and the more foolish will cry out that Truth is shattered past repair. Some of our lesser formulae are glass shades-verbal inspiration was one-and their shattering is great grief to the lower middle class intellect, because they conferred such distinction upon the official Parlour. The admirers of glass shades do not see the tragedy of the younger generation who are driven from their home into the garish, undesirable freedom of the street by the formal symmetry of the dreary parlour, opened only for chilly use on Sundays. Can we not give them sound doctrine in a more acceptable shape? They would welcome it. See how they greet an honest book in which the deepest problems are handled with simplicity however ignorant. They have not received enough instruction to be able to recognise the tragic humour of a situation which finds them so ignorant that they applaud when Comte's Religion of Humanity is proclaimed as the newest truth; when Kant's Thingin-Itself stalks, an unrecognised ghost, full across the path' of a distracted but inattentive Hamlet who cannot understand why his world is out of joint; when Lotze's MOD. 
vindication of Personality is so completely ignored that Time seems hardly yet pregnant with it; when all the most indefensible blossoms of mediaeval speculation have been culled and gathered into a bouquet of unapproachable hideousness and labelled official Christianity! So long as there is evidence of honest thought, they welcome anything. Why not? In their own ignorance who can expect them to be swift to mark the ignorance of others? They are tired of childish lullabies. What they ask is a clarion-call to thought and prayer. Dare we refuse them? This book cannot begin to satisfy their need, nor is it meant to. But its faults, its errors, its weaknesses, its difficulties, do constitute a challenge to those who are worthier to serve the younger thought of England. I am certain that it is possible to restate the Christian Fundamentals in terms that are clear and simple, yet commend themselves under modern conditions; for they are true. The way to such a new formulation must be paved with hard thought, and this book is but one short length of paving. Let others correct and trim it, lay it more truly, pave the rest of the road; then let it be beautified, made straight and pleasant, till a highway appears in which men may walk surely, and way-faring men, even fools, not err therein.

I wish to take this opportunity of expressing my gratitude for the ready help given to me in the course of my work. Dr J. E. McTaggart and Canon V. F. Storr have read Chapters I-III and made valuable suggestions and criticisms, and they have further allowed me the privilege of a full discussion of certain questions. They are, however, in no way responsible for the general views that are here put forward. Most of their suggestions have been embodied, or modifications of expression made to meet the points they raised. Some few, depending on a definite difference of standpoint, have been passed over after full consideration. 


\section{Preface}

To Mrs R. B. Goodden I am indebted for several valuable hints, and much suggestive criticism while the writing of the book was in progress.

To my wife, my thanks are, as always, due for assistance of every kind, and for using curb and spur as need was. Her power of critical judgment, her accuracy and originality of thought, have been invaluable. Besides this more general assistance she further undertook the dull labour of compiling the synopsis and of revising the book in proof.

The blame of faults of all kinds must rest only on myself, the credit of some thoughts that are of value must be shared with these my friends.

$$
\text { S. A. MCD. }
$$

\section{WINTON,}

January 1918. 



\section{SYNOPSIS}

\section{PRELIMINARY CONSIDERATIONS}

Both plain man and philosopher agree as to the reality and necessity of the conceptions of Immanence and Transcendence,

but there is divergence of opinion as to the interpretation of the terms

Summary of the discussion of the matter in Evolutiox and Spiritual Life; which led to the conclusion that " just as God is Transcendent and Immanent, so man too is transcendent and immanent" . . . . . .

The personal nature of God is assumed throughout this book as a fundamental truth. . . . . Criticism of the theories expressed by the phrases "Box Immanence," and "Body Immanence" or "Work Immanence," the last being the nearest to the truth . . .

What is Reality for God? Are time and space as real for $\mathrm{Him}$ as for us? . . . . . . . .

What is the relation of His Attributes to His Real Being?

The type of the Absolutely Real is the Unity of self-consciousness;

which involves internal differentiation

God's Attributes are seen as the projections of His Personal Nature into time and space conditions . . . The connection between being and becoming

God's work can only be accomplished by the free co-operation of men's wills. God and men ind well the Cosmos, and together work out their freedom from limitation . .

Plurality is real. Men cannot be fragments of God, because personality cannot fragment

Perfect penetrability will solve the difficulty of plurality in the simultaneous 
The reality of immanence is of a different kind from the absolute reality of transcendence; but immanence is continually passing over into transcendence with the removal of limitation

In the end man imposes self-limitation upon himself, becoming like God in so doing . . . . . .

A mathematical illustration of this truth . . . . 24

The problem of the limitation of the knowledge of God; . 26

brought about by the existence of other wills not in line with His will

Consideration of the difficulty involved in the idea that as Transcendent God knows everything, while as Immanent His knowledge is limited.

Ultimate Reality for God and man lies in relationship-love

Recapitulation

\section{CHAPTER I}

\section{THE TRIUNITY OF GOD}

"Creative finalism" best describes the evolutionary process, as it is truer to see in it tractation rather than impulsion. $A$ brief account of orthodox Christian teaching as to the nature of the Being of God . . . . . . . .

(I) Our knowledge of the existence of God rests on His selfrevelation under conditions apprehensible to us, which means, directly or indirectly, apprehensible to our reason

(2) Our knowledge of the nature of God, as seen in His manward aspects, rests on our recognition of His attributes .

As far as God is Immanent His attributes are ideals and not realities; and He moves towards them with the passing away of His Immanence. His omnipotence, omniscience, etc., are not complete in time and space. As Transcendent He can have no Attributes, and we shall know Him eventually as I AM, as Eternal Love

Even now, in as far as we are transcendent and capable of love, we know God directly and come into immediate contact with $\mathrm{Him}$, without the mediation of His attributes

(3) Our knowledge of the essential or subjective Being of God rests in part upon His special revelation throughout the ages to men who sought the truth single-heartedly, which revela- 
tion was completed in the revelation of the Incarnation; but

also in part on man's knowledge that personality can only mean one thing; imperfect or perfect as may be, but essentially the same; that, so, if we are persons and God is Personal, we can learn His real and absolute being by learning our own, through the infinite projection of that selfknowledge so slowly won

Definitions of the word hypostasis. It is proposed to use it in this book as almost interchangeable with 'person'.

God is self-differentiated into I and Thou-the Logos is begotten of God and so is eternally His Other,

but unity is restored by the action of the Holy Spirit proceeding equally from Father and from Son. Being and Thought are made one again in the Essential Freedom of the Spirit

Love implies activity, functioning externally as well as internally; therefore God created a world in which loving beings would come to be; . . . . .

and He indwells the world as Holy Spirit, . . .

and became Incarnate in order that His Experience might be wholly coincident with man's, to the end that created spirits might become one with Him in love

Formulation of some of the difficulties that are involved in the conception of the Holy Trinity . . . . .

\section{CHAPTER II}

\section{THE TRIUNITY OF MAN}

Mediate knowledge of another person, be he man or God, must precede immediate knowledge . . . . .

We can argue from man's personality to that of God; man is the microcosm of the whole of God

The existence of other beings external to a man is necessary to his process of becoming

Man is creative; he is begotten; and he indwells matter .

The fatherhood of man. . . . . . . . 65

The sonship of man . . . . . . . . . 67

The mediating function of man is fulfilled through his body. . . . . . . . . 
The body is a means of self-manifestation, both to the self and to others

The free spirit, or principle of unity, in man

Spirit is immanent in matter when the matter serves as the vehicle of the spirit's activities, for then the sense of the otherness of the matter is lost

God can think the Cosmos as an 'other,' as a self-limitation; but inasmuch as His purpose is being worked out through His ind welling, it becomes no longer an 'other' but a part of Himself

For man, matter only acquires meaning, as opposed to mere otherness, when he for the time indwells it. All matter acquires its meaning and purpose from the fact that it is indwelt by God

Man can look upon himself as I and thou; but he knows that he is one, and this unity is brought about by his spirit of freedom

Freedom to fulfil the ends willed by the self completes the unity of the self

The three aspects of activity (fatherhood), thought (sonship) and the freedom (spirithood) that makes it possible for the self to link the two first together, are as necessary to man's transcendent existence as to his existence in time and space

Revelation apart, we see the necessity for the triune functioning of God, in His relation to the Cosmos. The creative function of the Father; the mediating function of the Son; and the energising force of the indwelling Spirit . Oneness is threefold, when it is the oneness of a person

And each of the three aspects is necessarily hypostatised when we think of it, e.g. I cannot think of myself as creative merely, but as a creative being

\section{CHAPTER III}

\section{THE TRIUNITY OF PERSONALITY}

The psychologist finds the human mind to be threefold; the philosopher declares human personality to be threefold; the Christian theologian believes Divine Personality to be threefold 


\section{Syropsis}

The PSYCHOLOGIST divides the mind-states into cognition, affection and conation

Cognition is the act of the mind whereby it perceives and associates

Affection is the feeling or emotion which links the cognitive function to the

Conation, the creative striving, the action, which results .

The element of freedom in any person resides, of course, in the middle term, the affection. This term unites the other two.

The three functions are always present and acting, though one may predominate at any moment . . .

The freedom and unity of a person depend upon this threefold functioning

The PHILOSOPHER analyses human personality into three constituents, will, intellect and emotion. Wilfrid Richmond in his Personality as a Philosophical Principle shows that in every activity of the will, intellect and emotion play their part. Similarly, into every activity of the intellect, will and emotion enter. And in every activity of emotion, will and intellect are found. The three are inseparable parts of one whole. Personality can be defined as the capacity for fellowship

It is clear that conation is the manifestation of will, cognition the basis of intellect, while affection emerges as emotion

The THEOLOGIAN conceives God as Father, Son and Spirit. Each Person of the Godhead is not merely a mode or aspect, but has all three essentials of a complete Personality

There is a close connection, which we shall prove to be identity, between conation, will and Fatherhood; . . also between cognition, intellect and Sonship; . . . and between affection, emotion and Spirithood . . Freedom resides in the emotion; the highest emotion, perfect love, is perfect freedom, while the lower the emotion (e.g. fear) the greater the limitation . . 99

Perfect love is an emotion of transcendence . . . . 103

In the relation of the personality to itself also are found those three aspects 
Freedom comes with the unity of three differents. Unity is a system, which we may designate Infinite Reciprocity

PAGE

Each hypostasis is not merely a being, it is a person, as each contains all three elements, though the emphasis is differently placed in each

The Godhead, if it is a Personality, must be in fact a Unity, which unity is substantiated or determined as itself, by three Persons, completely interpenetrating, yet each differentiated from the others by the stress or emphasis of its individual functioning .

Consideration of the difficulty that by the above reasoning personalities might be split up into three persons an indefinite number of times

Recapitulation

\section{SOME IMPLICATIONS OF THE INCARNATION}

In the past, the Divinity of Christ, rather than His Humanity, was insisted upon,

though recent thought has begun to swing in the opposite direction, and to emphasise the doctrine of the Kenosis as originally taught by St John and St Paul .

Every human being, during pre-natal and post-natal life, recapitulates, physically, mentally and spiritually, the history of the evolution of the human race . . .

Christ, as a human being, did this too

He identified Himself with the whole of organic life and development by recapitulating it in His own experience .

The evolution of man has been misdirected by his own sin, and we have seen reason to believe that the whole human race is imbued with a taint of positive evil

Hence appears a dilemma: either Christ must have been affected with the stain of humanity's misdirection of its own evolution, or there must have been something not quite normally human in the nature of His Manhood

We are forced to reject the first alternative. Christ was Perfect Man, not merely an example of the best that was possible to mankind gone wrong 
But if Christ did not bear the burden of the misdirection of the race through sin, can we say that He was completely identified with fallen humanity?

Yes, because of His own free will he identified Himself with fallen mankind. His will brought about the identification as the necessary conseguence of complete interpenetration. His experience of isolation from God on the Cross was the isolation of manhood that had failed, not of His own perfect Manhood

The Virgin Birth symbolises the necessary break with normal human inheritance which made Christ's freedom from inherited disability possible

A discussion of the difficulties involved in Christ's apparent memory of Transcendent Existence. "Before Abraham was, I am"

All three Persons of the Holy Trinity are Immanent in the Cosmos as well as Transcendent

The relation between the Incarnate Son and the Holy Trinity

Bergson's theory of memory throws light on our problem of Christ's memory

As Perfect Man Christ would have a strong sense of union with God, just as good and pure men-mystics especiallyhave had in all ages. And inasmuch as the perfection of His Manhood exceeded the imperfection of that of ordinary men, so would His sense of union with God have exceeded theirs, even to the extent of making it possible for Him to realise real and complete union with the Father

Thus His knowledge of oneness with the Father was an intuition rather than a memory, and was $H$ is in virtue of His Manhood

\section{CHAPTER V \\ SOME IMPLICATIONS OF THE INCARNATION (continued)}

An attempt to trace the effect of the Incarnation of the Son upon His Eternal Being necessitates an inquiry into the nature of memory

(a) Freud's theory. Every impression received by the senses leaves its mark on the brain 
The 'censor' in the mind represses lawless ideas. 'Repressions' and their results (phobias and symptoms of many kinds)

The method of psycho-analysis for discovering repressioncomplexes, .

which can also be discovered by the interpretation of dreams, since every dream is a wish-fulfilment

The formation of repression-complexes can be prevented by 'sublimation,' i.e. by consciously directing the impulse along other channels, since the danger lies in preventing its discharge in some activity

Freud's theory is materialistic; but a mechanical basis is what we should expect, as a determinate environment is necessary for the emergence of free spirits

(b) Bergson divides memory into habit and pure memory, the habit-phenomena being localised in the brain . 159

All memory is directed towards the future . . . 160

Freud, all unintentionally, admits teleology, since he states that the censor is working towards an end

Freud's description of the one 'censor' does not tally perfectly with the facts of mental life. It would be truer to say that each lower impulse is repressed by a corresponding higher idea, so that as many 'censors' are called into being as there exist anti-social impulses to be dealt with

The past is ever active in the now, yet the spirit must leave past stages behind . . . . . . . I64

The danger arising from the "conspiracy of silence" . . 166

The place of the censor in the history of evolution . . 168

As all memories persist, and as Christ passed through all the stages of a man's growth and development, therefore He is as near to us in childhood as in manhood, and can enter perfectly into all our experience.

His perfect Manhood is taken up into His Godhead . . 169

Though the abstract idea of the necessity of the Incarnation commends itself to man's reason, somehow the actualisation of it in time (the coming of Christ in a certain year of the Roman Empire) gives rise to questionings .

But these difficulties disappear before a truer view of the nature of time. The Incarnation is an eternal fact 
A discussion of the nature of the memory of the ascended Christ

Can we reconcile the idea of an added experience to the idea of a Transcendent God?

Is the end experienced by God even before process?

The study of personality, and the doctrine of the Trinity, furnish us with material for the solution of this problem .

\section{CHAPTER VI}

\section{IMMORTALITY}

Chance impressions received in early childhood, especially emotional shocks, have a very great effect on the mental outlook of the adult

There exists widespread doubt as to human immortality in spite of a strong yearning for life after death. This is due to the unsound theological teaching prevalent, with its insistence on the unlikeness of God and man . . .

Personal being both changes and persists through change .

If personality can be extinguished the universe is not rational, for all development is crowned with the emergence of personality

The great argument for the immortality of man lies in the identity of his nature with that of God. Human transcendence is the same as Divine Transcendence . . .

The difficulty of accepting this idea lies in the fact that the timelessness of man had a beginning, while that of God always existed. Bnt timelessness is, however, a quality of being, of personality. Does the fact that our personality is in part transcendent mean that it is also immortal?

Personality in its essence connotes a threefold being; and the threefold nature of man is the same as the threefold nature of God, and the enduringness (timelessness) of man is the same as the enduringness (timelessness) of God . . . .

The difficulty that God is uncaused, man caused, is met by the contention that personality is personality whatever its genesis, and that enduringness is gne of its qualities . The question of memory in other possible existences; and an argument against the theory of re-incarnation on earth . The Doctrine of the Trinity gives a fresh cause for certainty of our immortality 


\section{CHAPTER VII}

\section{THE AWAKENING OF PERSONALITY}

Progress in freedom is the keynote of evolution

Man is free to choose consciously between right and wrong courses of action. Christ, as Man, had to make such decisions constantly.

It seems that God must constantly renew the will to suffer with His world

God's self-limitation, from the creation of matter to the Incarnation, is one act, and the different stages cannot be isolated without falling into the fallacy of dualism. Matter is simply the tool of spirit; the medium through which it works; the means by which growing personalities fulfil their destiny. It has no objective reality apart from mind .

A discussion of Bergson's idez of the "inturning of the consciousness on itself" in connection with the recurrence of "closed systems" in the universe

True freedom lies in self-limitation; and the process of winning freedom becomes identical with the process of the self-imposition of laws

Systems tend to expand until finally there emerges the fellowship of all perfected selves in perfect communion .

\section{CHAPTER VIII}

\section{THE EVOLUTION OF TRANSCENDENCE}

Recapitulation

The conclusion to which we are driven is that man's nature and experience is the same as God's, differing only in degree.

Creation, to be satisfying to the creator, must lead to something new and something eternal

The evolution of transcendence is the essence of the process

The material in which this process takes place is the selflimitation of the Transcendent God . . . . 225

To be like God, men must be self-limiting too . . 225

When men learn to realise matter as mediating God's will, they will lose all sense of its otherness, and the oppression of the feeling of determination from without 
Growing control over circumstances, growing freedom, characterises the process, and the end is self-limitation with love as its motive

The problem of degrees of reality and of double consciousness for man and for God

God is Immanent; and experiences the temporal series .

Absolute freedom may express itself in self-limitation

God is Transcendent; and experiences simultaneity. How can these two experiences co-exist? . . . . .

Man's own experience furaishes the material for a solution Transcendence and Immanence are necessary correlatives of each other. As God is Love, $\mathrm{He}$ is eternally creative and therefore eternally Immanent. Nevertheless, Immanence is derivative, and owes its existence to the nature of Transcendence

The question of the Transcendence of Christ during His Incarnation

God experienced the full consciousness of Christhood; though Christ was not fully conscious of the Eternal series. The greater included the less, not the less the greater. Christ experienced real self-limitation

232

In man the double consciousness exists, and we are sometimes aware of ourselves as transcendent beings, at other times as immanent. It is a question of attention. Why should this not be true of God? . . . .

Creativeness-therefore Tri-unity-is the very essence of God's Being, and hence the idea of a "God before Creation" is meaningless . . . . . . . .

Being implies process. The wholeness of the Whole realising Itself as Love is perpetually re-affirmed by process. This is the meaning of the statement that God is Personal, and the Doctrine of the Holy Trinity is the affirmation of that basal truth. Perfect freedom issuing in complete self-limitation is the end of the process for man,

the guarantee of whose immortality rests upon the nature of personality, and upon the identical character of personality in man and God

ApPENDIx A. Note on Freud's conception of the Censor.

APPENDIX B. Note on some conceptions of primitive religion, and their possible relation with Trinitarian Doctrine . . . . . . . . . 



\section{PRELIMINARY CONSIDERATIONS}

Nore. As suggested in the Preface, the study of this chapter may be postponed with advantage until the first five chapters, at any rate, have been read.

IMMANENCE and transcendence are words that must be used again and again in any study directed towards the fuller understanding of the problems of God and the universe, for the concepts they express are essential to any ultimate discussion of the facts of experience.

In the Universe we find change proceeding within the realm of Time and Space. We live in a world of becoming; and from the process of becoming we ourselves are not exempt.

Yet there is within us something that will not rest satisfied with a theory of mere becoming, mere change, mere process. Our minds demand unity in the whole; something stable that lies behind the flux of things. The Many cannot bring us rest without the One. Process has nothing for us unless it is directed towards an End. Becoming has no real meaning without its correlative Being. Time and Space, however real they may seem, yet set themselves up as being in some relation of opposition to a far vaguer concept, in which is neither Time nor Space, that lies almost unrecognised in the back of our mind ${ }^{1}$ : the concept of Simultaneity.

The intuitive grasp of these facts has its results even among men who do not think deeply or clearly. Natural

1 Cf. Pringle Pattison, The Idea of God in Recent Philosophy. p. 368. "If we speak of the Divine Activity as an eternal act, that means for us, if we throw it, as we must, into terms of time, an act which is being accomplished now, and which we are belping to accomplish...the whole life of God is poured into what we call our human 'Now'." ef passim.

MCD. 
religion; ready acceptance of dogmatic religion; belief in the soul and immortality; these are the offspring of such vague ideas. When real thought is there the result is still the same; metaphysical systems, theodicies, philosophies of religion, all reflect the dual aspect of Reality as being and yet becoming-as becoming and yet being.

The simple man who knows there is a God and the philosopher who almost ${ }^{1}$ proves His existence alike are driven to conclude that $\mathrm{He}$ lies behind the world, behind all process in some sense, as a great Creative Cause. He is therefore Transcendent.

The simple man who knows that his life is somehow guided and controlled by God, Who is near, Who is more than externally omnipresent, Who is in all that exists for, and happens to, a man, and the philosopher who again almost ${ }^{1}$ proves that change and process must be a real part of the experience of a God Who indwells, and must indwell, His created universe, are alike forced to believe that God is not simply far away, but actually present in His creation, Himself experiencing all the changes that go on in it. God is therefore Immanent ${ }^{2}$.

1 Almost in both cases, for logical thought, however unassailably accurate, starts from its unprovable postulates and axioms, confirmed, but not absolutely and ultimately justified, by experience, without which no thought would be possible.

2 For the purposes of the present discussion I make no apology for assuming the existence of God. The arguments in favour of such an assumption which fall into line with the evolutionary philosophy we are endeavouring to set forth will be found in my Evolution and the Need of Atonement.' Flint's Theism is a standard work, on the more general arguments, though somewhat out of date; Professor Seth's (Pringle Pattison's) books on the subject are helpful, and there is a valuable summary in a few pages in Lotze's Microcosmus, Bk IX. ch. iv. 2. Newest and most notable of all is Pringle Pattison's noble book on The Idea of God in recent Philosophy. 


\section{Preliminary Considerations}

But when these conclusions have been reached men have only touched the fringe of the problems they involve. What do we mean by immanence and transcendence? Do we all mean the same thing? Apparently not, if we may judge by the very various doctrines that are held compatible with belief in these two aspects of the activity of God. One says God is Impassible, another that $\mathrm{He}$ suffers with His creation. To one change is an illusion of limited existence ${ }^{1}$, to another it is the reflection of the process by which God is making Himself ${ }^{2}$, to another it is the expression of a kind of relaxation of the limitations set upon free action by matter ${ }^{3}$. The existence of such a range of different conceptions, all acknowledging both aspects in some measure, yet varying between an emphasis on transcendence that almost excludes immanence to an emphasis on immanence that almost excludes transcendence, surely points to a vaguenessin definition of terms that is little short of disastrous".

We have dealt at some length elsewhere ${ }^{5}$ with certain aspects of the two conceptions of immanence and transscendence and I do not propose simply to repeat the arguments already used. It will be remembered that our main conclusion was this. Because there is a creation, and the cosmos shows many indications of order, and of being a rational whole; because an ultimate standard of morality is indicated; and because there appears to be something that persists through change in an unchanging self-identity, we believe that God is Transcendent. Because change enters into our everyday experience,

1 Buddhism, and some forms of Hinduism.

2 Bergson.

a Driesch; and, in a different manner, to a limited extent the present writer.

- A useful summary of Christian and philosophic thought on the matter will be found in F. Platt's Fernley Lectures on Immanence and Christian Thought.

- Evolution and Spiritual Life. 
and yet is directed to an end, and is seen as purposeful and progressive when regarded at large; and because even our individual lives seem to be guided by some influence that indwells us, yet is not ourself; we believe that God is Immanent.

If $\mathrm{He}$ is immanent, $\mathrm{He}$ must be limited by both the contingency ${ }^{1}$ and mechanism of the universe (which contingency includes, and perhaps only includes, the effects of the freedom which all organised beings present in greater or less measure; while the mechanism appears to be the expression of the conditions requisite for development and progress).

But if $\mathrm{He}$ is transcendent as well, this limitation must be a self-limitation, willed by $\mathrm{Him}$ for some end or purpose; which purpose we found in the satisfaction of His Being as Love through the eventual entering in of other beings to share $\mathrm{His}$ perfect experience.

We then turned to the consideration of these created beings, and found in them too, as was to be expected, a persistence through change, an independence of Time and Space, a permanent ego, that showed all the characteristics of transcendence (though an imperfect transcendence, limited by all kinds of cosmical conditions) as well as finding all the phenomena of change and becoming that are characteristic of immanence. 'As was to be expected,' because any being who is destined eventually to share the perfect experience of God, and is being prepared for it by a process of free self-creation, made possible by the self-limitation of God, must surely have some point d'appui with the real and absolute nature of God, as well as with that nature as revealed in

1 I use the term as a convenient mode of expressing the true freedom of the activity of life, not as indicating a chasm between a transcendent creative God, and free man. The immanence of God cannot in fact be left out, and if He is immanent He shares the human Now. Cf. Pringle Pattison, op. cit. pp. 374-375. 


\section{Preliminary Considerations}

the processes of limitation and change. On a priori grounds we should look for some such possibility of relation, and this could only exist if created beings possessed some measure of transcendence; and we unquestionably find this. Thus we were driven to conclude that just as God is transcendent and immanent, so man too is transcendent and immanent; and is passing more and more from immanence to transcendence as he progresses. This is indeed the mark and sign of human progress, individual and racial. But between the immanence and transcendence of God and man there is a difference, which is causal in nature. Man is not simply immanent and transcendent as God is immanent and transcendent, but also because God is immanent and transcendent.

Along these lines we sought the meaning and reality of eternal life, to which we shall return in the present book. What is needed now is a clear statement of what we mean and, equally important, of what we do not mean by these two terms we so constantly use. The present chapter will therefore be devoted to a definition and a critique of the ideas involved in the terms immanence and transcendence as applied to God and to man. This will also entail a critique of the correlation of immanence with time and space, and a discussion of degrees of reality and knowledge. It is clear that any adequate consideration would entail a survey of almost all the material of metaphysic. No such ambitious attempt will be made here. We shall only endeavour to clarify our ideas, and narrow the limits of discussion by indicating clearly the boundaries.

Evidently, we are making in all this the assumption that God is Personal. And indeed that assumption will be found to be the very starting point of our inquiry, and, except incidentally, we shall offer no justification of it. Since Lotze wrote his Microcosmus the conception 
has been placed on a firm basis of thought, and by now very many of the greatest minds admit that this conception, which constitutes the very groundwork of religion (even though later, abstract speculations may have masked it in some quarters), is justifiable on metaphysical grounds; while I would make bold to say that hardly one is uninfluenced by it ${ }^{1}$. The chief metaphysical difficulty of belief in Divine Personality is that to think of the Ego is at once to think of the Non-Egoof something outside the Personality. Lotze escapes the difficulty by distinguishing between thought and experience, thus getting away from the Hegelian standpoint. "We admit that the Ego is thinkable only in relation to the Non-Ego, but we add that it may be experienced previous to and out of every such relation, and that to this is due the possibility of its subsequently becoming thinkable in that relation ${ }^{2}$." Lotze elaborates this proposition by showing that, though the actions of finite personalities depend on external stimuli, the con-

1 For those who wish for something on a smaller scale than Lotze's Microcosmus, F. B. Jevons's Personality and Harte's The Philosophical Treatment of Divine Personality may serve as good introductions-the former dealing mainly with the concepts of personality, the latter with its extension to the personality of God. Illingworth's Personality, Human and Divine is a standard book; Platt's Immanence and Christian Thought, Driesch's Problem of Individuality, Haldane's Mechanism, Life and Personality are all suggestive in their own departments; and many other works might be cited. Most important of all, perhans, is W. Richmond's Essay on Personality as a Philosophical Principle. Professor Pringle Pattison's Gifford Lectures, The Idea of God in Recent Philosophy, which have appeared since the bulk of this book was written, should be in the hands of every serious student. The implications of personality are there dealt with very fully.

Microcosmus, Bk IX. Ch. iv. p. 680, trs. Hamilton and Jones. This Chapter, together with Bk II, Ch. v., should be read carefully by the student of Personality. 


\section{Preliminary Considerations}

tent of their feelings and sensations, and hence the form of their activities, is purely self-determined from within ${ }^{1}$. The need of external stimulus is due to the limitation of finite personality, and is not inherent in personalty per se. Personality is an ideal, and like all ideals pertains in its unconditioned form only to the Infinite 2 . In the present work we shall attempt to extend Lotze's conception of self-conditioned personal activity, and to show that it involves a triunity of functioning, that is present even in human beings, and that supplies the ground of reciprocity which is essential to a personal being. In this way we shall be able more or less to avoid Lotze's divorce between thought and experience, for we shall see that the triune self can think itself as its own other, and indeed that this self-thought is in itself a necessary part of its experience. From such a conception, the step to the doctrine of the Holy Trinity is not a long one.

It is desirable then that we start with the definition of immanence and a discussion of its problems, for since we assume a God, on other grounds, the definition of transcendence will largely formulate itself, by implication, as we proceed.

The moment we conceive of God as immanent in His creation two main classes of problems appear and demand solution-problems of His Activity, and problems of Relativity.

We may call these the conative and the epistemological problems, since Action involves Will, and Relativity involves degrees of reality and hence God's knowledge of process.

Let us take action first.

God created the universe and indwells it. What do

${ }^{1}$ Cf. the discussion on the freedom of emotion, infra, ch. iii. pp. $100-103$.

2 Microcosmus, Bk Ix. pp. 683 segq. 
we mean by this statement? Do we mean that the whole universe is, as it were, an assortment of strangely mixed phenomena packed together in a box which is God? Does the universe exist in God only? Is it all a manifestation of Him? For this is. really what immanence means for the pantheist. If so, either it is His complete manifestation, in which case transcendence goes, and we have pure pantheism; or else it does not manifest Him fully, in which case something lies behind-His transcendence-with which we should seem to be altogether out of touch, since it does not enter into the phenomenal world at all. Of course, a third alternative is possible, even on this view. We may say that we have in ourselves something transcendent, that enables us to reach out beyond the phenomenal universe and make contact with His transcendence; but really this begs the question. If we make any such assumption we assume in fact that there is a part of us which God does not indwell, which is outside Him, which does not exist in Him only, yet, ex hypothesi, is created by Him. In making this assumption ${ }^{1}$ we have really got away from the pure form of what we may term the Box-Immanence theory. At present it is needless to discuss the issues involved in any of these possibilities, for the theory itself is radically unsound, as we shall see.

The other alternative we may term the theory of Body-Immanence or Work-Immanence. According to this view God in creating was limited by the nature of what $\mathrm{He}$ had to create. Since the object of creation was the emergence of free beings who should freely enter into and share His perfect Experience of Love, the creation must be of such a nature that freedom could emerge, since freedom cannot be itself created directly,

1 Which undoubtedly does express one aspect of the truth, as far as its emphasis on human transcendence is concerned, though on the immanental side it is open to grave objection. 


\section{Preliminary Considerations}

from its very nature. Compulsory freedom would not be freedom at all, and the creation of freedom would involve compulsion, and so, a contradiction.

If freedom is to emerge, it must emerge from determination, and hence the essence of creation must be limitation.

Now if all Reality is comprehended in the experience of God, and if, for the sake of simplifying argument, and fully recognising the contradictory and really meaningless $^{1}$ assumption involved, we imagine, not a time but a state, when nothing existed save God only, that creation, in so far as it is real, must be a limitation of part of His experience, and so a self-limitation, since His whole experience is Himself ${ }^{2}$. (Of the nature of this self-experience of God we shall have more to say hereafter, and we shall further see that our argument holds good, whether there be other beings sharing that experience, or God alone.)

As freedom emerges in the creature and becomes more and more perfected, the will of the creature becoming in greater harmony with the Will of the Creator, the self-limitation of God is done away. Thus it becomes true in a sense to call the Universe the Body of God. For a body is at once a limitation, a means by which freedom is achieved, and a means of self-manifestation to others; the body is indwelt by the self or spirit; yet it is not that self, but rather the material through which the self works - the expression of the fact that the self is limited.

But such a view is very incomplete. It is true that the Universe may be conceived as the Body of God; His limitation; the means by which He regains freedom; and His self-manifestation. But fragments of it are also actually the bodies of other spirits-men-subserving

1 Vide infra, p. 12 and ch. viii. pp. 239-240.

2 For a discussion of the reality of the cosmos see pp. $4^{\mathrm{I}-44}$. et passim. 
these same functions for them. Indeed in a wider sense we may speak of all those parts of the whole universe of which a man is conscious as being his body; and I am doubtful whether we are even justified in introducing the qualifying clause. Each man is probably affected in some degree by the whole universe, whether he is conscious of the fact or no, and it is probably wiser to make the fuller statement at once and say that in the widest sense the whole universe is the body of each man in it, even though he has his own fragment of it as his individual body, in the common acceptation of the term.

Again, here at once we find ourselves involved in the idea of reciprocity, which lies at the heart of the problems we have to consider. For, when we speak of the Universe as the Body of God, we imply that it is, among other things, a means of His self-manifestation. Manifestation to whom? Obviously to other beings; He has no need to manifest Himself in limited form to Himself. The very use of the term body involves us in the idea of relationship with other beings. Further, we have seen that, if we give the widest meaning to the concept of body, this same universe is the body of these other beings (who are yet, ex hypothesi, other, and so not parts of God), much of it being common to all such beings, while each has his individual body or body proper-a thing peculiar to himself, and yet a part of the universe, or larger body, of all other beings-which is his means of manifesting himself to other human beings and to God. If we adopt this body-symbol, we have therefore to face such problems as those of the existence of individual bodies; of a greater body common in the main to all, of which the individual body is a part (in other words we have to look on the sum-total of the material environment as the body of each man, while admitting that a certain part of that environment becomes specialised and subordinated to his use as the body of common parlance); 


\section{Preliminary Considerations}

of the difficult question of whether the whole universe is the individual body of God (which really lands us again in Box-immanence and also in a contradiction); and of the host of enigmas that present themselves in regard to the relation of this body of God to the bodies of men.

It will be well, therefore, to avoid this term, in spite of its obvious suggestiveness. Now I am well aware that a good many of the problems that present themselves are in the last resort problems of terminology. The word body has such a very definite connotation that any extension of its meaning however justifiable, however really implicit in the very conception of a body, as ordinarily understood, must bring many quite needless difficulties; just as the conceptions of idealism bring us up against all the apparent objections that everyday, phenomenal existence presents. If therefore another expression can be found less 'polarised' in its meaning, and at the same time freer from the objections that obtrude themselves when we are driven to speak of a body which is common to many beings, and of which different parts have different degrees of mediateness in their relation to different beings, it will be desirable to use it. Such a term, I think, may be found in the phrase Work-Immanence, and to this term we shall adhere, even though it will involve a consideration of the relation between the body and the work.

What, then, do we mean by Work-Immanence, and what is the radical unsoundness of the conception of Box-Immanence? Very simply, we mean by WorkImmanence, that the phenomenal and noumenal universe is not wholly within God-a part or even a manifestation of His Being ${ }^{1}$ - but is rather something which

1 The Universe, as His creation, must be a manifestation of His Nature and His Being, but it is primarily the medium created for self-manifestation of the created, finite centres of being we call men. The implications of this fact will be discussed later. 
He creates as the means of realising the emergence of free beings, which is itself the purpose of His Creation. The Universe is His work; it is, naturally, within His experience, but it is not merely a part of Himself. It is the expression of the fact that $\mathrm{He}$ has limited Himself; it is the region of His experience in which $\mathrm{He}$ is undergoing process or becoming, and in which $\mathrm{He}$ is therefore in duration, at least, and probably in space. At the same time we must guard very carefully against any spatial conception of immanence itself, or we shall be landed once more in the box difficulty.

At this point it is clear that we are up against the problems of Reality and of Knowledge, as well as the problems of Time and Space. Is the experience of becoming - the immanental experience-as real for God as His transcendent experience? Are time and space as real for Him as for us? What is Reality for God? Is His knowledge complete in the immanent sphere? Such are a few of the questions that confront us.

Let us begin with Reality. In order to get a clear view of the nature of the issues we will begin with the same contradictory and really meaningless ${ }^{1}$ assumption that there was a state when God existed alone, before any creation. What would Reality mean then for God? Clearly, His self-experience. Of the nature of this selfexperience we shall have much to say in the succceding chapters, and we shall see that it involves a Trinitarian

1 Meaningless, because it implies a before and after in the transcendent experience of God, which experience is essentially simultaneous-it introduces a time-element in to absolute Being. Contradictory because it implies a creative will which only became active at a certain moment, and so introduces change into the nature of God. God is Cause of the Cosmos only because the Cosmos as a whole is the expression of the nature of His Being as Love, which term implies activity and the existence of 'otherness.' The fact that God is eternally creative does not, of course, affect the obvious truth that this universe had a beginning. 


\section{Preliminary Considerations}

conception of the Godhead. Now God is revealed in the Cosmos as possessed of Will, Power, Activity, Wisdom, Righteousness, Eternity, Love. Either these are attributes, representing simply His relations to the limited world He has created, in which case we are left with the hopeless difficulty of the Kantian Thing-in-Itself, unknowable, - the bare formlessness that remains when the attributes are stripped away-or else in some way they are expressions of His Real Nature. Anyhow, as they stand, they are the characteristics which we should postulate of an Eternal Personality, for they underlie that capacity for fellowship which is the most satisfactory definition of personality ${ }^{1}$, as we shall see later. Unquestionably some of these terms do represent His relation to other beings in the Universe of His creation; certain of them are normative, for instance, and these are not for Himself, but for His creatures. On the other hand it is clear that such terms as Eternity and Love are for Himself as well as for His creatures. They are absolute, not normative, and so are not attributes in any exact sense. How then are we to escape from the Kantian ding-an-sich? The attributes of God are certainly the manifestation, or rather the projection, of His real nature into a cosmos that is in time and space, and so is becoming. Nevertheless though they are attributes, whose meaning is not for the Transcendent God, but for His creatures ${ }^{2}$, and for Himself as immanently related to His creatures; they are also the expression of His Real and Eternal Being. Although we, in so far as we are immanent, can only know Him through His attributes, we are not thereby cut off from all knowledge of Himself, for these represent the time and space equivalent of His Real and Eternal Being. Moreover, as we shall see ${ }^{3}$, we have a link with His Real and Time-

3 W. Richmond, Essay on Personality as a Philosophical Principle.

2 See ch. i. pp. 40-49.

ah. vi. 
less Being, through our own transcendence; and the experience which this brings confirms our belief that even through His attributes we achieve true, if incomplete, knowledge of the Absolute God.

If, then, God is Eternal Love, He is Eternal Reciprocity; and Wisdom, Knowledge, Righteousness, Power, Activity, Will, are simply the manifestations of this Love in the sphere of becoming. For Love is active; does involve will, knowledge, goodness, directed towards, and existing for, any beings who are 'other' than God, and who cannot as yet enter into the full reciprocity with Him that is implied in the term Perfect Love.

Now the type of the Absolutely Real is the unity of self-consciousness. There is nothing so real, nothing that conveys to us such a sense of absoluteness and finality as the fact that I am, I will and I love, and that I know that I am, I will, and I love. My will becomes translated into action, and much of this action is incompatible with love as yet; but even to ordinary men with ordinary vision, love has a stability and value that nothing else has. Through love we get away from time altogether, and forget its very existence.

For our hypothetical God-before-a-Cosmos then, we are driven to define ultimate Reality as the experience of self-consciousness.

The realisation of such an experience, however, involves a contradiction if we think of God as a pure Unity without internal differentiation. A unity cannot be in any sense reciprocative-or indeed active, or anything else at all but blank unity. God cannot be, or even experience, Love, if $\mathrm{He}$ is purely One, for He cannot love Himself; there is no room for the reciprocity which is the essential condition of love; and hence $\mathrm{He}$ cannot be Personal. If we assume that $\mathrm{He}$ is One and yet Personal (that is to say, if we add to the concept of unity something else) we are still in a difficulty, for He ceases, ipso 
facto, to be self-existent. For what does this added concept of personality mean but a reciprocity between God and beings outside Himself? Only by taking the reciprocity as internal can we make Him at once personal and self-existent ${ }^{1}$. And internal reciprocity involves a differentiation within the Godhead, which brings us once more to the confines of Trinitarian doctrine; and it is along these lines that we shall, and must, seek the solution of the problem. We have the fact before us that the most real thing for us is the unity of self-consciousness. We find that this unity involves an internal differentiation. A similar differentiation must also exist in ourselves, if we are truly self-conscious and self-existent, apart from our relations with others-and we shall find that it does in fact exist. Knowing, then, that it exists in ourselves, we find less inherent difficulty in postulating its existence in the God Whom common experience tells us to be Personal.

With this assumption the difficulty of the ding-an-sich goes, as we have said, for the attributes of God become simply the projection of His Personal nature into time and space conditions, and are true áma uyá $\sigma \mu a \tau a$, revealing Him as the source of Radiance; but further, as we shall see, the very fact that we too are personal beings gives us immediate reciprocal relations with His Transcendent Personality, because all personal being is, in itself, essentially transcendent in so far as it is truly personal; and so we are not dependent solely on our experience of God's attributes for our knowledge of Him.

Not God's Will, not even His Purpose, but Himself indwells the cosmos. Immanence is the result of creative

1 It is for the purpose of establishing the need for internal differentiation within the Godhead, if the Godhead is to be selfexistent, as it must be, that we have considered the abstract and impossible conception of God-before-creation. Of course, as has already been said, God must really be eternally creative. 
will, of purposive control, but it is neither, but something far more-God's very Self manifested under selfimposed conditions of limitation, whose existence is the guarantee of love and purpose.

If, then, Absolute Reality is for God-again the Godbefore-creation-the experience of the unity of self-consciousness, what are we to say of the plurality that is introduced by His creative activity? What is the relation of God to His Work? What is the connection between being and becoming? Putting the problem in a somewhat different form, is the equation $I=I$ necessarily true under all conditions?

I think a rough analogy may help us here. When Pygmalion set to work he had first to obtain the necessary material. He then shaped out the statue; this was the expression of his purpose-his work, in the ordinary conception of the term. Last of all the legend tells of the creation of Galatea herself in the perfect guise he had framed for her; a coming that was the final triumph of the activity of his personal will.

In a sense the marble was real, the statue was real, and Galatea real; but we instinctively recognise that we have to deal with three very different kinds of reality when we speak of the material, the work, and the personal being.

The analogy is a very rough one, but it serves its purpose in helping us to define our terms. It fails in these two respects; Pygmalion's marble-the material-is taken for granted; and the entry of spirit into Galatea, though led up to by the work of many gradations of urgent desire, was itself effected in a moment. In considering the problem of Reality - which is inseparable from the problem of Immanence-we have to face the origin of the material universe and the gradual emergence of the free spirits which crown the work-in which the work finds its fruition-as well as the work itself. 
Now, if we assume, as we have done elsewhere ${ }^{1}$, that Eternal Love is of necessity externally creative, in order that it may realise its self-abnegating nature through other beings who may enter into and share the perfect experience, it is clear that a dualism must be created, at any rate in Time; for we have seen that to love, the creature must be free, and to be free he must be placed in conditions out of which he can win freedom. Further, as long as there is anything of the clash of wills which such conditions make possible between God and men, and between men themselves, there must be plurality. When men become perfect; their wills in full accord with God's will; their love, like God's², a perfect selfabnegation; their experience the same as God's-a perfect reciprocity; dualism goes, and plurality vanishes into, or rather is included in, a fuller unity ${ }^{3}$. Until then there is the cosmos of God's self-limitation. This is the material of His work 4 .

In this cosmos is order, purpose, form; progress towards freedom under the urging of the vital impulse is manifest; there is that reduction or release of the bonds of determination which Driesch calls entelechy. This form, or order, we may compare roughly to the

1 Evolution and Spiritual Life, passim.

2 Vide infra, ch. vii. 'Evolution and Spiritual Life, ch. vi.

- A caveat may here be entered against the easy idealism which, accepting over-eagerly the physical reasoning by which matter is refined down and down till it is ultimately represented by stresses in an all-pervading something, passes far ahead of legitimate inference, and argues that matter is not matter at all, and that, by an infinite fining-down of matter, we shall reach only spirit. Matter is matter, even if it is not so lumpy as we used to think, and to call it spirit will not make it any the less matter. What this matter is we do not know, and shall not till the coming of the Coccigrues. All that we may say legitimately is, that it is the expression of God's self-limitation, that it is radically unlike spirit, in that it is not free; that it is the material of God's work-and of man's.

MeD. 
statue. It is something different from, and more than, the mere material, on the basis of which it is framed; as the shape grows more defined we see a reflection of the creative mind; it is the creator's work. But until the free spirit comes into it, it is incomplete, and the Creator's will and desire, which prompted the work, remain unsatisfied.

Let us repeat. We have before seen reason to define matter-or better, Nature-as the expression of God's self-limitation ${ }^{1}$. It is because God has limited Himself that the achieval of freedom out of determined conditions is possible for His creatures. His self-limitation, then, provides the material.

But when we regard the work we have to recognise that two factors come in; God, indwelling and inspiring His creation, and the free spirits that come to be in the world. Both of these are formative principles; the final product - the human person-depends on the one as the environment, on the other as the developing organism -or to speak more truly, the developing spirit. The immanence of God is thus closely linked with the immanence of man, as we see again and again. (Fuller discussion of this point may be reserved till we consider the immanence and transcendence of man.) In other words the completion-the coming of living spirit-is a gradual process, determined primarily no doubt by the urgent, loving Will of God, even as Galatea came in response to the yearning of Pygmalion, but yet itself the free response of a free impulse in the 'work.' Thus it becomes clear that the Pantheists are in a measure right, in so far as the material of the Universe is within the experience of God as the expression of His selflimitation, but they are wofully wrong in so far as the universe itself is the work of free spirits as well as of God, and is not altogether a part of God. The material is in

1 Evolution and Spiritual Life, p. 168. 
God's experience, and He indwells it, but it is in man's too, and he indwells it. The work is God's as He frees Himself from His self-limitation, but it can only be brought to completion through the free cooperation of men's wills; the work is man's too, as he frees himself from eternal limitation.

Is man in God, then? or will he be when all is completed? Is pantheism thus far true? Obviously, no; and for the same reason that the Box-Immanence theory is impossible. The type of absolute Reality and Unity is self-consciousness-personality-and personality cannot fragment ${ }^{1}$. If the doctrine of pantheism were true the universe would be a fragment of God, the work would be a fragment of God, men would be fragments of God-and the unity of God's personality would be lost. God's personality would be only in process of becoming, or, at best, there would be a perpetual alternation of kenosis and fulfilment; an aimless activity; the systole and diastole of a cosmic heartbeat that led to no true activity, because to no end. There would only be potential unity. God, by creating,

1 But the student of abnormal psychology may object that we do actually meet with the fragmentation of personalities in the pathological condition known as dissociation. I think the answer lies in the fact that the state is pathological. There is a failure of coordination among the neurones which leads to an alternation in the phases of manifestation of the personality. One part and then another predominates. But the failure is in the mechanism, as is shown by the fact that the mechanism can be set right by suitable treatment. Moreover, the cases themselves show clearly enough that although the memory of one phase may be absent from consciousness during another, as in the case of Miss Beau. champ, it yet acts as a determining factor working in the sub. conscious. The memories of one state are, I think, never wholly absent: they can be evoked and brought into conscionsness under hypnosis, and on this fact is based the treatment which leads to the restoration of the normal state. 
would have ceased to be transcendent, and so, would have ceased to be God at all. The apparent unity of man, too, would be merely the unity of an atom, while yet purposive unity must be postulated of each man, because after all man does not exist merely in a world of his own, but is capable of acting on others, in consequence of his unity, in such a way that apparent cosmical order is produced: the Universe, as a whole, manifesting orderly activity and indicating one Universal Truth. No such tissue of contradictions can ${ }^{\circ}$ be maintained for a moment. If God ever was Personal, He must remain Personal, in spite of a Created Cosmos; personality is the one stable thing, that cannot cease nor fragment. The universe is the material of God's work and of man's work too. It is created by God for the purpose of the work, and $\mathrm{He}$ indwells it. It limits Him, and is the expression of limitation in His experience. It is externally objective for Him as well as for us, in so far as external objectiveness strictly means not-self, and so, limiting-self.

True, objectiveness has another meaning which is often confused with this-here we reach the second part of the question we have just asked-Isman in God, then? Other selves are probably objects even to a transcendent self, when they are themselves transcendent. But their objectiveness does not constitute an external plurality, for they are perfectly penetrable. $A$ is $A$ and $B$ is $B$; but $A$ can wholly place himself at the view-point of $B$, and $B$ of $A$-there is no externality in the relation, even though the $A$-ness of $A$ and the $B$-ness of $B$ remain in their self-identity. Paradoxical though this may seem, we shall find it true even within the circle of a single personality. I can think myself as my own object; and this fact has a far deeper significance than is generally recognised.

Immanence is thus seen as the Consequence of a 


\section{Preliminary Considerations}

Ground. The Ground is the Transcendent God, Whose Nature is Love eternally. The consequence is perpetual creative self-limitation-immanence. Creation is not merely the effect produced by a Causal God, for it is the expression of His very Nature. Because $\mathrm{He}$ is what $\mathrm{He}$ is, perpetually-renewed creation expresses His activity of Love-creation means limitation,-limitation, immanence. Because God is Transcendent, He must become Immanent.

Having thus reached the conception of an immanence in a Work which is itself seen as the collaboration of men with God in working out His Will, we turn next to the problem of degrees of reality, and to the question, not yet touched upon, of whether the equation $I=I$ is universally valid, so that we may fit these two matters into their position in the doctrines of immanence and transcendence. Then, after a few words about the immanence and transcendence of man, we shall be ready to attempt a conspectus of the widely diffused matters with which we have been concerning ourselves, in the hope of achieving some clear ideas which will guide us in our further investigations.

Some retraversing of the ground is here unavoidable, if we are to make our thought lucid. We have already indicated that the type and expression of absolute Reality is the experienced unity of self-consciousness. This experience is essentially transcendent, for it is of the nature $I=I$ and has no innate relations of change or becoming; though it has the internal relation of reciprocity as an essential feature, the self being its own object; as is implied in the term self-consciousness. We have seen that if God is Love, the need of external activity is at least intelligible, if not (as I think it is) necessarily involved. At any rate we have the fact that there is a cosmos, and that this does represent an external activity of God, since the pantheistic interpre- 
tation is not valid. This external activity involves the creation of a work-material which is the expression of God's self-limitation. But in the very idea of a material lies the complete negation of reciprocity. The material is a part of God's experience in which reciprocity, and consequently Reality of the kind we have called absolute, is absent. Yet the limitation, or material, is real for God. iVe find thus two different types of Reality, whose relations become clear as we consider the work for which the material serves and exists.

This work is process or becoming, and with it space and time appear as implications, for external material involves extensity; process involves duration; and extensity and duration together produce what we call space. The work is shared by God and men; and therefore it is clear that God too is becoming. This is, after all, the idea that lies at the root of the doctrine of immanence. Is this becoming in duration and extensity real for Him? Unquestionably; if not, it is not real for us either, and thought becomes impossible, action valueless ${ }^{1}$. But it is real in a sense that obviously differs from absolute Reality. The unity of perfect self-consciousness is not there, both because there is limitation and because there is plurality. We have already argued, however, that, because persons are interpenetrating, the process, the plurality, and the limitation, will cease when all are perfected and transcendent. Reality will then again be absolute for God, and for men as well; for it will be, once more, the unity of perfect reciprocity, which is absolute Reality. (Of course, God has not ceased to experience absolute Reality inasmuch à $\mathrm{He}$ remains Transcendent; it is immanence, and all that this implies, that is only relatively real for Him.) God is Love; in those three words is the whole of ultimate truth;-God; the cause of all: God is; the absolute of

1 See note on Degrees of Reality, ch. i. pp. 42-44. 


\section{Preliminary Considerations}

Transcendent Being: God is Love; the whole doctrine of unity in reciprocity, of the Holy Trinity, of creative activity, of self-abnegation are implicit in this one sentence; and the present book, with its predecessors, may claim to be a brief and feeble commentary on this one little statement of all the Christian creed.

Our point at present is, that the Reality of Immanence is for God (and as we shall see, for man also) not merely of a different degree, but of a different kind from the Absolute Reality of Transcendence. But inasmuch as His Immanence is continuously passing back into His Transcendence, with the removal of the limitations set by the opposition of men's wills and their lack of reciprocity, immanent Reality is constantly passing over into absolute Reality.

This conception involves the problem of whether absolute Reality is receiving addition, and if so, whether the term absolute is applicable at all. The consideration of this we will postpone for a few pages.

Turning to man, we find the same passing of immanence into transcendence with the coming of full selfconsciousness, and we see that an internal reciprocity is involved in the self-consciousness of man as well as in that of God, since man too thinks himself as his own object ${ }^{1}$. Again we find the material, which for man, too, is a limitation - for freedom can only be won, as we have repeatedly insisted, out of limitations. Again we find the work, the creative shaping of life's plan, which is the moulding of the spirit in time and space. Again there is the growing self-experience which leaves time and change behind; the $I$ that simply is. Thus at first sight all appears the same as for God.

But it is not so. The limitation of the immanent stage in man is not a self-limitation, but primarily a limitation that comes from without. Only with growing self-

1 Vide infra, ch. iii. 
knowledge, growing union with God, does it become in any degree imposed from within. It only becomes a self-limitation of the same kind as God's self-limitation, in self-surrendering, self-sacrificing Love. In this man shows his Godhead even on earth. The only other form of limitation willed by man is sin; and sin is the surrender of self to the bonds of external things. In sin I am not the captain of my soul. As soon as we set up codes which may not be transgressed because they represent our growing sense of union with God, we begin to grow more like Him in that we impose self-limitation, and concurrently, free ourselves from the chains of circumstance. Doubtless when we enter into the perfect experience of reciprocal union with Him, we shall enter into His everlasting self-abnegation of creative selflimitation-if it really be everlasting, as seems necessarily the case. Then indeed shall we be like God; one with Him in Perfect Love. As yet we can be united with Him in so far as we are transcendent; but our experience of immanence is not the same as His. For us, immanent experience starts as the only reality; only gradually do we discover that, though real within its own sphere, it has nothing absolute about it, and cannot, hence, be part of the Ultimate Reality of the transcendent sphere.

$I=I$ is, then, the expression of the nature of transcendent experience. It is finally true in the sphere of the Absolute, and is a complete statement of the nature of absolute Reality (for the ' $I$ ' implies all the qualities of personality, which in the long run can be summed up in the one word Love ${ }^{1}$ ).

But the equation does not hold good when the limitation of creation has come to pass. $I_{c}<I$-where $I_{c}$ stands for the $I$ limited by creation, $I$ for the wholly transcendent self,-for limitation has come in. The perfect reciprocity and perfect unity are done away for

1 Since personality is capacity for fellowship. 
the time in one region of the self-experience (though God does not cease to be transcendent, because in the cosmos $\mathrm{He}$ is immanent). This symbolic statement is, however, incomplete, for it is static, and does not represent the dynamic nature of immanence. This we may express by saying that $I_{0}=f(I)$-that the immanent $I$ is a function of the transcendent $I^{\mathbf{1}}$. For us the great point is that the initial transcendent Reality is perfect reciprocity, and the perpetual cycle of creation returns to this again. The absolute experience of God is no fuller; only, others share it. For consider. In perfect reciprocity there is complete self-abnegation, complete sharing of experience ${ }^{2}$. Nothing new is introduced by the entry of others to share this experience; nor even by the entry of God into conditions of pain and limitation, since there is self-abnegation eternally in the self-relations of a God who is Love. (Death has no transcendent analogue; it is purely a phenomenon of limitation in time and matter, and is merely an extension of selfsacrifice. It is a stage, a crisis of life, not life's ending.)

I I am not sure that a competent mathematician could not formulate an equation expressing the rate of change of $I_{c}$ towards $I$, in terms of the relation between organism and environment, and the pari passu removal of God's self-limitation-an equation of becoming - that would be suggestive- -though it must be fundamentally remote from the truth, since no equation can take count of contingency, and freedom begins as contingency, even if it ends as harmonious self-determination. The equation would perhaps have to be of the type

$$
I=\int_{I_{c}=x+(I) \Sigma(a+b++)}^{I_{c}=0} \int_{I=0}^{I=\infty} f\left(I_{c}, I\right) \partial I_{c} \partial I
$$

if transcendence were wholly lost-which of course it is not-where $a+b+\ldots$ are phenomenal experiences of the created beings; but I am not mathematician enough to envisage the form it must take.

- This only becomes intelligible in the Transcendent Godhead when we assume the doctrine of the Trinity (vide infra). 
The importance of this we shall see when we consider the bearing of the statement that Christ took the manhood into God. If we believe that God is eternally creative, His eternal self-sacrifice involves suffering; and we are only posed by the question "Does not the actualisation of potential suffering constitute a new experience for God?" when with the words actual and potential we unjustifiably introduce the time-conceptions of 'before' and 'after' into our thought of simultaneous, Eternal Being.

Alike for man and God, then, in relation to the work, there is limitation by the material. For man this means external limitation, which must be overcome, and yet without which there could be no progress-the limitation of matter and duration; for God it means sclflimitation, determined by the conditions of the problem -the necessity for His creatures to win their own freedom.

What does this limitation mean in regard to God's knowledge? In transcendence there is complete penetrability, and so, complete knowledge in spite of complete freedom of all the personal beings - (for pure freedom is pure reciprocity, looked at in one way; and the two are seen to be statements of the same fact when we remember that the only eternal emotion is love, and love is complete mutuality and therefore complete knowledge ${ }^{1}$ ). The Transcendent God penetrates perfectly the transcendent man, as far as the region of man's transcendence extends. But in immanence, freedom and reciprocity are limited, and hence knowledge is limited. The immanent God cannot know the emotions and springs of action of immanent men fully (or vice versa), any more than immanent men know fully' about each other. He can only know in so far as men are ready to share their experience with Him.

2 Vide infra. 
But does the Transcendent God know about immanent men fully? Again the answer must be no, for these are different regions of His experience. As Transcendent God he does not experience men fully, for $\mathrm{He}$ is not transcendent in the region of $\mathrm{His}$ experience in which $\mathrm{He}$ is immanent.

Yet $\mathrm{He}$ is absolutely transcendent. How are we to reconcile the two statements with each other, and, above all, how can we reconcile them with the common conviction that 'God knows'?

Let us consider this last point to begin with. Our position, reached through our argument, is quite clear and consistent, and it will be well to restate it, for the correct statement of a problem generally brings us within sight of the solution.

God is immanent, which involves His limitation. Men individually are free to develope as they will, but they too are limited. Limitation means absence of freedom in some region or regions of experience. This means a certain degree of impenetrability; and impenetrability eventually meansimperfect love; for all the transcendent activities of the perfect personality are involved in that term love. But men are limited externally; have never been free; have never known perfect love.

God too is limited, and this means imperfect penetrability; but not for Himself. He is perfectly penetrable, for His limitation is internal and self-determined; the very issue of eternal love. He can be penetrated, but men have not yet learned union with Him; He cannot penetrate their hearts unasked, for $\mathrm{He}$ has given them freedom; they may and do bar Him out. Barred out, He cannot know their inmost lives, for there is sin there. Once more we see the creation and the Nature of God as one Whole, whose individual parts are meaningless when isolated, and only acquire their true significance when they are seen in relation to each other. 
For God, immanence means the winning, not of personality itself, but the freedom of its manifestation in the cosmos. Fellowship is as yet incomplete in that region of His experience. What this means we can partly understand if we think of ourselves in a room full of unsympathetic people. We and they alike are unable to reach the others' point of view; and so we are in part ignorant of them and they of us. Lack of fellowship involves lack of knowledge, and the lack is there on both sides. In just this kind of way God's knowledge of us must be incomplete, in so far as $\mathrm{He}$ is Immanent, as well as our knowledge of Him, for there is much in us that must be 'unsympathetic' for Him.

But what of transcendence? Surely God's knowledge of us, as far as we are transcendent, is immediate and complete? None the less there is contingency in the cosmos-and contingency real for God-because there are wills at work that are not wholly in accord with His. If this be so, He cannot know the individual acts of individual wills beforehand, when those acts do not spring from a sense of fellowship with Him, but are retrograde: prompted by alien, lower impulses. As Transcendent the completeness and fulfilment are real for Him already - the whole is eternally present-but not the individual wrong acts.

Thus it would seem that God's knowledge is limited by other wills not yet at one with Him; not only His knowledge as self-limited and indwelling the region of His self-limitation, but His transcendent knowledge. For in that region of His experience He has given up transcendence for the sake of men. Only as we get into touch with His timeless, changeless Being, does $\mathrm{He}$ regain transcendence in us.

I do not for a moment mean to imply the existence of two consciousnesses in God. The artificiality of any such suggestion would be equalled by its uselessness. 
None the less, there are, as we have already been constrained to admit, degrees of reality, and the consciousness of these different levels of Reality must itself lie on different levels. We know this in ourselves. In certain of our activities we treat the phenomenal as if it were the absolutely real. This is right and necessary, since, for the purpose we have in view at the moment, it is the only reality that concerns us, and that we can use.

At other times we see life steadily and whole, and phenomenal reality takes its proper rank. We are using our consciousness at the level of transcendence, and higher, even absolute, reality is within our range.

May we not imagine something of the same kind to be true of God? Must not God be a Pragmatist in regard to the reality of Process-for Process is Real to Him - even while He sees the whole? Is not the problem of the double consciousness of God simply another aspect of the problem of degrees of Reality-that is to say, is it not a fact that He has the 'pragmatic' consciousness of immanence, even while He has, at the same time, the allembracing consciousness of the Whole; the Ultimately. Real?

We shall find it very necessary to bear this question in mind when we come to consider the nature of Christ's consciousness, - we shall set out some final conclusions in the last chapter.

Once more we are met with a new realisation of what His self-limitation means, and gain a little more insight into His love. For God's Transcendent Self process in time and space is not absolutely Real, though it is real for Him in the region of His immanence in exactly the same degree in which His Immanence is real for Him.

But can a thing be at the same time real and not real $-A$ and not $A$ ? What of the Principle of Identity?for this is the root of the problem. Logically, no, actually, yes. For logic moves in one plane-the plane 
of causality - and only holds good there; and here we are dealing with two planes.

Let us take a simple illustration. I hear a call for help from the nursery; shout 'all right! I'm coming!' run upstairs to see what is the matter, and find the child has burnt himself. The call produces sound-waves, sets the tympanum vibrating and stimulates sense-organs which produce brain-changes in me. Contraction of various muscles sets my voice to work to initiate trains of soundwaves which will produce brain-changes in the child. Contraction of other muscles produces motion, and finally contact with the child. But the pain does not cause the child's call any more than his call causes my speech and my movements. There is a break in the causal chain at each end. My free choice under the stimulus of anxiety and emotions sets two causal chains in action; the pain emotion of the child initiates another causal chain of events. Emotion is itself the centre of freedom, but there is a break at each end, where emotion, freely acting, selects the desired causal chain. In short, causality only holds good where the whole action moves in one plane-in this case within the categories of time and space-and no logic can envisage the whole process, because its content is richer and fuller than the reason. The importance of this will be seen later ${ }^{1}$. Now apply this to the problem in hand. If $A$ is becoming it continues to be $A$, but yet grows fuller in content. Thus $A$ is $A$ or not $A$ according as one takes into account from the first the larger concept of Order, or merely the logical concept of identity-according as one fixes one's attention on the whole, or on the stage which exists at one given moment ${ }^{2}$.

Thus for God as Transcendent Being $A$ is $A$; the end

1 See ch. iii. p. 98.

' Cf. Driesch, The Problem of Individuality, ch. iii.; especially the passage on the disjunctive category, p. 56. 
is seen as real in a sense in which the process is not. For God as Immanent Being $A$ is not $A$. And both these are true for man as well. The end is before process for the Transcendent God, but the stages of process by which that end is reached are not within His transcendent knowledge, for they are not in the plane of transcendence but of limitation. As Immanent, God cannot have transcendent knowledge, so here, too, His knowledge about man is limited. Thus, returning to the equation $I=I$ and applying the thought we have just been discussing, we find it true for the Transcendent God (and for transcendent man); and true further (through the concept of Order) for the Transcendent God even while Immanence exists - and this helps us to some understanding of the fact that God remains Transcendent even while $\mathrm{He}$ is Immanent.

But it is not true for Immanent God or immanent man. God is becoming, as well as man; and thus we get degrees of reality; for in immanence is imperfect reciprocity, and so imperfect unity, imperfect knowledge, and actual duration.

Yet this relativity which we have perforce introduced into our conceptions of reality and knowledge does not leave us without a hold on the absolutely Real' ${ }^{1}$ : without some power of envisaging the whole. Man is transcendent; and transcendence is his anchor in the absolutely Real, preventing drift in the currents and storms of relative knowledge and reality. For transcendence is the experience of reciprocity, and the unity that comes from, and is, that; and man, by his transcendence, is linked with the self-experience of God, which is absolute Reality. There is no fear of drift or serious mistake. All that is good, all that makes for love and self-abnegation, belongs to the realm of the absolutely Real-for

1 For a full discussion of the relativity of knowledge and Reality see Bradley, Essays on Truth and Reality, cf. also chb. iii.-vi. infra. 
absolutely Real can have no other meaning than this. And this statement brings us back to our starting point; we are sure of our facts because Personality is the one real, stable thing we know; and Personality is the capacity for fellowship, which is Love. True unity is, in a sense, the unity of a system, but that system is infinite reciprocity, or Love; and so, is Personality. As our discussion proceeds this great truth will become continually more full of meaning. In man we find that unity is based on this. Man is a unity; made one in the freedom of emotion ${ }^{1}$. He is his own object, but yet he is still consciously one. The plurality that bears so hardly on his life, the misunderstandings and lack of insight that are the source of all his pain and sorrow, are the signs-manual of his limitation-of his lack of freedom, real to him, but not so real as the timeless unity that is himself. Man, like God, is immanent, but man touches the Eternal Godhead in transcendence. With growing freedom comes growing love, which brings him more and more into the union of complete transcendence. Here lies the power for good that those who believe in us wield - they see through change into the stable self, and make us more truly self-conscious; make us realise more our eternal being; make us ashamed to do anything that may hamper the spirit with fresh bonds. In that measure in which we are in communion with the Transcendent God, and realise our fellowship with Him, we know this inspiration in its highest form.

We are now ready to gather up the threads.

An attempt to formulate what we meant by Immanence showed us that we could only do so by keeping steadily in view the conception of Transcendence, since only thus can we keep in touch with the whole. Transcendence means both unity and activity, as well as unchanging permanence.

1 Vide infra, ch. iii. 
The only thing we know that is active, permanent, and yet essentially one is personality. It is active because it is in itself a reciprocity. The full meaning of this we shall develope later, but it may be summed up by saying that the completed personality is Love; while even limited personality is best defined as capacity for fellowship. By this at once the oppression of eternal sameness is removed; and the external activity that seeks to share the Perfect Experience becomes intelligible, while yet that Experience remains the one and indivisible Whole whose perfection cannot receive addition. Eternal Life is seen as the sharing of God's infinite Reciprocity.

Now if Personal Being is the essence of unity and permanence, any theory of what we have termed BoxImmanence, any Pantheism, becomes impossible, for it would entail the fragmentation of Eternal Personality; and fragmentation means the destruction of that unity which is fundamental for the very existence of personality. If it be true that all that is in the cosmos is part of God, He is no longer One, and so, no longer Personal. Instead we have innumerable fragments-persons who manifest a unity within themselves that may itself be fictitious-nay, must, for what safeguard have we against further fragmentation?-and inanimate systems that have a mirage-like unity of their own. Thought, knowledge, even activity, become meaningless and useless on any such system. And here, I think, lies the weakness of the Neo-Hegelianism that finds its unity in the sum total of finite, or at least microcosmic, personalities. The very unity, activity and reciprocity of each human personality, its permanence amid change, its transcendence, demand imperatively a larger Personal Cause, whose activity of love brings the cosmos into being.

The only other conception of Immanence that seemed 
possible was what we called Work-Immanence. The cosmos is external to God, inasmuch as it is a limitation of perfect mutuality and freedom, while it is within Him, inasmuch as it is a portion of His own Experience that is limited by the activity of self-renouncement which is an eternal part of Love. In this material other personalities are born, for whose sake indeed it came to be, and they limit God yet further, through their externality and limited penetrability. But they grow. They grow towards freedom, which at the long last is Love; and growing, they restore to God the Perfect Unity of unrestricted Love. Thus God is becoming. Yet He is becoming, finding self-realisation, in His own Work, as His Eternal Will sees its thought take shape and life eternal; much as the sculptor realises both his ideal and himself in his work. In these two senses God is immanent; $\mathrm{He}$ is becoming with His work; $\mathrm{He}$ is realising Himself in His work. This is Work-Immanence.

Turn now from the material to the Work. Man is a true personality, however fettered. He too createscreates himself and other men; and he is immanent in just the sense that God is immanent, because he too is a personal being. But, being personal, he simply is, persists through change, endures, and so is transcendent. Thought, Will, Emotion, the trinity of personality, is his. He too is satisfied in internal reciprocity, yet craves that others share his experience. He is like God in this also; and the fuller development of this theme will guide us in our attempt to understand the meaning of the doctrine of the Holy Trinity.

The difference lies here-that for the creature immanence is the means of winning transcendence; for God immanence is the only mode of giving the power of transcendence to His creatures. God's immanence is creative self-abnegation; the creature's is, at first, selfrealisation, self-winning alone, even though from the 
very first there is a kind of self-denial in the refusal to remain unprogressive. Since the Transcendence of God implies His activity as well as His unity, it is clear that His Transcendence involves His Immanence, for immanence means the immanence of the transcendent due to its activity; while His Transcendence implies His Immanence, for transcendence has no meaning apart from the transcendence of the immanent. The two are completely correlative. To the fuller elaboration of these suggestions we shall apply our thought in the last two chapters when we consider the evolution of transcendence. 


\section{CHAPTER I}

\section{THE TRIUNITY OF GOD}

BeCAUSE men are divine, created in the image of God and destined to eternal communion with Him, our spirits rove in a perpetual quest while we indwell the sphere of time. Furnished with our Roll, which tells us what to seek and how to seek, we pursue our journey. This Roll, which is God's revelation of Himself to men, through men, and through the Perfect Man, is annotated with marginal notes filling out the text with the experience and wisdom of generations; and year by year fresh appendices of revelation are added, each with its own commentary. Soiled by the mud of falls in slippery places; torn by the careless haste of doubtful and hopeless moments; mildewed with neglect, when it lay forgotten in arbours of careless ease; in parts illegible, in parts virgin and never read; it is still our most precious possession and only guide, for in it lie recorded the revelation of God and the wisdom of the ages. Our quest is God Himself; the Roll, our knowledge of Him.

Because of the impress of the divine similitude upon our nature we are drawn to God as the needle is drawn to the magnet. In life $M$. Bergson sees the urging of a vital impulse; it is truer, looking on all process as teleological, to see in the process of life tractation rather than impulsion. Mere impulsion brings purposeless change, unless it is directed towards a Causative Reality which does not change. If it. be so directed, impulsion is a meaningless term. The final causation is not in Life itself, but in the Causative Reality; not in process, but in the end. Nevertheless the word impulsion does present an important truth. Process and its causation are different aspects-consequence and ground-of one 
great whole. Revelation and evolution are the obverse and reverse of the medal. The life-process is not determined from without; its end may be, indeed is, but not itself. The individual can respond to his environment in many ways, choosing his future path. And when the choice is conscious, the responsibility of choice rests upon the chooser. The individual creates, as well as God-creates his own future, and adds to the environment of others; himself becomes a source of tractation; a causative Reality. This aspect of the process of Creative Evolution, or, to use the suggestive term introduced by Cunningham ${ }^{1}$, of Creative Finalism, has been dealt with at some length in my Evolution and the Need of Atonement and Evolution and Spiritual Life. The purpose of the present book is rather to attempt an examination of the other side, and to consider, from the standpoint of the Christian conception of God, what is the nature of the Causative Reality, and what is the foundation of the tractative force that makes for creative finalism. If it be objected that to do this is to offer a recension of the Roll of our metaphor, and that to dare to make such a recension is bold and even impious, we must agree to the first in some measure, and in part also to the second.

Such an examination does involve a critical correlation of all the evidence, if not a recension. It does involve an apparent, though not a real, reduction of revelation to the level of other evidence, because of the human and fallible medium of that revelation, and because of its partial and progressive nature. And unquestionably the attempt is a bold one, foredoomed to partial failure. It cannot approach completeness, and the purview of one man is very limited and one-sided. But yet we dare to believe that no such attempt is im-

1 An Introduction to the Study of the Philosophy of Bergson, by W. A. Cunningham, 1916. 
pious. Human nature is divine: the mirror of the Eternal; and we can only envisage the Unknown through its known counterpart. Because of this, the effort to understand the Godhead through the study of manhood is the most hopeful method open to the partial powors of reason.

We shall therefore start from the basis of human personality and our knowledge of the laws which govern it, and try to construct some conception of the Divine Personality and the laws of Self-determination which govern its Activities; in order to find, if we may, a sure foundation in reason for the revealed Nature of the Godhead.

Before we begin our proper task it will be well to remind ourselves briefly of the dogmatic teaching of orthodox Christianity as to the nature of the Being of God, casting it in a modern mould. To this and to the formulation of difficulties and questionings the present chapter is devoted.

(I) Our knowledge of the existence of God rests on His self-revelation under conditions apprehensible to us, which means, directly or indirectly, to our reason.

(2) Our knowledge of the Nature of $\operatorname{God}^{1}$ as seen in His manward aspects-of what we may call His Objective Being-rests on our recognition of His attributes, which are manifested to us in that self-revelation, and on the fact that our own nature renders such recognition possible.

(3) Our knowledge of the essential or subjective Being ${ }^{1}$ of God - the Being of God for Himself-rests in part on His special revelation throughout the

1 For justification of this distinction between God-for-Us (limited human beings) and God-for-Himself, and discussion of the problem of the thing-in-itself which is apparently involved, see Preliminary Considerations, pp. 12-16. 
ages to men who sought the truth single-heartedly, which revelation was completed in the revelation of the Incarnation, but also in part on man's knowledge-instinctive more than reasoned, as a general rule, but knowledge none the less - that personality can only mean one thing; imperfect or perfect as may be, but essentially the same; that, so, if we are persons and God is Personal, we can learn His real and absolute Being by learning our own, through the infinite projection of that self-knowledge so slowly won.

(I) With the proofs of the existence of God we have no intention of dealing in the present work. These proofs find their premisses in the nature of knowledge, in the existence of mind, in the evidence of purpose in phenomena, in the existence of moral values and their judgment; they are elaborated in countless volumes along the lines of metaphysics, of ethics, of epistemology, of physical and biological science. Whenever and however the thought of man presses reasoning about phenomena to its ultimate issue, God is found. There may be many turnings aside; false logic may for a time obscure the truth, but sooner or later reason finds a God. The attitude of the mystic who claims, and probably claims justly, that he has immediate spiritual proof that God is, just as a calculating genius arrives immediately at the solution of a complex problem of arithmetic, is hereby vindicated, and he takes comfort in the fact. Nevertheless by so doing he implicitly admits, what he explicitly denies, that the revelation of God's existence is an appeal to reason. Man cannot know complete content unless his reason approves that which his intuition acclaims. Intuition may be the guide to reason, but his whole being must be satisfied before he can rest. We are never satisfied unless our reason approves what we believe, though we may not have trained that reason to 
search -very deeply. If we accept statements made by authority, for example, our preliminary acceptance of that authority is based on reasoning, of however inadequate a kind; if we accept the reality of mystic intuition we at least justify the claims of intuition by argument. And for our purpose it is immaterial whether the belief comes first or the argument; whether we argue because we believe or believe because we argue. Very likely belief is prior to its formal justification; very likely it begins as a vague judgment of experience as a whole, without formal justification by completely logical methods. But the important fact for us to remember is that we do in fact justify or attempt to justify our beliefs by an appeal to reason.

We see evidence of this in the progressive unfolding of the idea of God in primitive and more advanced religions. The representation of God at any stage is such as appeals to the mind of man as rational. Thus our belief in God rests in the long run on an appeal to reason, even if it does not originate there. The basis of faith is clearly defined; it is no mere longing and vague aspiration.

Bearing this fact in mind we may pass on to our second point, while keeping clearly before us the knowledge that, God being the Eternal One, the Causative Being, we could know nothing at all of Him except by His revelation of Himself to our reason. That this is implicit in, and inevitable from, the nature of His Personal Being is another matter to which we shall return later.

(2) Our rational knowledge of God rests on the recognition of His attributes. Were He simply One, there would be nothing to be known in that empty unity. We know Him in the determinations of His essential Being.

These attributes we indicate by such terms as Activity, Omnipotence, Omniscience, Wisdom, Righteousness. Love and Eternity are different from the rest, 
as we shall see, but we must consider them also. God is Eternal, the unchangeable I AM. But it is no dead unchangeableness; rather it comprehends within itself a never-ending activity. Besides the inner activity of eternal reciprocity, this activity manifests itself externally as creation. Why, if the internal activity of reciprocity is perfect, God's activity should function externally at all, is a question which may be reserved for the present. The most certain fact of our experience is that ourselves and the universe exist, and that, since we believe that there is a God, and must believe it, ourselves and the universe do represent the external functioning of the activity of God.

We cannot fully understand the next point, but God is certainly pure thought and knowledge, though not only pure thought and knowledge. He knows Himself, and knowing Himself $\mathrm{He}$ is omniscient, comprehending all knowledge within the circle of His Being and His Activities. In all His creation $\mathrm{He}$ is omnipresent; nothing is without the perfect round of His experience. $\mathrm{He}$ is within His creation, filling it with His presence; but yet His creation is not within Himself. It is in process of becoming through Him; $\mathrm{He}$ is, yet is becoming in it. He is not the creation which He indwells, but the creation is in Him as well as through Him. It is real, but is not the absolute Reality of His transcendent experience, since it is becoming ${ }^{1}$. God is then omni-

1 Cf. Bradley, Essays on Truth and Reality, e.g. "And so again it is with the becoming and the endless incompletion of the world. To deny that this side of things is fact would in my view be absurd. But on the other hand to accept this side of things as real in itself and unconditionally, and to proclaim it as being in its own character the last word about the Universe, to me seems no less ridiculous. In this volume I have urged that what matters and what is ultimately good, is the whole, and that there is no aspect of life which, abstracted and sct utterly by itself, can 
present, and omniscient of all reality. That which is becoming has not yet achieved absolute reality, but is in process of achieving it. Thus it is only relatively real, and so is susceptible only of relative knowledge ${ }^{1}$. Hence, in so far as God is indwelling the Universe He knows it with the relative knowledge of a being who is in process. He knows it as man knows it; that is to say, His knowledge reaches only up to a point, and differs from man's in degree, not in kind. The Immanent God is limited by the contingency common to the knowledge of all immanent beings. But in so far as all process is comprehended within the circle of the eternal activity of Godhead, the partial knowledge of process which is being experienced is swallowed up in the perfect knowledge of Transcendent Experience of activity in which there is no process nor duration, but only the perfect experience of simultaneous Reality ${ }^{2}$.

retain goodness. And on the other side I have insisted (if I may repeat this) upon the absolute, the unassailable right of every aspect of life to its own place, function and liberty." Op.cit. pp. $471,472$.

1 By relative knowledge I mean knowledge of things which are real, but only in conditions of time and space. For a discussion of the subject see Bradley, Appearance and Reality.

I I imagine that the relations of being to becoming, and of becoming to being, can never be satisfactorily determined by the human mind. They involve the whole perplexing question of the degrees of Reality, with which the present scribe is certainly not competent to deal. Nevertheless a brief discussion may clear the air and present the problem to our minds in its naked simplicitya simplicity that only adds to its difficulty. Absolute Being we can only define as the full experience of self-conditioned Reality. Becoming is not absolute, because it is conditioned by something that is not-self. It is not merely the experience of duration, but rather of that which is implied in the word duration - of something that produces the changes of becoming. There could be no duration without change; there could be no change without something 
Being Omniscient God is also Omnipotent. This omnipotence is realised externally as the power of creating beings external to Himself. He is eternally

to cause that change as well as something that changes-an externality is implied in the very word duration.

These definitions do not involve immobility, inactivity, in Absolute Being, unless it be defined as pure unity as well, but they do involve only internal activity. As soon as external activity starts, being is transformed into becoming, in part of the Reality experienced at any rate, if we give to absolute being the faculty of experience at all-as we do when we postulate a personal God. And at once we reach the problem of degrees of Reality.

Is becoming then real? It is real in the sphere of duration. It is a real experience in the realm in which, owing to duration, we are able to look upon related experiences as cause and effect; or more truly, because of their relatedness, as Ground and Consequence. But in the absolute sphere it is outside the realm of real experience. It is recognised as being there-a fact-but only by transjecting absolute being, by an effort of thought, into the sphere where it is not absolute. This becomes clearer when we think of human experience. The great, absolute reality to me, as regards myself, is that $I$ am. It requires a refocusing, an accommodation of the mind's eye, to pass from that to I become and visualise that fact. Yet both are to me truisms, and I recognise their obvious reality in different planes. And thus to pass does not alter the reality of the fact that I am, even to me. The difference lies here; that this is more absolutely and antecedently real than that $I$ become; and to grasp that I become, at all, I have to pass from the absolutely real on which my attention has been fixed to the relatively real of everyday experience, by a conscious effort. The necessity of this effort does not however in the least invalidate the truth that I experience both kinds of reality. Apply this now to God. God may-must-know that He is becoming. The experience is real to Him in His relation to the Universe; but to His Absolute Being it is only relatively real-appreciated as real only by the effort (if we may call it so) of transjection into the durationsphere; which effort is the realisation of self-limitation.

Finally, this becoming will only cease to be even relatively real 
making something new; beings who are centres of activity external to Himself, yet comprehended within the circle of the perfect experience. His omnipotence is manifested in self-limitation-a kenosis eternally destined to fulfilment as a pleroma.

All His activities are determined by His Goodness. In perfect wisdom and in perfect righteousness He promulgates His self-determined fiat. It is hard at first to see what can be meant by the goodness of God, His righteousness and His wisdom. Surely, a man may say, goodness implies choice, and the possibility of evil. If you postulate goodness of God you at once introduce the possibility of evil; you return to the cosmogony of the Zend Avesta; the opposing principles of good and evil, Ormuzd and Ahriman, come into being.

Let us first consider the point in relation to the universe. Righteousness and wisdom supply a norm whereby the fluctuating standards of mankind may be regulated. They correct the mutability of human thought. In relation to the created universe then, the postulation of these attributes is in fact an affirmation of the freedom of man to choose as he will. He can choose whether he will be like God or no; he is truly free.

for God when His creatures are united with Him; enfolded in the union of perfect love. Then there can be no more becoming, even though there is a certain measure, not of externality, since there is perfect interpenetration, but of otherness due to the absence of fusion or absorption of personalities into one impersonal essence. The otherness will be the same in kind as the otherness which differentiates the Persons of the Godhead, though differing in degree, since men are caused, God uncaused. But as all will be complete and transcendent there can be no change, and so no becoming. The activity will be mutual, interpenetrative. (The cessation of becoming for the Timeless and Absolute Being, only suggests a difficulty - how anything can cease for the Absolute God-when the origin of the experience of becoming in self-limitation is forgotten. See Preliminary Considerations.) 
We see then that goodness postulated of the Godhead opposes an unchanging moral standard to all the changes and chances of humanity's vagaries. God is good in relation to His creatures. Evil is not His creation, but theirs. It is the misapplication of freedom; the refusal to conform to the true standard. This we have worked out at length elsewhere.

But in what sense can we say that God is absolutely good? for the goodness we have been describing, is in a sense relative. The question can only arise from an incomplete understanding of the problem. Absolute goodness is simply the expression of the nature of the Godhead; for it is the expression of His Love, which we have next to consider. Being absolute, it is not relative to anything. It is not goodness-as-compared-with-evilness, but simply the manifestation of eternal love. As goodness it only comes to have a meaning when it becomes normative; that is, when it is considered as relative to that which is becoming - to that which is not in itself absolute. In other words, like the attributes of Omnipotence, Omniscience, Omnipresence, it is a mode of manifestation of the Godhead to beings external to Himself. It is not an attribute of God-for-Himself alone. His internal activity is for Himself: His eternity, and His love. These are included in the $I A m$. They have a meaning apart from creative activity. The others are expressions of His nature, to His creatures. And since we shall see that God's activity is implicit in His love, we find that the attributes of God for Himself are summed up in the phrase "God is love"; the 'is" being not of time but expressing His eternal simultaneity. The other attributes we may call, using the word of the writer to the Hebrews, ámauyá $\mu a \tau a$, beams of His Radiance, made visible as they fall upon the created world.

A very striking fact now becomes apparent. We have 
to say that Omnipotence, Omniscience, Omnipresence, Goodness are attributes of God: means of His self-manifestation to others: of the revelation of His absolute Nature; and yet at the same time we have to say.that "of course as Immanent God, He cannot be Omnipotent, Omniscient, Omnipresent in an absolute sense, or even Good." The terms are all relative to His Universe; and once we get to the universe we find His activity, and so the manifestation of His attributes, hampered by a very real contingency. He would be omniscient, but for the fact that man is free; He would be omnipotent but for the fact that to manifest omnipotence would involve self-contradiction, since $\mathrm{He}$ has granted man free activity; He would be omnipresent if man did not keep Him out of that part of his soul which is dedicated to evil; He would be good, if man would recognise Him as the Norm-but man insists that Good is something else, freely chooses something else as Good, and since Good is merely normative, God cannot be that Good. Real Good is the manifestation-to-others of Love. But what men call good is a certain easy-going kind of happiness-mongering. And that is therefore Good; it is what they mean by Good. The whole problem of pain arises from taking man's norm of goodness, assuming that it is the same as God's norm, and then calling it absolute-two fatal blunders. There is no such thing as absolute Good. Good ought to mean absolute love seen as a normative principle in the sphere of becoming. It does mean something quite different. Therefore God is.not even manifested to men as good. In this fact lies, perhaps, the solution of the problem of pain. The question is seen to be one of terminology. Goodness is properly the manifestation of Love under the condition of limitation. What men call good is a creation of their own inadequate reason, and in this sense God is not good. Our main point, however, is something different 
-that Good is merely a normative principle. God is not Good for Himself-He is simply Love. But Love, in its manifestation to beings who are incomplete and becoming, must impose a norm; and this norm is goodness. Man, moreover, by importing mistaken meanings into the term, confuses the issue, and creates for himself an artificial but insoluble problem of pain.

As far as the Immanent God, then, is concerned, His attributes are ideals rather than realities. They represent what would be if men's wills were completely free, and wholly aligned with His, and were yet becoming. In other words the attributes become true at the moment when they cease to be. For when they became true God would cease to be immanent; all change would be swallowed up in transcendence. Thus Omnipotence, Omniscience, Omnipresence, Goodness, are ideals of the Immanent God; divine, far-off events to which the whole creation moves together with Him. Though these are His attributes, He achieves neither the one nor the other, as Immanent; as Transcendent He can have no attributes, for transcendent knowledge of Him must be immediate. We shall know Him as I AM : as Eternal Love. Viewed from this angle, the self-limitation of God in creation acquires fresh meaning, becomes fresh marvel. We seem to get behind God's attributes to His real Being, which is Love. We get behind difficulties ethical, difficulties spiritual, difficulties natoral, into a blinding dazzle of the eternal Truth that is so overwhelming that we have to get used to it before we can see at all. But one of the great realities the light brings out seems to be that man realises the relation between the immanence of God and of himself, seeing both as aspects of the great Whole of God's love, as Ground and Consequence; that he recognises the event to which both move; recognises the love of God that is content to accept even self-limitation of His own attributes- 
His own powers of manifesting Himself - for the sake of His creation; begins to understand what that day, when all that is in part shall be done away, will mean for God as well as for Him; begins to share God's joy beforehand.

In relation to Himself, then, God is Love; in relation to His universe $\mathrm{He}$ is, or, strictly, approaches, Wisdom, Power, Knowledge, Goodness as well. But we must later inquire into the implications of the eternal fact of Love as God's self-expression, and we shall find that it is rooted in the inter-relation of persons. Indeed in the three words 'God is Love' the personality and plurality of the Godhead are implicitly stated. In His creation, too-in the finite universe-as soon as personality comes into being, love has a meaning. Man becomes able to realise something of the real nature of God's Being when he begins to understand the word love, and He begins to understand what love is only when he reaches the stage of self-consciousness and becomes a person. Understanding, however feebly, he comes into personal contact and communion with God Himself; no longer merely experiences the manifestation of $\mathrm{His}$ attributes, which are His relations to the universe, in so far as it is external to Him. For love, even faulty human love, is not of time, but constitutes the bond of union between eternal beings. Not until the transcendent ego comes into being does love exist, and this love expresses the realisation of the mutual penetrability of persons, which lies at the root of eternal life. Man still, of course, experiences the attributes of God, because he is still becoming; but he learns to understand them; learns their significance as the beams of love's radiance; and so learning he is beginning to understand God. God is revealed in His attributes-in the illumination of the universe by the divine radiancy the source is made manifest-but man, because he is personal, as God is personal, is not content to rest in the knowledge of God's 
nature from His attributes. He must know God Himself as one person knows another. And the beginning and ending of this knowledge can be found only in love.

(3) In the end of the last section we foreshadowed the method by which we propose to approach the problems of the doctrine of the Holy Trinity. Personality and Love are the wards of the key by which we shall try to unlock one of the doors of our understanding of this central mystery of Godhead. For the moment, however, we will rest content with offering a brief résumé of the doctrine as usually held by the Church. This is generally assumed to be based mainly on revelation. How far this assumption is true, and what the nature of that revelation is, we shall have briefly to consider later.

The Christian doctrine of the Godhead is, then, that It is Three in One and One in Three. The One God exists in the Unity of perfect Love, yet there are three hypostases in Him. These hypostases are not attributes, nor varying manifestations of activity; for alike in Father, Son, and Holy Spirit, all the divine attributes are present in relation to the Cosmos, and of each is it equally true that God is Love, where the three words receive each one the signification we have already given to them. Neither are they personae, masks, for each reveals, not hides, the Godhead. Nor are they aspects, for each reveals the complete Godhead, at any rate by implication. In fact.the word hypostasis has undergone many changes in the exact shade of its meaning. Originally it denoted simply the idea of reality. In the Stoic Philosophy it was equivalent to ovं ia ${ }^{1}$. At the time of the council of Nicaea it lay rather more than midway between mode and person, inclining to the latter. Dörner, one of the protagonists of the Kenotic theory, definitely states that a distinction must be drawn between hypostasis and person-tending in this to the

1 Ottley, The Doctrine of the Incarnation, p. 576.

MOD. 
impersonal conception of the being of the Logos before the Incarnation which was so characteristic, in a different form, of the theology of the Eastern Fathers ${ }^{1}$. With such a point of view I cannot agree. Valuable though it is in laying stress upon the reality of the kenosis and the gradual growth of our Lord's human personality, anything which seems to depersonalise the Holy Trinity in any degree appears to me essentially mistaken. I propose to use the terms hypostasis and person as almost ${ }^{2}$ interchangeable; and indeed we shall find that, as our argument proceeds, the personal nature of each hypostasis becomes more and more marked. Thus, though we use the word Logos, and indeed start from a conception of the Logos almost Philonic, from the very first we shall have always in the back of our minds the personal, not the impersonal idea of His nature. In each hypostasis, then, is the whole nature of Godhead revealed. Each is a Person, in the modern sense of the term, fully self-revealing, not a persona, the mask that conceals the common clay of the actor, as the original word meant, nor even an actor in the drama of the universe, as it later came to mean ${ }^{3}$. In the modern sense a Person is a complete self-identity, fundamentally different from all others; conscious of others; with his own peculiar experience, yet able to share the experience of others. A person is self-revealing, penetrable, penetrating; manifesting attributes by which he-may be apprehended by others. Yet in the closer relationships the apprehension is largely, and can be imagined completely,

1 For these, as for other points of detail, I am indebted to Professor H. R. Mackintosh's admirable work on The Person of Jesus Christ.

Not quite. See the discussion of the emphasis of each hypostasis, ch. iii. pp. 108 seqq.

- In Trinitarian doctrine the word was introduced by Tertullian from Roman Law. Ottley, op. cit. p. 578. 
independent of these attributes, being mediated by pure mutuality, of which love is the expression. In this sense the Godhead is three Persons. On the other hand we must be most careful not to entangle our thought in false conceptions which endanger the essential monotheism that underlies both Christian and metaphysical belief in God. "If the term 'person' in Trinitarian doctrine is more than 'aspect,' it is certainly less than 'individual.' After all, it is a fundamental truth that the world is upheld by God, not by a constituent, or part of God. There are spheres in which division of labour is unmeaning1." "Person, in Trinitarian usage, is a mode of being which serves as a ground or basis (a real ground or basis) of special function, but just stops short of separate individuality, since it implies distinction without division 2." Moreover God is Three Persons eternally, and not merely in relation to the Cosmos as Sabellius taught. He could not be Father unless $\mathrm{He}$ was self-distinguished into an Other. $\mathrm{He}$ could not be the Son unless He was similarly self-distinguished. Further He would be Chaos, not Order, if there were not a divine Principle of Thought in Him which made Him rational in His mutual and eternal Activity. For in the Eternal God, Thought and Being are one.

This eternal Principle of Thought, or Logos, mediates His activities. The Logos is thus in a sense derivative, but yet a definite and distinct Hypostasis. The Logos is Begotten of God, and so is His Son; eternally His Other. The Logos is the expression of God's recognition of Otherness in Himself, without which Activity and Love would be impossible: $\mathrm{He}$ is the reality of God's self-division into I and Thou. And without this reality of self-differentiation, God could not be self-conscious.

1 Mackintosh, The Person of Jesus Christ, P. 485.

2 Sanday, quoted by Mackintosh, op. cit. p. 524. 
Yet in I and Thou, taken alone, unity is lost. Of necessity the Godhead is divided into I and Thou, Father and Son. If this were all, God would suffer compulsion, not merely from the impossibility of contradicting His own nature, as I and Thou only, and no more-and this would involve the impossibility of creation-but also by the necessary distinction of Thought and Being. The unity is restored in the Holy Spirit, proceeding equally from Father and Son. Being and Thought are made One again in the Essential Freedom of the Spirit. The Holy Spirit is thus the expression of God's recognition of the Principle of Freedom in Himself, making the activities of the Godhead glorious in Love ${ }^{1}$. He realises the eternal creative fiat of the Father through which the Godhead is active and self-conscious, making Godhead not pure Thought-not merely rational instead of chaotic,-but Personal Being also. The Spirit as it were re-unites pure activity with derivative order, as Personal Being, in virtue of the fact that the Holy Spirit Himself is derivative from, and correlative with, Activity and Order, as Freedom. Using abstract words like these in their own meaning such a statement is void of any intelligible signification. The words themselves must be made real, and more, must be hypostatised, before one can begin to apprehend the truth which they signify. I suppose it will always be more difficult to grasp even the fringe of the truth which is expressed in the personification of the Holy Spirit than it is to do so in the case of the Father and the Son. "I" and "Thou" are personal words. "He" implies a relationship more external, which cannot be applicable to the divine Trinity; and we have no word that implies the perfect relationship of a third person

1 I am aware that the principle of Freedom has been often assigned, as by Dorner, to the Logos, but this seems to me to originate in an incomplete appreciation of the melaphysic of Trinitarian doctrine. 
to other two. This is necessarily so, because our personalities are still in a large measure isolated; we have gone so little way towards perfect union in plurality. Mutuality we are beginning to understand, but we confine it to two persons. Moreover the simple relation of mutuality between two persons seems to us so almost perfect, that a third would spoil it. The familiar proverb that 'two is company; three, none,' goes far deeper than is generally recognised.

The necessity for this Third Person of the Holy Trinity will emerge more clearly when we come to study the human personality. Meantime, we must content ourselves with saying that the Godhead is, from the necessity of its own nature as Love, differentiated into I and Thou, Father and Son; the Father Originative and Active, the Son derivative as the mediating Principle of Ordered Reason, limiting the Father, as it would seem at first sight, in the modes of His Activity. But since such limitation is a contradiction of the pure self-determination of the Godhead, from Each proceeds the hypostasis of Freedom which makes the mutuality of Father and Son perfect once more in the mutuality of Each with the Holy Spirit, who retrocedes into Each again.

But as we look deeper into the mystery of the eternal Personality of God we seem to see a need of the Effulgence or a $\pi a \dot{v} y a \sigma \mu a$ of His Glory, upon an objective manifold. Love implies activity, functioning externally as well as internally. "Perfect Love craves that others should share that perfection, not in order that It may be increased or made more perfect thereby, but because love's nature is centrifugal as well as centripetal. Just because God experiences perfection which cannot be added to, He must needs, in the utter self-lessness of perfect love, make others share it. As we have seen elsewhere Love implies the existence of an eternal subjective or internal manifold, but it desider- 
ates an objective, external manifold as well, to share that experience. Such an external manifold must consist of beings who can share the experience of perfect love to the full, in complete union with God, but who yet cannot share the primordial mutuality of His own internal or subjective manifold. He is when they were not. They are the creation of His Fatherhood, derived from his fiat through the mediating activity of the Logos in a cosmos indwelt by His Free Spirit. They cannot. be God, even when they share His experience. All this we have dealt with at some length in Evolution and Spiritual Life, and it is only necessary to refer to it here in order to connect our ideas of the Eternal Being of God with His manifestation of Himself in the world.

In relation to the world, then, the Fatherhood of God expresses itself in creation, whereby personal beings shall eventually be enabled to share His perfect experience. In itself this is a proof of His Love, as Father. But in the method of creation mediated by the Logos, in order that the freedom of the spirit of man shall not be impugned-and such impugning would involve an unthinkable schism in the Godhead, since the Principle of Freedom unites Pure Being with Pure Thought in the three hypostases of the Holy Trinity-God suffers selflimitation in creating the conditions through which freedom may be won by His creatures, thereby rendering one portion of His experience imperfect; and yet further, suffers the possibility of external limitation from the wilful misuse of their freedom by His creatures; which possibility is eventually actualised in sin.

Finally, that freedom may be possible, and may be realised in the union of the common experience of process by Himself as well as His creatures, He indwells the world as the Holy Spirit. Thus God Himself undergoes the changes of process, in the conditions which we call duration and matter, in order that His Experience 
may be in all ways identical with that of His creatures as they evolve from unconsciousness to consciousness, so that eventually union may be complete; for this same end the Mediating Logos becomes Incarnate, in order that, sharing to the full men's experience as limited personal beings, He may be one with them, and they with Him, in the experience of bodily limitation, and that, with Him, they may transcend duration and enter into eternal life. By man's sin the Incarnation is made to involve at-one-ment in another sense, as the renewal of the possibility for which the creature was made. The barrier between man and God must be done away. For this end God as Christ experiences all the isolation of $\sin$ in needless suffering, Himself sinless, thus once more sharing man's experience to the full, and making union between man and God again possible. Through the Incarnation they are at one, and if man will accept this at-one-ness-for he cannot be compelled without his freedom being impugned, and so one part of his god-likeness, and hence his power of entering into real love of God-he passes, in union with God, through limitation into transcendence. These points again have already been dealt with, and reference should be made to Evolution and the Need of Atonement and Evolution and Spiritual Life for their fuller treatment.

In the foregoing brief account we have summarised in modern form what seem to us the essential implications of the traditional doctrines of Christianity in regard to the nature of the Godhead. If in places we have been dogmatic in disputed matters, it is of set purpose. We have set down nothing, we believe, that is antagonistic to the fundamental teachings of the Church in any degree. But in disputed matters, such as the deeper problems of the Incarnation and Atonement, we have definitely chosen that expression of the truth which seems to us to fit in best with the aspects of human 
personality which we shall shortly have to discuss. The basis of all that we have said is to be found in the Bible. The right of interpretation has been freely used, without, we believe, overstepping legitimate bounds. Chapter and verse have not been given; the task would be a long one and for our present purpose unnecessary, since the scriptural basis is to be found in many theological treatises ${ }^{1}$. The present chapter is simply meant to set out the teaching of the Church; assuming the Authority of the Bible and the Authority of Tradition. With several other questions on which we have but touched we shall have to deal more in detail. For instance, it is certainly true to say that the hypostasis of the Holy Spirit is far less clearly delineated in the revelation of the Bible than are those of the Father and the Son.

Again, the whole process of reason which sub-divides the Eternal, Absolute Godhead into three modes, while contending that they are not modes at all, but hypostases or persons, seems at first sight artificial and arbitrary. We can think of the three Persons of the Godhead in relation to the created cosmos, though in doing so, we are very apt to lose sight of the unity of the Godhead in a kind of veiled tritheism, but when we come to try to carry our thought back to the absolute aspect of Godhead, without time or change, or anything but transcendent activity, we cannot help feeling that the three Persons are modes of His relation to the cosmos. Even when it is pointed out that in the realm of the Absolute Pure Unity must be wholly inactive and so indistinguishable from Pure Nothingness, reason gives

1 In Martensen's Christian Dogmatics, for example, many references are given in the course of a most able conspectus of the orthodox Christian doctrine in regard to the Trinity, as understood by a mind well versed in metaphysic, and the same is true of Mackintosh's The Person of Jesus Christ, Ottley's The Doctrine of the Incarnation, and many other works. 
but a grudging consent. However reason's hold on the idea of the Nature of Eternal Being is at best very shaky. And this is necessarily the case, for human thought reaches out into and intersects the Absolute in a very small portion of its own perimeter. Only a very small portion of ourselves has reached transcendence. Mostly we are concerned with existence under the conditions of determined immanence- of life lived under the conditions of time and space; of life which is in process. I am as well as I become; but as yet most of me is still becoming. I am there to experience becoming, and in so far I am transcendent. But it is only that part of me which has achieved transcendence that can enter into relation with the Absolute Being of God ${ }^{1}$. Further, my transcendent self is not pure thought or Reason. Thought is only one side of that self's activities; and though the human intellect must be satisfied, it cannot of itself achieve complete knowledge. Herein lies the greatest difficulty of our task. We can only communicate our beliefs to others in words, however much we can influence those with whom we are in direct and intimate contact by the conviction of our whole being. These words must appeal mainly to the intellect, if we attempt to express in them a formal proof of the grounds of our belief. Thus such proof must be even to ourselves incomplete. To complete it we have to try to express implications not founded on pure thought, but appealing to other sides of our personality. In a book which professes to appeal mainly to the reason such implications are not acceptable even if they are realised at all; and besides, too often miss their mark altogether, passing unrecognised.

We must be prepared, therefore, to meet with objections like the following. "I am prepared to grant that undifferentiated Unity is equivalent to Nothingness

1 Evolution and Spirilual Life, ch. vi. 
I am prepared to grant the need of postulating an internal manifold in the Godhead, in order to explain the known fact of God's activity. But why hypostatise these modes? And, why Three Persons? Why not two or four or a dozen? Why even this apotheosis of Personality at all? Again why appeal to revelation, which, after all, may merely represent man's own attempts to reach an understanding of the Nature of God? In fact, this is what revelation is; if God were really and directly revealing Himself $\mathrm{He}$ surely would not make so many mistakes, give views of Himself so partial as to produce a totally erroneous impression. That such mistakes, such erroneous impressions, did historically occur, not only among the less favoured nations of the world, but also among the Jews, is abundantly clear from the Bible itself. Why then claim anything divine in this record of man's search after God?"

Many such questions may be justly asked; and at present we shall attempt no categorical answer. Instead we shall examine certain aspects of human personality, and argue from the known. By doing this we may reasonably hope to find some indications of the meaning of divine Personality, some foreshadowing of the eternal answer to these questionings. The last however we may dismiss with a word. The evolution of man's idea of God, which is the salient feature that emerges from a study of comparative religion, is only explicable on the assumption that there is a God who is revealing Himself. Evolution implies Revelation, in the last resort ${ }^{1}$. In the present study we shall devote little attention to Revelation. This does not mean that we refuse to it its proper place. We merely assume it as obviously underlying the whole of the questions we discuss.

3 A fact which is admirably brought out in F. B. Jevons' little handbook on The Idea of God in early Religions. 


\section{CHAPTER II}

\section{THE TRIUNITY OF MAN}

LET us now turn from the question of revealed religion to consider man's own conception of God-how it arises and what are its salient features. No doubt, to Christian and metaphysician alike, it is obvious that we can only pretend to do this. Revelation is the correlative of evolution. Man could know nothing of God if He did not reveal Himself through His attributes, and even if we say arbitrarily that we are going to examine man's conception of God from the purely human standpoint, the claim to use such a method is artificial, and amounts to no more than a statement that we propose to follow more or less closely the historical order of man's expanding ideas of God, as he appreciates more truly God's attributes. Yet even such an obvious truth requires further analysis before we can see its meaning.

These attributes, as we have seen, constitute the modes in which God is manifested to beings external to Himself. Their significance is in relation to the Cosmos, not to Himself. Men, in so far as they are external to God, can only know Him at second-hand, through the mediation of His attributes. Such knowledge, being external, can never satisfy. The spirit of man yearns towards immediate knowledge of God. It craves union with Him, in which alone is true immediacy. We can never be content to know what God is, we need to know Himself. But we can only learn to know God through knowing what $\mathrm{He}$ is. Mediate knowledge must precede immediate. The reason for this is obvious. Really to know a person-to know him, not merely his attributes -means to love him. Aimer c'est tout comprendre; 
but also, Tout comprendre c'est aimer. The first is true for creative timeless being, the second for being that is in time. You can not love a person till you know him; and to know him means first to know his attributeshis thoughts, his interests, his activities, his character. When you know his attributes and approve them ${ }^{1}$ you love him; that is, you seek to share his life; to know him; and so to know his activities from the inside. Further, to know and love you must approve. There must be a similitude and inner sympathy between your own nature and his. Therefore, if you love a person you can gain some understanding of his nature by examining your own. The commonplace that opposite natures attract one another is blatantly untrue, though complementary natures no doubt do. A religious man is not intensely attracted by a profane man whose inmost thoughts are blasphemies. A pure man is not attracted by a moral leper. An able man is not attracted by another simply because that other is stupid, and has the most profound contempt for capacity and thought. A wise man is not attracted by a fool. On the other hand a deep thinker who is conscious of lack of humour may be attracted by one who adds humour to interest in thought. A man who is sombre in his religion may be attracted by a beautiful soul which is also blessed with joie de vivre. The sense of lack does seek fulfilment in union with another. This fact is very suggestive, but it has nothing to do with the statement that like repels like and attracts unlike. Two men who suffer from identical defects will very likely repel one another; but this is because of the absence of like qualities in each, not their presence. The lack which each feels is not

1 Approval is necessary, for love is interpenetration, all but identification without the loss of self-identity. Disapproval is on a pedestal, and you cannot love from a pedestal. True approval has nothing in it of de-haut-en-bas, for the approval is fellowship. 
satisfied by the other. The best human friendship is that between persons who are identical in almost all of their positive qualities and yet supply each other's lack as well-a lack perhaps hardly realised. Apply this fact to the relation between man and God, and it is evident that by considering those qualities of man in virtue of which he loves God and those of whose lack in himself he is conscious as a loss or defect, we may arrive at some approximately true idea of the qualities or attributes of God.

But this is not all. Because man persists, transcending time-because he is there to experience change, and is not himself simple change-his nature has in it something that is timeless. His self-hood is transcendent, and its reaching out towards God is evidence of similitude of essential being. Man's attributes are like God's attributes, and so man is drawn to God through knowledge of Him as a Being external to himself; but besides this, and evidenced by this, his essential being is like the Essential Being of God, and so he craves union with Him. This of course is the underlying fact in human friendship too. The similarity of attributes, which represent men's external relations, is evidence of an inner similarity which craves satisfaction in union; the immediate experience of the relationship of interpenetration. But this union or love goes behind change into perdurable realities of existence. We love one another with our real, lasting selves, not with the temporary attraction of our immanent, changing nature, - at least such partial affections, if they exist at all without commingling of the higher, are not worthy of the name of love and have nothing in common with its true nature.

Man, then, is drawn to God by the similarity of his own attributes to those of God; by examining the attributes of the human personality,-the projections of the self towards others, - we can gain some insight into the 
attributes of God. We can argue from man's personality to God's, since we have seen that God is a Person. But we can do more. Attributes reveal, if only partially, the real being. Man loves God and feels the need of union with Him because his real transcendent being is similar to God's Being. otherwise there could be no attraction; for attributes, after all, are derivative, not primary. Because man is in some degree absolute he is not utterly debarred from absolute or immediate knowledge of God; his absolute being resembles God's, on the principle we have enunciated; we can argue from the one to the other. From the attributes and being of the human personality, then, we shall attempt to obtain a partial presentation of the attributes and Being of God. If it be objected that in doing this we are assuming that God is completely mirrored in the microcosm of man's soul, we simply answer that we do assume it and are prepared to justify the assumption. For if the idea of the external activity of Love which demands that other beings should share the Perfect Experience means anything at all, it means what it says, that Love wishes to share with others Perfect Experience-the whole and not a part; and that therefore man must be eventually at any rate the microcosm of the whole of God. As Athanasius expresses it " $\mathrm{He}$ was made man, that we might be made God" "- Thus then, to hark back to our original statement of the object of our present examination, it is clear that to turn our back on revelation for the purpose of argument is not to deny its existence. The self-revelation of God is implicit in the fact that men exist. That their attributes resemble His, that their being mirrors His, is due to the very fact that $\mathrm{He}$ is Love, and Love is, on one side of its nature, centrifugal and therefore creative. Creation is Love's selfrevelation to itself, but it is also Love's revelation to the

1 Quoted by Mackintosh, cp. cit. p. 184 . 
other selves which it brings into being. It is thus clear that though we may neglect revelation for the moment, as we try to trace the image of macrocosmic Reality in the microcosm of human personality, we implicitly accept its existence; its causal significance, and its meaning in process ${ }^{1}$.

The existence of other beings external to a man is necessary to his process of becoming. He is not satisfied internally, in the mere reality of self-activities. I cannot, for instance, rest satisfied in being myself, loving myself, thinking myself. A person who even approaches such purely internal activity is most repulsive. The only reason we need give for this at the moment is, that man is imperfect, incomplete. (The ultimate reason lies obviously in his causedness-man is not self caused; less obviously, but more truly, in the centrifugal nature of Absolute Love, which itself can never be satisfied with purely internal activity, since in

1 In arguing from human personality to the Divine we are doing no new thing-in searching for the mirrored image of the trinity in unity and unity in trinity of Godhead in the nature of humanity. "It is notorious that Augustine rested upon a trinity in the individual human mind-memory, understanding, and will in one place; the mind, self-knowledge, and self-love in anotherand that he used this psychological analogy without misgiving to interpret the supreme Godhead, arguing on this basis that each of the Persons singly is equal to all the Persons together, each, that is, is simply God in a certain aspect. In like manner, Aquinas views the three Persons as respectively the principles of Origination, Wisdom and Will. There is obviously no tritheism in a construction based on the analogy of a single human consciousness." (Mackintosh, op. cit. p. 523.) We are in a large measure going over a familiar track. Only, we contend that the greater knowledge of psychology which modern research has achieved, renders the path more certain. We claim to find not merely analogy between, but identity in, the nature of human and Divine personality. 
that self-abnegation is lacking.) Moreover, he inhabits the sphere of time which others also inhabit, and so his attributes must exist for others whether he likes it or no. The only attribute of such a man would be selfishness. Further he could not become, if his activities were purely centripetal; he would not progress, but would stick at a dead level of imperfection. However, we need not worry our minds about this unpleasant hypothetical being, for he could not exist long. Man is a dependent creature. He has to eat and drink at least; to this extent he has to recognise the existence of something that is not self. And to eat and drink he generally needs to recognise the existence of other people-butchers; publicans or water-works officials; landowners and the like; or he will soon find himself in difficulties. Even if he is a savage, he will have to admit the existence of others born and bred in similar briar-patches, because they may take a fancy to his means of subsistence, or even, in a distressingly destructive manner, to himself.

For man, then, there is external otherness, which is essential to his becoming. This otherness includes other things and other beings. He makes use of the other things as tools; as far as he can manifesting the rudiments of creative activity. In his normal relationship with other beings also he is creative; he creates in some measure their environment as well as his own. Otherness is thus the basis of his ability to create. If, being comparatively civilised, he starts a general shop, he creates desires and the means of widening activities. Even if he is a primitive savage, every act he performs alters the environment not only of himself but of all his neighbours. The man who first hit on the use of a fish hook was a true creator.

Then he begets, expanding his own life in the lives of others. He is himself begotten. He is himself influenced 
by the environment created by others. Thus he is, in a sense, both father and son.

$\mathrm{He}$ also inspires and indwells matter, both in his own body, in which he gives matter a sacramental meaning, and in the external matter of which he makes a tool, whether it be hammer or arrow, or a rock-chimney or tree up which he climbs in pursuit of some aim. Whatever he does, he-for the moment-makes external matter part of his body, subserving his desires. He makes it, too, sacramental. This he does of the motion of his own will acting with some degree of freedom. He is creative, he is begotten; and with his whole nature, begotten and crcative, he indwells determinate matter making it subserve his free ends.

Let us next analyse these three conceptions more in detail, as the fatherhood, sonship and freedom of man.

The idea of fatherhood is creative, but is not merely creative. Will and direction and love come in. Mere parentage, of course, is not fatherhood at all. One could not speak of a father-snail in anything but a metaphorical sense. Unintelligent cooperation in the production of a small jelly in which a number of fertile cells are embedded is not fatherhood ${ }^{1}$. Even higher up, among birds for example, where parenthood includes an element of direction or care, and apparent affection (the reality of which is however open to considerable doubt), there is no true fatherhood. Not mere creation, whether of environment or new individual, is required, but purposive creation. Fatherhood is the expanding of the self into wider circles of influence. It recognises others and seeks to share its experience with them. Itself becoming, it influences the becoming of others.

1 As a matter of fact the production of the jelly is not strictly and directly the father's doing at all, and it is anyhow a secondary adaptation; but one must include motherhood as an essential component of the creative act we call fatherhood.

MCD. 
Itself creative, it seeks expansion in its creation-an expansion that involves others. All creation of the environment of others is fatherhood, in so far as it is conscious.

Human fatherhood is thus still closely associated with mere reproduction, which is the preeminent, though by no means the sole manifestation of the creative activity of animals, as we have seen ${ }^{1}$. Among animals parenthood and the creation of environmental conditions for others are alike processes the significance of which is not realised. They are unconscious. Human fatherhood goes far beyond either mere parenthood or mere unconscious influence over the destinies of others. It entails knowledge and will; and further it consciously creates an environment that is spiritual. This creation all men and women worthy of the name feel to be the most important of all their activities, however feebly they may fulfil it. Man is a centre of will and thought, and by this will and thought he originates.

In time and matter, then, man is active with the particular kind of activity we call creative. This creative activity, whatever its apparent lowly origin in the satisfaction of desire, whether reproductive or other, without thought or understanding of its consequences for others, becomes definitely and consciously purposive in the higher stages. The fact that the environment of others will be affected is understood, and in a large measure, even in man as he is now, this furnishes the motive of action.

We see then that creative activity is always intimately connected with other beings, and comes eventually to realise its own motive as thought and as love. Its final purpose, we have found ${ }^{2}$, is interpenetration and union, -the sharing of experience; for towards this man is

1 Evolution and the Need of Atonement, ch. i.

- Evolution and Spiritual Life. 
tending, and in this alone he finds rest. The time-process of creative activity is completed and explained in mutual relationship. Further, since the recognition of this is dependent on the realisation of the ego as a persisting and real existence amid all change, the thing which underlies the creative impulse is timeless. The process of man's fatherhood is to be explained in the light of the end; it is continuous with the unconscious fatherhood of the lower organisms, but the meaning of this last is to be found in what it becomes or tends to, not in what it was. As soon as self-consciousness is reached the self is recognised as a purposive creator, and the passage into the timeless begins. Man is always passing from immanence into transcendence, from duration to simultaneity, from process to pure being 1 .

But man's creativeness is not wholly external in its activity. He is creative for himself as well as for others. He creates himself for himself, in Time, in the process of his own becoming. In that measure in which he is transcendent he is a perpetual source of the activity of love, directed both inwardly upon himself, as the motive of his being, and the material of his inner experience, and outwardly upon others, as the means of sharing the experience of mutuality, both in the creative sense of wishing others to share his experience, and in the dependent sense of wishing to share the experience of those others himself. Thus in the father aspect of man there is something that is of eternity, not of time. Man creates because he is, not because he becomes. Animals create, but they do so unconsciously; their creative activity is an insurance policy contingent on the life that is yet to be, and only maturing when that life is actualised.

Turn now to the aspect of man's sonship.

He feels his dependence as well as his independence.

' Evolution and Spiritual Life, chb. v, and vi. 
$\mathrm{He}$ is conscious that his existence depends on the activities of others. As he realises more of the problems of the world he lives in, he begins to understand that he, and his parents, and all other men, depend for their existence on the activity of God. In other words, he is conscious of sonship in the sense of external causedness. This simple recognition of himself as a result, an effect, is of the same nature as the recognition of simple parenthood. They are two links in the chain of becoming, when becoming is looked at as the process of an external manifold. They are the correlatives of progress by evolution. Both are in themselves essentially temporal. They have nothing of the permanence of pure being. They are in time and of time; and only of time, because they have no meaning except as process. To know that one is caused, by itself gives no glimmer of light upon the motive of that causation, no faintest acquaintance with the essential causal activity, any more than to be an unconscious cause gives any notion of the motive of causation or knowledge of the nature of causal activity. Only when the concept of causality is absorbed in the higher concept of the whole-of Ground and Consequence -does the true nature of causal activity become clear.

As we have already seen, man is also conscious of sonship - of dependence on others-in a more subtle manner, from his own inner need of sharing others' experience as well as of making them share his own. Thus the reaching out of personality into others, the mutual interpenetration that is so fundamental a character of personality, involves the external relations of both fatherhood and sonship-the wish to add to the environment, or more basally, to the experience, of others; and the wish to add to, or rather to fulfil or complete, our own experience by sharing that of others. Both ways, the relation is one of pure otherness, and as long as we are imperfect, it is a time-relation of becom- 
ing, differing in this from our conception of the absolute mutuality of God's experience.

As we have just said, however, the creative activity of man is not purely external; there is a fatherhooda will-that is directed inwards upon the self. Is there also an aspect or entity - we will not discuss which at present-which is also directed upon the self, and which differs in being a dependent and mediatorial function from that creative aspect or entity we have discussed?

Undoubtedly there is this other way in which man is conscious of what we may term sonship. He knows himself, can stand aside, and, so to speak, watch himself. He can think himself as mediator between his will and his activities. And so thinking he realises that he is mediator.

In point of fact it is his body which thus mediates in his actual human life. The activities of the will are realised in action, as ends, through the mediatorial activity of the body. This would seem to be purely a phenomenon of limitation in time and matter, and not in any true sense sonship-in any sense, that is, which may be compared to the sonship of the Logos-for it would seem to have no sort of connection with the transcendent ego. We need, then, to go back and examine this matter a great deal more carefully and in detail.

What is a man's body? It is unquestionably the means by which man's creative will becomes discharged in action, and it is, further, the substratum out of which the innate freedom of the life process becomes able to realise itself as conscious activity. As we have seen ${ }^{1}$, without the determined basis of the body in which effect followed cause in certain sequence, the freedom of self-determination could never be achieved. And achieved it must be, not merely given from outside, if

1 Evolution and Spiritual Life, ch. iii. 
it is to be true freedom. Starting then at the point at which self-consciousness has been achieved, which is all that is necessary for our present purpose, we see the body as the mediator of that self-consciousness in so far as it affects external objects. All the activities of the self are given effect through the body. The body has thus a very real mediating function between will and ends.

Let us next inquire what is the nature of these activities. In the first place there are activities which concern only the individual himself. He feels a personal need of food, of warmth, of shelter, of amusement, to take only the simplest needs which bring him into relation with external objects as things capable of satisfying him. He makes tools of these objects in order to satisfy his needs and desires. But as man becomes more advanced he begins to feel a need for personal intercourse-for sharing his experience with others and for entering into others' experience himself. The body now becomes a means of self-manifestation, through speech, through writing, through reading, through actions directed to the good of others as well as of himself. These last are determined by the beginnings of sympathy and love.

As time, goes on men begin to interpenetrate each others' personality by more subtle means. The body has thus acquired a function which grows to be of greater and greater import to man. It is the means of a self-manifestation which grows less and less material. But one cannot conceive of the function itself ever ceasing to be required. The essential of personality is relationship. We express this truth when we say that God is Love, and when we make love the highest of human activities. It would seem then that there must always be a means of self-manifestation. This is what we mean when we express our belief that personality itself is indestructible, and that the power of relationship is one 
of the deepest functions of personality. We shall each be ourselves in timeless existence as well as in time, but the self-identity is no mere isolation, but interpenetration ${ }^{2}$

Thus our bodies have two functions. They mediate between our wishes and our ends when those ends, whether they concern persons or things, are regarded simply as objects external to ourselves; but they also come to mediate between ourselves and other beings, the self and the other being regarded as persons, and so sharing their experience more and more completely. This function, later achieved, is the higher, and moves outside the sphere of time, in Reality. For consider. You love because you abide. That of you which functions in love is your real eternal self, which does not change. The permanent voir loves the permanent he. (Grammar must lapse when its correct use involves a misrepresentation of the mutual causality of relationship.) Because I am I love; not because I become or change. Rather, in spite of the fact of change, I love. I am not change itself, because $I$ experience change; and the same is equally true of the beings I love. As we shall see when we come to consider the doctrine of the Trinity in more detail, Eternally Begotten connotes, not process, but reality of relationship ${ }^{2}$. So too, the

1 At first sight this would seem to contradict the fact we have already stated, that in timeless existence, with its perfect penetration, selves know each other directly, without the mediation of attributes-that attributes are the means of manifestation of a personality to other personalities that are in process, and so are in duration. This is not really so. The spiritual body is not an attribute, but the expression of the self-identity. The perfected selves are different, since their process of becoming has been different. They are self-identities. $A$ is still $A$, and $B$ still $B$, though each is perfect. (See Evolution and Spiritual Life, ch. vi.) The spiritual body is thus simply the ground of distinction of the self-identity.

2 Cf. the Note on this point, ch. vii. p. 204, in which the general 
essence of my relationship to other persons is eternal and real. It is this relationship which is involved in the power of manifesting the self to others. The love that creates the environment of others, directing their experience and expanding it, belongs to fatherhood; the sharing of experience belongs to sonship and depends on the power of manifesting the personality.

Thus between myself and others there is an activity which mediates the sharing of experience.

We have yet to consider that mediation in relation to the self whose activities of love it mediates.

Man is to himself his own other. This statement may appear strange, artificial, untrue, at first sight, but a little consideration will show that it is none the less fact. We have seen that man can stand outside himself, can think himself, can love himself. He is capable of introspection. He can and does think himself as a creative, loving being. In this act of introspection his body, in the sense of his power of self-manifestation, is regarded in its relation to himself, not to others. He manifests himself to himself. The mediatorial function of his 'body' discharges itself of its activities towards his own thought, not towards the thought of others. I can think of myself I am I; I am this, that and the other, which together make up the me-ness of me. Here I mediate myself to myself. I see myself through the medium of pure thought. In fact I think myself. Thus in the unity that I call myself there is I and thou, though I am so certain that I am one that it is difficult for me to concede the fact. Yet the very existence of introspection is proof of its reality.

We see, then, that though the mediating function of the body eventually becomes sublimated from the pure time-process of a linking of will and ends, becoming the argument is summarised as far as it relates to this particular point. 
means of manifestation of the personality to others, it eternally persists in this absolutely real form, in relation to others. But still further, as soon as I become selfconscious, that is to say, as soon as I become in some degree transcendent, a self that perdures, I can think myself as an other; in relation to myself the manifestation of my personality becomes a self-manifestation; and so I think myself through the mediation of my self-manifestation. The importance of this fact will become clear as we pursue our argument further. Consciousness in the Bergsonian sense-what Bergson calls unconscious consciousness-would seem to be the recognition of an other; self-consciousness would seem to be the recognition of the self as an other, as distinct from external others, for self-consciousness is based on introspection ${ }^{1}$.

We must now turn to the third aspect of man's consciousness. If he simply regarded himself as I and thou in introspection-as himself and his own other,-he would have no sense of unity. Yet the most salient feature of his self-knowledge is that he knows himself as one. 'I may be driven to subdivide myself into I and thou - fatherhood and sonship, as we have called them, -but I am I when all is said and done. Whence does this consciousness of unity spring, if our previous analysis of being into I and thou is correct?

Before we attempt an answer to this question we must investigate the nature of immanence from a point of view which differs in some degree from that we previously took in considering the evolution of man in relation to God's purpose 2 .

Immanence involves the existence of otherness, and

1 This self-consciousness of the personal being becomes only fully satisfied, of course, in the consciousness of the union of the self with others.

Evolution and the Need of Atonement, and Evolution and Spiritual Life: 
otherness of a particular kind. This 'other' is a limitation external to the self. Yet the self indwells it. Immanence is not consciousness of otherness, but exactly the reverse. We can only speak of immanence when the indwelling spirit ceases to be conscious of the otherness of that which it indrells. This point is of such vital importance, especially in its bearing upon our belief in the immanence of God, that we must examine it at some length.

We can speak of spirit as immanent in matter only when that matter serves as the vehicle of the spirit's activities. Matter in which spirit is immanent bears the impress of that spirit. Applying this to ourselves we see at once that not merely our body, but all the matter with which we come into intimate contact through making use of it, bears the impress of our spirit. To take a very superficial illustration, it is a commonplace to say that you can judge a man by his belongings-his books, his pictures, his furniture, his carpets, his wallpapers, his hangings, and the way in which he arranges his possessions.

But this is hardly what we mean by immanence. It is upon a mere reflection of the personality of the man that we here pass judgment. What interests us in our inquiry is a subtler point-the fact that when a man makes use of tools, while he is using them he truly indwells them. He is conscious of this, though we spectators may not be. When a man speaks through a telephone he loses all sense of the telephone's othernessat any rate if it is in good order. It becomes for him temporarily the vehicle of his spirit. $\mathrm{He}$ is no longer conscious of wires and receiver and transmitter. The fact that he is utilising magnets and cells and grains of carbon in loose contact has no meaning for him at the moment. The machine as a whole has become for him temporarily part of himself. And the same is true of the 
listener at the other end of the wire. The telephone is nothing more than the means of communication of thought; it is no more and no less alien to the speaker than his voice. So too the hammer and saw, the piano, the pen, and all the other 'tools' a man uses. For the time they become part of his body. He can think of them as 'others,' just as he can think of his hand or his voice as an 'other.' His hand and his voice are not himself any more than his pen and his hammer are. He can think of each as 'others.' But the point is that when he is using them he does not so think. As long as they are the means of manifesting his spirit he forgets or disregards their otherness. For him, in fact, they are not others just then. As soon as he ceases to use them they may become 'others' again for him. His hand is less likely to be regarded as an 'other' than the hammer is, because it is less likely to be mislaid, being in more constant and intimate relation with him-though in passing it may be worth while to remark that the more often anything is used the less likely it is to be mislaid. The capacity for being mislaid is not a bad practical test of the degree in which we regard a thing as an other in ordinary life1. A good carpenter never mislays his tools, and we say that his tools are almost a part of himself.

1 After a discussion of this point late at night with the two people with whom the greater part of this book has been threshed out, one of them dreamed that the whole essence of immanental philosophy could be summed up in a single phrase. That phrase was remembered and noted on waking. It was 'a man does not mislay his only pair of trousers'! Could a more apt illustration of the point be found? Much of interest on the phenomena and meaning of mislaying and forgetting, may be found in Freud's Psychopathology of Every-day Life, though a caveat may perhaps be entered in regard to the metaphysical basis of all Freud's work, since the stand point adopted is that of a somewhat crude materialistic determinism. 
Immanence would then seem to be, for man, the temporary or more or less permanent cessation of recognition of the otherness of an object, for the purpose of achieving an.end; such cessation of recognition being thus conditioned by an element of will.

Nevertheless man is in fact still limited by the nature of the object; even with a thing so much a part of him as his hand he cannot see or smell; it is in fact an 'other.' This is obvious, for it is external to him, and mediating in function; through it he achieves something, because he is still becoming. We may therefore say that, as far as man is concerned, immanence is the using of an 'other' for the spirit's purpose of becoming, the spirit finding in it something beyond mere otherness, and indeed neglecting this aspect as use is made of it. Otherness is for the time swallowed up in the more inclusive concept of mediation.

When one applies this same thought to the Immanence of God in the Cosmos it is seen as singularly suggestive. God can, apparently, think the Cosmos as an 'other,' as a self-limitation; but inasmuch as His purpose is being worked out through His indwelling, it becomes no longer an other, but a part of Himself; though in fact it is a limitation, He does not recognise it as a limitation while $\mathrm{He}$ works in it. This underlies Christ's words ' my Father worketh until now, and I work.'

Now in becoming a tool for man matter is only subserving that which we have seen is its proper function. Man implicitly recognises this in neglecting its otherness. A tool is for him a means to an end. Thus, like God, he looks on matter as purposive. As soon, that is, as he, a conscious bcing, becomes immanent in matter he does so because he finds purpose not only in himself but in matter also. The stone on the beach which is clearly perceived by the child, is there for him to throw. Matter is there that man may use it, be it hand or hand- 
saw. He guides it, inspires it, gives to it its true value as an instrument, because he sees purpose in it. But in matter qua matter; in unperceived matter, if for the moment we assume that such a thing could exist; there would be no purpose; matter derives all its meaning from spirit.

We have seen that for man matter only acquires meaning as opposed to mere otherness-which is really potential meaning-when he for the time indwells it. This is one of the great arguments for the immanence of God. When we remember that we have learned to look on matter as the expression of the self-limitation of the Godhead, much light is thrown on the conception of God's immanence. For such matter is purposeful-has a meaning - and by the analogy of man's immanence it would seem that it is, and must be, indwelt by the spirit of God. Thus from man's immanence we argue to the nature of God's immanence, since we conclude on many grounds that man's spirit is similar in nature to God's spirit. Man's spirit is immanent in the same sense that God is immanent. Man makes use of the mediating function of matter for the manifestation and perfection of his freedom. His will through the mediation of matter achieves freedom in time.

His indwelling spirit ever urges him on towards perfection - that is, towards the completion of his unity ${ }^{1}$. As we have seen, as soon as man becomes transcendent he is able to look upon himself as both I and thou, but he is at the same time conscious of the fact that he is one, and that the completeness of his unity is made possible because of the internal activities of his being as its own subject and object. The completion of this unity is the work of what we may call his spirit of freedom. Let us, then, see what is the function of his freedom in

1 In union, eventually; but for the moment we are arguing as if personality could exist in isolation. 
relation both to the time-process of his becoming and to his absolute being.

We have shown already at length that evolution is the process whereby personal freedom is achieved. At first this striving is unconscious. The vital impulse is ever struggling to achieve freedom. That its objective is thus constant is due to the fact that the impulse exists in a cosmos which is the expression of God's purpose. Besides internal impulsion the organism is subject to external tractation; or, in biological terms we may say that the direction of evolution is pre-destined by the nature of the environment. The response of the individual is free, the direction of the evolution as a whole is determined ${ }^{1}$. When, however, we consider freedom in relation to the individual, we see that it exists as the factor which makes for self-determination. In the unconscious organism freedom is manifested merely as the power of utilising the environment in a very limited degree, making it subserve the organism's ends. When self-consciousness dawns, through the inturning of the consciousness upon itself, making the individual able to think himself as a 'thou,' the freedom becomes the means of completing the personality, through the addition of the knowledge 'I can' to the knowledge that 'I am' and that 'I wish.' Before the dawn of self-consciousness there was need or craving, and its fulfilment. Now there is I need, I wish, I can fulfil, I can find satis- faction in fulfilment. Thus freedom becomes involved in the completion of the ego. One can hardly conceive the nature of an experience which included simply $I$ am and $I$ wish, without. $I$ can. A truncated personality that knew itself, but simply as a bundle of volitions to which it could not give the least effect, would at any rate not be a unity ${ }^{2}$. I should think myself, and I should think

1 Evolution and the Need of Atonement, ch. i.

- Possibly this statement would not hold good for a pure 
my volitions, but nothing would link those volitions to the self. The self would be conscious of derivatives of itself in the volitions, but the volitions could not retrocede into the self again in fulfilment. And, in point of fact, it is impossible to speculate on the origin of volitions that were all from their very nature unfulfillable. A volition can only arise as the result of some relation between cause and effect ${ }^{1}$. Every wish implies that wishes are capable of fulfilment. Even the child who cries for the moon does so because his wishes for other round white things, the breast, the rattle, the ball, ,have been satisfied-because he knows that his wishes so often meet with fulfilment. And, in fact, his wish for the moon may receive satisfaction in a symbolic form, as we shall see when we study the mechanism of the mind from the Freudian point of view.

Only by the self-fulfilment of volitions can the personality develope and progress as a conscious unity. It is by wishing, and trying, in the certainty that the use of the right means will ensure success, that man developes himself and advances beyond what he was. Thus, then, we find that the personality which is becoming, and exists in time, completes and fulfils itself, experiences the emotion of satisfaction, and gains increasing knowledge of its essential unity, by means of its freedom. By the reflex of this freedom the self is made more glorious continually; more a self. The existence of the vital impulse is evidence of God's purpose and His in dwelling; man's personality is evidence of something new-the cooperation of conscious beings with God. The spirit of man completes and perfects itself, working

determinist; but I cannot feel that a determinist can see reality as one whole; personality must appear to him as epiphenomenal, or else some of its most prominent characteristics must be illusory.

1 More strictly, since we are endeavouring to see Reality as a whole, between ground and consequence. 
with the spirit of God. All that a personal being is at any stage is due to this cooperation, vitalised for him by the force of the questing of all creation--by the elan vital. In time and matter he indwells, but this indwelling is the means of his becoming; and what he becomes is due to the interaction of his whole self-his will, his activity, his freedom - with his environment, which is the self-limited, and so indwelling, Spirit of God.

We have seen that man's personality is made one, a unity, by his freedom. But this is while he is in process of being made, or rather, of becoming. We have previously argued that in his transcendental ego his creative aspect and his mediating aspect must exist. If this be so, it is clear that his freedom-aspect must also perdure in the realm of pure being, for otherwise he would be unable to fulfil any activity whatsoever; he would be eternally incomplete, and so not a person. In this respect what we have said of his time-existence applies with the more force to his simultaneous or timeless existence ${ }^{1}$. For consider.

Man is in part already transcendent, as we have seen. $\mathrm{He}$ has an absolute existence which persists through change, albeit it is yet incomplete. What we find to be characteristic of this partial transcendence (if we may use so self-contradictory a phrase, in the absence of a better, and remembering that all it implies is that being really exists for us as well as becoming, in spite of the fact that conditions are such as to make us often lose sight of the Ground in the practical urgency of the Consequence) must be true of absolute existence without any becoming; for absolute being can have only one

1 If indeed simultaneity be purely timeless, which is, to say the least of it, donbtful, at all events in relation to the experience of time-existence as real. If durational time had no reality at all for the transcendent God, neither would process have any; and then immanence would become unreal and the cosmos meaningless. 
nature, or metaphysical thought becomes impossible, landing us in a hopeless tangle of contradiction entirely at variance with our experience. We know that in fact the world is ordered and rational, not chaotic. It is characteristic of our absolute being that we know ourselves and think ourselves as reasonably, not chaotically, active. The nature of that activity need not concern us as yet, though it is in fact interpenetration or love (which involves an emotion) in the ultimate resort; will, knowledge, goodness, power, creation all subserve this end. If, then, I know myself as essentially active ; if I can think myself as active: view my own activity from the standpoint of my own thought: it is clear that I must and do also view myself as able for that activity, free to will it, free to think it, free to carry it out; and that I must find satisfaction in so doing. My thought and my activity are unified in my freedom. Apart from my freedom I should be pure activity and pure thought, without the possibility of acting or thinking, without any sort of link between activity or thought. And this is simply meaningless. Meaning is imported at once by, and only by, my freedom to act and think-my freedom in acting and thinking. My freedom-aspect proceeds equally from my activity and my thought. The three aspects together make up the fact that I am, which statement of my nature implies my unity.

We are now ready to carry out our inquiry into the meaning of these three aspects or modes of our personality more systematically and in detail. We are compelled, as we have seen ${ }^{1}$, to postulate a God alike from biological considerations and from many others. We are driven to see a purpose in creation, which purpose is the emergency of free beings who shall one day enter into true union with God and be like Him. The Genesis statement that "In the Image of God created He him"

1 Evolution and the Neud of Alowement.

MCD. 
is radically true. Since, then, we find these three modes or aspects in man's personality, we are bound to search for their meaning, for we find that they do exist under material conditions now, and it seems from our investigation that they have an eternal meaning.

It is natural that, arguing anthropomorphically from his own nature, man should see three aspects in the nature of God, even before the revelation of Christ. And it is too late in the day for it to be necessary for us to state at length that there is essential truth underlying anthropomorphism; the fact is so obvious ${ }^{1}$. The existence of a triunity, in manhood then, if it is real, not only gives a simple explanation of man's belief in the triunity of the Godhead, but points also to the fact that this belief is probably correct. It is natural that we should see in ourselves a reflection of the nature of the Godhead, and argue from our own nature to that of God; and if it be the fact that human personality would be incomplete without these three aspects, we have a strong argument for the triunity of the Godhead, if God be indeed personal.

Of the nature of the Godhead we have evidence in revelation, but we also find it implicit in the phenomenal universe. The creative function of the Father, with its implied purpose, is deducible from the nature of what $\mathrm{He}$ creates as well as other things-which purpose is the sharing of an experience whose character is love; the necessary mediating function of the Son, which bridges over the gap between time and eternity and makes the union of the finite with the infinite possible (and in passing we may remind ourselves that this mediation is not necessary simply because of sin; its method was modified by sin, that is all); the energising force of the

' Reference may be made to Jevons' Introduction to the Study of Comparative Religion and his Idea of God in Early Religions for justification of this statement. 
spirit indwelling a cosmos whose movement towards freedom is urged by the vital impulse and drawn by the Spirit of God Who is free; all these are evidence at least of a triunity of functioning of the Godhead in time. Their transcendent aspect need not concern us at the moment.

The connection between the three-fold activities of God and man is too close and clear to be put aside. Apparently oneness is threefold, when it is the oneness of a person, and must be threefold from the nature of personality. Triunity is what personality means and connotes. The incompleteness of the lower organisms lies just in this, that they have no bond of self-realisation between their creative power and their freedom. Creation for them is unconscious, freedom is unconscious, bodily mediation is unconscious. Each of these is merely a process in time; the creatures are becoming; but they are not. They are in no way transcendent. They cannot use their volition for truly creative purposes, they cannot think themselves, they cannot act with self-realised freedom. They have not achieved in the least measure the unity of absolute being.

We must next inquire whether these three things concerning which we have been reasoning are aspects, modes, of personal being, or whether they are anything more.

As long as we are dealing with unconscious organisms it is, I think, not arguable that they are more than aspects. Looked at from one outside point of view the organism is creative; looked at from another it is mediating; looked at from another it is to a certain extent free. But all through the organism is looked at. We stand outside and reason about it; it does not reason about itself. We see that it is an organism which behaves in this way, and we, as outsiders, analyse its behaviour. But when we come to ourselves, and analy'se ourselves through introspection, we find a difference. 
I cannot think of myself as creative or active simply, but as a creative or active being; I cannot think of mysclf as a mere other to myself but as a being that is another for myself; a being which mediates thought; I cannot think of myself as free; but as a free being.

Which ever of these aspects of myself I consider I promptly hypostatise it. Without this process of hypostasis I cannot think myself at all.

The full significance of this and the suggestions that follow will only emerge when we have made a much more detailed study of personality, which we shall do in the next chapter.

I can then, and not merely can, but I must and do, look upon myself as three hypostatised functions, three personal entities, when I, by introspection, consider what makes up the unity that I call myself.

Our next questions follow at once from this, and are vitally important. Are these hypostatised functions really three separate beings? And if they are not, am I not regarding one being, who is myself, in three different aspects, and for the moment attaching the particalar aspect $I$ am regarding to the concept of being; by a certain process of abstraction excluding the others from my purview for the time?

Certainly we must answer the first of these questions in the negative. I am one, and any process of abstract reasoning which appears to make me three is shown to be false in its premisses by the very fact that it reaches a conclusion definitely at variance with the very concrete fact of which I am more certain than of any other.

Is not, then, my hypostatising of the three aspects of my being due to an artificial process of abstraction? Again we must unhesitatingly answer No; though the full reasons for doing so will only appear after we have analysed the concept of personality in considerable detail. For the moment we can only say that in these 
three modes we do exist for ourselves, and in them our relations to the cosmos are comprised. I know myself as creator, in pure thought, and to others I am manifested as the cause of part of their environment and as mediating my own volitions in regard to them. I know myself as a unity, free to create and to mediate; and others know my influence on their environment, created by me through the mediation of my thought and my modes of contact with that environment, as the expression of my free decision as one being. That is to say, both for myself and for others my hypostases are three, yet I am one. The science of psychology recognises these three in some sort as conation-the creative striving; as cognition-the mediatorial function; and as affection-the feeling which links the cognitive and conative functions and completes my power of affecting the sphere which I indwell, through their free use by myself as a purposive being. The order of these for the psychologist is of course cognition-the incoming perception; affection - the internal emotion; and conation -the striving, or outgoing effect, whether an effect on the self or on an other, which represents the function of the will in creation. Our next task, then, is to analyse the concept of human personality, in order to see more clearly that the three realities of my personal being are not merely aspects, but hypostases. 


\section{CHAPTER III \\ THE TRIUNITY OF PERSONALITY}

WHEN the human mind is analysed into its constituents for the purposes of the psychologist, or the human personality for the purposes of the philosopher, the number of those constituents is found to be three. Even by itself, this fact is interesting when we remember that, in the religion which takes fullest account of the personal nature of God, the Trinity of the Godhead is the fundamental doctrine. However, by itself the coincidence may be of no evidential value; it may be merely curious. If on close examination it should turn out that psychologist, philosopher, and Christian dogmatist mean the same, or nearly the same, thing, mutatis mutandis, when they speak of the threefold aspect of manhood and of Godhead-if each is expressing in his own way his partial vision of one underlying truth-the fact becomes more than interesting. It becomes peculiarly suggestive. If, finally, it can be shown, that the idea of Godhead which the Christian theologian formalises in what he calls the doctrine of the Holy Trinity is not merely an unjustified and anthropomorphic projection of what he knows of limited personality into his representation of God, the facts become more than suggestive; they point to the nature of ultimate truth. The Trinity in Unity of the Personal God is then an essential part, at least, of Reality.

Clearly we must examine very carefully these conceptions of the nature of personality, alike from the point of the psychologist, philosopher, and theologian. As we saw at the end of the last chapter, the psychologist divides the activities of personal existence into 
cognition, affection and conation. He is concerned with these because his work is to analyse the behaviour of living things: their purposive striving to achieve an end.

Cognition involves the part played by the processes of apperception and association, which link both the logical relations between objects and the historical sequence of events. I appoint to my small boys definite 'boundaries' on the sea-beach within which they may play at will without special permission from any grown-up. As I write, I see from my window one of them scrambling along a sea-wall towards a martello tower, outside these boundaries. The observation links itself with the fact that the tide is in, and the water deep. Other apperception-masses are correlated with this. I know that he can hardly swim, and that if he fell off the wall he would be drowned. I know that he is disobeying orders, for which the penalty is deprivation of his 'boundaries' for twenty-four hours, with consequent imprisonment in the house except when a grown-up wants to go out. I, further, see that nurse is on the beach with the baby, and I wonder if she has given the boy permission to go onto the sea-wall. I know that she. cannot swim, and consequently, that her presence is not much of a safeguard. And so on and so on. Apperception mass calls to associated apperception mass across the deeps of my mind, through logical connection (climbfall; water-drown; etc.) and sequence association (command-disobedience-punishment-similaroccurrences in the past; swimming-swimming lessons-progressover-fearlessness, etc.). These trains of cognitive process give rise to, or at least furnish the immediate stimulus for, a conative impulse through the emotion or affection of anxiety. I decide to lean out of the window and shout to him to ask whether he has nurse's permission to be there. This I do, influencing his mind and setting in motion another cycle of cognition, affection 
and conation in him. He replies that he has permission. Exit the punishment-complex; but the danger-complex gives rise to a fresh conative impulse, and I decide to tell him to come back. I do so, again influencing his mind, and the result is not merely speech on his part, but action. He comes back.

Here is a simple illustration of the three parts of my psychic activity as it appears in relation to another person. But we may examine it from a somewhat different point of view.

My reason, mediated by my brain, recognises the situation, itself mediated by the sensation of sight. My body, through my voice, mediates my will to alter that situation. My body again, through my ear, mediates a fuller understanding of the situation. And, finally, through my voice it mediates the desired change. Moreover, in relation to my son, the environment has changed. Through the action of my will, a fresh environmental factor has come into being-my command overriding the nurse's permission-to which he responds by appropriate action. I have created a fresh environmental factor for him; no doubt awakening all kinds of associated memories of the effects of disobedience and so on, since he is a person who, like myself, makes judgments of experience. Habit too comes in. All these have more or less potency in determining the response of every living organism to environmental stimulus, whether that response be conscious or unconscious.

Yet again, I know that I willed to create this environment, and that I need not have done so if I had not preferred being over-careful to the boy running risks. I willed to do it freely - to allow my anxiety-emotion to have play-being conscious that the matter which I indwelt-my body, and the air-would mediate the fulfilment of my desires, because I indwelt it. I did not think of the air as an 'other,' though it undoubtedly is 
an other for me. For the moment it became part of myself, while it subserved my purposes. My indwelling and $\mathrm{my}$ freedom being completed in affection, united my cognition and my conation, making it possible for me as one personal being to influence my son, another personal being. Without this I could not have influenced him at all. Thus it would seem that the affection or emotion is, not freedom itself, but the index of freedom. Through emotion, cognition is linked with conation. Without emotion there would be no unity in our mental life. Incoming tides of cognition would sweep over us; and outgoing tides of conation; related to each other only as stimulus and response: unrelated to any self. They are unified, and the personality is completed and made free, in the sense of being truly purposive and not merely causative, by affection.

It is because I-am one and free through my emotion, in spite of my conation and cognition being per se, and ideally, independent activities, that I car influence other people and things. For cognition and conation are in a certain degree, though not wholly, independent. I can perceive and correlate without any externally creative impulse following, as when I lie among the heather and drink in the beauty of the hills, the sea, the rocks ${ }^{1}$. I can will and create without the stimulus of immediate cognition, calling up memories on which to base my creation-say, of fresh plans for my children-in the dark and with closed eyes, by linking conation with emotion. Though cognition and conation are respectively predominant in these two cases, emotion is clearly present in each, and really, some trace of the third activity. In actual practice every mental process of a self includes all three activities, though one may predominate. Only in lunatics and possibly in babies do we get anything

1 Conation is, however, present in a subordinate degree, since the claim of the thing perceived is endorsed by the,will, cf. p. 92. 
approaching the isolated functioning of one activityand this, just because the lunatic and the new-born child are not self-conscious unities.

Really, I must will myself to appreciate scenery. I must relate my past experience in planning the future, calling up mental images. Yet mere cognition has nothing whatever to do with mere conation, and mere conation has nothing to do with mere cognition. They are related only in the unity of myself. And this unity is based on the fact that $I$ recognise, $I$ will, and that I am free to do these things. The free unity of my personality issues in cognition and conation; but my cognition and my conation equally issue in my free unity. I could not think nor will unless I were one and free, but equally I could not be one and free unless I could think and will. Will, thought and emotion are the boundaries of the triangle which is myself. Without any one of them I could not be myself, I could not be free any more than there could be a triangle with one of its three sides missing. The illustration is spatial and crude, but it may serve to indicate the truth we are labouring.

Let us turn now from the psychologist to the philosopher. For a careful, systematic, and extraordinarily suggestive account of the meaning of personality to the metaphysician the reader is urgently advised to study Wilfrid Richmond's Essay on Personality as a Philosophical Principlex. We have already had occasion to refer to this work, and shall have occasion again, but no passing reference can convey anything of the valuable material with which a careful reading ${ }^{2}$ will stock the mind.

Briefly, the argument of the book is this.

1 Again I would refer the reader to Pringle Pattison's Gifford Lectures, although the subject of personality is dealt with there for the most part incidentally, and to Jevons' Personality.

" "Careful reading," for the book is not always lucid. 
Starting with the premiss that we know personality by experience, and indeed, that it is the preeminent fact of experience, the author goes on to show that personality has the dramatic meaning of self-manifestation, the legal meaning of membership of a society of persons, and the theological meaning of capacity for communion in the absolute reality of the Eternal Being; while in modern parlance it is simply accented individuality, but always in relation to a society. Mr Richmond himself defines personality as "the capacity of society, fellow-

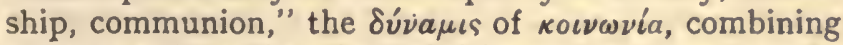
the suggestions of earlier definitions. He shows that the idea of personality as a limitation is entirely contrary to experience; all personality is intensified in the collective association after which it strives, whether we consider the region of desire and will, of intellect, or of emotion. This third chapter is perhaps the most important in the book, and should be carefully studied. After a brief examination of the relation of mere feeling to self-consciousness, he proceeds to analyse the phenomena of will, of intellect, and of emotion, as representing the three chief aspects and functions of personality. Now it is particularly interesting to notice that he subdivides each of these, and considers them under three heads.

Will is examined in regard to its motive, its mediation in motives, and its ultimate principle as an impulse towards communion. In motives it is clear that intellectual consciousness of purpose, and an emotional content, are involved, whether the motive be personal or social. Moreover there is mediation in motives, for whether in duty, desire, or affection, the immediate motive is considered mediately in its relation to general principles. And the ultimate principle has always relation to communion between the self and the world, whether the immediate motive be desire, duty or affection. More- 
over each involves both an intellectual process of cognition, and an emotional element.

Intellect is next examined as perception, mediation, and knowledge.

Perception is shown to be the experience of a bond of union between the thing and that thing's relation to the perceiving self; the thing and its quality as predicated by perceptive judgment are both elements of one single experience. But perception involves will, since both the object and its qualities, which are obtruded upon the mind, are acknowledged and acted on by that mind. I perceive a chair; and in doing so I accept its existence, and its qualification of myself. Its qualification of myself is realised by me as an emotion ${ }^{1}$. Thus in perception both will and emotion have their part. But perception is also collective in nature; our perception is, we assume, the same as the perception of another would be if he were in our place.

Very generally however we seek a verification and explanation of our perceptions. We then resolve facts into ulterior facts, all linked together; and the linkage, not the perception any longer, becomes the real thing for us. We find mediation and interdependence. Finally through verification and explanation, we reach scientific proof, confirming the truth we have perceived. But the scientific method is really an appeal to a collective standard. In this whole process will plays its part, as the acceptance of the chain linking the perceived phenomena; and the conviction of the truth we have verified is emotional.

But further, all beliefs have to be correlated and rounded off into one coherent whole. Philosophy is concerned with the nature of this whole and leads to knowledge. When philosophy takes cognisance of all the facts, especially the facts of causality and commuOp. cit. pp. 89 seqq. 
nion, which are really known to us only through our knowledge of personality, the only whole which can be found is a Personal God. Only in the knowledge of a personal God can intellect, will and emotion all and alike find satisfaction.

Thirdly, when we study. Emotion, we find that it emerges from feeling-unlike intellect, which emerges from perception-but as it expands, growing from the self-centred emotion of pleasure through the disinterested emotion of beauty, to the emotion of love, which is at the same time directed towards the self, and towards others, transcending all selfishness in pure reciprocity, we find it fulfilling itself in religion, in which will and intellect and emotion achieve complete fulfilment. It is the great unifying principle that completes the freedom of man. In this notion of the communion of love we find an ideal of reality that comprehends all that is and all that could be-an ultimate Reality which has nothing beyond itself, since it includes everything in the perfect satisfaction of all personal existence.

Now for our present purposes the most suggestive fact of Mr Richmond's analysis and we need not necessarily agree with him in every detail-is this:you may, and must, subdivide the activities of the personality into will, intellect, and emotion, but the very subdivision defeats itself, for you find that in every activity of the will intellect and emotion have their part ; in every activity of the intellect, will and emotion; and in every activity of emotion, will and intellect. The three are inseparable parts of one whole, and have no true independence in a personal being or isolated selfexistence.

Now when we find that the psychologist from his limited and purely descriptive standpoint in just the same way is bound to subdivide the activities of the mind into three, cognition, affection and conation, we 
begin to wonder what the meaning is. For conation is the manifestation of will, cognition is the basis of intellect, and affection emerges from feeling or sensation, and is emotional. It is unfortunate that Richmond, by taking will, intellect, and emotion in that order, obscures the relation of these with the terms of the psychologist, even though he makes the relation with the terms of the theologian more easy to grasp. We have to remember that the three terms arc in each case the expression of the existence of a cycle. Richmond starts - and metaphysically he is right-with the creative phase of the cycle. Macdougall, for example, startsand psychologically he is right-with the perceptive or mediatorial phase of the cycle. But for theologian, philosopher, and psychologist alike, the cycle consists of creation, mediation, and the unifying emotion which is the basis of freedom. This will become more clear as our argument proceeds.

Will, intellect, and emotion form the inseparable triad of consciousness. They are therefore essential to conscious being; my being as a person depends on them. The unity of a person is threefold, and must be threefold; that is what the word personality connotes, through its underlying suggestion of capacity for fellowship. The lower organisms are not persons, because they cannot will, though they can strive; cannot know, though they can be affected in a way analogous to, if not identical with, sensation; cannot experience emotion, though they can adapt themselves to the serial relations of their environment. The highest animals are on the threshold of true willing and feeling, though probably their intellectual processes get very little beyond simple perception. But in none of these do they reach the sense of communion, which involves as its very starting point the consciousness of the self and the consciousness of the freedom of the self. They may live as interde- 
pendent members of communities, but they are never, as far as we can judge, conscious of themselves as parts of a community, with interests and duties that can only be fulfilled in fellowship. They are not truly free.

Let us now turn to the concept of the theologian. He realises that God is a Person. For reasons which we need not here recapitulate, he further recognises in the Godhead a trinity. This trinity he hypostatises as Father, Son, and Holy Spirit. The Father wills and creates; but He loves too, and His creation is an ordered whole, manifesting reason. The Son is the Divine Reason, and mediates the Father's activity as the Word begotten of the Father. He creates and loves, and in these activities will and emotion play their part.

The Holy Spirit is the Indwelling and Guiding Principle of Unity, the Essential Love of God, proceeding from the Father and the Son; by Whom is freedom, and through Whom man comes freely to know God. And freedom involves knowledge and will.

Thus each Person of the Godhead is not merely a mode or aspect but has all the three essentials of a complete Personality.

Now when we think of what we have said of the nature of human personality, we remember that here too we found will, involving intellect and emotion; intellect, involving will and emotion; and emotion, involving will and intellect. Further, in an earlier chapter, we saw that man is himself creative, mediating and freely indwelling - is himself father, son, and spirit. However we regard personality we find it triune.

Clearly, our next task is to find the relation between the conation, cognition and affection of the psychologist ; the will, intellect, and emotion of the philosopher; and the wider concepts of fatherhood, sonship and spirithood; before we can relate all these to the theologian's doctrine, and arrive at our final issue-the 
question whether these really represent three persons, or three aspects, in the Godhead; and what is the relation of these infinites of Godhead to the finites of humanity.

Now it is clear that the three heads under which the philosopher considers personality are essentially the same as those of the psychologist. These last are narrower, for psychology is a descriptive science, and has little concern with the ultimate reality which is the goal of philosophy. Nevertheless philosophy, whatever its final purpose, must start from the known. Thus, when the philosopher reasons about personality, his starting-point must be the descriptive analysis of the psychologist.

Remarking only that conation, cognition, and affection are included in the wider categories of will, intellect, and emotion, we may therefore pass on to consider the relation of these three with fatherhood, sonship and indwelling spirithood.

We have seen that conation and will are essentially creative in function. They are always directed towards an 'other,' and they only rise to the full height of realisation when that 'other' is a person. Thus the creative aspect of will is essentially fatherhood in its relation to others. But into every act of fatherhood intellect and emotion enter, as we have seen. Fatherhood is absolutely inseparable from these.

Again cognition and intellect form the basis of pure thought. You cannot think without an 'other' which is there to be thought. And the process of thinking an other involves the perception of its existence, and the recognition of the fact that its relation to the thinker is apprehensible in the category of order or reason, and not of chaos. But to think a thing is not an end-initself. The thought must be purposive, and so related to creation, and must also be the realisation of a bond 
between the thinker and the thing thought. Thought thus mediates between will, on the one hand, the realisation of relationship on the other hand, and the thing as the object of this will and this relationship. In other words, the dependence of thought on will, and the relationship between subject and object which both imply, is implicitly recognised. Thought mediates between will and relationship, in the directedness of each upon the object of that will and relationship. If the object is a person $B, A$ being the thinker and willer, there is further the consciousness that each of these factors is also present in that person $B$ directed upon $A$. Finally, as dependent primarily on cognition, so long as there is any external other, and determining conation, but also proceeding both from the thought and the will, is an emotion. In this emotion the purpose both of the will and the thought is to be found. It unites the two in a common bond of sympathy, and without it both would be meaningless, because purposeless. Ultimately, pure emotion is a free cause ${ }^{1}$, itself governed by no relation of external causality nor rational sequence, even though in the experience of a limited being in his relation to external objects no doubt it is true to say that sensation precedes and gives rise to emotion. But even here the emotion is not caused by the sensation, though it is aroused by this. A blow from a stick does not cause

1 This statement is unaffected by the fact that in a limited human personality, emotion is dependent on afferent impulses to a large extent, and not entirely on internal states determined solely by the nature of the personality. We shall discuss this more in detail when we consider Freud's psychology. At present we need only say that the apparent dependence of emotion in man upon external causation is simply the evidence and result of that emotion not being free. It is the mark of limitation. How suggestive this is in regard to the self-limitation of God in creation, is at once obvious. It shows how self-limitation must involvo suffering. To this we shall return. 
painful emotion, though I feel pain after it. The emotion that is associated with pain is not the effect of the blow, but the way in which my mind expresses something that lies behind and originates a suitable volition and action to the afferent stimulus of the blow, which is itself an expcrience of limitation. If I were not limited, the blow would not hurt. Indeed it would be impossible. But stick and the emotion associated with the sensation of pain belong to totally different categories, and one cannot cause the other. Strict causality only holds when the action moves within one category. No doubt the emotion is related to pain, when the whole is considered. But the point with which we are concerned is, that this relation is not one of strict causality, but is dependent on the fact that the being who is conscious of the emotion is free in some measure, limited in some measure. In short, the possibility of the pain-emotion is rooted in the whole nature of personal being as creative, and so self-limiting. To return to the illustration we used awhile ago, the call of a child in pain. There is a causal chain linking the call to the effect on my ear, another linking my will to help with my approach to the child; but there is a break at each end. The child is free to call, and chooses to call, I am free to interpret the call, and to rush to help. But because the child and $I$ are, in different degrees, thinking beings, the whole process does not move simply in the plane of causality: freedom comes in-the freedom of a true emotion. The case is a good one for illustrative purposes, since the partial development of the child's personality is intermediate between the man whose freedom of emotion is large, and the animal which is almost without freedom, and in which the pain-sensation produces a reflex, practically untinged by emotion. Pain itself, then, is simply the sensation-link which relates the limited mediating function of cognition-which 
mediates the relation between the other (stick) and the self (me) - with the (again limited) creative function of conation. In the emotion associated with it lies what freedom of response there may be: of choice of the form which the creative function shall take. When the emotion is less intermingled with mere sensation, its uncausedness is still more obvious. The emotion associated with beauty links my perception of external things, which is now in part the intellectual recognition of order, to my creative sense that I can cause order. The perception of beauty is markedly creative. It is the harmonising of my experience of outside phenomena with my knowledge of myself as a free cause of outside phenomena. The sense of beauty is the realisation of the possible harmoniousness of all experience, making me will to make experience truly harmonious. Beauty produces a yearning, that is creative in essence, for higher things ${ }^{1}$. My emotion directs my creative imagination towards the ideal of harmony.

The full emotion of love, which is the common multiple of all partial emotions, is itself perfect freedom, making cognition one with conation, in a perfect unity of harmonious experience, whose harmony is called into

1 The yearning which is the most characteristic feature associated with the recognition of Beauty in an object is singularly suggestive. When I see that a thing is beautiful I seem to understand it, get inside it, feel that it has a message for me-a message of its relationship. And the result is a voiceless cry "I want! I.want I" Now this yearning is far less prominent in the sense of reciprocal love, and yet there is a close resemblance between the emotion of beauty and love. There is far more sense of satisfaction, of rest, here. Il may plansibly be argued, on these grounds, that Beauty is really a felt-relationship, and that the dissatisfied yearning is the expression of the fact that perfect relationship is reciprocal. This is not the place to develope a theory of aesthetic, but I cannot help feeling that in this problem of relationship a clue to the meaning and nature of Beauty may be found. 
being by the knowledge of complete freedom, and in love we find satisfaction of the sense of beauty also, for there is harmony of relationship. In theory, emotion qua emotion is uncaused, determining causal activity; in fact it is both centripetal and centrifugal. Centripetal, in that it is roused, in limited beings, by external stimuli, which seem to be themselves the causes of it, simply because we live in determined conditions in which our emotions are not free, and tend to search for causes instead of inhibitions-we are so accustomed to the relation of cause and effect as essential correlatives when physical determination is in question, that we mistakenly carry over the same reasoning from one level of experience to another-centrifugal, in that all emotions are creative manifestations of our real self to ourselves and to others.

Fmotion is the originative force that urges to selfunderstanding and self-revelation.

This idea of the uncausedness of pure emotion is difficult, and one's first impulse is to deny it; especially if, like my freest and most constant critic, one has had a psychological training. We will therefore consider it more at length.

Will, intellect, and emotion all emerge from the primitive complex of pure sensation. Pure sensation or feeling is, so to speak, the lower layer which underlies consciousness. Out of consciousness arises consciousness of objects, and then consciousness of subject. Consciousness of objects is perception, consciousness of subject in relation to objects is true self-consciousness. Feeling can now be analysed in relation to the self; that which determines its creative aspect recognised as an emotion. Emotions themselves are of very different grades. The lowest no doubt are those associated with fear and pain. But in every emotion, even these, the realisation of the freedom of the self to act forms a part 
of the content of the emotion. Pain involves the realisation that I am in some measure free to avoid the repetition of the blow; it links cognition with conation. But what I feel is a sensation-pain, not freedom? Quite so. The emotion aroused by pain involves the realisation that I am only partially free-that I am limited by my body. Pain-emotion is an emotion of limitation. But it is none the less true that I realise that my freedom exists; that the pain gives rise to a conative attempt to increase my freedom; and that the small measure of freedom I do possess lies in the region of emotion'.

So with fear. Fear is an emotion of limitation; but it usually gives rise to conation. Where it does this only to a very limited extent, as in the phobias of anxiety-neurosis, it loses much of its character of an emotion and becomes to a large extent a simple feeling. In the fear of anxiety-neurosis I, to a considerable extent, lose my self-consciousness. My self shrivels to the likeness of a pea floating in a vast ocean of fear-sensation. I lose my freedom in a great measure; even in so far as I am conscious of my self at all, it is only to be conscious that I am not free, but limited. In this sense of limitation the horror of great fear lies. There are, thus, emotions which are dependent for their existence

1 It may be objected here that, as we have denied true emotion to the animal, allowing to it only sensation, we have denied all freedom to the animal, in patent contradiction of our whole philosophy of life. This is not the case. It is clear that in the present discussion we are speaking of the freedom of the true alternative, as manifested in conscious choice. All we can say is, that in animals the measure of freedom they possess lies in the happenings, whatever they may be, that link the perception or sensation with the subsequent action. And the same is true of a man. Actually, the freedom he possesses at present is small: such freedom as he has lies in the same region as in animals: the difference is that man is conscious of this region, and gives to it, as he experiences it, the title of emotion. 
on the fact of limitation, whether self-imposed or imposed from without. They are the emotions of immanence-sorrow, fear, hate and all their congeners. But themselves are free, or rather, find their ground in the creative and self-renouncing nature of personal being. They are not consequences of the material conditions of limitation, nor caused by them, but both are alike dependent on the nature of free personal being.

But turn to an emotion such as pleasure. In pleasure there is a great uprush of the sense of power-of freedom. The creative self is acutely experienced. Limitations are minimised. In a sense pleasure may be said to be caused, but the statement by itself is onesided. Certain sensations or feelings, which no doubt have origin in perceptions, make me acutely conscious of myself as controlling my own destiny. Pleasure is the realisation of freedom, by the minimising of limitation.

As we have said the highest emotion, which has an absolute and timeless existence, is love. It is the most acutely self-conscious and creative of all. It is conscious of nothing but the subject and the object as interpenetrative and mutually acting on each other. There is no sense of limitation at all-only the perfection of freedom. It is uncaused, by any external causation. We are now speaking, of course, of perfect love in perfect mutuality. At first it might seem that the love is caused by the object. This is not so; it is merely directed towards the object while it flows out from its own spontaneous self-generation. It is creative; or rather, gives rise to a creative impulse ${ }^{1}$; it is also receptive; but in its perfection it is not limited, still less caused, by the object towards which it is directed. It is causal-crea-

1 This creative aspect of love is familiar in the idealisations of a lover. To the world his mistress is simply Ann Eliza Brown: to himself she is unique; peerless, and almost perfect. And he is right - only no one else has the creative genius to understand it. 
tive; itself uncaused, yet perfected by mutuality. When that mutuality is incomplete, the 'other' is known as a limitation; and the sense that the emotion's freedom is not perfect, is felt as painful yearning. The love is limited from without, and so in a sense experiences external causation. But perfect love is an emotion of transcendence.

Thus we see that an emotion is ideally uncaused, though in our own actual experience it is intimately connected with the nexus of causality. It is the selfexpression of freedom. In the region of emotion freedom is introduced into will and thought alike, because in the region of emotion we find the motive of creative activity. Without it, will would be simple, purposeless causation; thought would be blank, miserable order alone. It enters into each, supplies the lack of each, and unites both together. It indwells each, and so indwelling, unites them. Furthermore, when the external object, that is thought and willed and felt, is personal, the emotion may rise to the height of love or perfect mutuality of communion, for the object is itself then subject, and the first subject, object also. Love is the only emotion that is perfectly free, and it only when it is the sole emotion; and love expresses the reality of perfect communion.

Thus we see that when we pursue the ideas of will, intellect, and emotion to their source we find they are identical with our original concepts of fatherhood, sonship, and spirithood.

It would, however, seem that these are merely aspects of personality. They are very different from moods, it is true. A mood is the partial expression of a personality through the purposeful suppression of another integral part, one part thus receiving over-emphasis at the expense of another. A mood is really the refusal to share with another person the whole of our nature. We 
deliberately reserve something. It is the refusal of communion. And when our mood has relation to things only, as when we are alone; if, for instance, the mood is one of ill-temper; we are really fixing our mind on the otherness of things, instead of on their relatedness to us, as things of which we can make use, in which we can manifest our immanence. We refuse to recognise the unity of the cosmos, attending only to the perceived aspect of discreteness. Thus a mood, being partial, and involving reservation, is entirely different from fatherhood, sonship and spirithood. Whatever these may be, they are at least not partial. Each by itself involves the other two, though it is not the other two, and so involves the whole.

Along the line we have just been pursuing we can get no further. In relation to others, whether beings or things, we can only say that personality has three activities of functioning, which are interdependent and inseparable; and that, the more completely developed the personality, the more inseparable are the functions; while yet they can never merge into one another nor grow less distinct.

But when we turn again, as we did in chapter $I$, to the relation of the personality to itself as an absolute being, we gain more light.

I am not eternally and originally self-existent, but dependent on the creative will of God. Consequently I must be always conscious that my creativeness is derivative and not primary; that my thought cannot satisfy itself completely in thinking myself, since I am not all ; that my freedom cannot find satisfaction in

1 I do not mean to imply that God either could rest satisfied with purely centripetal activities; really, the idea of God-beforeany-cosmos, though convenient as a starting-point for certain trains of reasoning, is self-contradictory, for in what we understand by the concept God there is something eternally centrifugal, creative. 
knowing myself free, without recognising that there is a freedom which caused my freedom. I cannot be for myself alone; and yet $I$ cannot be in an absolute sense at all if I feel that God is an external other for myself. An external other must be a limitation, since it predicates conditions which are not my conditions. Otherness can only not be a limitation when it is internalised in perfect union. For instance, my will is not a limitation of my thought, nor is my freedom a limitation of either, for these are all myself. Again I do not feel that others, with whom I was in perfect sympathy, would in any sense limit me by their otherness, because I should penetrate it, and they would penetrate my otherness. In earthly life I never reach this, but I do find that the more my love for friends approaches perfection, the less they limit me and I them. Rather they develope my personality, and I theirs. Similarly, if I know God's will and thought and freedom as my own, while yet I am not God but myself, I find fulfilment, not limitation, in Him. And reverently we may say that the same is true for God. Each to each is no longer 'other' externally, since we interpenetrate and share the same experience, but each remains himself, and so is an 'other' in a sense that includes no limitation, but is, so to speak, internalised, having become mere differentiation. Yet though I cannot be for myself alone, even in the transcendent existence we have just considered, and to which we approach only in a very small measure in this life; though I cannot exist for myself even in the sense that God exists for Himself; yet I am self-existent, though not purely selfexistent. I can will myself, think myself, freely; yet know myself one, in so far as I am. My will is not an abstract quality that is part of myself. I am a creative being. Myintellect is not an abstract quality that enables me to think myself. I am a thinking being. My emotion is not an abstract quality that enables a whole that is 
me to love freely. I am a freely loving being. I cannot abstract each of these qualities and all that it implies and leave a residue that is myself, for these qualities make up myself. I cannot abstract them and leave pure empty being; the residue would be nothing. Take away will, intellect, and emotion from being and there is nothing at all left. These make up that of which we are conscious as being; and the idea of a being that is wholly unrelated to any consciousness is meaningless; esse est percipi, at least, if percipi be referred to any mode of consciousness of any being. But I can abstract two of these qualities and yet leave being. A purely creative being is thinkable; a purely thoughtful being is thinkable; a purely loving being is thinkable. Yet each is incomplete, unable to act except as a machine. One can imagine a machine that constantly turns out organised objects; whose sole activity this is; and that machine would therefore $b e$. So too one can imagine a being that simply thinks the relations of its others; and a being that simply experiences emotion in regard to its others ${ }^{1}$. But each would be a mere machine without spontaneity. Freedom only comes in when all three are linked together. Freedom thus comes with the unity of three differents. Unity is a system, which we may designate by the term Infinite Reciprocity.

But further we must note that these incomplete beings we have just been discussing are not in fact self-existent. They can only exist, even in thought, in relation to their others. For self-existence a unity composed of these three thinkable beings is needed. And notice that it must be a unity, not a mere union. It is because they are one that they can be self-existent and self-satisfying -indeed that the beings can become selves at all. A

1. Though the emotion would be a painful one: a sense of lack: a yearning: since the being would not be free to act, or to experience an emotion that was creative. 
personal self is thus composed of three ideal beings or hypostases united into one, and thus is free to will, think, love itself internally as its own other, as well as willing, thinking, loving a plurality of others. We see thus that, whether we consider human or divine personality, we are driven to the conclusion that it must be made up of three qualities, each made real, and saved from mere abstraction, by the essential qualification of being.

It is perfectly true that we can regard the three as qualities of one entity, as they are in fact. We have said that they cannot be self-existent otherwise. The point is not that these are three entities composing one real being, which is manifestly untrue, but that these are three qualities, each of which can be thought of as compounded with being; which cannot be thought of abstractly, apart from being; and which yet only compose one real entity where they are combined.

But though this leads us towards the Christian doctrine of the Trinity of the Godhead, it does not really attain the full doctrine of the Trinity. The hypostases seem to be beings, but not persons. We have a unity in trinity and a trinity in unity; but the unity is a Person, while the trinity is apparently made up of beings merely, and only of beings through a process of analysis which results in something remote from reality.

This difficulty is in fact due, however, simply to the artificial process of abstraction by means of which we had to analyse the material of our problem. We have already seen that Richmond rightly insists on the impossibility of considering the will of a person as entirely unconnected with thought and emotion; and this interdependence is equally true of thought and emotion themselves. Into every creative process thought and emotion enter; every thought involves will and emotion; every emotion, thought and will. Practically then, when we think of a transcendent personality - that is to say, 
of a personality which simply is, and does not undergo process in duration - we think of a unity substantiated, or determined as what it is, by three self-determining qualities compounded with being, of which we may speak when we abstract each from the rest-a creative being, a thinking being, and a freely-loving being-which interpenetrate in such a way that the creative being is not merely a creative being, but also thinks and freely experiences emotion, and so with each of the others. But then, each being must be in a sense a person, since each is a being manifesting will, intellect and emotion, though one or other of these three predominates, thus differentiating the three persons of the transcendent personality, and making them not mere identities. And all three are necessary to compose the unity which we call the personality. If this be true of any transcendent personality, it must be true of the Personality of God. The Godhead if it is a Personality must be a unity, which unity is substantiated or determined as itself, by three persons, completely interpenetrating, yet each differentiated from the others by the stress or emphasis of its individual functioning. yet none of these Persons could actually exist apart from the rest: the three are substantiated in one Being.

Thus, from our consideration of personality we have been led to the conclusion that any personality that simply is, in simultaneity, is composed of three hypostases which are not merely aspects but in very fact persons, though not self-existent persons that could exist as complete, in isolation; and that without these three the personality could not exist at all. Consequently, if God be personal, He must also be Three Persons in One God.

Our conclusion, if valid, must also hold good of human personality under the limited conditions of earthly life; for we have seen that as soon as an organism becomes 
self-conscious it enters in some degree upon transcendence. The completion of personality is the completion of the passage from immanence into transcendencefrom becoming to being.

One point of objection to the theory outlined above is very obvious. "What is there to prevent our pressing the same reasoning further, and seeing in each of the three persons of a complete personality yet three other persons, and so on, in infinite regression: personalities that become "fine by degrees and beautifully less"? Since primary emotions, for instance, involve elements of will and intellect; since a primary will and intellect involve each other, and emotion, in a secondary degree, why should we stop short where we do? Why 3 , why not (3)", persons in each personality? One may be driven to the illogical, unscientific answer of Professor Ptthmllsprts when Ellie asked him why there aren't any Water Babies- "Because there ain't." One may be driven to the argumentum ad hominem and say "Do you mean to tell me that you are $(3)^{n}$ persons?" Only then one's opponent will inconveniently answer, "No, I am only one; not even three, as you pretend! If I am three I don't see why I am not (3)n, and I know I am not, therefore I will remain one till further notice, thank you." I am not at all sure that the objection can be satisfactorily met at all, nor even that it is desirable to meet it. I am certain, however, that it is not a fatal one. The only answer I can give verges perhaps on petitio principii, but I do not think it really leads us into that logical quicksand. It is this.

In the idea of infinite regress we are using a spatial image of a linear type. If we must use a spatial image at all here, it should be of a circular type. Imagine three hoops, the circumference of each composed of three equal lengths of material perfectly joined, yet one third twice as heavy as either of the others. Call the heavy 
third in one emotion; in the next, will; in the last, thought. No one, separated and by itself, will balance evenly; it will take up a certain position in relation to external objects; but if all three be imagined joined together in such a way that the heavy thirds do not overlap each other, we shall have a perfectly balanced whole. Let this whole stand for the personality, the individual hoops for the hypostases. A crude illustration, and no argument, if you will! But if we are going to have spatial images at all, I think this is closer to the truth than any linear one. For the whole, perfect personality is, so to speak, circular; complete and self-enclosing, with never a ragged end to stick out.

This point seems to me important. After all, the type of an infinite regress to which philosophers raise objection is what we may call the linear type, as for instance, 'in the problem of causality. In such cases the one term $B$ is dependent on the preceding term $A$, but $A$ is not dependent on $B$. Here unquestionably the idea of infinite regress is not permissible. But in what we may call the circular type, where $A$ and $B$ and $C$, etc., the terms, each involve the others equally and reciprocally, yet when artificially isolated show this peculiarity:-that $A, B$ and $C$ involve $a, b$ and $c$, and $a, b$ and $c$ involve $a^{\prime}, b^{\prime}$ and $c^{\prime}$, and so on; $a, b$ and $c, a^{\prime}, b^{\prime}$ and $c^{\prime}$, etc., each representing the same thing as $A, B$ and $C$, only rarified, so to speak-I am not at all sure that objection can be maintained. And this is certainly the type with which we have to deal in considering the trinity of personality. So long as the whole is not in time there is no First-inthe-series; and we have seen that the essential feature of personality is that it is not itself in time, though it may indwell the temporal conditions of a cosmos.

Imagery apart, each hypostasis of the full personality is complete, and identical with the rest in all but emphasis. Will, emotion, thought - these merge into one 
another. They are not separable entities, as, for our analysis, we have had to conceive them. When this is realised there is no room for infinite regress, at all events in the ordinary sense.

We have considered the problem so far as coldly and dispassionately as we were able. The full significance of what we have said is beyond us, but we must nevertheless attempt some examination of its bearings, both in relation to evolution, and in relation to our individual experience. Before we do this however, it is important to run over again the main stages of our proof, in order to show that, though the method is circular, since we started with an analysis of the meaning of the Trinity, and returned, after analysis of personality, through synthesis of personality back to the Trinity, yet our argument itself was not circular, for we did not assume that which we had to prove.

We first analysed to a certain extent the conceptions of Fatherhood, Sonship, and Spirithood in the Godhead, and showed that similar manifestations were to be found in the activities of men. Man as well as God is father, son and spirit. We next considered the psychologist's analysis of mind into cognition, affection and conation, and saw that it was included in the philosopher's more complete analysis of personality into intellect, emotion and will. We then showed that none of these three was in actual fact able to stand on its own merits. Abstractly, we can consider each separately, but in actual fact the activity of any one of the three involves the subordinate exercise of the other two. We notice further that while the abstract concepts of a creative being, a thinking being, and a feeling being were possible, they remained unreal-mechanical abstractionsas long as we did not personalise them by admitting a measure of the other two qualities into the particular being we were considering. On admitting these quali- 
ties, the beings at once became persons composing one Real Person, yet differentiated from one another in the emphasis of functioning. But because a perfect personality must be perfectly balanced in its functioning, it becomes clear that the personality must itself be a complete unity made up of these three differentiated persons, each of which is an essential part of personality, yet, by a strange apparent contradiction, is a person itself. Moreover it is not that we lay an artificial stress in thought upon first one and then another of these activities. An appeal to experience excludes the possibility of this. For consider the experience of Christians. They do in fact claim, not on grounds of intellect, but of revelation and of their individual experience, that God did create, that God in Jesus Christ was in fact the Incarnate Mediator of the Creative Will, which will He had mediated as the Logos ${ }^{1}$, and that God was actually the Indwelling Spirit of Freedom, guiding the world into all Truth, which Truth is the free experience of Reality. And universal experience backs them up. There is a world, when all is said and done; there is purpose not chaos; there is emotion; there is progress towards freedom. At least, the intellect affirms these things. Since there is a world, in which certain classes of phenomena

1 It may be said that the stress we have laid on the Mediatorial aspect of the Son's activity exaggerates one side and lands us, or tends to land us, in the same demiurgic conception that spoiled Gnosticism, or the impersonality that ruined Philonism. If the criticism were valid, we should find ourselves, in fact, drifting into the quicksand of Docetism, on which so much of Eastern Patristic theology found shipwreck, or narrowly escaped it. But really against onesided emphasis of this kind we have guarded ourselves most carefully by our insistence on the personal self-identity of the Logos as eternal Being; an aspect that will become more and more prominent as our study goes deeper; and by our categorical statements that Christ's personality did not begin with the Incarnation, but was, rather, limited thereby. 
are manifested, there must be an absolute Reality behind. That is the conclusion of philosophy. Since natural phenomena exhibit the characteristics we associate with mind when we meet them on the smaller scale, and since such queer things as moral judgments, for instance, do exist in ourselves, the Absolute Reality must be a Personal God. That is the conclusion of metaphysical theology.

Again, historically, Christ did come into the world and teach certain things, and many claim to have personal experience that what $\mathrm{He}$ taught is true. There was a coming of the Holy Ghost in power, whatever that may mean; and its practical effect was the vitalising of the Christian Church under conditions which, humanly speaking, and for a false religion, were hopeless, since the Church consisted mainly of illiterate men, living in a conquered country torn with political dissensions; amid a people whose religious leaders were occupied with a stern struggle for formalism, not freedom; amid a people destined shortly to cease to be a nation, to be submerged in the sweeping tide of excellent, if worldly, government, and then to be given over to disorder and oppression.

The threefold activity of God is a reality, not a theory. It is His actual revelation of Himself in cosmical conditions.

So too is the threefold activity of man a reality. And our study of the limited personality of which we have immediate experience leads us to realise that each man is really three persons, and only becomes a true unity when these three persons are all active equally.

Lastly, let us again formulate, quite definitely, what are these three persons of personality-for such we must call them. A perfectly clear statement on this matter is essential, for here is the thread which must connect together all the many things we have yet to consider. 
We have called the functions of the three fatherhood, sonship, spirithood; we will call the persons themselves father, son, and spirit. The terms are convenient, because Christianity has rendered them familiar, and, besides, they serve to remind us that, because man and God alike are personal, what we say of the personality of the perfect man is a fortiori true of God.

Fatherhood is creative. But because it is essentially and always related to sonship and spirithood, it is personal itself, and not merely part of a person. In fatherhood the stress is upon will, but its function is achieved by thought and love, This creative will is outwardly directed towards others which it calls into being from the necessity of its own internal determination towards creation; but it is also inwardly directed upon the self, as determining the nature of its self-experience. A person is internally, as well as externally, active.

Sonship is mediating. It mediates the relation of creator to created externally in the reasonable order of experience, and it also mediates the internal relation of the person to himself in thought, making the person his own other. A person knows himself, as well as others. Nevertheless the self-thought is willed, and it is vivified by the emotion of love. But the stress is upon thought, mediating relationship.

Spirithood is, as we have seen, harder to realise, for $I$ and thou are closely related, but we have no word for-which means we have no articulate thought of a third relationship between persons equally close ${ }^{\mathbf{1}}$.

1 Mackintosh even goes so far as to say "Moreover, the argument for a vital duality can never yield a trinity; it gives no help in conceiving the third Person of the Godhead, thus failing at a crucial point. One feels that the last part of this objection is unanswerable, and must be accepted frankly. No speculative argument known to the present writer has the slightest value as proving a third divine distinction which is either 'Holy' or 
Yet the idea of spirithood is perfectly simple, really. The stress is upon the emotion that is eternal and absolute: love. And since the essence of love is freedom, through spirithood freedom is introduced into the whole personality. We have seen that even the descriptive science of psychology recognises this; for in its middle term, affection, which lies between the afferent perception and the efferent striving, must lie the element of freedom, if it exists at all. And it is in the middle term that we find emotion. Spirithood is then the freedom of love. It proceeds from will and thought; will and thought both play their part in spirithood; but it retrocedes into them again, as an essential factor in their activities. Externally, spirithood then becomes the indwelling of free spirit in others. It confers the possibility of interpenetration, through the mediation of relation in sonship. Internally, it completes the unity of the personality through its retrocession into fatherhood and sonship, from which again it proceeds, thus completing the freedom of the whole personality.

'Spirit.' And the fact is a strong reminder that the origin of the idea of spirit, in its Trinitarian meaning, lies not in philosophic thought, but in history and life" (The Person of Jesus Chrisi. p. 519). In spite of the great measure of truth in this conclusion, I cannot but think it overstated. 


\section{CHAPTER IV}

\section{SOME IMPLICATIONS OF THE INCARNATION}

WE may now turn away from our discussion of the triune nature of God and man, to consider the revelation of the Godhead under the conditions in which we ourselves live and move, for this is, in truth, the fullest revelation of manhood itself.

An increasing number of the Christians of to-day are ready to accept the Incarnation of the Godhead as Jesus Christ the Saviour in all its fullness. Not so many years ago the man who professed a belief that the Manhood of Christ was true manhood, with all manhood's limitations in the regions of knowledge and power, was looked upon with suspicion. St Paul's and St John's teaching of the kenosis, in its plain meaning, was hidden in a cupboard; and, lest any inquisitive person should by chance open the door, that doctrinal skeleton was discreetly wrapped in an ambiguous robe of commonplaces, so that its outlines should be veiled. The Divinity of Christ was rightly insisted on, but in such a way that often His Manhood became an epiphenomenon, and hence ultimately unreal. At any rate it was isolated from the true spiritual series. The divinity of common manhood was forgotten; the unsullied godhead that is enshrined in even fallen humanity was unseen; because the spots that defiled the wrapping robes were examined through a lens that left the rest out of focus. Humanity itself seemed a disgrace when no clear thought distinguished sin from limitation. The miracles of Christ were evidences of Divinity, not of Humanity made perfect in limitation. His prophecies and eschatological teach- 


\section{CH.Iv] Some Implications of the Incarnation II 7}

ing were dissevered wholly from the prophetic tradition. God took the form of man, not manhood itself.

Happily, in England, the last quarter of a century has seen a great change-a return to the doctrine of Kenosis which is emphatic in St John and St Paul, traceable in Irenaeus, fundamental in Luther, and overdeveloped in Igth century German theology ${ }^{1}$. We see the Godhead now in Christ become true Man, accepting all the limitations of manhood in order to make the fellowship of man with God complete and eternal. We see the Christ, not disgraced by the limitations of humanity, but pointing the divinity of manhood's spirit. We see His Godhead, not in His miracles, but in His teaching, and above all in His personality; we know it within ourselves through the sense of union'with God which acceptance of Him brings; we know it in the falling away of the burden of sin.

Yet even to-day, though we recognise-that no atonement could have been wrought if Christ had not emptied Himself of Godhead, accepting the full limitations of fallen manhood, we hardly yet realise the complete meaning of what we say, and its deep significance for the relations between the Transcendent God and an evolving world-for the doctrine of the Holy Trinity and the doctrine of Immanence. Our purpose in the present chapter is to try to search out something of this meaning, as far as one or two of the leading facts of evolution and of human psychology are concerned.

Jesus was born a child, as man is born a child (we will for the moment leave on one side the question of the Virgin Birth). Now a human child, in passing through its embryonic development, recapitulates, in brief and incompletely, the whole history of its evolution. Ontogeny recapitulates Phylogeny, is the form of statement of this Law of Von Baer familiar to students 1 Cf. Mackintosh, The Person of Jesus Christ. 


\section{I1S Sumc Inptisiations of the Innarnation Icas.}

of bisinga. Mam steres this iodinjdual Hife as a single cell

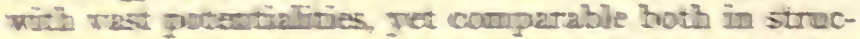

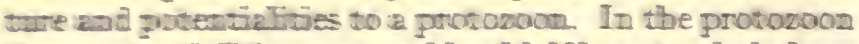

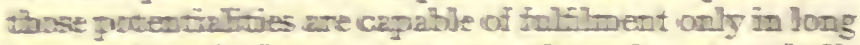
waves of erolutionsery progress thromgh many id di-

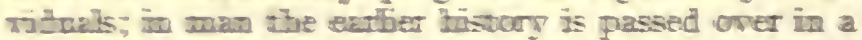
Jew shorr wreeks, the whole in the pettry span af a single Iffe-tione; that is all the cifferenoe. The protozan stage is followued by woe in which the simple ootlenteratr- the anewdonstagt-is recogrisable. Then oomes the tregining of cothomite advance, when the organ ceallad the cowolum, gining rise to hidners, generative

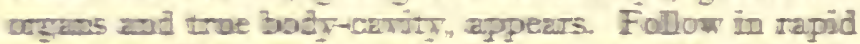
snccession the primitixe cliordate animal; the fish-filse

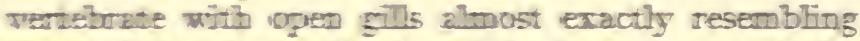
thase of the sherl; the lnog-fish stage; traces of the

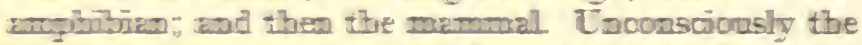
ergecuism ackrowludgas its dependence on the past

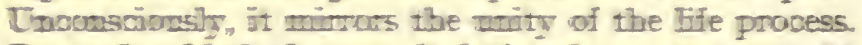

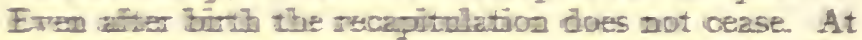
birth the cinld still shoms traces of the ape, in the oprovas bug-iok, the intered feet, the early down, the Ines-lim 'as, strong eaomgh to support the body's weight

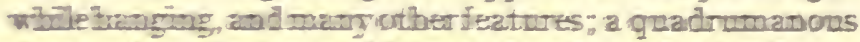
stage, where fest are additionsl hands, and a tendency to grugres on fer firabs preoudes the enect position.

Further, the sometal dextelopment of the child recepiculetes cacestrall tistury. The child at first is conscions only uf areaus and eads; he uses tools, but does not make them. Then curwes the inturning of the conscionswass apon itselff, the making of tools, and finally, trae ictrongtection it the froll recugaition of the ego.

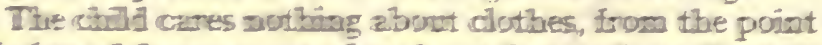
iof triew of decsmor: aur bloss be at first look on them as

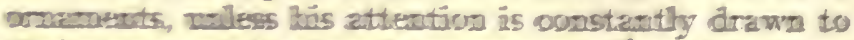

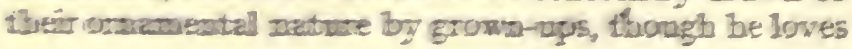




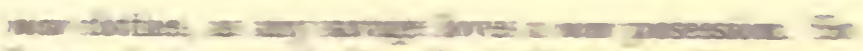

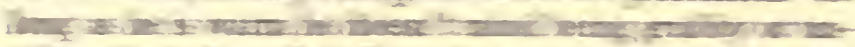

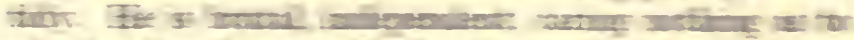

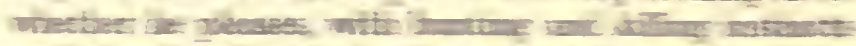

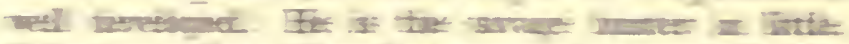

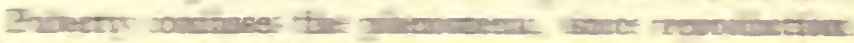

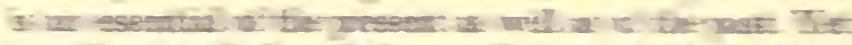

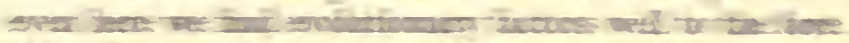

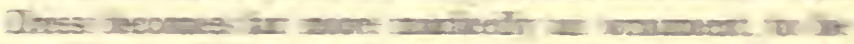

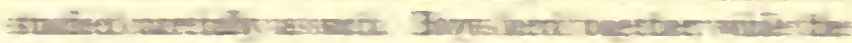

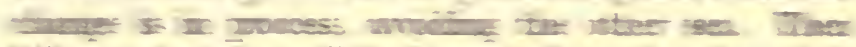

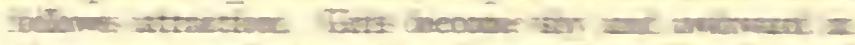

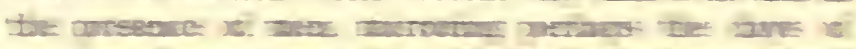

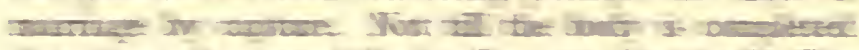

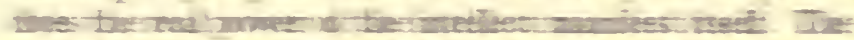

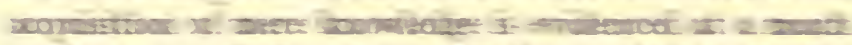

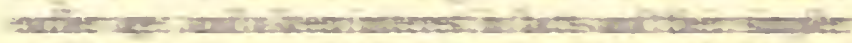

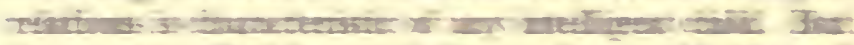

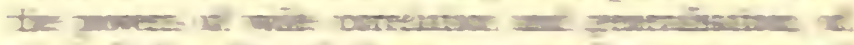

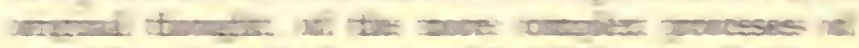

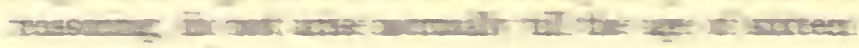

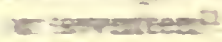

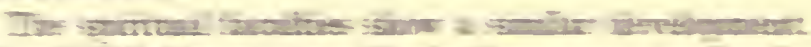

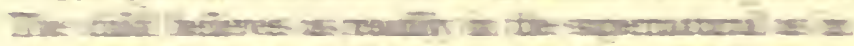

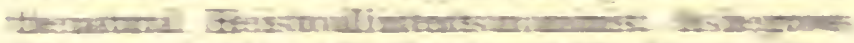

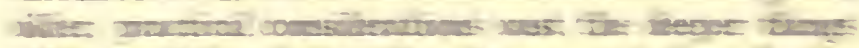

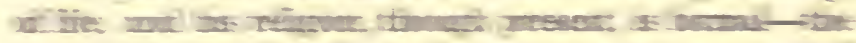

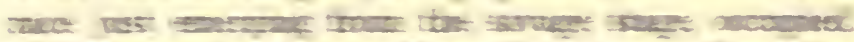

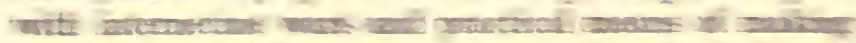

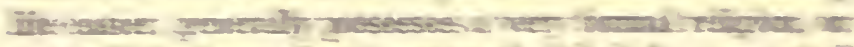

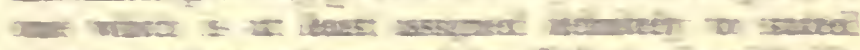

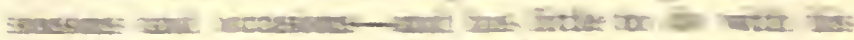

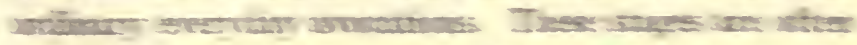

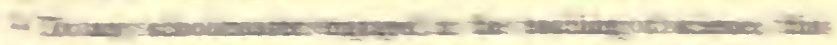

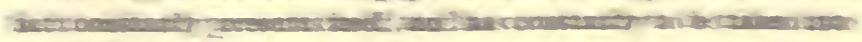

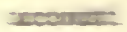




\section{Some Implications of the Incarnation [CH.}

overshadowed, however, by a feeling of the nearness of God, due in large measure to the fact that imagination plays so large a part in child-life that the unseen is as real as the seen, as long as the imaginative stage lasts.

Then comes the time when facts have to be correlated. This is often a time of scepticism, or at least a time of doubt, when there seems little to link spiritual teaching with practical facts. And finally, arising out of this comes the stage of fuller spiritual experience. (As with all generalisations, individual cases often' occur which refuse to fall into line; facts are obstinate things. But in the main what we have said is true.)

Now, if we accept the true humanity of Christ, if we believe in His Incarnation in any real sense; we must believe that He went through the same stages of physical development as an ordinary child does. As we hope to show, there is nothing irreverent, but rather something singularly beautiful, singularly helpful and suggestive, in, the knowledge that $\mathrm{He}$, like ourselves, passed through a protozoan-stage, a shark-stage, and the rest. But dare we draw the line even here? Does not our mind urge us to make the plunge, to say that $\mathrm{He}$ must have gone through all the psychical, the mental and spiritual, stages of familiar childhood, as well as the physical? May not our boldness bring a great reward ${ }^{1}$ ? For the course of boldness is the course of honesty. If we really mean that Christ was Very Man we must be honest with our own thought, nor fear the truth that comes. Must we not say that in mind and spirit Christ passed through the stages of primitive man just as any child passes through these stages, though at each stage He showed Himself the highest possible manifestation of that stage? Must we not admit that the full realisa-

1 Take, for example, the singular freshness and beauty and stimulus of Glover's The Jesus of History, in which the humanity of Our Lord is treated as really human. 


\section{Iv] Some Implications of the Incarnation 121}

tion of His Mission and even of His own Divinity did not come to Him till $\mathrm{He}$ was a full-grown man? Before we consider the help that such an idea gives, let us consider its apparent difficulty.

We have been accustomed to think of Him as realising His true Nature and His Mission from the earliest years. Partly, this is due to the piety of ages of literature and art. The Holy Child is pictured as a child with sad eyes, old beyond His years, already looking upon the sorrows of the future. Raphacl loved to paint Him so. The Madonna of the Grand Duke shows it, and the Sistine Madonna; even His play with the goldfinch is tender, and has none of the abandon of childhood. Sacred legend is full of His praeternatural wisdom, and His preoccupation with His life-work. But is there anything of this in the Gospels? Mary ponders His future in her heart, Simeon and Anna can look into it, but we are not told that $\mathrm{He}$ did. We hear little of his childhood or adolescence, except that He worked as a common carpenter; and even that from legend, and by implication from the Gospels; and that he played children's games ${ }^{1}$. Had He been unlike other children, except in perfect sweetness of character, and goodness, it is hard to believe that we should not have heard of it, though the argument from silence is always a precarious one. For myself, I love to think of Him romping with other children, a true child, without care or thought; forgetful, as children are forgetful; happy, as children are happy; loving toys and games as children love them.

1 Surely this is not an unjustified inference from Lc. vii. 32. At any rate T. R. Glover takes this view (The Jesus of Hislory, p. 36) in commenting on Christ's parable of the children playing at weddings and funerals. It is also clear from His nature parables that He must have gone out into the country often for recreation and amusement, for His work as a carpenter did not take Him there. He speaks with all the knowledge of a shepherd or an agriculturalist. 


\section{Some Implications of the Incarnation [CH.}

The one incident we know that seems to contradict this view, is the story of His discussion with the doctors in the Temple. But does it really contradict it? He forgets the time like any child. He is preoccupied with a sense of the nearness of God, with an interest in spiritual things; but any one who has had much to do with children of six to twelve years of age knows their simple and heartfelt interest in these things; their sense of God's presence ${ }^{1}$. Is not this an instance of the same thing, only at a somewhat later age, when the faith of less perfect children is commonly dominated by the vivid reality of the age of fighting and hunting instincts? Though by the age of twelve in most the realisation of the divine is somewhat overlaid by the pressing interests of immediate life, this is not always so, and in One who grew in grace as Jesus grew, it could not be so at all. Was His interest more than the perfect example of the wisdom, insight and love of a little child? Are we to make Him different from all the rest of humanity, and so to lose the gift which His true Manhood brought, by attributing to $\mathrm{Him}$ a premature realisation of Divinity? Is it not true to say that our inclination to do this is the result of a mistaken piety which was soimpressed with the sinfulness of fallen man that in all reverence it wished to place Christ as far away as possible from manhood as we know it; a piety that has left those enduring memorials in art and legend which still exercise so potent an influence? Is not this attitude also partly due to a belief in the omniscience and omnipotence of God, commonly not carefully thought out nor accurately defined? The belief is in a sense true in the transcendent sphere, though only in a sense as we have seen, but it cannot be true of the Godhead immanent in time and matter, if

"Surely " hearing them and asking them questions" implies listening to them and asking them questions childishly wise, not posing them with mature dilemmas? 
man is really free and if God really experiences process; as He must, if there is to be an ultimate union founded on a common experience. To this fact we have before referred, both in the present book and, at more length, in Evolution and Spiritual Life.

If omnipotence and omniscience cannot be postulated of the Godhead as limited by self-determined acceptance of the contingency of the cosmos He has created, still less, surely, can it be imagined in the Godhead Incarnate as a true human being. While clinging to our belief in the Divinity of Christ-without which the Atonement can have no meaning for us; without which we must be of all men most miserable, left still in our sins: having a perfect Pattern, and no power to make ourselves like Him-we must cling equally to our belief in His Manhood. If $\mathrm{He}$ was not true Man, as far as human vision can see, we are no nearer to atonement ${ }^{1}$. If $\mathrm{He}$ did not share our nature completely we cannot enter into complete union with Him; we cannot pass with Him through death into life eternal. The Atonement depends equally upon His perfect Manhood and His perfect Godhead.

1 Cf. Mackintosh op. cit. passim, e.g. "A real Kenosis is a moral as well as a theological necessity: the impulse from which it sprang was moral; it is the moral constitution of Godhead which made it possible; moral forces sustained the self-reduced Life on earth and gave it spiritual value," p. 472.

"Every theory which accepts a real incarnation must deny that the lowliness of our life is incongruous with Godhead," p. 474.

"We cannot think of the Incarnate One as confining Himself from moment to moment, by explicit volition, within the frontiers of manhood. That would simply lead back to the old untenable conception of a krypsis by which the divine self in Christ veils His loftier attributes, now less, now more, and is actuated in each case by didactic motives. To return thus to a theoretic duality of mental life in Our Lord against which all modern Christology has been a protest, is surely to sin against light," p. $4^{82}$. 


\section{I24 Some Implications of the Incarnation [cH.}

But if we accept His Manhood in the fullest possible sense, not only do we find the key which unlocks the mysteries of atonement, but we find light shed upon all the processes of the tangled past. The windings of the thread of consciousness end in comparative simplicity when self-consciousness is reached. There is meaning even in the tangle.

Let us take the physical side first, in the conventional way, though it is in fact impossible really to separate the physical and the spiritual.

If Christ went through the ordinary stages of human development, recapitulating the ancestral history of the race, He became identified not merely with the human race as it was then, but with all it had been in the dim ages before consciousness became self-consciousness. He took into His own Nature all the history of past struggle, all the stages of groping blindly amid the overwhelming press of a determined environment. $\mathrm{He}$ was identified with the whole process of evolving spirit ${ }^{1}$.

And this was not a mere matter of outward, physical form. He was very man, of the substance of His Mother. Through His Mother the continuity of the germ-plasm was preserved inviolate. The question of the Virgin Birth does not enter into this. His substance, and His Manhood's potentialities, were in fact the very substance and the very potentialities that had run through the whole chain of living organisms from the first simple beginning of life. This is, of course, only true, if the theory of the continuity of the germ-plasm, generally upheld by biologists, is itself true, either in

1 This is at least suggestive in relation to the problem of the lower animals. Whatever the truth as to their destiny-and this apparently we cannot know in the present life; at any rate there is no sign nor hope of progress in knowledge as yet-we can at least feel that Christ is linked with the whole evolutionary process, and 80 with every creature that has borne its part therein. 
its pure Weissmannian form or some modification of that. But surely it is a very glorious and uplifting thing to realise that Christ's Manhood took into itself all the past history of life; that $\mathrm{He}$ was one with the creation not only in His conscious, but in His pre-conscious existence upon earth. It lends much meaning to St Paul's phrase "The whole creation groaneth and travaileth together until now, waiting for the adoption, to wit the redemption of their bodies "-bodies; the means of winning personality as well as of manifesting it to others.

At this point it clearly becomes necessary to consider briefly the difficult questions involved in the doctrines of Original Sin, and of the Virgin Birth. The two are closely linked.

In a previous volume we discussed the problem of original sin from the biological standpoint, and came to certain definite conclusions ${ }^{1}$. We there saw reason to believe that the whole human race was imbued with a taint of positive evil, less by inheritance of the acquired character of sin, which is to the biologist a questionable proposition, than by a cessation of selection of the higher moral type. Possibly also development in response to a sinful environment, created by the evil doings of men, has something to do with the unquestionable obliquity of man's moral nature. As Wendell Holmes said long ago, "For one man that squints with his eyes there are twenty that squint with their brains" - and we may add 20,000 that squint with their souls. The human race, through this taint, was developing along wrong lines, and, by analogy, one is inclined to say that of itself it could not get on the right lines again. Certainly the impossibility of retracing developmental steps made in a wrong direction is a fact in the evolution of the body, and it is not unreasonable to suppose that the same is true of the spiritual evolution of the race, since in other

1 Evolution and the Need of Atonement, 2nd edn, pp. 143 seqq. 


\section{Some Implications of the. Incarnation [cH.}

ways this seems to be subject to the same laws as bodily evolution. Indeed, it is hard to see how it could be otherwise, for evolution is one process; the whole world is a definite means to a definite end.

Thus we found indicated at least a possibility that man was barred out from God not only by the imperfection involved in his own individual sins, but also by a radical taint of imperfection in the whole human race, due to the misdirection of conscious evolution. It is true that with human beings a new factor has come into play - the will. But the will is a thing of the individual, not of the race, and it is hard to see therefore, that it can have any bearing on the existence of a race-taint.

If our analysis of original sin was just, or if there be anything at all that is true in the doctrine of original sin, it would seem as if Christ must either be affected with the stain of humanity's misdirection of its own evolution, or else as if there must be something not perfectly and normally human in the nature of His Manhood.

The alternatives both involve serious difficulties. If He was tainted with original $\sin$, in the sense we have given to the words above, how could $\mathrm{He}$ be exempt from the consequences of the barrier between man and God that it set up? If $\mathrm{He}$ was not so tainted, can $\mathrm{He}$ be called perfect man?

Before discussing these difficulties it may be well to face an objection that might naturally, though not, I think, altogether legitimately, be raised to a discussion of even the possibility of original sin affecting our Lord. The objection lies in applying the word sin, however reverently the question be considered, to any part of the nature of the sinless Saviour. With this point of view I have the strongest sympathy. It is certainly right. But it only applies to the unfortunate phrase original sin-a legacy from earlier theology, with whose literal meaning very many Christians of to-day entirely 
disagree. $\operatorname{Sin}$ is the conscious misdirection of the will, as we have so often said. It is failure in a sense, but only in a sense. It is failure to do what is recognised as the right. Sin cannot be inherited; only its consequences can. A perfectly good man, perfectly good up to the possibilities of his then stage, that is, might be entirely sinless himself, and yet inherit the necessity to develope along wrong lines, through the misdirection of humanity's evolution. The barrier which kept him from perfection might be real enough, even though he did right himself, up to his lights, in every act of his life, and so was personally sinless. This is a purely theoretical matter, but it serves to show the point we want to emphasise-that the inheritance of the taint which raised a barrier between man and God is possible for a being perfectly sinless; that there is no question of the blasphemous attribution of $\sin$ to Christ in discussing the possibility of His inheriting something which we have seen reason to believe may be inherent in all men. Indeed, it is using an unfortunate phrase when we even describe it as a taint. In those who sinned it was a taint; in those who inherit the nature debarred from perfection, it is a consequence-a disability. Having thus cleared away possible misunderstanding, we may proceed to develope our argument.

Suppose that Christ did inherit the nature of a humanity that possessed 'positive imperfection,' as we have called it ${ }^{1}$; would He not be thereby barred out from God as man? And would not this disability make the Incarnation of no avail as Atonement? Would His Manhood be anything more than manhood as perfect as it could be when clogged with the chain of such a past? Of course, if we were wrong in believing that there was anything of the nature of original sin and of positive imperfectness due to misdirection of progress, the pro-

1 Evolution and the Need of Alonement, p. 144. 


\section{Some Implications of the Incarnation [CH.}

blem ceases to have any meaning. And this is possible. But we followed our thought out carefully, and it led us to the conclusion that such a disability existed. It is unsafe simply to assume we were wrong, when our conclusion brings us face to face with a difficulty; especially when the whole feeling of men for generations upon generations has tended to establish the belief that a disability is imposed upon the race by past sin; even if that belief is only in part intuitive; even if it is mainly based on a false theory of creation. Assuming that we were right in believing in the existence of original sin in the sense defined, it is almost impossible not to answer the above questions in the affirmative. Surely, Christ came to earth to be the perfection of manhood, not merely to be an example of the best that was possible to manhood gone wrong, and eternally limited by that going wrong. He took upon Himself manhood, with all its limitations; He bore the burden of conscious isolation from God upon the Cross, and the isolation of all manhood was upon Him. But $\mathrm{He}$ was not Himself, even as man, eternally barred out from God, else were no atonement possible. His manhood passed, through isolation, into perfect union with Godhead. But what do we mean by saying that $\mathrm{He}$ experienced to the full the isolation of manhood? I think we mean that as man $\mathrm{He}$ entered so completely into the sense of isolation that it filled His whole Being for the time, to the exclusion of the personal sense of eternal life. We have said ${ }^{1}$ that "The second kenosis was the acceptance of the voluntary misuse of the powers which progress had brought and all its consequences, and acceptance of the results of a choice of that which was not free in preference to that which tended towards greater freedom. It was the acceptance, not only of the necessary pain of becoming, but of the penalty of failure. It was the

1 Evolution and the Need of Atonement, and edn, p. 166. 
complete identification of the Godhead in Christ with the process of development, as Head of the human race; but it was also the identification of God with the failure of that process, in time, and under the then conditions." Christ actually experienced upon the Cross the isolation of essential manhood from His Godhead, in time, we believe, through the identification of Himself with the manhood of the whole human race. But nevertheless His own manhood must have been perfect, otherwise He would have experienced not merely the isolation of others in Himself, but the isolation of His own nature from His own nature. It was not really $H$ is manhood that was isolated, but the manhood of all others with which $\mathrm{He}$ had identified Himself. If His own manhood had been imperfect there must have been an intrinsic schism between that and His Godhead-an unthinkable thing. Had this been the case, His Manhood could never have been taken up into His Godhead, and so man could never, in union with $\mathrm{Him}$, have passed through death into life. Moreover, such an idea introduces hopeless contradictions as soon as we begin to think of the Holy Trinity 'after' the second kenosis-the Incarnation.

But on the other hand, if we reject the conception of Jesus suffering under the inherited disability of the human race, are we not faced with the dilemma, that in this case His Nature differed from that of common men, and that therefore men cannot be completely identified with Him? Is $\mathrm{He}$ one with men as they are?

In considering this we must distinguish carefully between the race and the individual. The salvation which Christ wrought is the salvation of individual men, not of the race as a whole. That was made clear in our discussion of the Atonement. Men are left free to accept or not to accept the gift of God in Jesus. 
Their freedom is not impugned. They must claim the gift by the free action of their individual wills. Therefore, we need not consider the race as a whole-only the individual. But nevertheless the individual is subject to the disability of racial misdirection; he is not exempt from the consequences of 'original sin.' Through it the race is evolving along a path that can never lead to perfection; through it any individual member of the race is misdirected in his own evolution. This point we did not make quite clear in our discussion in Evolution and the Need of Atonement. Individual as well as racial evolution has to be considered, when once we begin to deal with beings who are self-conscious, and are passing into personal transcendence. Owing partly to the cessation of selection due to sin, the race is evolving along wrong lines. But we believe that the destiny of all individuals is the same-union with God. Each individual, being an eternal spirit, is himself to reach the very goal. The goal of the race is the goal of its individual members. In this the process has got beyond the stage that obtains for the lower organisms, as far as we can comprehend it. There, it seems.as if the individual but hands on the torch and itself drops by the way. The human individual lights the torch of another, runs by his side a little way, and then drops to rest. But he picks himself up again and runs another stage, and perhaps another and another, until he himself at length arrives at the throne of God. Death does not end his course. None are necessarily destined never to reach that goal-pace John Calvin and the Predestinarians. Life may be a lottery, but no one draws a blank.

But if this is the case the misdirection of the race becomes the misdirection of the individual. If the whole race has got on to a wrong line of development, each component individual must likewise be on the wrong line; for the progress of a race of self-conscious beings 
is the progress of its individual members; its hindrances are their hindrances.

Each individual man, then, bears the burden of the misdirection of the race through $\sin$. If Christ did not bear this same burden, can we say that $\mathrm{He}$ was completely identified with fallen humanity? The answer to this question is implicit in two things we have said already. The will has to be reckoned with when we speak of any human being; and Christ's experience of isolation was the experience of the isolation of manhood from Godhead, in time, through the identification of Himself with the manhood of the whole human race. "It was not really $H$ is manhood that was isolated, but the manhood of all others with which He had identified Himself." His Will brought about the identification as the necessary consequence of complete interpenetration. In this identification $\mathrm{He}$ had the full experience of isolation; but as we have already said it was the isolation of the manhood that had failed, not of the manhood that was perfect-His own. This point is not adequately discussed nor clearly thought out in Evolution and the Need of Atonement (pp. 165 ff.). Indeed on p. 165 there is actual misstatement. The sentence "Suppose, sinless Himself, He became in very fact, Man, born into the full consequences of race-failure, living as man, dying as man, suffering complete alienation from freedom and immortality as man" contains not merely a careless confusion of thought but a definitely untrue statement, so far as I can see, though it does not invalidate the rest of the argument at all. Christ did accept "the full consequences of race-failure"; He did "suffer complete alienation from freedom and immortality as man." But He was not "born into them." He was Himself the perfection of manhood, yet increasingly throughout His life, and fully at the moment of complete realisation of His Mission, upon the Cross, He laid 


\section{Some Implications of the Incarnation [CH.}

aside even the perfection of manhood at its then stage, and through the act of His Will, identified Himself completely with fallen manhood. His own manhood remained perfect, but He laid it aside, ceased to experience it, and so identified Himself wholly and completely with the human race as it actually was. We can therefore be entirely united with His experience, we can pass through death with Him; and because His own manhood was perfect, and so not alienated from God, with Him man passes into union with God.

At first sight this view may appear to be tinged with docetism. It may be said that we are making the substantial reality of His manhood an appearance only, not a reality, when we claim that $\mathrm{He}$ only identified Himself with isolated manhood. The answer to this objection is twofold. In the first place we contend that He did actually, and not merely in appearance, experience manhood, becoming in very fact man; perfect man, however, yet with all a man's possibilities of failure and imperfection. There is nothing docetic in this. In the second place $\mathrm{He}$ identifies Himself with fallen manhood, even though He Himself is the perfection of manhood, by an exercise of His own Will. His Will makes Him Man in the great kenosis of the Incarnation; His Will makes Him experience man's isolation from God, though He is not isolated in His own nature. And note that this is a real isolation, and not an appearance only. Through the penetrability of perfect humanity He can enter into, and take His stand at, the position of the sinner, making the sinner's experience His own, while yet $\mathrm{He}$ remains Himself ${ }^{1}$. And the converse process, which completes identification, the sinner making the experience of Christ his own, we have held to complete the essential moment of the process of atonement, man

${ }^{1}$ See the discussion on penetrability in Evolution and Spiritual Life, ch. vi. 
entering into complete union with Christ ${ }^{1}$. In such a view there is nothing docetic, nothing unreal. In kenosis and identification alike it is the Will of Christ which supplies the motive power.

Now if Christ's Human Nature was perfect, there must have been somewhere a break with the normal human inheritance in order that the heritage of disability might be escaped. And this leads us to the question of the Virgin Birth.

No doubt some other means might have been chosen, though it is hard to see what that means could have been.

No doubt it is true that the whole matter is a mystery which we cannot solve. But it does at least seem congruous that the Divine nature of Christ should have been emphasised, and that the break with the tradition of disability should have been symbolised, by a miraculous and Divine Generation, in which the Human and Divine aspects are visible equally. Whether the Virgin Birth was a fact or a pious interpretation is an altogether different problem, which can, I think, only be solved on the.grounds of historical evidence. But of its congruity there can be no question. The birth of Christ must in some sense have been miraculous if $\mathrm{He}$ was God and if there is any truth in our contention that original sin, even in the sense of inherited disability, is a real thing. The Virgin Birth seems to emphasise this truth, and point to the miracle, in a way which lays stress on just the points that need stress. Anyhow, as we have said, our object is to establish the congruity of the miraculous conception, not its actuality. On the latter point it would be impertinent to dogmatise, considering what divided opinions are held by scholars. What it symbolises is the important thing, not the mode

1 Evolution and the Need of Atonement, and the present work, passim. 


\section{Some Implications of the Incarnation [CH.}

of the miracle. Probably, belief on this matter will never be united. The whole is so tinged with the false, and I would even say wicked, depreciation of hallowed sexual intercourse, that is the legacy of a celibate priesthood, that dispassionate examination is difficult for many. Mr Box ${ }^{1}$ has recently given us a careful, if not wholly unbiased, survey of the evidence, and one cannot do more, as one may not honestly do less, than express the personal opinion that he makes a very strong case in his defence of the Virgin Birth as an historical fact. While deprecating any bitterness of contention with those who equally honestly believe otherwise, regarding the evidence as inconclusive or dubious, one ought at least to state, with all the force one may, that, whether the mode of Christ's birth was that or not, at least it involved a miracle. The doctrine underlying belief in the Virgin Birth is true, whether the expression of the truth followed that mode ${ }^{2}$ or not.

This same doctrine of the complete limitation of Christ to the powers of perfect manhood incarnate under cosmical conditions helps towards an understanding of many questions that at one time and another puzzle us. His eschatological teaching, which seems not always to see clearly beyond the fall of Jerusalem; His human hunger, His human fatigue, His human griefs and disillusionments, His inability to see into the future ("If it be possible let this cup pass from me," and again, "Of that time knoweth no man, not even the Son, nor the angels, but only the Father"); even His human fallibility in judging the character of Judas Iscariotall these cease to provide difficulties when we accept His Manhood as a real thing, and not an epiphenomenon of Godhead. And we have seen already what clear light is shed upon the mysteries of the Atonement. Even if we

1 The Virgin Birth of Jesus.

As the present scribe himself believes. 
cannot understand it, we are not driven to explanations that shock our moral sense or our rational intelligence?

1 In this connection it will not be out of place to quote the weighed words of a recent writer to whom we have had occasion to refer more than once;-" "This, however, brings up the question whether the Son Incarnate can ever have known Himself to be divine. Was the Kenosis such that it annulled even the consciousness of a higher relationship? Some writers have contended that to the end Christ remained nnaware of His being God in flesh, urging that on no other terms can we assert the genuinely hnman character of His experience. In particular, it has been held that while sin was an impossibility for Jesus, we may conceive this impossibility as having been hidden from Himself, so that $\mathrm{He}$ faced each new conflict with that reality of effort, that refusal to count the issue a foregone conclusion which is vitally characteristic of moral life. And from this it might seem to follow that His primary descent into the sphere of finitude had veiled in nescience His eternal relationship with the Father. Yet we need not entangle the two positions with each other. It can only have been in mature manhood and perhaps intermittently that Christ became aware of His divinity- which must have remained for Him an object of faith to the very end. Now, if incarnation means divine self-subjection to the conditions of our life, it does appear that even such a discovery on Christ's part of His own essential sonship must inevitably suggest to Him the total impossibility of moral failure. But while His assurance of victory can never have been mechanical, or such as to dispense Him from vigilance, or effort, or seasons of depression, it was none the less real and commanding. There is no reason why His consciousness of unique intimacy with the Father, and of the crucial importance of His mission, should not have imparted to Jesus, in each temptation, a firmly-based confidence of victory, though He knew not in advance how, or how soon, the final triumph would be vouchsafed.

In any case, it is only by degrees that the full meaning of $\mathrm{His}$ relationship to the Father, with its eternal implicates, can have broken on Jesus' mind. The self-sacrifice in which His earthly life originated drew a veil over these ultimate realities." (Mackintosh, op. cit. pp. $4^{80-48 r}$.) 
I36 Some Implications of the Incarnation [сн.

One point of difficulty however remains. If Christ was purely human in His Manhood; if upon earth His was the divinity of manhood, not of Godhead: if $\mathrm{He}$ laid aside His Godhead for a time, He could have no memory of His Being in the Transcendent unity of the Godhead.

If this be so, how are we to interpret His constant references to His pre-existence :- "Before Abraham was, I am"; "I came forth from the Father, and again I go to the Father"? Before we begin to consider this we must clear our ideas of what we mean by the laying aside of Godhead, as far as we may.

It is abundantly clear that the Holy Trinity cannot have ceased to exist during the period of the Incarnation. To believe that the perfect Being of God can ever have been imperfect, is not merely inconceivable to human reason, but contradicts the very fundamentals of the idea of Godhead, making ultimate theistic thought impossible. It is in flat opposition alike to intuition and to intellectual belief. That the mediating Logos should ever have ceased to coexist with the Father and the Holy Spirit is impossible. The transcendent Godhead was never anything but perfect and complete.

But creation-itself involved in the very nature of Godhead-involved the immanence of the Godhead; a self-limitation in determined.conditions for the sake of the freedom that was to be in the creature. Furthermore, immanence must be postulated of all the Persons of the Holy Trinity. For consider. The creative Will of the Father is mediated by the Logos. "Without Him (the Logos) was not anything made that was made." Although we state this in the phraseology of revelation, the fact itself is implicit in the nature of personality, as we have seen. But once the cosmos is created, the Will of the Father is limited in regard to it, by the very conditions of cosmical existence. Yet there 
is purpose in the world. We cannot look on it as outside the scope of the Father's Will. That purpose we have seen to be the achieval of freedom by the creature; when the freedom of the creature is come, the selflimitation of the Father will be swallowed up in fulfilment $^{1}$. The Will of the Father in creation-even if, as seems necessary, creation is a perpetual processis thus directed towards the ultimate freedom of His Will in perfect harmony with the wills of other beings. With them, thus, His Will is in process of becoming, within the sphere of immanent existence. In other words, the Father is immanent in His creation, as well as the Logos who mediates His Will. Finally, since the issue is the emergence of love in freedom, the Holy Spirit must also be in process of becoming and must be immanent, as our study of the nature of personality shows. Thus we see that because the Divine Trinity is a Unity, all the Persons of the Godhead must indwell the world, in the immanent process. We must thus look on the Trinity as at the same time immanent and transcendent.

But further, because each Person is interpenetrated, and determined as Himself, by the other Two, while yet the stress of His nature is peculiar to Himself; because, in fact, the Persons are true hypostases-distinctions, each of which expresses the whole essence of Godheadthe immanent Father and Holy Spirit must have taken part in the Godhead Incarnate in human flesh. This is the truth which is misunderstood, and twisted out of its proper significance, in the heresy of Patripassianism. The Incarnation was the Incarnation of the Son, but in the Son all Godhead is comprised, though the emphasis of His Personality is not the emphasis of the Personality of the Father or of the Holy Ghost.

1 Evolution and Spiritual Life, passim. 
$13^{8}$ Some Implications of the Incarnation [сн.

In the Incarnation, then, the Logos laid aside full Godhead.

In so far as we are able to understand what is beyond understanding, since it is not wholly existent in the sphere in which intellect (as we know it, and as opposed to pure knowledge) moves, what meaning do we then attach to the laying aside of Godhead by the Son? Surely we mean at least this. The Son passed from immanence into the complete limitation of humanity. He no longer indwelt the world Himself in His own hypostasis, though He still indwelt it, through the unity of the Godhead, in the hypostases of the Father and the Son. He no longer indwelt the world; $\mathrm{He}$ was in the world - and the world knew Him not, and His own received Him not. He was still the Son. He mediated the Will of the Father through the unity of the Holy Spirit in fullest measure, in the complete limitation of Godhead to the measure of the divinity of man; even to being Himself caused. He limited Himself even to the acceptance of the terminus a quo of human nature, in order that humanity might reach its proper terminus ad quem. He who was the Mediating Cause of all, became caused Himself. He accepted the evolutionary stages of childhood, even to its ignorance of the divinity of human nature. To this He gradually won, as men win knowledge. To the full knowledge of His own divine Godhead He only won through death. This must be so, if He became truly man; and unless He became truly man, as far as I can see the atonement could not have been consummated.

Yet all the while $\mathrm{He}$ was the Divine Logos, in the realm of Transcendence. Only, His Incarnate Being was distinguished completely from His Transcendent ${ }^{1}$.

2 Except, of course, in so far as His human transcendence united Him with the Transcendent God, in the same way that our human transcendence unites us with God. 
Does this seem a difficult, contradictory statement? It is no more so than the doctrine, now universally accepted by theologians, that the Godhead is immanent in the world and in time and at the same time transcendent in the eternal sphere. The two conceptions differ only in degree, not in kind. The immanence is completed in a fuller sense: that is all ${ }^{1}$. Of their ultimate meaning we can understand little. Perhaps the most we can do is to say that while the Transcendent God knows all and sees the end completed and whole, as well as knowing His own becoming, the Immanent God knows only becoming, and cannot, in virtue of His own sclf-limitation, know the end. Yet this form of words is unsatisfactory, for it seems to imply a division of the Godhead, which is not there; we can intuitively grasp the correlative truths of immanence and tran. scendence, but we cannot express them in words, nor formulate them so as to satisfy our intellect.

All we are concerned with here, however, is to show that no fresh difficulty is introduced by the idea of the complete kenosis of the Godhead in Christ ${ }^{2}$. It differs only in degree from immanence.

A friend with whom I was discussing my rough sketch of the chapters on personality, and the general view therein developed of the triune nature of personality, made the penetrating remark, "If you apply that to the Personality of Christ you will be making God Immanent in Himself." This criticism conveys both a

1 See ch, viii.

2 In considering immanence at all we are really brought up against the problem of the consciousness of God, for it appears as if there must be two consciousnesses, and that involves an impossible dualism. In the consciousness of Christ the problem reaches its most acute phase. This question will be discussed at length in the final chapter, though it is touched upon in that on Preliminary Considerations. 


\section{40 Some Implications of the Incarnation [CH.}

true and a false idea. The true idea is, that if Christ had emptied Himself of Godhead and become Man in very fact, God must have been immanent in Him in exactly the same sense that God is immanent in every man who admits Him to fellowship as well as in the world of inanimate matter. He indwells each part of the cosmos, is limited by it, and through it is becoming -influenced by the changes of a finite experience. But, since Christ was Perfect, God was not limited by Him in any sense but that which is implicit in the durational conditions of human existence upon earth; there was no super-added limitation of $\sin$.

The false idea is that God was immanent in God. Christ is eternally the divine Logos; but on earth $\mathrm{He}$ laid His Eternal Divinity aside and became Man. His own Godhead, and the Godhead of the Father and the Spirit, were immanent in His Manhood. His Godhead was not immanent in His Godhead, for that He had laid aside; put it off, emptied Himself of it ; in becoming man. To believe otherwise would be to involve ourselves in a maze of unthinkable absurdities. Godhead is perfect and complete, and cannot be immanent in Itself. "The Word became (not adopted the form of) Flesh (Very Man) and dwelt among us, and we saw His Glory, the Glory of the Only Begotten of the Father"-but we only saw His glory in retrospective vision, when $\mathrm{He}$ had taken it again. "His own received Him not" at the time of His manifestation. Even His disciples only comprehended His Divine Being after His Resurrection. Peter might call Him "the Christ, the Son of the Living God," but we must remember what the term 'Christ,' and more especially what the term 'Son of God,' meant to the Jew. In Daniel it is used of an angel (and from this prophet the similar term 'Son of Man' is derived, or at least shown to be a term general in apocalyptic literature); we find analogous usages in Genesis vi. 2, Job 
i. 6 and xxxviii. 7 ; and in Hosea the chosen are called Sons of God, i. 101. By analogy with other phrases also we should hesitate to read into Peter's words ${ }^{2}$ a more definite meaning than "chosen messenger of God" or "Messiah"- -for the phrase had this recognised significance. Had the disciples understood really who He was, they could hardly have been oppressed with doubt so frequently; could hardly have been so disheartened by the Crucifixion (cf. the disciples on the road to Emmaus). The doctrine of immanence makes it clear, apart from all other arguments, that Christ was truly man.

The Nicene Creed implies this in the words kai rap-

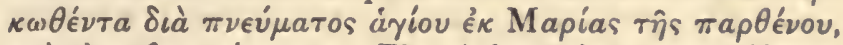

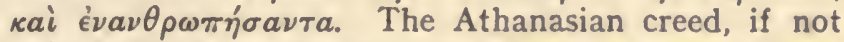
quite explicit, is sufficiently so:-Dominus noster Jesus Christus Dei Filius Deus et homo est. Deus est ex substantia Patris ante saecula genitus; et homo est ex substantia matris in saeculo natus (from the position of the emphasis,-Deus...homo-His Manhood is as His Godhead; part of His nature). Perfectus Deus, perfectus homo; ex anima rationali et humana carne subsistens. (His manhood is real and perfect manhood, not its form or appearance.) Aequalis Patri secundum divinitatem; minor Patre secundum humanitatem (kenosis). Qui licet Deus sit et homo; non duo sed tamen unus est Christus.

It is true that the point is confused afterwards by the use of a questionable analogy. Nam sicut anima rationalis et caro unus est homo; ita Deus et homo unus est Christus. This implies that the Manhood was the fleshly envelope of a spirit that was God, and had not emptied Itself of Godhead-a statement in patent contradiction of that a few verses before, perfectus homo.

1 Cf. Driver's Genesis, p. 82. Sanday, art. Son of God, in Hastings' D.B.

If they do not represent a later addition to the more simple statement of the Marcan and Lucan accounts. 
But I cannot think this to be more than a confusion of thought. If we believe in the Atonement it seems to me that we must cling to the truth of the Incarnation; must never let go our belief in the perfect humanity of Jesus, and so in His kenosis. The Godhead was not immanent in His Godhead; the statement involves a contradiction; it was immanent in His Manhood, as it is immanent in the manhood of each one of us. But because limitation is part of the real experience of God, being viewed by Him as part of the Whole which expresses His Being in all its fullness, His complete limitation in manhood does not make Him any the less really God. The limitation is not in the plane of absolute reality, nor of an eternal existence that is merely a totum simul, but as part of a reality-an eternal existence-that is a whole because it expresses the activity of Divine Being.

Having discussed what we mean by the laying aside of Godhead we may now return to the questions we asked in regard to our Lord's consciousness of His Divinity and Mission, and His memory of existence in the Eternal Unity of the Godhead.

In this matter Bergson's doctrine of Pure Memoryone of the fundamentals of his system-will be found decidedly helpful. The doctrine is so simple and satisfying that I cannot but believe that it represents a real truth, if not the whole truth. Readers of Bergson's philosophy will remember that he distinguishes entirely between memory and perception, and does not say, as many psychologists do, that memory is a weaker kind of perception. Pure perception is entirely in the present; pure memory is entirely in the past. But the past is not that which has ceased to exist; it has only ceased to act. The relation between action, perception and memory is vital. Action is the means of progress. Perception enables the vital impulse to react with the environment in 
adaptation. Only that which is of $u s e$ is perceived. We see many things which we do not perceive at all, because they are of no practical importance to us at the moment ${ }^{1}$. All the past also exists, in memory; but we are only conscious of that fragment of it which will be of practical use to us at a given instant, We call up into the present again-into the moment of action-what will be of value. The brain is the mechanism by which perceptions and memories can be brought to bear on actuality; its complexity enables the organism to have a choice in the mode of its response.

Now we saw in Evolution and Spiritual Life (pp. I82r85), that memory canhot exist in transcendence, because it moves in the past, and is related to limitation. But we have accepted the idea that Christ suffered human limitation, and so being removed from the - simultaneity of transcendence to the time-series of a human state, there would seem at first sight to be no reason for denying that He had memory of the experience of transcendent unity. And this conception of a memory of transcendent experience in Jesus is borne out by many phrases of St John, such as those we have

1 Anyone who has practical acquaintance with psycho-analytic work, or who is even fairly familiar with the literature of the subject, will realise how many things occur in memory that have never been perceived in the strict sense. In illustration of this I may further quote the experience of a friend who dreamed one night that the ss. - was wrecked and her captain drowned. (I forget the names, but they were clearly present in the mind of the dreamer.) On opening the paper, the first thing that caught her eye was an account of the wreck. She was horrified, believing herself to be afflicted with second sight. It afterwards transpired that an account of the wreck was given in the Stop Press column of the previous night's paper, which she had not read, but which was lying on a chest in such a position that her eyes must have rested on the paper as she passed through the hall, though she had not consciously perceived it. 


\section{I44 Some Implications of the Incarnation [cH.}

already quoted, and "I and my Father are one"; "I in them and thou in me, that they may be perfected into one"; "that they may all be one, even as thou, Father, art in me, and $\mathrm{I}$ in thee, that they also may be one in us." Indeed the whole of this seventeenth chapter of St 'John's Gospel, as well as other passages, might be quoted in opposition to any denial of Christ's memory of existcnce with the Father. And whether the words reported were actually Christ's words or not, they must at least convey the meaning which some of Christ's words brought to the Evangelist in retrospect. Christ then, certainly spoke as if Hewere conscious of complete union with God, at times; though in the moment of isolation (Eloi! Eloi! lama sabachthani) this consciousness was completely absent; and at many other times partially so, as we saw in discussing His limitations. This is very puzzling. Does it connote a realisation of His own Divinity? If so how, being conscious of such union, could He be perfect man? How, if at one time He was so conscious, through the coexistence of His divinity with His humanity, could $\mathrm{He}$ lose the divine consciousness, in part or completely at other times? Perhaps no real answer can be given to this problem.

Yet a tentative effort to understand it may not be wholly fruitless.

In the first place perfect manhood would give Him a sense of union with the Father, such as no other man ever experienced; especially since, as we have seen, His perfectness excluded the barrier of original sin which divided other men from God. The mystic saint has something of this experience even under the conditions of fallen manhood. This would suffice to explain such expressions as "I and the Father are One." But does it suffice to explain such expressions as "Before Abraham was, I am"; "I came out from the Father and I return to the Father"; "He that hath seen me hath seen the 
Father," and others of the same kind? If not, what explanation can we give? For it is hardly justifiable to say here, as some critics do in regard to similar problems, that the Evangelist in retrospect puts sayings into the mouth of Jesus which really represent the understanding that came after His resurrection. Even though there may be some truth in such a contention, we cannot believe that he deliberately gave a false impression for the sake of establishing a theological dogma. Whatever Christ's actual words, He must have said things that gave this impression; otherwise the Gospel of St John would never have been accepted at a time when tradition was so fresh. And the sayings are so congruous and so closely associated with the whole character and ministry of Jesus that we cannot but believe that they, or words like them, were actually spoken by Him.

On the other hand they seem quite definitely to contradict other sayings, in which He expresses a sense of dependence upon, and ignorance of the full purpose of, the Will of the Father.

Any idea of a kind of alternation of the divine and human consciousness is out of the question. It is irreconcileable with His perfect manhood. We must find some other explanation.

Now His Godhead and His Manhood were alike real; and the manhood existed in the conditions of matter and becoming. If as Man Christ could have had any memory of transcendent union with the Father, the difficulty would be solved. For, according to Bergson's exposition, His memory could make use of the reality which for Him, as a being experiencing duration, was existent, yet in the past, bringing it into the present again for the purposes of immediate action.

The value of this memory, in enforcing His teaching, is at once obvious. He could speak with certain knowledge, as one having authority, and not as the scribes.

MCD. 


\section{46 Some Implications of the Incarnation [CH.}

The question is, could $\mathrm{He}$, as Man, have such a memory? Would it not introduce the Godhead again into His Manhood, and so make Him not perfect Man?

We must ask, in the first place, could such memory be the same as our memory? Most of our memories are memories of perception, and, for us, perception is associated with the recognition of matter. Of experience which takes place without the mediation of matter external to the personality we have little knowledge. But we have memories not directly connected with perception. We can remember an emotion, for instance-that is, we can remember an internal state-though such memories are usually connected with a perception that gave rise to them For instance, we can remember the emotion of love of some particular person, or the beauty of a particular scene or symphony. Those memories are not memories of the perceptions themselves, but of the emotions to which they gave rise. Even further, we can remember the emotional state of some particular epoch of our lives, without remembering any of the perceptual experience that caused those emotions. We can remember the religious sentimentality of adolescence, for example, or the misery of doubt at a slightly later period. Memory does not seem to be completely tied up with perception; other experiences, such as those of internal states, can be recalled. Therefore there seems no ground for excluding the possibility of Christ's memory of transcendent experience on the ground that it was not perceived in the ordinary sense, but was rather allied to emotion.

But this memory seems to have included the sense of His uncausedness, as well as of the perfect unity of transcendent Godhead (Before Abralıam was I am). It was a memory of absolute existence, such as no other man could have. The difficulty is, could Christ have it and yet remain Man? Could He bring what would be 
useful out of the storehouse of memory, to meet some eventuality, and yet have resigned His Godhead and become completely man?

Unquestionably, any of the views we have suggested leaves us faced with a very grave difficulty, and one which we cannot really solve. Perhaps we cannot do more than say He must have been Perfect Man, and that the record seems to show that such memories did exist for Him, during His earthly life, leaving all possibility of solution on one side. It is possible, of course, that the records wrongly import some of His own post-resurrection teaching into the years of His ministry. But it is at best a supposition-a pis-aller. Again, one may say. that the whole process of the Incarnation is outside our understanding, and that things which seem incompatible to man may not really be so to God. But this evading of the issue is even less satisfactory than the last. Even God cannot make a contradiction true, and it is exactly a contradiction with which we seem to be faced. True, opposites may be reconciled in a higher synthesis, but the higher synthesis of Manhood and Godhead is transcendent union, which is precisely what we do not want here. We are concerned with Christ's Manhood, and His Manhood alone, in the present connection. Let us then attack the problem from the side of ordinary manhood, as we have done before, and follow further an argument we adumbrated a few pages back.

Men are intuitively conscious of union with God. In some sense the kingdom of heaven is within them here and now. They are conscious that they share the activities of a Spirit that is higher than themselves, and that they have a life that is not purely material. In Christ this intuition must have been far freer and purer; and one can readily believe that it extended to the realisation of real and complete union with the Father, except in the timeless moment of isolation. With the complete- 


\section{Some Implications of the Incarnation [CH.}

ness of this realisation of union would come inevitably the sense of eternal existence without any terminus a quo as far as His transcendent ego was concerned. Even an ordinary man feels at times some sense of union with God, and then his sense of causedness is in abeyance. The feeling of love and union ousts all else but itself. May we not then believe that Christ realised His oneness with the Father, even to the extent of realising His own eternal existence, without any memory of His own transcendent experience? May we not believe that $\mathrm{He}$ knew from this very realisation that $\mathrm{He}$ was before Abraham, that $\mathrm{He}$ came forth, and must have come forth, from the Father, because of the very perfectness of His manhood? May we not believe this, and yet hold fast to the fact that He was very Man? Would such a noble expansion of a form of knowledge that is common to all men, make Him any the less man? I think not. It may be said that all we have done is to use another word to describe the same fact. Instead of calling His realisation a memory we now call it an intuition. This is true. Nevertheless the two conceptions which the words involve are poles apart. The one implies a consciousness of Godhead that is incompatible with perfect manhood; the other implies no direct consciousness of Godhead, but simply the completion of the human instinct of union with God, that is in every man in some degree; and from this completion, by a secondary mental process, the realisation that He Himself was eternally one with God, and not merely united with Him-a secondary mental process in the realm of intellect.

If this analysis be true, we are driven to deny that the Human Christ had any memory of existence with the Father before His Incarnation, while His intuition of perfect oneness with the Father led Him to the realisation that $\mathrm{He}$ must have been eternally one with Him. And this conception is fully consonant with the view, 
held by most thoughtful Christians of to-day, - surely a reasonable view, when one remembers that His ministry did not begin till He was nearly thirty years old-and with the outlines of the Gospel story, that only with the passage of the years did He come to the full understanding of His mission.

At any rate, we cannot gain more light along the line of investigation we have chosen.

One cannot do more than express a tentative opinion on a matter that is necessarily beyond our understanding; but in honesty one cannot do less than state the opinion to which one is impelled. It may not, and indeed cannot, be completely satisfactory; but it is worth while to formulate views, even if incomplete and in parts erroneous, that others may envisage the problems, and abler minds lead us gradually nearer to the truth. F. W. Robertson, more than seventy years ago, in His sermon on "The Good Shepherd" " insisted on the need for an honest facing of the nature of Our Lord's human$i^{2}{ }^{2}$. We have been trying to examine some of the more outstanding difficulties of our belief to the best of our ability. The most we can hope is that we have cleared the way for future thought, and have ourselves thought carefully and reverently. However questionable our conclusions may seem to some, the attempt will have been worth while, if it leads them to formulate a more satisfying theory.

Our own examination has led us to two definite results. (I) Christ was fully Man, with all the limitations that are necessary to manhood, but without the disability which seems probably inherent in fallen manhood. He put on manhood, but it was perfect. Being perfect, He could identify Himself completely with

i Sermons, 2nd series.

- See Storr, Development of English Theology in the Nireteenth Century, pp. 416-417. 


\section{50 Some Implications of the Incarnation [CH. IV}

others, for perfect freedom is perfect service; the perfection of human freedom is the perfection of human service; and service is self-limitation. Of His own will He took upon Himself the burden of fallen manhood, through the penetrability of personal being, and experienced its isolation. He was Man; He identified Himself with "fallen" manhood. But He Himself was perfect man, without the race-disability of manhood. Otherwise $\mathrm{He}$ could not have brought about atonement, for His Being would not have been as perfectly penetrable as is possible for manhood; He could never have drawn the whole world into the love of the Father.

(2) In His manhood it is doubtful if $\mathrm{He}$ could have any memory of Transcendent Godhead, for if $\mathrm{He}$ had He would not have been truly man. Those words of His which seem to point to such a memory are probably to be interpreted rather in the light of the intuitive knowledge of union with God that every saint possesses at times and in some degree. They represent the experience which makes His teaching that the Kingdom of Heaven is within us, and that we are even here and now in eternal life, awaken in the heart an answering certainty that nothing can shake.

Nore. On p. 136 we quoted Jn i. 3 in its usual form. If we

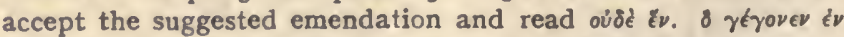
aủr $\hat{\varphi}$ Swiे $\dot{\eta} v$, our immediate contention is unaffected, while our general discussion of the perpetual mediatorial activity of the Son receives illumination and fresh cogency. 


\section{CHAPTER V}

\section{SOME IMPLICATIONS OF THE INCARNATION (cont.)}

ACCEPTANCE of the true Manhood of Jesus Christ involves us in the difficulties of yet another problem, very different in some respects from those we have hitherto been considering, yet related to them. If $\mathrm{He}$ was Man, passed through the stages of a man's development, suffered the limitation of a man's intellect, in a word, became as man becomes, we must try to trace out the influence of these processes upon His Eternal Being. For if the changes were real for Him, as they must have been, we cannot simply say that because $\mathrm{He}$ is God as well as Man, they can have had no effect upon that. To say this would be to deny their reality.

We have already examined the question of the memory of transcendent experience in the earthly life of Christ. We must now do exactly the opposite; examine the earthly memory of Christ and see whether and how it affects His transcendent Being.

Once more we can start with human experience and argue from it with the more confidence, that, ex hypothesi, Christ was perfectly human. Further, since we believe that man, though human, has an eternal destiny, and is already in part transcendent, both sides of the problem are before us as we consider that experience.

For this purpose we will glean what we can from two of the most suggestive contemporary writers on memory, -Freud and Bergson. Working for different ends, looking at life from opposed standpoints, the one expounding a new scheme of materialism, the other, almost, a new scheme of pantheism, we shall find that they yet supplement and confirm each other in a remarkable manner. 


\section{Some Implications of the Incarnation [cH.}

Freud's basal dogma is that every experience persists in memory. The brain - for him the brain ${ }^{1}$ constitutes the seat of memory, and mental processes are physiological phenomena - retains each least impression. The past leaves its indelible mark. In waking life the effect of many of these impressions is imperceptible except in so far as they mark out and render easy a path of discharge for the response to some stimulus, through habit-formation. (For the brain has its paths, some well-worn tracks, some little frequented, but none ever overgrown and obliterated. Rarely in later life does a discharge leap over the hedge, and trample out a new way.)

This imperceptibility of the effect of so many stimuli and their responses agrees well with Bergson's view that we only remember that which at the moment we can use. In dreams, however, the mind moves along the winding, intertwined paths which in the day are so little used. Every dream, says Freud-and this is one of the central moments of his teaching-expresses a wish-fulfilment. The mind wishes to repeat some experience; or to get the complete fruition of some joy that was itself cut short or unattained in waking life.

Simple dreams of wish-fulfilment occur in grown men and women, but not commonly. Another factor has come in. In children one finds them constantly. If a child has not been over-drilled, his dreams are almost always simple wish-fulfilments. Anyone who has healthy young children may easily verify this statement for himself. As far as we can judge, it is the same with animals. We are all familiar with the joyous hunting dreams of dogs, and their (presumably victorious) dream-fights.

1 Or ratber the region between the organic elements of the brain-paths, whatever that may mean (Interpretation of Dreams, p. 484). 
But in the adult there is something more. Men do not generally dream simple dreams. To explain this and other things Freud creates a new entity, the Censor, who is in very truth censor morum. Religion, social convention, law, have created a code which governs our very innermost selves far more despotically than we imagine. Many desires are in opposition to this code. We shrink from them. We repress them, refuse to let them come into our consciousness at all; these old, lawless desires. And so it comes about that perhaps we do not know we have some of them at all, for we have never allowed them to come into consciousness. (It must be clearly understood that the censor itself is an unconscious agent ${ }^{1}$ ) ) How then is it possible to discover their existence? In one way only. By their works ye shall know them. They lie at the root of many diseases; those diseases are their great works. All the phobias, the unreasoning fears that stalk after a man unseen by all the rest of the world, - fear of open spaces, fear of closed rooms, other definite fears whose name is legion, blank unassociated fear of fear; strange and obscene fetish worship, of whose existence few but the students of abnormal mind-states know; impotence; physical weakness, mental weakness; many forms of madness; paralysis of certain types; all these and end-. less other diseases, down to the border-line between eccentricity and disease where lie such things as the comprehensive hospitality of the old maid, towards countless and often repulsive pets, are the great works of repression-complexes. An example may serve to illustrate the way in which a repressed idea finds outlet in some distorted form, producing physical symptoms of disease. Mr X., a man of about thirty, was obsessed with a perfectly formless fear. The paroxysms became more and more frequent, and the result on his physical health

1 Appendix B. See also the illustrative case given below. 
[CH.

was disastrous; all kinds of symptoms manifested themselves. Voyages, rest-cures, drugs were without avail. $\mathrm{Mr} X$. was dying of fear. Eventually he went to a nervespecialist who recognised the probability that some repression underlay the physical symptoms. The clue was in this case obtained by automatic writing under light hypnosis. As a child of twelve $\mathrm{Mr} X$. had been in the room when his father had a fatal seizure of pulmonary embolism in middle age. The shock of this had been so great, and the memory of it so painful, that it had been completely driven from the consciousness. Under light hypnosis the doctor's questions recalled it: to the "question "What are you afraid of?" came the reply "Father's death1." "Why?" "Shall die same." With the approach of the age at which the father died, the repressed fear of childhood became operative! The patient had, of course, only to be told that this was the origin of his formless fear, and that medical examination showed that there was no symptom of the disease, to ensure complete immunity from the paroxysms of fear; and restoration to normal health rapidly followed. But we can trace the work of repression in lesser things too. The slip of the tongue or pen has a clear meaning for those who know how to interpret it ${ }^{2}$. A simple example that happened in my own presence a few weeks ago may illustrate this. One of the little boys of a lady who has suffered all her life with great pain in the eyes, has weak eyes, though otherwise he is exceptionally muscular and vigorous. I know that she is always

2 The patient did not know what he had written.

2 Cf. Freud, Psychopathology of Every-day Life; Ernest Jones, Papers on Psychoanalysis; Bernard Hart, Psychology of Insanity, etc.; as well as Freud's chief work The Interpretation of Dreams. Many careful readers and students will doubtless come to the conclusion that here, as in many other matters, Freud extends his generalisations beyond legitimate bounds. 
haunted with a fear-almost certainly unfounded-she does not speak of, that the boy will suffer as she does. Someone was commenting on his skill in the gymnasium, and his mother said, "Yes, he has wonderfully strong eyes," she meant to say arms, but the repressed, and at the time unconscious, wish that his eyes were as strong as his arms, expressed itself, uncalled.

Again, if you agree with a man that he shall answer a string of words, spoken one by one, each with the first word that enters his mind, you will find that the existence of a repression-complex is indicated by a longer interval, a peculiar, unexpected, word, or no word at all. This pause is the work of the repression-complex, or rather of the unconsciously-acting censor; and by choosing your words, and by careful questioning; by the method known as free association, or by automatic writing; best of all, in many cases, by the use of hypnosis, you can often discover the nature of the complex, even if it is entirely unknown to the person. Do you cunningly object, "How do you know you are right?" there is a convincing answer, "By the good pragmatic test, that if a disease afflicts the man in question, having discovered the hidden cause, you can cure the disease ${ }^{1}$. It works, and that is the pragmatist's test of truth. In such matters we are all pragmatists." Besides, even in the case of normal minds, you can call up forgotten incidents of early life with which some repression-complex is associated, as any one who has any practical knowledge of the methods of psychoanalysis knows.

But chiefest of all, dreams reveal to us the thing which was repressed. The superficial content, the apparent content, of a dream is determined by pre-

1 I would by no means say that you will be curing the disease by the best or most expeditious way in a great many instances. Even where the case is susceptible of psychoanalytic cure, treatment by suggestion is often preferable, for many reasons. 


\section{Some Implications of the Incarnation [CH.}

ceding events of working life, generally the events of the previous evening; its real meaning lies deep in the accumulation of material in the unconscious. Fragments of unimportant happenings are irresponsibly selected, though occasionally somatic stimuli provide the immediate cause, and perhaps shape the dream. Dreams appear most often motiveless and disconnected when such fragments as can be remembered are considered by the waking mind, and they rapidly fade from memory. This disconnectedness and impermanence is due to more than one cause. Partly, dream-episodes, except the simple dreams of wish-fulfilment, are really without sequence, because the apparent content of the dream is of little importance: has nothing to do with the real meaning. Partly, as soon as the dreamer wakes the critical moments of the dream are repressed from consciousness by the censor. In sleep, the censor dozes, and passes matter for publication whose disguise is too transparent for this to be allowed when the whole mind is fully awake. Therefore the censor does the next best thing; he calls the dream in from circulation and wields his blue pencil freely. What finally emerges is as futile as were the articles of military correspondents in the early stages of the war.

The true content of the dream lies deeper. It is veiled in ambiguous symbols. Real meanings are often expressed by their contraries. Fear, for instance, is a wish inverted. All this is conditioned by the necessity of escaping the eagle eye of the censor.

Thus, the interpretation of dreams is a matter for the expert alone. Only those who have the requisite knowledge of psychology and physiology can attempt it.

Once more it may be asked how one can possibly tell what is the true interpretation, if sometimes the interpretation is straightforward, sometimes by contraries, and if everything of importance is masked by some 
visual symbol or some word-play depending on a silly assonance?

Of course, often one cannot; but often one can, and here the answer is again the answer of the pragmatist. The analysis of dreams is now used by specialists for the diagnosis of certain types of disease. The repressed complex, which, it must be remembered, never emerges at all into consciousness, is discovered, brought into consciousness, verified; and with, or sometimes without, further treatment, the disease is cured. If there is treatment, it is based on the discovery of the repressioncomplex. But the important point is, that the pudding is proved in the eating.

Perhaps, since we all live in conditions that make imperative the repression of many potent desires, it may seem strange that we do not all suffer from repressioncomplexes, since these desires cannot ' abreact' or be fulfilled. But it is just here that the hopefulness of Freud's discoveries comes in. If an illegitimate desire is faced and fought, it can be directed into other channels. It becomes 'sublimated '. Sexual desire, to take the most familiar instance (with which Freud's works are all unduly permeated), may be sublimated into pure love, if its existence is recognised. If, for instance the person plunges into public work in order to forget a passion, the force of the passion is poured straight in the work, and not bottled up, to emerge later as a symptom, always

1 Some workers in this field are inclined to give a far less important place to 'sublimation' than is given by Bernard Hart, for example. They contend that in most cases the mere fact of facing and fighting an anti-social impulse brings the whole matter so strongly into consciousness that repression does not occur in normal subjects, and sublimation is rendered unnecessary. With this I do not altogether agree. The acquisition of new functions by organs is a common phenomenon, and I see no reason to suppose that we have not here an analogous phenomenon. 


\section{$15^{8}$ Some Implications of the Incarnation [cH.}

provided that the work is directly linked in his own mind with the idea to be mastered. In the same way the passion may be linked with an emotion, if the linking is done consciously, and the substituted emotion is one that can receive full outlet. If not, it will find some abnormal and symbolic path of discharge, its natural path being blocked. Extreme instances of this are familiar to all medical attendants of lunatic asylums; less marked cases constantly present themselves in ordinary life to those who have the requisite knowledge. In one instance I have recently come across, the discharge path is a peculiar form of unconscious egomania. I may not here enter into the details of the case, or explain why it should have taken this particular form, but I know enough of the history to be certain of my interpretation.

It is not possible, nor desirable, for our present purpose to enter into more detail of this fascinating study; the rough outline given is all that we require.

Now in all Freud's work the mechanical basis on which the mind operates is made abundantly clear. So much so indeed, that Freud himself is betrayed by it into the crudest materialism.

But a mechanical basis is exactly what we should

1 The serious student, if he has the requisite knowledge, is strongly advised to study Freud's own works, if he be of strong stomach, and also Dr Ernest Jones' Psychoanalysis. Something also may be gained from Munsterberg's Psychotherapy, and Dr Wingfield's Introduction to the Study of Hypnotism, as well as many other works. But those who have no medical knowledge, or no special reason for wishing to pursue the matter further, will find all that they require in Dr Bernard Hart's little shilling book on The Psychology of Insanity, and they will be well advised to content themselves with this. Even though the book is professedly concerned with abnormal mental states, much information about the structure of the normal mind and its complexes is incidentally given. 
expect, for, as we have seen ${ }^{1}$, only on such a basis is the emergence of freedom in a determinate environment possible. We expect determination as the necessary basis of intellect. Freud's psychology only transgresses the bounds of legitimate (not necessarily correct, be it observed) inference when he endeavours to make consciousness an epiphenomenon of the brain states.

The special problems that concern us at present are rather (I) the meaning of memory on the mechanical side, (2) the nature and function of the Censor.

(I) Bergson, as we have said more than once, divides memory into habit and pure memory; the habit-phenomena being localised in the brain, as a mechanism², the pure memory not. The past truly exists for the individual, and that portion of it which may be of use in a given conjuncture is brought into present consciousness, and made effectual in practical life, through discharge along a selected path. Pure memory moves in the past-moves, that is, amid that which exists but has ceased to be useful-and is directed, like habit, to practical ends selecting what is of use and applying it: bringing it again into touch with actual experience. It is freer than habit; for in this last we see the discharge along a frequented path, of some familiar impulse gener-

1 Evolution and Spiritual Life, ch. iii.

3 A side-issue of some interest arises here. Is habit-memory determined by a molecular pattern; and is it heritable? There scems to be some evidence for the heritability of habits: we are at times appalled by the fidelity with which the outgrown tricks and habits of our boyhood are reenacted in our offspring, though, of course, it is the somewhat similar eavironment that brings them out. But habit-inheritance suggests the inheritance of an acquired character. Probably we should be ncarer the truth if we assumed that a certain molecular pattern exists and is inherited ; that this makes imitation, and similar response to similar stimuli, casy, and that by reiterated response the molecular pattern becomes identical. 
ated by a stimulus that bas been often repeated ${ }^{\boldsymbol{1}}$. All this harmonises very well, up to a point, with the Freudian view of repressions ${ }^{2}$. According to this latter school, impulses which, for social or religious reasons, cannot be satisfied in obviously appropriate action are either repressed from consciousness-in which case they may, if potent enough, break out and be discharged in some symbolic way; and then in extreme cases, the man may become abnormal, or even insane-or else their character is recognised in consciousness and they are bravely faced, instead of being relegated to Mrs Grundy's Chamber of Impossibles - when they achieve discharge along a higher path, harmlessly. In many cases these repressed desires are related to habits, and serve as the trigger through whose operation the path of habit is traversed by some impulse. Their symbolic or sublimated discharge acts in the normal individual as a safety-valve, and so fulfils the utilitarian function postulated by Bergson for all memories. Thus, though repressed by the censor, and so never entering into waking consciousness, they appear and function in dreams, and also, without appearing, become causal factors in the neuroses.

But, as Cunningham ${ }^{3}$ points out, all the past, and so all memory, is really directed towards the future. So also even the repressed ideas. It is an essential point in

1 It is possible to define memory simply as potential ideas. I do not think that such a definition clashes with Bergson's conception. According to him the past does exist, and by memory is selected from in so far as it becomes useful. According to the foregoing definition the potential ideas would become actual when an end could be subserved by their doing so. - To the practical psychologist the new definition may appear the more useful; to the metaphysician perhaps the other.

- See however Appendix A.

- An Introduction to the Study of the Philosophy of Bergson. 
Freud's doctrine, that every memory persists. Indeed he and his followers go so far as to make the impressions of early infancy of far-reaching importance in determining the life, conscious and unconscious, of later years; and in many ways the facts seem to bear out this view.

The past lives and is changed in the present. Thus Bergson.

I am what I am because of my past; but I am changing, modifying myself and being modified. Hence $\mathrm{My}$ self is the sum-total of my past experience, as related to that of me which persists. The full meaning of the past is only realised in the future. The past is ever operative in the present for the sake of the future. Thus Cunningham.

We see, then, that by introducing the idea of the transcendental ego we at once find a means of harmonising Freud and Bergson. Bergson, the pantheist, looks back on the urging of the vital impulse; Freud, the materialist, looks forward to the influence of the mechanism of past mental states upon the mechanism of future mental states.

For consider Freud's views. The associations found in psychoanalysis seem purely mechanical, but all the time there is an end, and a useful end, to be achieved by those associations; a teleological significance is introduced by Freud over and over again, implicitly and even explicitly, into the conception of the psychic activities. What, for example, could be more explicit than this statement;- " This primitive mental activity must have been modified by bitter practical experience into a more expedient secondary activity " " Here is teleology with a vengeance I The past is utilised, as it must be, to determine the present and the future. The past lives, is, in the present, and the organism must act in accordance with it, for there is the mechanical basis, and there

1 The Interpretation of Dreams. Trans. Brill, P. 446. MCD. 
is an end in view - the progress of the organism towards something which Freud does not define, but which must be adaptation, and which, hence, in accordance with our earlier arguments ${ }^{1}$, I unhesitatingly call freedom. And progress depends on what the organism is and has achieved, and so on its whole past.

(2) What then is the censor? Freud himself compares the objects of our 'internal perception,' as he calls it - all psychic formations, that is-to the images produced by the lenses of a telescope, the lenses representing the psychic perceptions, and the censorcorresponding to the refraction of the light by the telescope-lenses (op. cit. p. 484). Indeed he is inclined to believe in two refractive systems or censors, that between what he, in his peculiar terminology, calls the "unconscious" and the "foreconscious" (which is itself not in consciousness, but in which an accessible stream of psychic reactions continually flows, doing mind-work, and giving rise to fresh psychic formations) and that between the foreconscious and the conscious (op. cit. p. 490). The importance and the weakness of this idea of double censorship is discussed in an appendix. For our immediate purpose we need only point out that ultimately the censor is seen to be exercising a function which is directed towards definite ends. Indeed, it seems to me that we cannot define it except as the organism's recognition of an end in life. It is the unconscious self-judgment of the individual in his capacity of a believer in ends ${ }^{2}$. Certain things cannot pass the censor because it -or he-imposes the claims of safety, of social utility, of religion.

In the animal and the child the phenomena of censorship are absent. These only come with a stage of development when other ends besides the immediate

3 Evolution and the Need of Atonement.

- See however Appendix A for a fuller discussion of the matter. The problem is one which is essentially intricate and obscure. 
satisfaction of the individual's impulses are recognised. The child is still in the stage of development of the social organism which is pre-social, pre-religious, except in the most elementary sense. The complexities of higher social and religious life are unknown, inoperative as yet. Yet, on what are these claims of religion and society based? Surely, directly at any rate, on the progress of man. The child has not got them because his recapitulatory development has not reached this stage.

If they are based on progress, then since the very existence of the power of progress involves purpose, whose theoretic interpretation must be in terms of teleology, as we have seen ${ }^{1}$, their existence must be due to an end or aim in the life-process. The very existence of the censor, the very existence of the power of sublimation, is evidence of purpose; and more, of a purpose that is recognised and acted upon. The purpose, the end, is spiritual life. To that conclusion we were driven at the outset of our investigation ${ }^{2}$.

Thus the Freudian mechanism is what we should expect in organisms that are developing towards freedom on the foundation of the past, which in them is ever present as an actual, modifiable existence; while the Freudian censor is what we should expect as evidencing ${ }^{3}$ the unconscious self-judgment of an individual living in a community whose ideals express, not the desires and wishes of more primitive life, but the desires and wishes pertaining to that stage of spiritual advancement which the community has reached. There is no real inconsistency between Bergson and Freud. The fact

1 Evolution and the Need of Atonement, ch. i.

Ibid., cf. also Evolution and Spiritual Life, passim.

- Evidencing only, for Freud's censor is something different from the whole spirit of man; it is an unconscious mechanism which aids the operation of this last, which itself exercises a censorship of a wider character. 


\section{Some Implications of the Incarnation [сн.}

that repressions exist and that censorship exists cannot for a moment be questioned by anyone who possesses the slightest practical acquaintance with the facts. But I cannot help suspecting that the censor, in Freud's sense, has no real existence. It seems to me to be far more in accordance with the evidence to say that, in any given constellation of ideas, the censor is simply a second idea, or a second potential idea, belonging to a 'higher' level than that which it seeks to repress. In a hate-complex the lower idea may suggest murder: the censor is the higher, social, idea that murder is wrong in itself, or the still higher, spiritual, idea that hatred is wrong. In a man's sex-complex the lower idea is repressed by a higher idea of the status and nobility of womanhood, and so on. To say that the censor is a definite entity seems to me wholly unjustifiable. It is far more reasonable to contend that there are as many censors as there are impulses to be repressed: that the censor represents the mechanism of an unconscious judgment of each low impulse by the whole organism as it opposes a noble impulse to each ignoble one. For convenience, however, we will retain Freud's term, while giving it this fresh meaning.

Let us now apply what we have said to the mind of man in a more general way, in order that we may see how to apply it to the mind of the Man Christ Jesus.

All a man's past exists; and existence means persistence in the present. Nothing-not the least, trivial happening - can fail of its effect, or be obliterated. Not only does the man live over again in brief the whole history of his evolution, the past which has been created for him by his forbears: not only does that past enter into the present during his unconscious life, and persist as the foundation on which his being is erected; but the past which he himself has created for himself persists, though, to a large extent, not in consciousness. Yet alike in the past created for him and in the past he 
creates himself, there is much which belongs to lower stages of being. There are many impulses that date from preconscious times, which his spirit has outgrown. There are many impulses, many yieldings, which truly belong to stages left behind. Yielding voluntarily and with open eyes to such anachronistic impulses constitutes the positive act we call $\sin$. Sin too, then, persists in the ever-present past-ever present, because, through memory, it is ever active in the now. What a man is and will be is largely determined by what he has been.

Yet his growing spirit exercises censorship. He recognises unconsciously as well as consciously that there is much in his past that must not be imported into the present. Often he commits the dread mistake of being shocked. Lower impulses and past yieldings alike he refuses to admit into consciousness. He dare not face them, and packs them hurriedly out of sight. Instead of realising that only on the basis of the past can the future be built; instead of admitting to himself that, though he may attempt to delude himself into a belief that because he refuses to recognise them they have ceased to exist, they have not done so really; he actually brings himself to think that out of sight is truly out of 'mind.' He forgets the truth that underlies the old catch-word "Forgotten sin is not forgiven sin."

If only men could get rid of the terrible habit of being shocked at facts! No real being has caused anything like the harm and misery that Mrs Grundy has been responsible for, even though she be a veritable Mrs Harris. Countless lives have been wrecked morally, countless men and women who should have been healthy have been driven into invalidism, by the conspiracy of silence.

We are brought up in an atmosphere of prurient ignorance. We are taught nothing of the majesty and 
beauty of life that is founded on the struggles of millions of past years, not one of which but has left its indelible mark. We are left to grub out our knowledge from the muckheap; and it is naturally associated with muck in our minds. Few but the garbage-mongers and those whom they have lured into believing in the desirability of garbage, speak of the physical realities of part of our life. If we ask for knowledge and true instruction we are met with shifty avoidance of the issue. We are told that no one talks of these things except very wicked people. What wonder some seek elsewhere the knowledge that has been denied them by their guides? What wonder that one and all associate facts that are in themselves beautiful, with sin, or at least with a sense of shame? What wonder that we hesitate and use periphrases when we in our turn are asked questions? For we are blankly ignorant ourselves of the reality; we only know the sordid side we have been taught. And if we do by chance find someone who will teach us simply and cleanly-as simply and cleanly as they used to teach us mathematics at school-in a perfectly matter of fact way, what a help it is to us! How we begin to understand, and understanding, to reverence, the life process!

Thank God a change is already upon us. Clean, matter-of-fact teaching about fatherhood and motherhood, about reproductive organs as well as about stomachs and brains and blood-vessels, is at length becoming fairly common. There is no fear that the beauty and mystery and sacred secrecies will be lost. These are far more appreciated where accurate knowledge exists, learned as simply as other knowledge, than where natural interest has been fed first on lies and then on filth self-gathered from the dunghill.

The result of the change will quickly become visible. Nervous diseases will be less common, for instead of 
obscene ideas accidentally or purposely garnered, and subsequently driven with horror from the grundy-consciousness which refuses to recognise them, only to remain in the subconscious and form the node of a network of repression-complexes, true ideas will be bravely faced, and lower impulses sublimated. The higher will replace the lower; the activities of organs will be transformed, as is so often the case in evolutionary progress; love will more and more replace mere promiscuous desire.

I have taken the case of sex because it is the most fundamental, and as Freud clearly shows, it lies at the bottom of many (though by no means of all, pace Freud and Jung) repression-complexes in one way or another. But what we have said is equally true of all other im. pulses whose existence we refuse to admit, even to ourselves, and drive into the sub-consciousness instead of facing them. Repressed anger or hatred, or, worst of all, jealousy, for example, have just the same evil result, and are susceptible of the same relief; and so with other things. Repression-complexes, and the diseases to which they give rise, are the offspring of ignorance and moral cowardice. All the past is operative, or potentially operative, in the present. Memory is not solely a matter of the past, though it moves in it; it is active in the present and determines the future. What we shall be depends on what we are, and this in its turn on what we have been.

Once more we see the solidarity of man with all his ancestors, since he recapitulates in development his ancestral history. Once more we begin to understand how, not the materiality of spirit, but the spirituality of matter, is emphasised in the whole evolutionary process. Memory is not a phenomenon of the brain; the brain merely serves as the organ for mediation between spirit and matter in this as in all other ways. It is the 
[CH.

telephone exchange. The blockage of a discharge path, whether through physical or psychic trauma, does not destroy the memory, or even in any way affect the spirit ${ }^{1}$. The pathetic decay of the faculties of aged people is a decay of the mediating powers of the brain, not the wearing-out of the spirit itself. Already the spirit is losing touch with its material surroundings. The soul is pluming itself for flight to a far country where the struggle and the progress will go forward among other conditions. The brain has served its turn and is being discarded. It is a machine worn out.

The censor points towards higher things. It is the means whereby we are enabled to forward consciously (as well as unconsciously) the process that has gone on through all the long history of unconscious evolution. Organs take on fresh functions. Fins become legs, swimbladders become lungs, gill arches become tracheal and laryngeal cartilages, rendering speech possible. But no one suspects the fish of consciously aiding the change. Now, however, man consciously and of his own freewill acknowledges the claims of higher life. He sees an end and strives for it. He recognises sexual passion as a basis of true love, sublimable into that. He recognises the desire of possession as indefinitely legitimate only when applied to spiritual things, and so his acquisitiveness is directed towards the acquisition of spiritual powers. He recognises ambition and pride and knowledge as finding their true fulfilment only in ambitious ideals of service, pride that will not stoop to things mean and base, because of the high calling of manhood, knowledge that sees beyond the appearance in to the reality.

All this must apply also to Christ in still greater measure, if He was truly man. No repression-complexes

1 See Bergson's analysis of the facts of aphasia in Matter and Memory. 
can have distorted His mind; for He knew and faced everything, He sublimated everything, making it true and perfect. His love was pure and perfect. His anger had no taint of self, but was a burning jealousy for the goodness and nobility of man's spirit; a hatred of its degradation. His ambition was for the salvation of men, and their perfecting. His pride was the pride of humble desire to do good. His knowledge was the knowledge of man's great destiny. On all the foundation of His sinless past was built His human character. All the past abode with $\mathrm{Him}$, and abides for ever. Therefore $\mathrm{He}$ can enter into every phase of man's becoming with perfect sympathy and understanding. Therefore $\mathrm{He}$ is as near to us in childhood as in manhood. Therefore $\mathrm{He}$ is as near to those whose brains have ceased to develope at an early stage-whom, because of their arrested development, we call idiots-as to those who have gone a long way, as men count distance, along the stony path of knowledge. In very truth $\mathrm{He}$ has taken the Manhood into God. He is Perfect God; but superadded is His perfect Manhood.

As the Athanasian Creed expresses it, $\mathrm{He}$ is equal to the Father as touching His Godhead, and inferior to the Father as touching His Manhood. Yet inferior only in a sense. He has Himself experienced the knowledge of being caused. He has Himself become, in the conditions of full Human limitation. Because He is Man, no experience of that becoming can ever die away. It lives in the present of transcendent being. Christ is man as well as God; He still experiences manhood, though manhood perfected to its ultimate completion. And the manhood He knows is the manhood He won for Himself, and the manhood won for Him by the struggle of past ages.

"It behoved him in all things to be made like unto His brethren, that He might be a merciful and faithful high-priest in all things pertaining to God, to make 
propitiation for the sins of the people. For in that $\mathrm{He}$ himself hath suffered being tempted, he is able to succour them that are tempted." "We have not a highpriest that cannot be touched with the feeling of our infirmities."

This it is that is the glory of the Christian certainty, that we know that all our Saviour's human past endures, not as transcendent memory-an impossible thing, since memory is directed towards activity in the conditions of limitation ${ }^{1}$ - but as an ever-present reality of eternal Manhood.

Before leaving this part of our subject we may refer briefly to a somewhat peculiar difficulty which most of us feel at one time or another-the difficulty of the historic Christ, and the historic Pentecost. We may be ready to admit as an abstract proposition that the coming of the Godhead as individual Man is the only means we can see of securing perfect union between men and God through unity of experience. But none the less it is rather a shock to find our abstract conceptions actualised in the concrete, even though, or perhaps it would be truer to say especially as, the concrete fact occurred before our own abstract thought. It would be so much simpler if our thoughts had come first, the historical event after. In fact our over-emphasised individualism rather resents being forestalled in any of its activities, and we forget that other individuals of many creeds and races had reached much the same abstract formula that we ourselves have achieved, even before the Event.

We cannot help wondering, in short, how much our own thought has been influenced by the traditional interpretation of the historic Jesus. Abstract thought does not seem to have received altogether fair play. And perhaps this is even more true of the historic Pente-

- Evolution and Spiritual Life, ch. vi. and supra, ch. iv. 
cost. We must analyse our difficulty and try to get it clearly formulated, before we can attempt to solve it. For in truth it is generally present to our minds in a very vague form.

We will begin with the problem of the historic Christ. The first point that arises is clearly this:-Why should Christ have come at that time and no other, in that nation and no other? It is all very well to say that the Jewish nation was in some sense prepared for the coming of the Messiah; that adds to the difficulty. How do we know that Jesus was not hailed as the Christ for that very reason? The fact that people were on the look out for some such manifestation only weakens the Christian position, for they would be sure to read miraculous power into the doings of some wonderful man who happened to be born at that time. Now this sort of argument, though it lies behind a great deal of our questioning, will not do at all. It is hopelessly muddleheaded; and we must above all think clearly. In the first place it simply throws overboard all our previous abstract thinking and starts afresh, and very badly. Either we were right or we were wrong in thinking that we had reasoned to the need of a coming of God in human form. If we were right, the fact that $\mathrm{He}$ was vaguely expected in the land in which He came, the fact that many other lands believed in similar comings without associating them with definite historical happenings to a definite, historical person, have nothing to do with us. If we were right in our abstract argument, there is no earthly reason why other people of other times and nations should not have argued in the same sort of way, though doubtless in a very inferior manner, for we are unquestionably the people and wisdom was at least born with us even if she will not die with us! If they did argue in the same sort of way, there is every reason that they should have tacked their imaginings 


\section{2

on to some mythical hero-Baldur, Krishna, or whomsoever it might bc-as in fact they did. But mark this difference. The hero to whom they attached the doctrine of incarnation was a hero of the distant past. Him to Whom the first Christians attached the doctrine was a man of their own circle. Many of us of to-day, who did not know Jesus in the time of His Flesh, have to argue frrst from abstract principles. But having come to a favourable decision we have no right to object to the fact that there was a historic Christ. If $\mathrm{He}$ must come as true Man He must have come in some particular nation and at some particular time. Now there are excellent reasons adducible by our human understanding, even, for His coming when and where He did. The Jewish religion was as a fact purer and truer in its conception of God than any other. The time was suitable for a Divine intervention, however hopeless for the stability of a merely human one, because the men of that nation had reached a point where further enlightenment was required if progress was to be maintained. The conditions were particularly suitable for a Divine intervention, however hopeless for the stability of a merely human one, with the oncoming Roman civilisation carrying culture over a considerable part of the world. The danger of narrow nationalism was escapable by the very fact that the Jewish nation was so soon to be scattered abroad. Christ could not be identified with any particular form of civilisation. In short, if the conditions were ideally unsuitable for the world-wide influence of a false Christ, they were ideally suitable for the world-wide influence of a true Christ. Is this suitability of condition then any real argument against the Incarnation having taken place then, rather than at any other time? The whole futile doubt apparently crumbles when we examine it.

But its real roots lie deeper, and this explains its 
extraordinary vitality. Our difficulty rests on the fact that the eternal policy and plan of God enters into time, and that God Himself enters into time. Here as elsewhere, it is really the old spectre of clock-time that haunts us. What we find trouble in believing is that Christ should have come in a certain year of the Roman Empire to redeem the world. And the difficulty would have been the same in whatever year of whatever empire $\mathrm{He}$ had come. Yet if $\mathrm{He}$ came as man at all $\mathrm{He}$ must have come in some place and year, as we compute space and time. We must not forget, however, that we compute space and time in this way solely as a matter of convenience, and that they have no absolute existence as we picture them, but are merely practical representations of a reality that is quite different. That reality is the fact that we experience change in duration. And one of the two most certain facts of our experience is change; the very essence of our belief, and the central moment of our thinking, is that the change is purposive, not meaningless; is directed towards an end. (The other certain fact, of course, is that we are there to experience the change, and ourselves endure in change.) There is no more difficulty really in believing in the Incarnation as an historic episode than there is in believing in the immanence of God, which belief is a necessary of theistic thought. The trouble is that we cannot or will not think clearly. True, immanence is an enduring process, while the Incarnation was but for a short time; but that only leads us back to the question whether the coming of God as man was really necessary to the scheme of creation. If it was, He could not have come in any other way than this and yet been truly man. I cannot help thinking that much of our difficulty lies in taking the temporal series as being purely temporal. Time is, after all, the medium in which we perceive the unfolding sequence of real activity, but the sequence itself is not 


\section{Some Implications of the Incarnation [CH.}

necessarily temporal, and the activity of which it is the expression is certainly not temporal. There is no real contradiction in the idea of an Eternal Series; for Eternity is not merely all-at-once-ness; neither, of course, is it mere duration without limits. Simultaneous activity perhaps gives us as true a conception of eternal life as any other phrase does, for in the term activity is implicit the idea of order, purpose, an end achieved through succession, while in the term simultaneous is suggested, not exactly timelessness, but the all-embracedness of the Activity in the Nature of the Eternal Being. Christ's incarnation is an Eternal Datum of God's Being. His coming in clock-time is our apprehension of Him, and His answering apprehension of our needs; the centre of material disturbances whose spreading waves, as they touch each human life, make it shine with the Christ-light; enabling us to see the thing hidden from us before, that Christ is God Incarnate in every man. The Incarnation is an eternal fact perpetually renewed. Christ taught this; Paul taught it-God in us; Christ in us. The Incarnation is an eternal process, manifested perpetually in the human, creaturely being. The Atonement is an eternal process, perpetually renewed as each soul finds its divinity, its union with God, in self-abnegation. But both had to be perceived as events in a temporal series: the light could only travel in a suitable medium to set the matter gleaming; the Nature and Being of God as Love, as self-surrender, had to be brought into the temporal series of Becoming, in the Atonement of the Divine Man, Christ Jesus.

The same sort of difficulty arises for our rough and ready theology, in regard to the coming of the Holy Spirit at Pentecost; but popular thought is perhaps nearer to the truth here than it is in its attitude to the Incarnation, because the conception of the Spirit seems less defined. Christ is such a very definite and tangible 
Person. The coming of the Holy Spirit is not generally felt to have been a coming in quite the same sense that the coming of the Son of Man was a coming. Most men feel that the Holy Spirit had always been in the world, inspiring, guiding towards unity through freedom, and that the Pentecostal gift was the realisation of His Presence, the sudden vision of unity and freedom, the sudden understanding of the truth, the beginning of recognition of $\mathrm{Him}$ who was guiding and still would guide into all truth. As in the old fairy-tales the fern seed dusted on the eyes made visible things before unseen, so the sudden overwhelming understanding of Christ opened the eyes of the apostles, dimmed by sorrow and perplexity, to the understanding of the things pertaining to the Kingdom of God. They saw all the history of souls in a vivid present. Henceforward the Holy Spirit was in them in a new manner. They knew His presence. The Pentecostal gift was a gift of open eyes; and there followed from it all the new powers that sight brings. Such an event must have come at a definite moment in time to a band of men who were gathered together waiting for -illumination, whose nature they did not guess. Such an event, such a Pentecost, still comes, often at a definite moment in time, sometimes by the gradual process of long years, to those who are looking for it. The Pentecost, as Moberly says, was the perpetual extension, or spiritual realisation, of the Incarnation.

Looked at in this way, the historic facts of the Incarnation and the Coming of the Holy Ghost seem to me each in its own way to lose all difficulty. They become simply parts of the great scheme of Creation in which God entered into limitation and change for the sake of His creatures who were to be perfected in the eternity of union with Him. They enter the temporal series, impinging on common life, yet belong to the Eternal Series. 


\section{Some Implications of the Incarnation [CH.}

We claim, then, that analysis of the effects of the psychic processes on a man's development-processes and development that Christ must have Himself experienced, if He was truly man-leads us to fuller understanding of the solidarity of men with God. We claim that if our belief that Christ took the Manhood into God means anything at all, it must mean two things; that the full experience, and the individual experiences, of manhood, and no empty abstract thing to which we attach a meaningless name of manhood, entered into, and became a part of, His eternal Being; and that something was added to the experience of God which could have been added in no other way, and which yet was essential to the realisation of His creative activity in the union of man with Himself.

These ideas raise two questions in our minds; -

(I) With the first we began this chapter. Does any memory, in the strict sense of His earthly life, yet linger in the ascended Christ, and will such memory always linger?

(2) How are we to reconcile the idea of an added experience with the idea of a Transcendent God; and more especially how are we to reconcile the necessity of this added experience for the fulfilment of creative purpose?

To the first question we must clearly answer both yes and no. Yes, for this reason. Christ, we know, is with us still. Those whose religious life is real and vital do not merely believe it; they know it as a certain fact of experience. From day to day $\mathrm{He}$ lives with them, guides them, comforts them, and opens to them fresh vistas of truth. With them $\mathrm{He}$ indwells the sphere of time. He draws from the deep well of His own humanity living water to refresh them when the way is weary. He enters into their humour, their appreciation of the friendly oddity of their relations with others, their loving delight in the whimsicalities of life. He loves life 
as they love it, in spite of its limitations, for the precious beginnings of understanding, the gradual breakingdown of partitions. He is in every moment of their life, gay and rollicking as well as sad. With them, and for them, He still indwells the sphere of time and limitation. With them He shares it, for them $\mathrm{He}$ accepts and rejoices in it; content, because $\mathrm{He}$ is satisfied with the travail as $\mathrm{He}$ watches and enters into each little forward step of understanding. Therefore memory must remain with Him as long as there are souls still moving on the upward path; as long as there are souls still unperfected. If, as one is fain to believe, there are other spheres of endeavour, other lives of approximation, planes of higher, freer service, in the soul's journey of approach by infinite gradation to the consummation of perfect union with God, He must be there too. And in every stage, as long as limitation endures, He must share that limitation, and memory be for Him the means by which He can keep perfect touch with every soul in every experience it has. His manhood is a perpetual reality, not a past episode. This is not the place to enlarge upon such ideas of future existence, however closely one may cling to them. They are speculative; though not wholly unsupported by evidence, even if such direct evidence as exists is not perfectly convincing; and those who disagree with them may dismiss them with this word. Only we must urge that if Christ is truly with us in this present, human life, then it would seem at least that His memory of human conditions must enter into His dealings with us.

But we answered no, as well as yes, and for this reason.

Memory cannot persist, as we have reasoned elsewhere, in transcendent Being ${ }^{1}$. We need not recapitulate the argument, but we may recall that it turned on

1 Evolution and Spiritual Life, chaps. v. and vi. MCD. 


\section{Some Implications of the Incarnation [cH.}

the fact that memory moves in the past and is selected from for the purposes of presentation, while transcendence connotes an eternal now, without past or future in its activities. If the premises be admitted, it is evident that in the Transcendent Son the memories of the Christlife cannot persist; only in so far as $\mathrm{He}$ is still the Christ, indwelling time together with His fellow man (or fellowsouls, if there be other grades of approach), can those memories remain. We must however remember that, in the chapters above referred to, we saw that the results of memories must persist even in transcendence. It is the experiences of $A$ that make up the $A$-ness of $A$. So, we are driven to conclude that the Christ-life must leave an eternal impress upon the Eternal Son. And this brings us to our second question; How are we to reconcile such an added experience with the idea of transcendence, and how could such addition be necessary for the possibility of realising Creative purpose?

Now, we have already $\operatorname{seen}^{1}$ that the Transcendent Experience of God is complete, yet can be added to without increasing, in the sense that others can enter into and share that same perfect Experience. Complete it must always be, since it is the perfect self-experience of a perfect God. Yet in a sense it can be added to, since the end of creation, which is the end of Eternal Love, is that others should enter into and share that perfect experience-which for them is not only a self-experience, but the experience of perfectly penetrable 'others' as well. $A$ experiences $A$, but he also experiences $B$ and $C$, not as separate units but as 'others' into whose nature and point of view he can enter fully. In the same way he experiences God. But we must remember that the converse is also true. God experiences $A$ and $B$ and $C$, in like manner, as well as Himself. And this experience seems at first sight to be something added. We must

2 Evolution and Spirilual Life, chaps. v. and vi. 
however not overlook the fact that the idea of an addition involves time-a before in which the added material of experience was not there-and that such a temporal conception is inadmissible when we are dealing with transcendent being. In fact, on such a view, we are driven to conclude that Eternal Love, which is the Nature of God, is always satisfied in an outpouring, realising its own completion and satisfaction of return from created beings as actual, even while the incoming tide of reciprocating love is delayed, in the temporal sphere, by the process of immanent becoming. That is to say, the whole process would seem to be in truth eternally now, though to men who inhabit duration a virtual image of before and after floats between them and the timeless light of Eternal Being. Reality is, so to speak, refracted by duration, which acts as a concave lens, and an image of the source is thus seen in a position different from the true one.

There is no addition. The Love of God is simply perfect and satisfied, in outpouring and return, in external and internal activity. That is its nature, and creation is but the projection of its activity into the sphere of becoming.

On this view the end is, even before process, for the end is not of time. The activity of God is eternal, purposive activity: Love's series, not Time's. To this it may be objected that any such doctrine is Predestinarian; irreconcileable with our doctrine of freedom; definitely opposed to our view, so often stated, that if the freedom of men is real, God cannot know any step till it is accomplished. I think the objection is partly superficial. It unquestionably is true that God cannot know any step till it is accomplished, for the step is process, and God cannot know process except by experience-which means that He must share man's experience of duration; a conclusion to which we have 


\section{I80 Some Implications of the Incarnation [CH.}

constantly. been driven. But here we are reasoning not about immanence and process, but about Transcendent Being. It may well be that to the Transcendent God the consummation is actual and present even while, in time, process is incomplete. $A$ 's returning flow of love may thus be reality for God in the sphere of Absolute Being, even while in the sphere of duration $A$ is still on the lowest rungs of the ladder, and his actual future, in time, all unknown and undetermined. Even as the Incarnation was involved in the creation, while yet its actualisation was a kenosis of the Godhead in Time brought about by the operation of the Will of the Son acting freely; so the final perfection was involved in the action (which is itself the nature) of God's creative love, while yet the attainment of that perfection was only possible by the free choice of men able to choose good or evil as they listed-a choice unknown and unknowable to God till it was made, since it was in time. All conscious action is anticipatory; sees the end before it is actualised; and yet a temporal series has to intervene, with all its contingency. Yet constantly-renewed will brings the desired end about, through inspiration of each successive stage.

To reason about transcendence is a difficult, if not an impossible task; but one may not set aside one's conviction that Transcendent Being must be eternally complete as well as perfect; and this being so, one must try to set down some attempt to reconcile the apparent antinomies that are of necessity involved in the conceptions of Immanence and Transcendence. Still, the view is unquestionably unsatisfactory, for it leaves the mind dissatisfied. At what point does it break down?

That the Transcendent Experience of God must be in itself perfect and complete is clear. That the introduction of any time element, any idea of before and after, into this Experience is inadmissible, is clear. And 
certainly creation does mean the entry of God into the sphere of becoming, with all the attendant struggle and pain. In the immanent sphere God does really suffer and become as well as man, though all is perfect and complete in transcendence. This is a contradiction, if you will, but no more so than the coexistence of immanence and transcendence in God and man; hardly more so than the coexistence of freedom and limitation or of mind and matter, and of these we are certain from our immediate experience.

The necessity of all - of immanence, of creation, of limitation, of struggle and achievement, of time itselflies in the very nature of Transcendent Love, with which everything is now.

Some additional light on this problem-altogether beyond finite understanding as it is, yet apprehensible because we are already in a measure transcendent-is thrown by our discussion on the nature of personality. In all personal being, even in time, there is an interaction of the three persons of personality, and so activity. There never is that pure unity which means inertia or nothingness. If persons were purely units, we might well despair, for we could get no inkling of the nature of Eternal Being. If God were a Person too, and personality meant mere unity, there could be no possible relation between us and Him, as far as I can see, for pure unity has nothing outside itself, and God and we would be mutually exclusive units. And this brings us to a hopeless contradiction in terms. In short, if personality meant unity there could be no reality such as we experience. All must be illusion. Apparent activity of every kind would be unreal. Love would be unreal, personal relations unreal, our very relations with the inorganic world unreal. Only in the triunity of personality is there room for activity. And activity we know to exist. 


\section{i 82 Some Implications of the Incarnation [CH.}

Let us then seek the solution on the lines of personal relationship. Now the doctrine of the Trinity furnishes us with just the element of personal intercourse in the transcendent sphere that makes the activity and love which Perfect Experience connotes, possible and intelligible. Surely the solution lies here-that Perfect Experience just means the activity of love. This, when perfect, cannot be added to, yet others may enter in and share it. For them this constitutes an addition to experience, but not for God. They share God's experience, but God does not share theirs in any new sense, for the experience was His all along. The only new point is that they are there to share it. The experience is not however made more perfect thereby, for it is perfect eternally. The question therefore narrows itself to this; does the entry of $A, B$ and $C$ into a sharing of the Perfect Experience constitute an addition for God, or is the existence of a potentiality for such entry as a result of creation equivalent to its actuality in the transcendent sphere? Is the end really there before process? If so, what is the use of process? we may ask. The end is real before process, but it could not be so but for the fact that process was to intervene, because the end-the creation of free personal beings-involves the existence of a durational series in which those beings win their personality.

But such a conclusion seems still to involve the idea of before and after in Transcendent Experience, though I think this is a difficulty in the main due to our taking the series which we perceive as temporal as being truly temporal even when we have carried over the rest of our thought into the eternal. We must no doubt be content to leave the difficulty unsolved, or partly so. But it is worth noting that this before and after has reference only to $A, B$ and $C$ 's participation in the Perfect Experience, and not to the Experience itself., And $A, B$ and $C$ are 
perceiving the temporal series, while the Transcendent Experience is eternal. It is relative to $A, B$ and $C$, not relative to Transcendent Experience. This I believe is the key, as we implied in the preliminary chapter. And with this we must leave the problem, confessing it in part unsolved, content only to have stated it ${ }^{1}$.

We need only remind ourselves that the need of the creation of $A, B$ and $C$, lies in the centrifugal and altruistic nature of love, which demands expansion, demands other subjects of the experience of love, not because it needs them itself for its own fuller satisfaction, but because its very nature demands that others should enter into its bliss; - not for its own sake, but for theirs; and that so, creation is ever present in, and belongs to, the eternal series of God's active Being.

We return then to the question of the addition of Christ's experience of humanity to His Divine Being. In the light of what we have just said tiois presents less difficulty than we might expect. Christ is the firstfruits. In Him humanity first enters into the Perfect Experience. By His bringing of Humanity into the Godhead, the entry of other human beings becomes possible, for there is the basis of perfect union between God on one side and the souls of men on the other. And, here too we see that before and after has reference, not to the Experience of the Son, and so of the whole

1 The preliminary and final chapters were written after this one. It will be noticed that the above problem is there dealt with in a less tentative manner. Nevertheless, in accordance with the plan of dealing with the various questions involved in our mode of treating the Doctrine of the Trinity in a series of essays converging on the doctrine, and then gathering up the threads, I thought best to leave each essay substantially in its original form, as I have stated in the preface, in order to show how constantly one is brought up against the same questions. 


\section{Some Implications of the Incarnation [CH.}

Transcendent Trinity, but to the Humanity which, in Him, enters into that Experience, through the completion of process. This I believe to be the true line of solution of the difficulty. We can only indicate it, not fill out the detail. The whole matter is too high for human reasoning. None the less it is our duty to face all problems fairly and squarely, nor seek ease in vagueness. In all search after knowledge the teaching of the Prophet holds, "line upon line, precept upon precept. Here a little, there a little," as well in knowledge of the things of eternity as of the things of time. No effort to understand, however humble and inchoate its beginnings, is without fruit; and no man may stand aside and yet hope to be of service to his fellows and to God. We simply dare not forbear to search, nor to set forth such little glimpses of truth as we believe we have gained. Each puny lantern lighted by some spark of the glowing Truth may serve to aid the footsteps of others who cry, with Goethe, "More Light!" Let this be our apology to those who would have high matters left alone ${ }^{1}$.

One chief point is seen to be emerging ever more clearly. There are not two totally different natures, God and man. Man is becoming as God by throwing off external limitation, God became man by putting on limitation. As Man, Christ had a beginning, though as

1 Had the eighteenth and nineteenth of Prof. Pringle Pattison's Gifford Lectures been published a year earlier this chapter might never have been written. That which I was groping after he has set forth with incomparable charm and lucidity. But since the problem is approached from a slightly different angle, I have allowed the chapter to stand practically unaltered after reading those lectures, only inserting a few explanatory words that bear the impress of his thought; for the conclusions are the same, though the method is different. To re-write might have been to gain in sureness, but it would have been to write a vision seen with other's eyes, and not one's own. 
v] Some Implications of the Incarnation 185

God He is timeless, and wholly of Eternity. The identification of God with man starts with the real experience of a beginning. After His life on earth Christ retook His Timelessness; yet there was included in that the reality of experienced beginning and human limitation. 


\section{CHAPTER VI}

\section{IMMORTALITY}

LEAving the subject of the nature of Christ's experience, we turn for the time being to one of which the immediate connection with our subject is not at first apparent.

As in some orchestral symphony heard for the first time new phrases develope and explain what has gone before and foreshadow what is yet to come, until, long before the end is reached, the listener feels he understands the Master's thought, yet sits in eager expectation till that thought has found its fulfilment in sound; so it is, or so it should be, as we open the ear of mind or heart to the developing harmony of the universe. But again and again, in music, we are conscious of a sudden chill. Our enthusiasm flickers and dies down, and the succession of sounds has no meaning for us. Oftenest, perhaps, the failure is the composer's. We thought him great, and he turns out to be but another little tin god, swollen to apparent power by an artificial pageantry of state; one more puny monarch in a world of operabouffe. But often the Master's magic is there; only, our attention is caught by some failure of rendering. Even so small a thing as a lagging 'cello, a drum not in perfect accord with the beat, a flute that misses the key by a fraction of a semitone, or wheezes bronchially, is enough. A very little thing; but we can no longer understand the Master's thought, nor even hear the harmony.

So, too, with our deepest searching into the developing harmony of the universe. Is our search intellectual? There is some flaw in the thought of the philosopher, 
and his system crumbles into dust. Or perhaps the flaw is trivial and unimportant. If it annoys us, so that we are constantly reminded of it, the result is the same. Even more vitally true is this of a search that is not merely intellectual but spiritual as well. If we try to find a perfect harmony of all the aspects of life, only too often does some really unimportant point cause us to lose our sense of proportion. We become obsessed, and all appreciation, even of the fragments which before we thought we had understood, falls away. One, as a child, sees a pig killed-sees its apparent terror and pain, and, when he asks for explanation, is told that God wills that animals suffer for the sake of providing men with food, and from that moment hates religion, feeling that it hypocritically orders the faithful to wear magic spectacles through which the horrors of a hideous world are made invisible. For such an one, if there is a God He is not good. Another has prayed earnestly and the loved one for whom he prayed has died, or taken to evil courses. "Whatsoever ye shall ask in my name" becomes a mockery, and Christ a self-deceiver or a lying prophet. Another watches the struggles of a parent in the clutches of chronic alcoholism, knows the misery it brings and the hopelessness of the struggle, and for him all talk of freedom is henceforth the meaningless babble of a fool.

If these and similar ideas arise in early childhood, when secrecy plays a great part in life, and the mind is not ready to make wider observations, a complex may be initiated which is difficult or impossible to eradicate. Unbelief can hardly be reprehended in such a case, as long as the life lived is good. Rather, one is inclined to do homage to a noble life so debarred from enjoyment and understanding; and one cannot but look forward to the joy of such a soul when another life removes the veil and the eyes see clearly. That there must be compensa- 
tion hereafter cannot be doubted by anyone who knows the love of God.

That such cases do exist I can vouch for out of my own experience. That they are far commoner causes of unbelief than we realise, I have little doubt. The influence of very early impressions upon the whole future outlook and life is brought out more clearly every day by medical research into psychology. And the responsibility thrown upon those who have to do with young children becomes more and more clear-almost terrible. A single great emotional shock may change the child for life.

One of the commonest doubts to bring discredit upon a spiritual interpretation of the universe is the doubt of immortality. Whether early acquaintance with death or the phenomena of mental decay be a cause of its widespread existence I do not know; it seems probable. The fact remains true; and that in spite of the almost universal yearning for life after death. Excellent reasons for belief may be given-not proofs, excepting those of an authoritative religion, but reasons strong enough to tilt the balance of probability down unmistakeably on the side of survival-and yet the doubt lingers.

Is it not at the least possible that one cause of the doubt lies in the firm line which popular theology draws between the nature of God and the nature of man? We are taught that God is everlasting; we are taught that men may have everlasting life; yet no attempt is made to show that everlasting life must mean the same thing for God as for men, or else the words become meaningless. We are taught that God is good, and man is evil; that God of His goodness saves man; makes him like Himself and confers the gift of immortality; and those who teach us thus do not see that in their very teaching they make man so radically unlike God that no bare assertion of authority can make one brought up in such 
a school of thought really believe in human immortality, once he has begun to question it. He is soaked to the core in a teaching that makes man different from God; he is then ordered to believe that because God is eternal, because Christ was God and was raised from the dead, because death had no dominion over His Godhead, man too must be immortal. Can we wonder that his intellect takes up arms against such logic? Can we blame him if he doubts? One thing is clear. If we are to give any intellectual, as opposed to authoritative, ground for belief in human immortality, we must start from the likeness of men to God, not the unlikeness. Authority of church and tradition is invaluable in its right place, but it will not help the man who questions all authority but that of his own intellect, and that of everyday pragmatism. No doubt he is mistaken in so questioning; but there is no use in simply telling him he is wrong. We must meet him on his own ground and give him intellectual and pragmatic reasons for accepting authority in the very matter of which he is in doubt. Let us begin, then, by summarising very briefly such $a$ priori arguments for immortality as are germane to our general treatment of the Christian religion from the standpoint of evolution. After that we shall be ready to attempt to show that the harmony of the universe appeals to man as harmony just because it does interpret all the longings of his heart, just because he is himself attuned to it. It is because man is like God, not because he is unlike, that his immortality is certain. Even among a priori arguments we may not admit any but those which are founded on experience, if we are going to argue from an evolutionary standpoint. If we thus limit our scope we are debarred from using the perfectly valid arguments of idealism pressed to its logical issuc ${ }^{1}$; we are debarred from using the arguments from revealed religion; we are

1 See McTaggart, Human Immortality and Preexistence. 
perhaps even debarred from using the argument from the uniqueness of individuality ${ }^{1}$. All these are, in a sense, founded on experience, but the discussion of them is bound to be along lines more or less remote from the principles of evolution.

But with the argument from the experience of personal existence it is otherwise. This touches both change, and persistence through change, since it deals with that form of change which is progress, and further, is conscious progress.

I change. That is the most vital of realities for a man, and the statement embraces both factors. The change is there, but it is not mere change, but the change of a person who so persists in his self-identity that we can speak of him as $I$ throughout. It is not $x$ who changes into $y$ and $y$ into $z$. If that were so $x$ would change today, $y$ to-morrow and $z$ the next day. There would be no continuity for the experient, however definite a serial continuity there might appear to be for an outside observer. A series of numbers in arithmetical progression has a certain continuity for us; each term is involved in the previous ones, and we can determine with absolute certainty any future term. But this continuity only exists for us; they are different numbers, and even if they could 'come alive,' as in a child's dream, they would still be different numbers, not one number that is changing.

So too if change were all that we experienced there would be no possibility of our experiencing anything at all. It would not be our experience, for we should not persist, nor have memories to enable us to relate our various experiences. (This, incidentally, is, one of the strongest arguments against the doctrine of reincarnation as usually held.)

1 See Royce's Ingersoll Lectures on The Conception of Immortality. 
If there were no memory in a being that was still undergoing change the consciousness would be so different that it would be meaningless to speak of the same personality at all ${ }^{1}$. The statement does not hold, however, of the completed and transcendent personality, where, it seems, there can be no memory either, if Bergson is right in his analysis of the nature of memory.

The fact of everyday experience is that $I$ changethat the same personality persists, though it is constantly being added to. There is, then, something of me that perdures through change, yet is constantly growing and expanding through the additions which experience of change brings.

I am immanent; I indwell time; but I am also transcendent; I perdure, undestroyed by time's changes. Part of me is not in time at all. Is this perduring but illusion? When earthly change ceases, shall I cease also? Is human transcendence but a mirage that mocks the traveller who thirsts to drink of the water of eternal life?

We can go back to the time-worn argument from the intelligibility of the universe. Experience shows that the world is ordered and intelligible. Life seems to be dominated by rationality. To say that man will cease to be himself when he ceases to act on the world's stage, becoming something else, as Hamlet celebrates the ending of a run by a gay supper, or Pepper's ghost becomes a thirsty commonplace drinking beer in the 'wings,' is to deny all real meaning to our chief experience: still more, to say that he will simply cease to be. If personality can be extinguished, the universe is not rational, for all development is crowned with the emergence of personality - tends to it; achieves apparent meaning in it-and personality itself becomes meaningless. The age-long processes of evolution lead nowhither. The oyster is as good for itself as Francis of Assisi for himself.

${ }^{1}$ Cf. M. Benson, The Venture of Rational Faith, p. 202. 
Progress is illusion and change is simply process. Instead of a whole creation groaning and travailing and waiting together, instead of the earnest expectation of the creature, we are but as the beasts, and must all perish together.

It may be said that we speak of the beasts that perish; why should we not ourselves perish too, to make way for some nobler creature who may be fit for God's company? Is it true to say that the universe must lose all meaning if man be not immortal? The answer to such a question is easy. In the first place, are we sure that the beasts do simply perish? Do we not rather trust the goodness of God and believe that somehow life will be made right for them as well as for us? Certainly many of us do; but this belief is really founded on our own belief in personal immortality. Because we are sure that God is just and loving to us, who believe ourselves able to understand something of His nature, and who will one day share His perfect experience, we are also sure that God will prove just and loving to all His creatures. Since, then, our belief in this matter is implicit in our belief in our own immortality, we must turn to this once more.

We are self-conscious; we know ourselves as persisting through our experiences. In this, as far as we can judge, we differ toto coelo from the lower animals. They know only their experiences, not themselves as experients. In man there is thus a new thing; and with it comes the power of understanding the apparent order and reason of the world. We cannot treat man as in the same category with the lower creatures. He is able to see himself as an end. If he is wrong, if his enduring self is but illusion, God has played him false. He stands convicted before the bar of our moral judgment, illusion though this be also; He is no God. If man's immortality' goes, God goes too.

This is, I think, a strong argument; but yet it leaves 
us in some measure unsatisfied. And the same is true of all the ordinary arguments for immortality. Why?

Press home this argument from the apparent reasonableness of the universe, and you find it is based on anthropomorphism - that much abused, innate conviction that comes so near to the truth. For why do we believe ourselves able to understand something of the nature of God? Unquestionably, because we believe that our best selves mirror God in little. And this is simply the reverse of a thought whose obverse is crude anthropomorphism. The savage pictures God as like himself, having the passions of a man; the philosopher of to-day pictures man as like God. The essential, enduring qualities of man's personality - his will, his love, his freedom-the very quality of endurance itself, are just the things that reason demands as postulable of God. And of God man postulates them, because his own actions are purposive and moral and loving, and there seems to be the need of purpose and morality and love in the Creator if the existence of these things in himself is at all to be understood. Purpose and morality and love are in the world, and we must needs contrive some explanation of the fact. Obverse and reverse, both are there also in the philosopher's subtler belief. The anthropomorphism of the savage is reached again by the latest thinker. The argument returns full-circle on itself, as any ultimately true argument must that involves a final cause. God is like man because man is like God.

It seems reasonable, but even yet we are unsatisfied. The poet-pessimist complained that of making many books there was no end, and that much study was but a weariness of the flesh. The man who thought himself born to set right a world whose times were out of joint opened a book and found-'Words, words, words.' So here. Once more, why? 
I believe that it is with the word like that doubt creeps in. When Paul of Samosata contended that Christ was like (ó $\left.\mu \circ o_{\circ}\right)$ to the Father he was condemned. Hosius of Cordova pleaded for the term ónoเovioı the same in likeness; the wisdom of Athanasius later supported the view; and it prevailed in spite of the subtle arguments of Eastern metaphysicians. I would make bold to say that we need an Athanasius to-day to perform a like service on behalf of men in defining their likeness to the Godhead, though certain reservations must be made. It is not enough for us to be told that we shall be like God one day, when we are made perfect. If we are to share fully His perfect experience, which is Reality, we must become of the same nature as $\mathrm{He}$ is. If we are to become of the same nature as $\mathrm{He}$, we must now be of that same nature, since we are already persons, capable of willing, of loving, of acting freely ${ }^{1}$. As long as there is room for us to feel that our transcendence is in any real way different from God's, so long will the doubt haunt us that perhaps, after all, our persistence through change, our perduring may have a time limit set to it. Till we realise this we shall always doubt the reality of our eternal life; we shall always fail to understand Christ's teaching that the kingdom of Heaven is within us now.

Such an idea may sound startling, even blasphemous, to some. We must therefore try not only to justify it, but also to show its necessity. We must see too exactly what we mean by it, for the fact that God is the cause

1 The Genesis statement of the creation of man in God's image and likeness, if it is to be taken in an ethical sense, as seems likely, missed fire among the Jews, and its meaning was never appreciated. Had it been understood the whole course of Christianity as well as of Judaism might have been different. But we find practically no further trace of it throughout the Old Testament. Cf. Charles, Eschatology, p. 54. 
of man-that $\mathrm{He}$ is uncreated, we created-cannot be overlooked.

We may take, first of all, the point to which reference has just been made, for the difficulty it introduces is fundamental. Can our timelessness be the same as the timelessness of God? For there is this obvious difference, that for God there is no terminus a quo, for us there is. Our timelessness has a beginning. This being so we have a difference at once, and there seems no reason to deny the possibility of an end as well as a beginning. Once you postulate a beginning of timelessness there seems little reason to stop short of setting a period to it as well; and then timelessness becomes merely a mode of securing continuity in the conscious organism-a convenience of consciousness.

Now this, of course, is simply a matter of inaccurate thinking. Timelessness is a quality, or, rather, an experience of being ; in arguing thus we are reifying it : making it an entity. It is not timelessness per se that endures, but personality. Timelessness or enduring is simply one of the essential features of personality.

The right question for us to ask is not " Does timelessness perdure endlessly? " but "Does personality connote immortality in virtue of its characteristic quality of timelessness?" - a very different thing. Our difficulty may then be stated thus. "Human personality has a beginning; this does differentiate it from any idea of Divine Personality we can form. Is there then any real reason for our belief that it cannot also be different from the divine in having an end? Does the fact that our personality is in part transcendent mean that it is also immortal?" Here we come to grips with the central problem. In attempting to solve it we must fix our attention on two things; the nature of personality, and the link between immanence and transcendence as qualities of personal being. 
In regard to this last we have elsewhere argued ${ }^{1}$ that men are becoming more and more transcendent as the experiences of change amplify and complete the lasting ego. I am constantly becoming; moving towards greater transcendence as my freedom grows. I am constantly passing from immanence to transcendence. But the very fact that I recognise my immanence argues my transcendence, since such recognition is only possible for a self-conscious being, and self-consciousness involves the knowledge of persistence through change. That is to say, the realisation of both immanence and transcendence is in fact the recognition of these as qualities of personal being, not as things in themselves. It is the ego which we qualify by these terms.

Similarly, we realise quite clearly the relation between the two. My experiences make me a freer, more self-determining being. Savoir faire comes from knowing and doing; to possess savoir faire means to be fit to cope with a new situation by drawing on what you are; and what you are depends on what use you have made of your experiences.

Thus an essential feature of human personality is the power of growth by experience and by addition. But yet in this very growth lies the formation of personality. Personality is in itself complete-will, love, freedom fulfil the whole circle of its activities. The passage from immanence to transcendence is the formation of personality, not an essential quality of it. True, for the satisfaction of the needs of Perfect Being it may be necessary for it perpetually to go through the process of becoming. This we have seen as the motive of the creative act of God-the reason of His passibility. But here we have to do, not with the fulfilling of God's personality, but with the creation of man's. The imman-

1 Evolution and Spiritual Life, chaps. v. and vi. 
ence of God is thus totally different in origin; it is the result of the perfection of His Personality, not of its imperfection.

Thus we become persons, perduring beings, through making time-experiences our own;-and to say our own implies that we are personal in some degree. In becoming persons we become transcendent.

Now we have already argued that the term personality connotes a trinity, of which will, emotion, and freedom are the three fundamentals. Of these three each involves the others, rendering possible fellowship, internal as well as external. This is what we mean by personality, and we mean nothing more nor less by the term. It does not matter whether we apply it to God or men; what it connotes is the same.

Let us remind ourselves why we arrived at this as a definition. We saw that, however the mind of man was analysed, whether by the methods of psychology or of metaphysics, these three characteristics stood out as the salient facts. We saw that they were all needed to make up one personal being. And we saw, further, that in man we find none in perfection, while all are increasing. A man cannot will and create perfectly, he cannot experience the full emotion of love, he is still limited. Yet in will, in love, in freedom he progresses, and goes on progressing.

On the other hand, again basing our arguments on experience, we saw reason to believe that there is a God Who wills to create, Who loves, Who is purely self-determined, even to the free acceptance of self-caused limitation for the fulfilling of His personal nature in sharing His personal experience. Assuming, that is, on the sure ground of our earthly experience, that the universe is rational, we found no possibility but this of an explanation that at once satisfies us and embraces all the facts. There must be a personal God, since there is a universe 
in which freedom and love and self-determination are being won by limited beings.

Now in arguing thus we implicitly maintain, what in our religion we often explicitly deny, that the person-

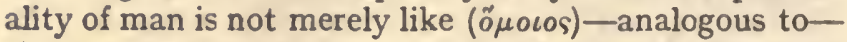
the personality of God, but is identically the same

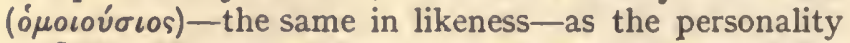
of God. All personalities are not one; we are not the personality of God; to maintain this would be to close our eyes to the most prominent feature of all personality: its uniqueness and individuality. But when we speak of the personality of man and of God we do mean exactly the same thing by the term. Of course, we allow that man's personality is incomplete; but in so far as it is personality at all we mean that it is God-like. The personality of men is the same as the personality of God. Now when we speak, in common phrase, of a man as having a marked personality, we mean that he isstrongly differentiated from his fellows, master of his fate in a wider sense than they, and always the same. Years after we last met him, if we meet him again we shall recognise him, and feel that, however he may have grown, he is the man we used to know. The idea of enduringness is inseparably linked with the conception of personality. More, we cannot reasonably give two meanings to the word enduringness. When we speak of the personality of God we mean the same as when we speak of the personality of man. We find the same triunity, the same modes of functioning. If in all these things man and God are the same, is it logical, is it reasonable to contend that in the one quality of enduringness God differs from man? We know as a fact of experience that man does endure: this is really one of our reasons for contending that he and God are alike personal. If we say that his enduring has a period set to it, God's not, we implicitly deny that man's personality is the same as God's; all 
thought about personality becomes impossible; the whole structure of religion falls about our ears, and with it goes all possibility of seeing the universe as rational. We are left with an ultimate confusion that gives the lie to our experience that the world is rationally ordered.

We are then left on the horns of this dilemma. Either the personality of man is the same as the personality of God, in which case man must be immortal, or else the apparent rationality of the cosmos is illusory, and ordered thought impossible. Can we hesitate between the two?

The doctrine of the Holy Trinity, looked at from the manward end, becomes thus the most cogent of arguments for human immortality. Because human personality is already in part transcendent, it must be immortal, since personality means the same thing for God and man, and God is eternal. .

We have still some minor difficulties, and two especially, to face. Of these the chief may be formulated in the question we have already asked, and partly answered. "How can it be maintained that the personality of man is the same as the personality of God, since God is uncaused, man caused?" Admitted, that there was a time 1 when man was not, and therefore when human personality was not. Admitted that God is the cause of man's existence, and man in no sense the cause-only the result-of God's existence. I cannot see that this really affects the question of the qualitative identity between the personalities of men and God, even apart from the fact that we cannot conceive of God's personality as being other than creative, and that thus we see the created cosmos as part of a whole which is founded in God's nature-a cosmos which is a consequence, not

- 1 But see note on the necessary qualifications of this statement, p. I2. 
an effect, of the Being of a God Who is the Ground of all. The difference seems to be quantitative. Personality is personality, however it came into being; and once it is there it must have the qualities of its nature or it would not be personality. Qualitatively, all personality must be the same in possessing individuality, lastingness, and the power of willing, loving, and acting freely. The term connotes these things. Quantitatively, it may be brought into existence, or be self-existent from eternity. It is still personality, whatever its origin. And our difficulty really arises in our ineradicable tendency to regard the eternal series as temporal. In human relations we assume this reality of personal being without feeling a difficulty. My children are as much personal beings as myself, though in a sense I am their cause. One of the qualities of personality-or rather, to speak more exactly, the result of all the qualities of personality-is the power to create; and when there is only one thing that is ultimately real, that is the thing which will be created. The creation of a temporary illusion cannot satisfy the creative need of a person. Creativeness is one of the qualities of personality, just as enduringness is. Paradox though it may involve, we mean this when we speak of a person.

Thus we see that in human experience antecedent existence is no bar to the reality and same-in-likeness of the antecedent and the subsequently created personalities. Why should we then make this an essential distinction between the personal natures of God and men? The only real point of difference is that God Is, regarded as in the temporal series, which is itself factitious, before all other persons, I am only before all subsequent persons 1 .

Lastly, among minor difficulties, what of memory? 
We have said that if there is no memory linking up a man's different existences, the consciousness will be so different that it is meaningless to speak of the same person; and we used this argument against the doctrine of reincarnation upon earth. But we have all along admitted the probability of other existences, of other grades of being and stages of approach. Here is no real difficulty however; for as long as there is becomingprogress-there must be memory, and with memory, continuity of personal experience. Where the difficulty does become real is at the point where man has been made perfect; for we have argued that in pure transcendence there must be pure simultaneity, and hence no memory.

The problem is more apparent than real; and the solution of it is involved in its statement. In pure transcendence process in duration has ceased. The individual is a self-identity whose nature is determined by past experiences of process. All it is is in an eternal now, in which there is no room for memory. It has finally escaped from the temporal illusion. For, if we define memory as potential ideas, no such things can exist in simultaneous being, where the whole personality eternally fulfills every activity, and nothing is latent. On the other hand, if, with Bergson, we say that memory exists in the past and is selected from in response to present needs, we can only claim that in simultaneous being everything is present; there cannot be at any moment a reservoir of unused past. No doubt we do not fully understand what such existence would mean; but at least it is clear that where everything is in the now there can be no question of lost identity. Absence of memory can only involve a loss of individuality while process is still going on in duration; while there is anything left uncompleted.

If the arguments we have just set forth are just, we 
find a fresh value in the doctrine of the Holy Trinity. Instead of being remote from our daily experience it impinges on it at just the point where we need it most; for in it we find fresh cause for certainty of our immortality. 


\section{CHAPTER VII}

\section{THE AWAKENING OF PERSONALITY}

IN the lowest stages of organic life we find the organism acting as a whole or unit, and as a whole or unit manifesting traces of freedom in its activities. Between its various parts there is a coordination of process that makes it obviously individual, while yet there is a large measure of dependence on the stimulus of outside circumstance.

In the individual organism there is evident some degree of choice, some first faint foreshadowing of volition, though not conscious volition. Even a paramoecium can store up habit-memories through repeated experience; even a crayfish can be taught to discriminate between possible alternatives ${ }^{1}$. That this discrimination exists means something else besides. There must be some trace of freedom, or true choice becomes impossible; and true choice, though in a very limited field, there appears to be. The mechanistic theory of tropisms, so dear to the German physiologist, who contends that all activities, from the simplest to the highest, can be interpreted in terms of chemical and physical stimuli, has received so many rude shocks that even from the point of view of natural science it would appear untenable; while the whole mechanistic theory is seen to be hopelessly self-contradictory when it is examined in relation to all the facts of experiencc, as Haldane, for example, admirably shows ${ }^{2}$, not only because it is based entirely on personal inferences and judgments from the

1 For an interesting summary of our present knowledge of the psychology of the lower animals see E. M. Smith, Mind in Animals.

- Mechanism, Life and Personality, J. S. Haldane. 
data of sensation, so that the mind-factor comes in inevitably - a fact which is a commonplace of philosophy -but because, if pressed, it is unable to explain the simplest phenomenon of the living organism.

When we turn from the individual organism to the race we find more or less steady progress in freedom. Such progress is the key-note of evolution. As we move upward we meet with a gradual change. Mere discrimination between possible courses of action becomes definite volition, and something that we may term will appears.

In the race, then, there is increasing freedom; in the individual this appears as increasing power of manifesting will. Something seems to indwell the whole process of life, giving to it an intrinsic value far above its apparent worth.

In all these early stages the creature is a unity in itself, an individual with individual aims. But yet it appears to be a part of some greater unity. The individual is merged in the race. Although individual it is not personal. Not being self-conscious, it cannot see beyond the moment's needs, nor realise the worth of its experiences as a whole. The organism only becomes a personal being when of freedom and will is begotten the consciousness that can say $I$ will-when it begins to think itself as its own object. The perpetual realisation of the self as its own object is one of the essential features of personality; and till this comes there is no personality ${ }^{1}$.

1 At first the insistence in Christian doctrine on the description of the Son as "Eternally Begotten of the Father" strikes us as strange and unnecessary; but the phrase acquires fresh meaning and new importance when we realise its significance as a statement of the Eternal Personality of the Godhead. If this internal essential of personal being were at any time absent from the Godheą, God would not be Personal, but a pure Unity, almost un- 
When once the organism has become a self, no long time elapses before it becomes conscious of moral claims, as we saw in our earlier studies ${ }^{1}$. Though the expression of morality may change, its root-principle does not. There is an absolute Ethic. The distinction between right and wrong is absolute, though views as to the rightness and wrongness of particular acts are to a large extent reflections of social conditions.

The fact of importance for our present inquiry is, that the self-conscious organism does in fact become early conscious of right and wrong, and has to make decisions between conflicting impulses.

Christ's life constituted the full entry of God into all the conditions of immanent, limited, human personality. It was the second kenosis; the issue and completion of the kenosis of the Godhead in creation. We find Christ's ministry beginning and ending with decisions between conflicting impulses. In the Desert $\mathrm{He}$ had to choose between a short and easy road to acceptance and kingship, and the via dolorosa of rejection and apparent

thinkable and meaningless. Actually the emphatic insistence on the Eternal Begetting of the Son is the sheet anchor of the Christian belief that God is Personal. The phrase defends the perpetual nature of the Processes of Divine activity. Though it may only have been formulated as a safeguard against heresies that threatened authoritative belief in the doctrine of the Holy Trinity: though its full significance may have been little understood; it remains one of the chief bulwarks against hopeless scepticisma categorical affirmation of the fact that divine and human personality are alike, both being based on a triunity of active functioning; and so, by implication, of the eternal nature of all personality. For in emphasising this aspect of the Godhead it emphasises the Godhead's Personal Being; and implicitly in all Christian thought personality is beld to mean one thing for God and man alike - that thing we call personality in man.

1 Evolution and the Need of Atonement and Evolution and Spiritual Life. 
failure; in the Garden came that choice again, when the bitter cup was already at His lips. And we cannot doubt that daily and hourly conflicts were His lot, as Man, throughout His life on earth.

So much for facts. But can we avoid the belief that, in an immanent God Who is Love, the suffering of evolution, the constant misdirection of progress, must entail a constant renewal of the will to endure, and that things must not be set temporarily right, eternally wrong, by a fiat of creative Power? Can Love see and share suffering, weigh immediate loss against ultimate gain, and yet not renew decisions constantly?

One cannot say too strongly how fatal any idea that raises a real barrier between the nature and experience of men and God must be to any solution of the Christian problems. Unless men are able to become like God altogether, they cannot be perfectly united with Him; unless God meant to make this possible, there is no conceivable purpose in the Incarnation; unless personality means altogether the same for God as for man, divine Personality has no real meaning for us; it becomes merely a term to cover ignorance. Unless our experience of process is one with God's, our hope of immortality becomes dim to vanishing; and, further, the hope of finding meaning in the Universe becomes illusory.

While this matter is before our minds it may be well to deal with an allied point. A quotation from Platt's Immanence and Christian Thought will perhaps make the matter at issue clear. "It is evident that when $\mathrm{He}$ creates free spirits and preserves their personality sacred as the finite likeness of His own, neither coercing nor ignoring it, God limits Himself in a way He does not when $\mathrm{He}$ creates and directs without let or hindrance the physical universe. Here finiteness in a true sense is assumed by God'." Such a statement taken by itself 1 Platt, Immanence and Christian Thought, p. 243. The criticism 
represents the sheer misconception of an ill-digested dualism. There is, of course, a change for God when man comes into being, for wills definitely opposing $\mathrm{His}$ will begin to work. His potential limitation becomes actual in a far-reaching sense. In this measure there is truth in Platt's idea-but in urging, even for a dialectical purpose, the distinction as between an inorganic universe and the wills of men he is guilty of a serious blunder, for from the rigid determinism of matter up to the limitation of the Incarnation you cannot isolate the stages of creation. The whole self-limitation of God is implicit in the first step of creation.

The utter untenability of any position which insists on an objective reality in the cosmos apart from personal wills is ably shown from the standpoint of a scientist, by Haldane ${ }^{1}$. He points out that the world is perceived as something of potential use or hindrance to the self, and we cannot separate it from our interest in it. What we see in it is determined by our attention, which itself depends on our needs as organisms. What we can use in fact, ceases to be an 'other' for us, as we have so often insisted, and is incorporated in ourself. "If I knew more about the piece of stone its teleological determination would be more perfect. If, for instance, I knew its exact chemical composition, and how to decompose it with ease into its elements, its potential value to me would possibly be greatly increased. And if I knew a means of liberating the enormous stores of energy locked up in the atoms of the stone, its potential value might be almost incalculable. If, finally, I knew what lies hidden behind the appearance of atoms, and energy, and all the other physical and chemical appearances in the

we here make must not be thought to imply a general condemnation of the book. On the contrary it may be recommended as a valuable statement of modern views.

1 Mechanism, Lifo, and Personality. 
stone, I could completely adjust mýself to it. Its teleological relations to me would be entirely transformed; it would be wholly a part of myself, and the end of my scientific study of the stone would be completely attained1." As we have seen from our special standpoint; as Haldane the physiologist shows; and Kant, and Hegel, and all the thinkers who are not self-deceived into a belief that the scientific abstraction we call matter is in its own form an ultimate reality; the material universe can only be understood as the medium in which a certain definite purpose is realised. That purpose is the development of personality. The cosmos is not self-existent; only the personalities for whose selffulfilment it exists-God's first, and then those of menare that. It is instinct with purpose; the means by which the Love of God is realised in creation. It only exists for God as a self-limitation of His activity; for men, at present, as an external limitation, through which they yet achieve and realise their own personalities. And out of matter, both that which is proper to himself as his body, and that which is external, each man goes on to create his own cosmos of self-limitation, for good and ill. For good, in so far as the self-limitation is refusal to use what he has for unworthy ends that will eventually raise a barrier between him and his own fulfilment-in so far, that is, as the object is creative. For ill, in so far as he uses what he has for evil purposes. Men are as gods, creating. Any thought which separates God's creation of the universe from His creation of man is hopelessly wide of the mark. As with matter, so too with time and space. Both of these are judgments upon the continuous process of becoming, in conditions of limitation. And what is becoming is the personalitywhether it be that of man, coming into being in the con-

1 Haldane, op. cit. pp. $112,113$. 
ditions of limitation, or that of God self-limited yet realising itself in the same conditions.

A few words may make clearer what we mean exactly by personality coming into being-for Bergson's description of the process as the inturning of the consciousness upon itself, though true enough, leaves a good deal unexplained. Our own reasoning has led us to exactly that conclusion, though we expressed it in somewhat different terms, as the completion of triunity by the subject becoming its own object. But this still leaves the question of what consciousness is - Bergson's unconscious consciousness-undetermined. That other point on which Bergson lays stress - the formation of approximately closed systems-is evidently a phenomenon germane to the whole question of consciousness, and I cannot help suspecting that the roots of the comparative weakness shown by him in handling both these matters lie very deep. May they not be due to his whole theory that reality holds nothing of the already-made, nothing transcendent; that no adequate provision is made by him for the material of becoming?

This material, we have argued, is simply the expression of a self-limitation of the Transcendent Godhead, whereby $\mathrm{He}$ empties Himself of transcendence in one region of His experience. In it the work is carried out - or rather, carries itself out in the main, though the direction of progress of the whole is determined by the nature of the Divine Environment.

In the work itself one of the most salient features is interdependence throughout; the correlation of all living organisms; a certain unity that is the expression of God's purpose.

For the organism that is totally lacking in self-consciousness there are no self-ends. For it are isolated choices and volitions, the expression of the fact that it copes with situations directly as they arise; but the unity

$\mathbf{M} \mathbf{C D}$. 
of purposive progress does not exist for $i t$. None the less the unity itself does exist; only it exists for personal beings alone-for God and for us.

The purpose is there; we see it in the adaptation of the race, we see it in the race's evolution; we see it in the close correlation between race and race of living things - the interdependencies of organised existence. God sees it too, with far clearer sight. The approximately closed system which is characteristic of the appearance we call the material universe, as well as the unity and solidarity that make the organic world, before the emergence of self-consciousness, an almost closed system, as well as the smaller and smaller units that compose it, are alike the expression of the plan or purpose of a Person; the plan or purpose of God's Personal activity. All unity, all solidarity, all appearance of system that we know, is the expression of personal activity.

Then human personality emerges, and is itself an evident unity, whose activities again, viewed as a whole, tend to form a nearly closed system once more. What is the significance of this constant recurrence of systems? Should we be far wrong in saying that they simply express the solidarity of fellowship - that they

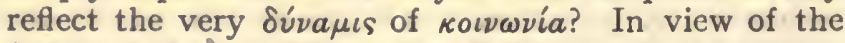
fact that all solidarity in every form in which it is known to us as human beings is the impress of personality; in view of the fact that we are driven to regard God as Personal, and that solidarity appears in the unselfconscious world we call His Creation; in view of the conception of the nature of creative purpose we have been driven to adopt; I do not think that we can come to any other conclusion.

The emergence of personality in the evolutionary process is thus seen under the guise of recognition of purpose -both the purpose of the self-activities and the purpose 
that is manifested in the whole cosmos-while its progressive development becomes a growing acquaintance with the full meaning of that purpose and solidarity. As well as being the recognition of purpose in the cosmos, it is the recognition that $I$ have purpose. Before, the purpose of another was blindly followed out in evolution as a whole; now the eyes see, and the self-purposes are visualised in accordance with the purpose manifested all around.

This, of course, simply brings us back to the recognition of self-hood, but it gives fuller meaning to Bergson's phrase "the inturning of the consciousness on itself." Bergson's "unconscious consciousness", is the blind following out of purpose under the urging of the vital impulse, or whatever else one chooses to call the claim of the creature to increasing freedom; self-consciousness is the recognition and self-chosen realisation of that same purpose, whose ultimate object is fellowship.

Let us, then, analyse this question of closed systems in relation to the origination of personality a little more closely. The operation of natural law appears always to tend towards the formation of such systems, be they atoms, planetary groups, animal colonies, or what you will. This is very fully set out in L'Evolution Creatrice.

The inorganic world consists of systems that are practically closed or isolated. As Bergson points out, this is not absolutely true. There are tenuous threads that bind the organised universe into one whole. There is unity, or the universe would not serve its purpose; and we have found purpose preeminently characteristic of all that exists. Similarly with the creatures that inhabit the earth. Each group-the organism and its congeners, their prey and their enemies-forms a nearly closed system. Much of the environment-sum bears no direct relation to the activities of the group. Bees have 
little relation with fishes. None the less we can see that there is some relation; some of the tenuous threads do link their destinies. Neither, for instance, could exist if the radiant energy of the sun were withdrawn. Bees are connected with other arthropods, and arthropods do impinge upon the perimeter of fish-experience. The universe does, in fact, evince a certain unity.

Nevertheless for practical reasons we treat systems as closed or isolable. There is a harmony or adjustment between the systems, but for many purposes we can neglect it. In dealing with ultimate issues we cannot. Each system is nearly closed, but there is a way of escape. A process of evolution is actually going on in the whole as well as in each part.

Now the isolation of a system represents the determination necessary for stability; its openness, the possibility of progress. As we have so often said, freedom can only emerge from a basis of determination. We human beings, with our self-determined actions, could not get on at all if we could not rely on the nature of the effect which some given action would produce. In the long run, self-determination becomes the predominant factor in life. We choose to do a thing, and do it. But our selfdetermination is rational and proceeds orderly. We get into tune with a larger harmony. As we have seen, this harmony depends on the personal nature of God and of ourselves, and represents the self-limitation which is expressed in interpenetration. You cannot win to fellowship without finding your self in self-loss. You can only gain your life in losing it. Personality is a system at once open and closed-closed, in that it is established in perfect reciprocity and completely satisfying experience; open, in that it perpetually craves that others should share that experience, and, acting on this, perpetually expands.

Let us take an analogy to illustrate further the parts 
played by external- and by self-determination, in the earliest stages of the development of personality. At first a state lives by a process of barter. Later a tokencurrency is accepted in lieu of goods in kind, for reasons of practical convenience. This closes the community, making a unit-state, which involves great gain, but also debarring it from any but a very limited trade in kind with other unit-states which have adopted a different currency. An inter-state currency becomes essential. Once this gold basis is established, import and export can be carried on, so long as imports do not exceed exports. When this inter-state currency becomes recognised as the only basis of exchange, internally as well as externally, the unit ceases to be isolated, and it can command all commodities.

Apply this to groups of organisms. Let imports and exports represent the results of freedom issuing in creative work. Let the gold basis be self-determinationtrue choice; the token currency the vital impulse.

Imagine what would happen if the gold basis were absent, and yet the limitation of natural economic laws did not exist. In exchange for exported necessaries each unit would be flooded with useless tokens which had no relation to the life of the state, and which no one within it would accept. It would also tend to be flooded with imported luxury-articles of no necessary use to itself as well as necessary articles, as inevitably happens in trading, for which it had exchanged the only currency of which its members understood the meaning. The result would be utter chaos. Everything turns upon the international gold basis.

So with the organism. Till self-determination is won there must be external limitation by rigid laws, or the issue will be chaos. When the meaning of activities is understood as part of a whole; when the ideas of solidarity, of purpose, of the organic relationship of indi- 
viduals, of the interpenetrative nexus of life, begin to dawn, self-determination comes, and order that proceeds from within. Till then the order must be imposed from without. In nature the final issue indicates that order is imposed with a purpose, and purpose implies, we have argued, a Personal God. The purpose is fellowship.

Now self-determination, and its correlative selflimitation, presuppose the recognition of the self. At first the activities of the creature are separate occurrences. Stimuli producing pure sensation give rise to the suitable impulse which issues in the right response. Somewhere in the region between the sensation and the impulse lurks a trace of freedom; we have seen that even before self-consciousness the creature is winning its way to greater control of matter. But this freedom is the freedom of the vital impulse, not of the individual organism. The race progresses, not the individual; the latter is a machine growing more perfect in its responses to repeated stimuli by habit, its own organisation being such as to render this inevitable. As we go up the scale the sensations and resulting impulses develope into true cognitions and conations. None the less, until they are unified by emotion-until the freedom expresses itself in the unifying medium of self-hood-there is nothing possible for the individual but external limitation. The laws of biological economics must impose that order which the creature cannot impose upon itself. Limitation is the only alternative to chaos; and this must be imposed from without until the stage of self-limitation is reached. When this dawns the other may be gradually relaxed; but until self-determination is perfect there must be dual control.

We now begin to see the index of true freedom in selflimitation; and the process of winning freedom becomes identical with the process of self-imposition of laws that 
have a universal currency. Wrong laws bring their own immediate retribution in the chaos which ensues.

Bergson's "inturning of the consciousness upon itself," which he postulates as the beginning of self-hood, assumes a fresh complexion. The beginning of self-hood is self-control. Possibly we see this dawning in animals such as dogs, which live under the stimulus of a personal environment. They seem to begin to judge between the courses of action. A well-trained dog will not steal mutton from the dinner-table even in the absence of his master.

Self-control involves the conception "I am I"; it relates the thought "I can" with "I will" and "I will not." At first there is vague appetition-want, not $I$ want. When the creature reaches the stage of this train of mental states; want-want something else more (say approval, or satisfaction in having followed a particular course)-therefore must not; there is a definite judgment of values, and a judgment implies a judge. Thus it would seem that the personality is initiated at that stage when a judgment of values appears; when there is recognition of the possibility of two courses and a balancing of their relative desirability. Such a judgment involves the existence of an emotion proper, for we may define an emotion as a tendency to act consciously in a certain manner for a certain reason that is consonant with the character of the person. We may notice that this definition also involves the existence of the self; and thus, from a slightly different standpoint, we sec that the arrival of personality in the evolutionary process coincides with the replacement of simple appetition by emotion.

These two conceptions may serve in some degree to render Bergson's statement about the inturning of the consciousness on itself less vague and difficult to grasp. Judgment of values, involving the change from mainly 
external to mainly internal determination of the path to be followed; emotion replacing appetition; these are the signs by which we may recognise the initiation of personality.

With these the system grows more open, including a larger range. Each closed system among men tends to expand-first the family, then the tribe, then the nation, then the universal brotherhood, last of all the true fellowship of eternal selves perfected, and linked with God and with each other in perfect mutuality. The limitations of external circumstance are replaced by self-limitation; freedom is found in self-determination. Men find their life in losing it. Their true self wins to its own in the self-abnegation of perfect fellowship.

We have argued that the basis of evolution of personality lies in the self-control that comes with the freedom of the true alternative, with judgments of value and the emotions that accompany them. The aspect of this which is concerned with transcendence we will leave to the next, and final, chapter. 


\section{CHAPTER VIII}

\section{THE EVOLUTION OF TRANSCENDENCE}

THE time has now come when the various suggestions we have made must be gathered up into a whole, the many partial theories built together into one structure. Till this is done we can form no judgment of our constructive work, nor attempt any fresh synthesis of the everyday phenomena of conscious life.

We began with an examination of the theories of Immanence. Box-Immanence we rejected as leading either to pure pantheism, or else to the insoluble riddle of the thing-in-itself, which leaves man wholly out of touch with Reality; and we showed that both of these are contrary to our experience. We are true, self-determined beings, not merely parts of God; and we know that we are not barred out from knowledge of Reality by any external unpierced wall, but only, and only in part, by our own limitations. We touch Reality, even though we do not grasp it.

Body-Immanence we rejected on the ground that the word body has too definite and limited a meaning, though there is much to be said for this form of expression.

Instead, we proposed the term Work-Immanence. Work implies first a Creative Mind and so a Creative Thinker; then the material; then the expression of the creative idea through the emergence of an entily which satisfies that Idea. The Creative Thinker is the Transcendent God; the thought or idea an expression of His Essential Being as Love, of the need of Love's fellowship, expanding in ever widening circles of being, all sharing the Perfect Experience. The material is the expression 
of the truth that fellowship must begin as self-limitation, and must be limitation until it is returned upon its centre in perfect reciprocity. The work is the gradual realisation of the idea as an actual experience; the entity is that which, by sharing the Perfect Experience, confirms its perfectness.

The problem of the apparent double consciousness that seems inevitable where transcendence and immanence coexist was met in part, but only in part, by an insistence on the importance of recognising degrees in Reality; by showing that partial experiences are only partial when they are considered out of relation to the Whole, through a process of abstraction inevitable for limited beings, but not inevitable for God. This mode of looking at the problem in no way detracts from or neglects the reality of partial experience, but lays stress on the fact that it is only real because of its relation to the whole; so that for God, who sees the Whole, the partial experiences have a truer reality than for man, through His full understanding that they are not real with a selfsubsistent reality apart from all else. We cannot grasp them in their fullness; He can.

Because phenomena are real for Him, we come into touch with His own Nature, on the planes of relative reality, through His attributes. These do not manifest His absolute Being, but they are the true functioning of His nature; its expression in the region of limitation. We are not confined to a knowledge of God's attributes while Himself remains far away and unknowable, for they are His manifestation in conditions that are real for $\mathrm{Him}$ as well as for us.

We then turned to the central motive of our discussion, and endeavoured to show that every self-conscious, active unit must be personal, and that personality could not exist as such if it were simply one, without any internal manifold. To demonstrate this we 
started with an analysis of the Christian doctrine of the Holy Trinity, and showed that it involved a Creative Will, a Mediating Activity, and a Free Spirit by whose reciprocal relation with both the Whole was substantiated as One. Further, it was found that no one of the three was independent of the others or could exist as itself without them. Thus any form of Tritheism, such as that commonly found in the popular expression of Christian dogmas, was shown to be utterly untenable, and false to the deepest insight.

We then turned to the detailed analysis of human personality, and there too found a triunity exactly corresponding to that postulated of the Godhead by the Christian faith.

Indeed, the penetrability of personal existence is in itself a strong argument for the plurality of persons in the Unity of the Godhead; for a personal differentiation of the Absolute; for the conception that Unity itself is made such by internal differentiation. The only other thing this penetrability could mean would be the existence of an impulse towards impersonal union, either in a society, in accordance with Durkheim's views ${ }^{1}$ - and these views, in their naked positivism, have been ably exposed by $\mathrm{Mr} \mathrm{Webb}^{2}$ (metaphysically, their basis is the same that led Hume to scepticism and Comte to Humanism, and they are open to the same objection, that they really amount to an attempt to convince people who do not exist that they do not exist, while the very fact that they are worth arguing with proves that they do, and that they are not mere social phenomena!) -or else in an Impersonal Essence, as in the extremest tenets of pantheism. Both the one and the other of these solutions leave out of account the fact that personality is the most real experience we have.

1 E. Durkheim, The Elementary Forms of the Religious Life.

2 C. C. J. Webb, Group Theories of Religion and the Individual. 
At this point we broke off to examine the nature of Christ's consciousness. This was necessary, since here we find the coincidence of Godhead with Manhood, brought about by the complete veiling of Godhead in Flesh; God manifesting the fullness of Godhead in its complete surrender: Himself emptying Himself and counting Godhead not a prize-a real surrender, made by full acceptance of conditions that start from the lower degrees of Reality as the only things known; of those conditions in which men begin their childhood.

Many problems were discussed, with the main purpose of showing that Godhead was not separated by an impassable gulf from even evolving manhood, because process is real for God as well as for man. We tried to face boldly the grave difficulty of Christ's Godhead, and found a partial answer in the conception of His perfect Manhood, taken in conjunction with this same reality of process. The answer, however, was only partial, and we have yet to endeavour to make it as complete as is possible to human understanding. His Manhood must be perfect; there must be no withholding, no reservation, in the kenosis. And the results of it must be eternally real, for man and for God, even though nothing new is added to God's being.

This dilemma too found its answer implicit in the wholeness of Reality, which is the truest expression of the meaning of eternal life.

All these points we pressed home by showing how Christ must have been limited by the mechanism of human conditions. To do this we selected the most purely determinist of all psychological writers, and, while pointing out the fallacies of his theoretical superstructure $^{1}$, accepted his facts, and showed that they in no way detracted from our conceptions of Christhood,

Appendix A. 
or of Godhead, but rather made it fuller, gave greater depth to our understanding of Christ's perfect Manhood.

Next we turned to the ordinary conception of human immortality, and tried to analyse the intuition on which it is based. From this study one chief point emergedthat any doctrine which laid the chief stress on the unlikeness of man to God was doomed to failure. Our hope of immortality rests on the fundamental likeness, identity even, between the experience of men and God ${ }^{1}$.

Finally we discussed the shadowy region in which Personality has its beginnings, and tried to give a more definite meaning to Bergson's phrase "the inturning of the consciousness upon itself."

It now becomes clear that, all through, our examination has tended towards one conclusion - that man's experience, including his self-experience, partial though it be, is yet the same as God's, differing in degree only, not

1 It is exactly here, in the self-identity and the absoluteness of all personality, that we join issue with Tuckwell (Religion and Reality, p. 152). "We do not say that the Absolute is a Person, because, as we have said, so far as we understand the legitimate significance of the word Person, it always imports finitude. It is, we hold, properly employed only where we distinguish the $I$ from a Thou; it has, therefore, always a social reference, a mutually exclusive or negative meaning towards other selves. The Absolute, therefore, as all-inclusive, cannot be said without a contradiction to be a Person, but may, we contend, accurately be termed in respect of its spirituality and unity a Perfect Self." This is going back to the days before Lotze, and the most it indicates is the 'Spiritual College' of McTaggart. Our whole argument has led us to postulate mutual inclusiveness, not exclusiveness, as characteristic of personality, and we have seen that every personality is internally substantiated as I and Thou, through a third relation which establishes its freedom. In short, Tuckwell unintentionally but exactly defines the necessity for a doctrine of the Trinity. 
in kind, from the Perfect Experience, and destined to become identical with that.

Man is immanent and transcendent; man's experience of reality takes cognisance of degrees, yet is one whole; man is triune because he is personal; we know that man is in eternal life already, and will experience it ever more fully because he sees already process and being as one whole, which whole is comprehended in the perfect experience of God, while yet each man's experience is his own; his self-identity indestructible.

We have, so to speak, woven some portions of a tapestry. They must now be joined so that we may trace the pattern, grotesquely inadequate though it must be; so that we may see how they limn a crude sketch of the Whole which is the Ultimate Reality. Many fragments will be lacking; a few of these we must weave and set in place. The largest of the missing fragments is that which completes the picture of the evolutionary aspect of personality, and this we must first supply. At best our tapestry will be no closer to a photographic record than is that of Bayeux. Below the main motive many creatures will be represented whose relation with the rest is unexplained, yet which somehow are necessary to the whole.

The ground-work of all is this-that creation must be the creation of something new. If this be not the case, all we have said of the nature of personality, all we have said of Reality, crumbles to ruin, and we are left to grope blindly in the dust-cloud of that great fall. If personal experience, with its judgment of the shapes and forms and purposes of Appearance, be unrelated to Reality, we have no criterion at all, and even our judgment of the structure of Appearance is valueless. If, on the other hand, we can make true value-judgments, touch Reality in its appearances, trust our intuitive knowledge that the form of things does really bear 
relation to their true content; if, in a word, we can trust our inmost consciousness that there is purpose in the Universe, then all creation of God and man is the creation of a new thing, made necessary by the nature of the old, and fulfilling the demands of its wholeness and self-existence. The Universe is no kaleidoscope, whose many turnings bring eventually a repetition of a selfsame pattern; no perpetual cycle of an evolution that becomes, and indeed is, only involution. Personal beings characterise the latest stages of the cosmic process. The knowledge of reality, and the self-knowledge which gives its unique character to personal experience, preclude all thought of man's mere geological significance. An age of man comparable to the age of giant reptiles is unbelievable because irrational. In man we can find some explanation of the giant reptiles, if an incomplete one; in the giant reptiles we find no explanation of man. Evolutionary series-even the blind-alley occupations of the failures-must be studied in the light of the end; and the end is personal being. Creation has led to something new, and something eternal. Anything else would mean an activity that is meaningless, as all activity without purpose, all activity which leads to the making of something in itself valueless, must be. Such activity could not satisfy any need at all in a creator.

If there be an Eternal Creator at all-as there must be-Creation must then lead eventually to something that is new and eternal. A question here arises, whose answer is implicit in every stage of our argument:Could the slages, even the buman stage, be passing time-phases in the development of something far greater than we can even begin to understand? Though the answer be implicit throughout we may state it explicitly though briefly here. No! No, because men are personal, and know themselves to be parts of a great, real Whole 
that is not in the future, but now; that is though it is becoming; that cannot end, because it is Real. No, because the universe is so constituted that its appearances betoken an underlying Reality. No, because we men are so constituted that we can make value-judgments; distinguish, and feel our communing with, that Reality. No, because ourselves are creators, and understand the meaningfulness and satisfying nature of crea- tive action. No, because only through knowing ourselves as part of that Reality is it real for us at all. Each further argument we set out will only make this more self-evident, once the truth is in our mind. Reality is the experience of God, but it is not only that. It is the experience of men as well, for the nature of the experience is fellowship. Fellowship involves self-surrender as well as creation; involves the union of individuals, who without it would be mere individuals. All this is real to us now, with a reality that is timeless. Fellowship, Love, is ever new, ever increasing, ever satisfies. It has no past or future; only a vivid present. It is ever expanding in creative activity. It finds a perfect expression of the self in selflessness which is yet utterly selfconscious, without a trace of self-loss. No easy doctrine of mere transmigration of souls to other earthly lives with lost identity can explain the self. That could satisfy neither the needs of a Personal God nor the needs of personal men. Stages there must be, infinite approach; but it must be the same person that approaches. There must be something new to satisfy the expansion, the centrifugal activity, of personal Being, but the new thing must be eternal. If not, as has been said, we are all out of touch with the real, and the world is out of joint.

The evolution of personality is wrapped up with the evolution of transcendence, which itself means a growing appreciation of the wholeness of Life. In the evolution of transcendence we must seek the key to man's nature; 
and, starting from the nature of immanence, it is with this we must therefore deal next.

A being becomes truly personal as soon as it can envisage itself as simply being, apart from the temporal series in which, for the most part, its activities are realised. For such a being the temporal series grows more and more, not an illusion, but a partial appearance, a mirror-image darkly seen, of the Eternal series which expresses activity without introducing before and after. Eternal life is appreciation of the Now. Immanence looks to the future for completion, regarding the temporal series; transcendence knows the Whole in spite of temporal limitation, because it acts and moves in the Eternal series.

Let us then start-as we must-with the material. Whatever be the nature of matter-and, as we have said, no amount of rarefying of matter by physical abstractions will make it any the less matter-we see that it expresses the nature of God in self-surrender; in selflimitation for the sake of others. Matter, pex se, is meaningless; it only acquires meaning from the purpose that it evidences. Looked at as part of a whole, as the means whereby the temporal series acquires significance in relation to the eternal, it has its place, fulfilling an inescapable need. There must be self-limitation, there must be determination, if something new and eternal is to come into being; and matter, whatever its real nature, expresses this, and fulfils the need. Matter is the material of God's work, the necessary evidence that His self-limitation is real when He makes a man.

In, and as the result of, these conditions, men come into being.

But we, to share God's experience, must be selflimiting; and the creation presupposes such a sharing eventually.

To be self-limiting men must be free; love must MCD. 
satisfy their inmost being and be to them the great reality of their life. Love must be won; its processes learned from the inside by progressive discovery. The oneness of all phenomena as parts of Being must be realised; and to achieve this men must see all as part of themselves-they must be first oppressed with the full sense of the otherness of things, before they can begin to know true immanence which sees the obverse of limitation as mediation; which sees purpose and a valid aim in the constraint imposed by external conditions, and, so seeing, begins to lose the oppression of determination from without.

Men, then, cannot even begin to be immanent till they are self-conscious, for immanence means the absorption of 'otherness' in mediation, and to recognise otherness at all involves the recognition of self-hood. In truth all these things - -self-consciousness and recognition of otherness; transcendence and immanence-involve each other, and are different aspects of one stage. Otherness cannot be recognised as such without self-consciousness; self-consciousness carries with it as correlative the stable, timeless, ego-consciousness of transcendence; and all otherness is seen as at least the material of immanence, for the 'other' is recognised as potentially usable to mediate self-ends. The nexus is close.

Phenomena, then, are recognised as being not merely dead factors exercising immutable control over us. It is true, they do shape man's destiny. He becomes what he becomes for better adaptation to the conditions of his being. But all the while he is the master, they the slaves who minister to his needs. They are recognised as mediators of the self-realisation of the ego.

Through external limitation men are led on to freedom-and find they have clutched a bubble. Freedom itself is valueless, and in their long progress they have learned to make value-judgments. 
Here, too, as everywhere, is no actual pause, no break. Insensibly, and side by side with growing freedom, grows the understanding that freedom by itself is valueless, because purposeless. A free mankind does not suddenly pause in its labours and ask, appalled, What is this freedom we have won? Individuals do, nations do, after some great cataclysm; but for men as a whole there is slow growth of comprehension in this, as in all else. Freedom is no sooner gained than it is freely tossed away. New limitations are embraced-limitations that proceed from within, not from without. The self-determination of freedom is the starting point of personality; its goal is the self-limitation which is inextricably intertwined with creative love.

Here is the initiation of an immanence akin to God's, for it is full of purpose. Through external limitation men win to self-limitation; and self-limitation, though it be immanence, is yet rooted and grounded in transcendence; for it is love-fellowship-that brings it to pass. The will, the emotion, the thought have taken action, identifying their good with a principle which formulates the very nature of God.

There is a kind of double consciousness at this stage, for in it coexist external limitation, together with achieved freedom imposing its own purposive restrictions on the self. There is consciousness of the ego as ultimately real, and consciousness of the phenomena as also real.

Yet in fact the two do not clash; and that, because there is some measure of appreciation of the Whole lying behind and synthesising our dual experience. We do know what purpose means, however dimly we can see the purpose in the whole.

The evolution of personality, then, though wrapped up in the evolution of transcendence, begins with immanence, when the material is recognised as material ${ }^{1}$. This

1 This is only another way of putting our previous statement 
personality deepens and widens, achieves form as our immanence shapes the work, which it does, be it noted, through the expression of a creative idea. So, finally, there emerges an entity-a self-which expresses and confirms the purpose of that idea, as the completed being of living, reciprocal Love-a being that is absolute and not of time.

The evolution of personality begins with immanence; yet it could not so begin but for transcendence-the knowledge of self-purposes that are real. Before the dawn of creaturely self-consciousness there was immanence, but it was God's, not the creature's. On this point we were not clear in an earlier work ${ }^{1}$. Yet, when once the conception of this occurs to the mind, its obvious truth precludes the possibility that one is mistaken. Before self-consciousness has dawned at all life can experience nothing but otherness, and even that is not known, for the knowledge of otherness connotes the knowledge of self as well, and this knowledge is a necessary condition of the true immanence which signifies purposive action in and through the recognition of matter as a means to an end, so that otherness is absorbed in mediation. Before this self-knowledge begins life must be but a bundle of needs and perceptions, as Hume wrongly claimed to be the case with man-needs and perceptions that are related to no self, but provoke only the instant response of self-preservation. Self-preservation, and the altruistic urging of the vital impulse-that is all there is in a life that is not personal; consciousness is merely the clearing-house for needs, not being conscious of

that "self-determination is the starting-point of personality." because the raison d'elve of freedom begins to be grasped in true immanence, as purposive; even though the discovery that the purpose is only achievable through self-abnegation does not come till later.

${ }^{1}$ Evolution and Spiritual Life. 
itself. Only God is conscious, and waiting, active not passive; Immanent because of His Transcendence.

Here once again we come face to face with the difficulty which, latent or patent, has dogged us all the while as we pursued our train of reasoning - the difficulty of the double experience of God. We, rightly, have approached it along the line of the degrees of Reality, but this is not enough. The very fact that we meet it again here shows it is scotched, not killed. We will, therefore, follow the rule that has been our guide throughout and try to set the difficulty down clearly and fully while keeping our fresh material before our minds, in spite of the repetition that such a proceeding involves, believing that in clear statement solution is generally to be found.

God is Immanent. Therefore He experiences process and is in the temporal series, wherein are before and after, and in which we have to face all the problems of determinism, as well as those of limitation ${ }^{1}$. In Transcendent

1 Tuckwell's mode of expressing the relation of immanence and transcendence in man as a principle of exfoliation is at least suggestive. "And so" he writes "all that happens to us, all that we hear and see, all that we think and feel, all that we call our history and experience is the exfoliation, under the form of time, of what is already implicit within us. Hence, let us repeat, we must regard time, not as real, not as 'the stuff' of which we are made, but only as the form of our exfoliation. Time is within us, we are not in time. Our ego is non-temporal. And so wo do not move or flow. We do not travel through life leaving our past behind us, as we leave the stations, the telegraph-posts, the villages and other objects behind us as we journey through the country by rail. All we experience is ever within us. If we think otherwise we are once more greatly deluded by a metaphor. To call life a journey is a useful and often beautiful figure of speech when employed for religious edification; but it is totally misleading if transferred to the sphere of metaphysics. What, then, I remember is in me still. It happened in time; but what happened 


\section{The Evolution of Transcendence}

[CH.

Reality there is no determinist problem, for freedom and love express and realise themselves in ebb as well as flow, and love shows greatest where freedom is least. Selflimitation, self-abnegation, suffering, are eternal implications of love. The problem only becomes insistent when we regard the Eternal from the standpoint of the temporal. Absolute Freedom is not, in fact, a thing determined in the past and then rehabilitating itself in an illusive garment of contingency; but a present experience which is not least expressed in limitation, so that be self-assumed. The Eternal Now is the perpetual reaffirmation of self-existent Being; and the only Being that can be at once self-existent, active and whole, yet interpenetrative with others in love to the obliteration of otherness, but not of identity, is the triune Being of Personality ${ }^{1}$. Everything is in what we must term the to me in time and time itself are both alike in me. I, therefore, own my past stifl, it qualifies me still. It is mine, because it is my very self exfoliated. It was in me implicitly before it happened, it is in me in its details now that it has happened. And I have neither left it behind me, nor am I carrying it along with me as I travel on. "For indeed $I$ do not move, I exfoliate or evolve." Religion and Reality, p. 197. And again, "We conclude, then, that the ego is transcendental. It is not in time; still less is it time itself or a mere stream of temporal consciousness. Our past experience is not over and done with, it is ours still; and it is ours still because the ego is eternal," ibid. p. 181. Our attention has already been directed to this line of argument in our discussion of memory as conceived by Freud and Bergson. In Tuckwell's statement the danger of pantheistic determinism is not altogether avoided; and indeed it is latent throughout the work from which we have been quoting. The fault lies in inadequate realisation of the fact that our transcendence is a consequence of the nature of God as Personal Being; that God's Being is the Ground.

1 A parallel line of thought, developed in most lucid detail, yet not the same because the triunity of personal being is not brought out, will be found in the nineteenth of Pringle Pattison's Gifford Lectures. 
simultaneous series of Eternity-simullaneous because there is no before or after-(Pringle Pattison's statement that "the past and the future are essentially relative, and indeed negative, conceptions, the no-more and the not-yet; but the 'is' of the present, if we take it as we do in action and in all direct experience, is not infected by the same relativity, and hence there is in it something comparable to eternity ${ }^{1}$," exactly expresses what we are striving to say) - a series because the activity is real; not merely seen as such through the refracting medium of immanent existence; and activity is essentially serial.

God is Transcendent and sees the Whole, and every part fulfilling its relation to It. As such, He sees His own Immanence as an integral and necessary part of that Whole; and it is real to Him. More, its process in the temporal series is real; and cosmic contingency-the constant reaffirmation of life's freedom to escape the determination of a real past that is no-more in a real future that is not-yet-is present fact for God? ${ }^{2}$.

How can these two consciousnesses co-exist as one? If they do not, then God has two consciousnesses, and this is an impossible contradiction. As before we will turn back to the known, experienced, case of man, and argue through this, and through the link of Christ-God in manhood-to the absolute consciousness of God.

We men find immanence real enough. The incorporation of matter for the purpose of discharging our activities - the disappearance of its otherness through purposive subordination-this is our every-day experience.

1 Op. cit. p. 369.

"Cf. the statement (Preliminary Considerations, p. 31 ) that "the end is before process for the Transcendent God, but the stages by which that end is reached are not within His transcendent knowledge, for they are not in the plane of transcendence but of limitation." 
Yet we know the temporal and spatial series-the causal series in which effect follows cause inevitably, according to the law of limitation - to be only a part in a whole that is more absolutely real. We emphasise our innate knowledge of this in the pragmatic distinctionpartly false though it be-we draw between the natural and the spiritual. Though the emphasis of our life is often wholly on the temporal series, for practical reasons, we can and do see the eternal as well. We do, as a matter of fact, see the end in some degree, in virtue of our transcendence, even though the future stages to that end are wholly unknown to us. This, we have already argued, must be true of God:

Yet there is no question of a double consciousness in us, even though in some degree, and at some time, we see the whole as being-accomplished (note the idea of completeness and finality that this present-past phrase suggests). We do this through our transcendent consciousness, yet all the while we know that things are working out in Time-in duration-serially.

One can, in fact, and does, accept without any sense of incongruity these two irreconcileables of immanent and transcendent knowledge in oneself.

Let us admit the truth of this, and turn to the parallel God-consciousness.

One can understand that, God being perfectly Transcendent, He sees everything as being-accomplished, already present as a Whole. The life-struggle, the pain, the self-surrender, are as integral and necessary parts of that Whole as is His own self-experience, for they are implicitly demanded by His character as Love. The temporal series, that is to say, is a necessary part of the whole; just as the light-giving of the moon is an integral part of what the moon represents to us. Yet we know that the light is only there because the sun shines on her; it is the reflecting power of real.moon that makes 
the sun's light visible. So for God, the temporal series is real, and contains contingency, even while reality is conditioned by something more absolutely real; even while in a higher plane He sees the whole.

Moreover, His transcendent consciousness is really saved from pure passiveness, which would be nothingness, by the coexistence of His immanent consciousness. Transcendent consciousness alone could not be selfexistent unless it were substantiated by immanence, for both are parts of one active whole. That whole is Love or Fellowship, and Love is active; cannot rest content with pure self-experience, but must ever be creating something new. If it could rest content and self-absorbed it would not be Love. Self-surrender, renunciation, and so immanence, are part of Love's Being. God must be eternally creative, or He would not be Himself; and our eternal life is to participate in that creative activity through perfect communion. The creativeseries is absolute and eternal for Him; even though change and duration are real, and His experience is receiving addition in time, in order that it may be substantiated as itself and retain its eternal character as being simply whole and perfect.

In His transcendent experience the stress is on the Whole; but the Whole is only a whole because the experience of self-surrender, and of the immanence and time-series this connotes, is real too, on a lower plane.

What do we mean by "on a lower plane"? Simply that immanence is derivative, however true it be to say that it is essential to the substantiation of Transcendent Love. Because of Transcendent Love, immanence exists-love's work. Transcendence preserves its character by, but does not owe it to, immanence, while immanence is solely conditioned by the higher reality of transcendence, apart from which it has no point of contact with the absolute and unconditioned. 
Now another point looms up and apparently leads us away from our argument concerning the dual consciousness. We shall find, however, that so far from leading us away, it is immediately seen as another road of approach.

If union between God and men is to be complete, God must-as we have so often said-experience the same as men ${ }^{1}$. For Him, too, there must be experience of conditions where the stress is on the temporal series. To this end God becomes Incarnate, as true Man. For Christ, as for other men, eternal and temporal are both present, in their differing degrees of reality.

None the less, the question of dual consciousness reaches its acutest form in the Incarnation. Christ was man. We have argued that unless His experience of manhood was identical with ours the Incarnation and Atonement would seem to be pointless, because not fulfilling the only condition that could make them valid for their purpose. God must have divested Himself of Godhead's powers when He became Incarnate. Yet Christ was God, we say, and God remained Transcendent and Immanent apart from Christhood. If Christ had no knowledge of His self-identity with Godhead how could $\mathrm{He}$ be God at all? We lately dismissed the theory of

1 Even, as the Man Christ Jesus, to the possibility of sin. The struggle, the possibility of limiting divine immanence by an ill will, must have been actual for Him. The distinction which Platt appears to draw (Immanence and Christian Thought, III. 6) between human and divine immanence cannot be maintained in the ultimate resort, for God, as Christ, must experience the full nature of humanity's limitations, yet Christ must be God. This same error becomes very prominent where Platt by implication isolates the creation of the physical universe from the creation of man, distinguishing between the types of immanence that they involve (ibid., p. 243). Any loss of touch with the Wholeness of Reality must be fatal to our thought. 
transmigration on just these grounds-that without conscious identity, identity is meaningless.

We will face this last point first, for it really depends on a confusion of thought. The doctrine of transmigration is an ethical doctrine which attempts to solve the moral problem of the universe by desiderating successive incarnations. Our objection was, that the moral problem was left unsolved if the being was not aware that in each stage he was receiving the due reward of deeds in former lives, because there would merely be an entity that was rewarded or punished for another entity's doings. Without experienced continuity the moral problem is no nearer to solution, because in each stage the being is conscious of his own sufferings and joys, but not of any previous existence whose actions determined these. From this point of view we urged that a reincarnation would not be the reincarnation of the same person. Further, it is important to note that each successive incarnation is imposed from without, as a judgment of the value of previous existence by an impartial and exterior judge.

All this is totally inapplicable to the Incarnation of Christ. The problem here is not a moral one, and no question of an outside Being imposing certain conditions of Incarnation comes in. God 'chose' for Himself, as a necessary part of the whole, implicit in the self-determination of his Being as Love, that He must become Incarnate. Without Incarnation the complete identity of experience between God and men, which is the necessary presupposition of perfect union, would be impossible; so creation would be vain.

Thus, though Christ did not experience the full consciousness of the Eternal series, God did experience the full consciousness of Christhood. The greater includes the less, but not the less the greater. There is no question, then, of dual consciousness or of lost identity, but only 
of the fulfilling of self-limitation. The possibility of all

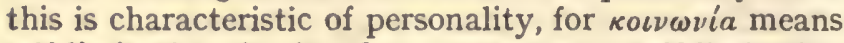
self-limitation in its first movement-self-limitation which vanishes in the fulfilment of reciprocity.

Let us turn back once more to man and see if, in the light of what we have just said, we can gain further illumination on the difficulty of Christhood.

We must not forget that, because God is immanent, $\mathrm{He}$ is necessarily incarnate in each of us. This is not an incarnation that could fulfil the union between man and God, however, for it is only through communion with our individually unique spirits that $\mathrm{He}$ is incarnate; it is so to speak a mediate, not an absolute or immediate incarnation; and the communion cannot be perfect, because of $\sin$. None the less $\mathrm{He}$ is incarnate in us, and in us Christ dies daily and the world is daily redeemed ${ }^{1}$.

God is also Indwelling Spirit, and the Transcendent One. All processes make up one Whole. Further, in us is found the same absence of full consciousness of the Eternal series that we found in Christ, and yet something of the same touch with the Eternal, through the Transcendent God,-and necessarily so, if Christ was true man; the experience of man and of Christ must be identical. When we men enwrap ourselves wholly in reasoning about the temporal series we fail to grasp the eternal at all. Yet when we reach out to the eternal the temporal remains real to us, and indeed only becomes the more important as we realise its inter-relations with the Eternal Whole - the relativeness of its reality. Evolving personality means for us evolving self-limitation; and when we discover this final purpose of freedom we become immanent in, instead of being merely limited externally by, the material which we subordinate to our will.

Sonship in man is indeed begotten only of fatherhood 1 Cf. Pringle Pattison, op. cit. p. 270. 
-of conscious will - and it is only realised through the perpetual indwelling of spirit. This lost sight of, will becomes aimless; mediating activity is directed to no goal; true unity is gone. Indwelling is the realisation of sonship, as fulfilling the active will of fatherhood. Fatherhood can only be itself through the cocxistence of the other two. Personality is a whole, and being whole itself, can reach out and touch the wholeness of Reality, which is itself Personal self-experience, even though it cannot embrace and comprehend it fully, till outside limitation be wholly swallowed up in transcendence and in the self-limitation that comes with that.

This is only another way of stating what we have already said-that human personality is only established when true immanence begins-purposive indwelling - when the phenomenal series is recognised as temporal, contrasted with, yet complementary to, the eternal series. Immanence and transcendence are absolutely correlative and complementary, because of the nature of personality. Fatherhood, sonship, and spirithood are the basis of colvwvia, whether for God or man. Personality is the ground-work of Love: the capacity for fellowship; and man's personality is the same as God's.

We see, then, that the problem of a double consciousness in God is artificial-the result of a pragmatic necessity for beings who live and act in a material environment to deal with parts as if they were the whole, to treat the relatively real as absolute reality.

This practical necessity infiltrates our thought in a thoroughly undesirable way. We cannot help doing in thought what we are accustomed to do when some chain of events calls for action, namely, ringing round a certain number of ideas about obviously related concrete facts as a closed system, deciding that these alone are relevant, and making them the foundation of our 
thought, just as if thought moved in the same plane as physical actions.

If we will only admit all the facts we see here the simple truth that there cannot be two consciousnesses in God, one of immanence, the other of transcendence, because there are not in our own experience; which experience is that of personality, and is, so, in touch with the Whole which is itself conditioned by Personal Being. We ourselves do not experience these two things as separate. It is a matter of attention only. Sometimes we concentrate on one, sometimes on the other; but when we attend to the one we are perfectly aware that the other is in the background, and that its presence bulks equally in the completeness of the whole.

We say it is a matter of attention. Attention of what? Of the ego. The ego is a whole. And it is only a whole

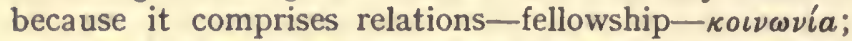
in short, because it is personal, and so a part of the Real Whole.

God, too, is Personal; and we have seen that personality has only one meaning. Our personality we know as incomplete, but otherwise identical with that personality which gives the only full reality to our conception of Deity. We are conscious of our personality as absolute, in spite of its incompleteness - a consciousness that would be paradoxical if personality were not the Ground of Reality in the absolute sphere. Once more, we know no such double consciousness as we have been discussing in ourselves. Why then attribute it to the Deity? Why should not His consciousness of Immanence and Transcendence be complementary too: a matter of attention, which involves no paradox because of the triune, active nature of His Being?

So too with Christ. Does not the same answer hold as good when God identifies Himself wholly with human nature in one specific Man, as when He identifies Him- 
self, as far as our freedom offers willing harbourage, with each individual man? Godhead reached the full measure of immanence in Christhood, that is all, and reached it from the same end as man. Christ went through the experience of unconscious life within His motler; God as Christ emptied Himself even of personality, and won it again in human-wise, that He might be one with humanity to the full, through the experience of the gradual dawning of consciousness in a world of 'others'; and through the experience of the incorporation of otherness, in the realisation of mediate activities, through immanence. Christ had no dual consciousness, but was as a man in all things. Neither had the Transcendent God a dual experience. He plumbed the depths of immanence, but He plumbed them because they were a necessary part of the Eternal Whole which is Reality.

That God became Christ at a historic period of time is a necessary implication of the fact that the timesequence is real in the plane of limitation. Time is real for man, and so it is for God, though it does not belong to the plane of absolute Reality. In immanent Christhood God subjected Himself to Reality as known to evolving personality, and eternal truth became expressed in the time-series. The Historic Christ was inevitable.

We find personality to be active fellowship. It is saved from the impenetrable isolation of pure unity through the three-fold nature which substantiates it as itself, and so, as One. Being threefold it can be itself, as fellowship, through internal activity, and is thus selfexistent. Nevertheless, because love is in its essence centrifugal, craving that the perfectness of all its experience should be shared, it must ever be externally creative. Though personality is self-existent, the idea of God-before-Creation contains a contradiction, since, without being creative, God could not be a Person. Does this seem a paradox - that God should be self-existent, 
yet only be so by creating others to share His existence? Does not such a statement imply that His existence is conditional, not absolute? Only, surely, if we draw an unreal line between Being and Process, forgetting that Being is Process, since only active Being has any meaning. God is the Ground, but the consequence is involved in the very nature of the Ground. Transcendence cannot be isolated from immanence, or it ceases to be transcendence. Personality cannot be isolated from creative activity, or it ceases to be personality. Personality is self-existent because it is the complete and active whole. God is Love apart from any attributes (or self-manifestations); but yet $\mathrm{He}$ would not be Love if $\mathrm{He}$ did not manifest Himself as such through His attributes. The attributes are the essential index of His Absolute Being. Process flows inevitably from Being to fulfil the wholeness of Reality. This it is that the doctrine of the Holy Trinity brings out. God is One because $\mathrm{He}$ is Three. $\mathrm{He}$ is Three because $\mathrm{He}$ is selfexistent Love. He is self-existent Love because He eternally makes, substantiates and vindicates Himself as Love through perpetual self-surrender, self-limitation, in order to share His Being with others who shall be able freely to participate in it. The Whole is whole simply because its wholeness is perpetually reaffirmed by process. The doctrine of the Holy Trinity is simply the affirmation of the basal truth that God is Personal.

In man we see process fulfilling its purpose. Men start in conditions of external determination by the 'otherness' of matter. They win to self-determination through the concurrently achieved knowledge of transcendence and immanence. Their growing freedom is signalised by growing, purposive self-limitation. All the evidence points to the final completeness of this selflimitation for the sake of roıvwvia. When it is complete, man's experience must become identical with 
God's, for complete immanence implies complete transcendence.

The identity of the experience of human personality and divine personality - the identity of Reality for man and God-is the guarantee of human immortality. Men cannot simply enjoy a vicarious immortality in some higher, worthier descendant, because immortality is a personal experience, and personal experience determines the nature of Reality; because the Kingdom of Heaven is within us even now, and we already know eternal life. The plurality with which we are in daily contact is but the index of a process in us that is yet unfinished. In completed, perfect union with God the Oneness of the Whole will be vindicated and shine forth as the great light illuminating all dark places, yet we shall retain the self-identity which is the hall mark of personal Being.

The difficulty of Ultimate Truth lies in its vast simplicity. It takes all the running that we can do to stay in the same place, if we try to follow philosophy. But after running the Red Queen lets us rest awhile, and even refreshes us with a dry biscuit or two. The biscuits may be nourishing, but they cannot quench our thirst. Not to the Philosophic Queen do we turn when we really need the water of life. None the less the killing race to keep up with her, the dry nourishment that is our reward when we are allowed to pause, the first shock of disappointment when we find ourselves still under the same tree, have their uses. We must take exercise if we would remain healthy, and it is a great thing to know that all our wanderings end in the familiar scenes, where we shall find those who are too young, or too old, or too feeble to run, waiting to welcome us under the shadow of the old Home-Tree; to find that they were right after all when they said that all our running could not get us further; and to sit down and munch our reward, the dry 
242 The Evolution of Transcendence [CH. viII

knowledge of why they were right, with thankfulness, knowing that the joy of quenching our thirst with living water will be the greater.

The Ultimate Truth is that "God is Love"; from this we start out, to it we return again, and find that all the while we were under its shadow. 


\section{APPENDIX A}

\section{NOTE ON FREUD'S CONCEPTION OF THE}

CENSOR

THE psychology of Freud and his school, although so far-reaching and possessed already of so large a literature, periodical and other, is yet so new that it is extremely difficult to frame a satisfactory critique of any part of it. This is especially the case for those who approach it with prepossessions in favour of any idealist or even libertarian philosophy, for Freud himself, like most, I believe, of his followers, is an uncompromising materialist and determinist.

Perhaps the most obvious flaw in his determinist philosophy is that to which attention has already been drawn. Whatever its nature, whatever the factors that determine its activities, the censor undoubtedly urges us forward to some end. This, as we have seen, Freud himself admits (see p. I6r). When we ask to what end, the answer can only be "progress," and we are brought up once more against the familiar question "What is progress?" to which question we found a clear answer, from biological considerations, in the earlier chapters of Evolution and the Need of Atonement. And this new psychology does not seem to me to introduce any fresh factor that would make us revise our conclusions; it merely teaches us more of the mechanism.

The matter cannot be dismissed thus lightly, however, for in the idea of progress itself there is no necessary accompaniment of freedom. Only if we can show that progress is, and connotes of necessity, progress in freedom, can we free ourselves from the incubus of determinism. And all the evidence of psycho-analysis points 
towards the purest determinism at first sight. We must therefore discuss these points in more detail.

In one case which I have come across within a few days of writing these lines, not personally, but which was related to me by the doctor who is treating it, without, of course, giving any clue as to the identity of the patient, the end for which the censor is working is suicide. Unfortunately, from the nature of the case, which those acquainted with the treatment and meaning of repression-complexes may readily make a guess at, I cannot, in a book of the present kind, discuss the symptoms and their origin in detail. But I will attempt to draw such conclusions as I can without doing this ${ }^{1}$.

The patient had no inclination towards normal pleasures even within perfectly legitimate bounds. $\mathrm{He}$ had however a strong leaning towards abnormal ones, which leaning was completely repressed into the unconscious. This repression, combined with other complications to which detailed reference is needless for the present purpose-hatred of a brutal uncle (with whom the patient lived) dating from childhood; an equally early poison-complex associated with mercury, to which in later years a suicide-complex associated with morphia became attached; an anti-religious complex dating from the fifth year-resulted in acute physical illness of a grave character.

When the cause of the repression was brought into consciousness, under treatment, it immediately produced intense loathing. The final result was, that the patient felt himself entirely cut off from all human fellowship ${ }^{2}$, and the only refuge seemed to be suicide.

1 The details of the case have been slightly altered, and much has been omitted and suppressed, in order to prevent any likelihood of recognition, but the main peculiarities are still clearly indicated.

2 This was partly the result of brutal suggestions on the part of 
The difficulty was further increased by a dissociation of personality of long standing. In the predominant personality all memory of the cause of the trouble was repressed by the censor, while its results - the suicide impulse-remained. Hence the great difficulty of treating the case. For example, as long as the mercury-complex could be kept in memory, all danger of suicide was avoided; but it was constantly destroyed by the second personality, and the associated morphia-complex produced repeated attempts at suicide. The same was true of the uncle-complex, which induced fear of crowds. In both instances we have an example of re-repression by the second personality - a unique case, as far as I know. Whether it will prove possible either to recombine the dual personality, or to reinforce the will-to-live in the dominant personality by suggestion, or to instate the attraction towards normal pleasures, remains to be seen. The case is still under treatment, but the prospects are dark ${ }^{1}$. Its interest for us lies in the fact that the censor is here playing a maleficent part, urging towards suicide, and seems to be totally independent of the higher will of the patient. In reviewing the problems suggested by this fact, we may first note that the influence of the censor is directed still towards an end, though an unsatisfactory one; it is still purposive. Secondly, we observe that the case is entirely abnormal, since we have to do with a split personality. But even allowing for these facts its difficulty must be recognised. The characteristic action of the censor is clearly marked, and is un-

the uncle that everyone would hate him and he would always be alone-another childhood memory.

1 There are now indications of a re-combination of the two personalities. Some memories of minor complexes have ceased to be repressed in the dominant personality, and there is some ground for hoping that the two may be ultimately fused, when all danger will be at an ead. 
questionably directed towards an end which is not for the progress of the patient; and further, it seems to be absolutely determined.

On the other hand before the patient seem to lie two possibilities, and two only; the greater evil of abnormal pleasure from which his soul revolts, and the lesser evil of suicide. I cannot help suspecting that it is a false reading of the evidence to say that the impulse to suicide is due to the feeling of isolation. I am inclined to think that, if all goes well, time will show that the real source of that impulse is not fear of isolation, but the reverse, the fear of over-intimacy of a particular kind that is dreaded-fear of temptation 1 . If this be the true interpretation, the difficulty vanishes. The censor becomes once more a moral agent, and not purely determined.

Another possible explanation is, that the censor concerned is that between the unconscious and the foreconscious (Freud's terminology), not that between the foreconscious and the conscious, if Freud is right in his theory of the double censorship.

But is he? The function of the censor seems to be to prevent certain psychic formations from entering consciousness. But the foreconscious is no more conscious than the unconscious. (We must remember that Freud gives a special ineaning to the term unconscious, and that neither his unconscious nor his foreconscious is in consciousness. Both come under the term unconscious in ordinary psychology.) If then there is a censor between the unconscious and the foreconscious its function must be totally different from that of the true censor. If one can attach any meaning at all to the idea, this lower censor must simply represent the inhibition of un-

1 Closely associated with this is an anti-religious complex-a hatred of Christ-dating from the fifth year, due to a brutal attack by one who called himself Jesus and threatened eternal damnation. Escape from the results of this complex is unlikely. 
conscious acts that would tend to undesirable habitformation. Such an inhibition may be conceived as active in the lower animals, and even in man, though the evidence for this type of inhibition, if it exists, is unknown to me. Undesirable acts are doubtless inhibited, and we call the inhibitory mechanism by what name we like; but to call it a censor seems to me unjustifiable, since the word censor connotes the mechanism which prevents certain kinds of psychic material from entering consciousness, and no consciousness comes in in this case. Would it not indeed be truer to say that the sphere of action of the one censor ${ }^{1}$ extends to the unconscious as well as the foreconscious? That is intelligible at least; Freud's suggestion seems to me unintelligible. If there is a lower censor, and this censor does represent inhibitions that occur in animals as well as men, clearly the difficulty of the case we are considering vanishes, for consciousness is not involved directly in the repression which is tending towards suicide, and where there is no consciousness there can be no moral problem. Merely, the mechanism is faced with a dilemma, and owing to diseased conditions in the brain-paths the morally wrong solution-if morality comes in, which it does not, except by unjustified projection of the onlooker's mind into conditions he only partly understands-is adopted. But such an explanation seems to me to be far-fetched, and to depend on the very doubtful existence of a hypothetical lower censor, which can only be stated to be a censor if one gives a meaning to the word differing entirely from its normal one. Let us then see on what grounds Freud assumes the existence of this queer phenomenon.

Freud's greatest contribution to psychology is his demonstration that consciousness is not coextensive with psychic processes; that unconscious psychic processes

1 In the sense in which we have elsewbere defined it (seo p. I62). 
exist and play a vast part in our life, and that the consciousness is really an organ for perceiving psychic processes. Given, then, these unconscious psychic formations, he is compelled, by the analysis of dream states and of hysterical and other psycho-neurotic phenomena, to adopt a belief in the existence of two layers (so to speak) of these formations, of which he terms the most primitive, and indeed the primary one, the unconscious, the other, in which the streams of psychic process flow, he terms the foreconscious. It is impossible to give the reasons for such an assumption here, but the facts appear to justify it. He then finds a resistance which prevents wishes, for example, which are in the unconscious from entering the more active stream of the foreconscious. To this resistance he applies the name of censor. But why? Apparently because he finds a similar resistance checking the intrusion of undesirable psychic formations into consciousness, and fails to see how totally different the nature of the two inhibitions must be, since their function is so different. For what does he mean by consciousness? What is its object? Freud himself, the determinist, speaks of the censor as "the criticising instance... which directs our waking life and determines our voluntary conscious actions" (italics mine) ${ }^{1}$. Here is a contradiction indeed! And it exactly represents, in a few simple words, the contradiction that runs all through his work. He cannot get away from voluntary actions, but because there is a psychic mechanism, he speaks of them as determined. Because this theory is presented in his own mind as schematic, he must banish contingency by introducing his schematic system of layers of consciousness, each with its inhibitions, as a true and complete picture of reality-or if not complete, only falling short by the absence of detail in some matters. Scientifically, he is right to abstract

1 Op. cit. trans. Brill, p. 428. 
in this way; the business of science is abstraction, and only by abstraction can formal knowledge increase; but to carry over the abstraction into the realm of metaphysic, as he does by implication, and more, is unpardonable. This failing is manifest throughout his work in regard to the censor. The tacit assumption throughout is that the censor's function is to guard consciousness; it is the conscious life that is endangered by the things that get repressed; it is for the sake of conscious life that they are repressed at all. The explicit state. ment is that the censor does not exist in the child; for the child's consciousness is not yet developed sufficiently to feel the pressure of social and other influences. And in face of these facts, we find the assumption that certain things are excluded from the foreconscious, kept in the unconscious (the material of the foreconscious being itself not in consciousness), by a censor! This for the sake of completeness in the theory put forward! I do not quarrel with any of the facts. There may well be a barrier between the unconscious and the foreconscious, but for sanity's sake let us remember that these things are abstractions; for clarity's sake let us attach the same meaning to the word 'censor' throughout. And above all, for the sake of the dignity of human reason, let us not confound a useful scientific abstraction with reality.

In face of Freud's inconsequent and muddled reifica. tion of abstractions, and confusion of terminology, I cannot think we shall gain much light on our difficult 'case' by referring the repression to the very dubious censor between the unconscious and the foreconscious, thus tacitly assuming a censor of a sort in animals. The whole conception of a censor seems to me to have meaning only in reference to consciousness. To confound a very helpful hypothesis with the known habit-formation directed towards the avoidance of pain or injury in all living organisms, as Freud definitely does, seems to me 
to be courting disaster. No doubt a mechanism such as he describes must exist for this purpose. No doubt, also, the avoidance of injury to the psychic arrangements by harmless discharge in dreams, etc., is due to some analogous (probably to a development of the same) mechanism. But this must not be confounded with the censor, to which its functions are ancillary.

However this may be, it seemed well to quote the facts of this specific case for the sake of honesty. But I cannot feel that they can justly be used as an argument against the teleological function of the censor, considering how open they are to various interpretations, and considering also how clearly that function comes out in the majority of Freud's cases of repression-complexes.

Next we may consider the objection that, allowing the function of the censor to be directed towards progress, there is still no evidence of freedom.

This contention receives support from other facts of which knowledge has been gained by the study of psycho-analysis. For instance, very many, if not all, lapsus linguae et calami have a definite meaning, and reveal the existence of repressed wishes or thoughts 1 . And again, if you ask a person to say a number, however large, it can often, perhaps always, be proved that a good reason for saying that number, of which he was totally unconscious, existed in his mind. Indeed psychoanalysts will go so far as to say he could not have said any other ${ }^{2}$.

On the other hand, if one argues thus one neglects the undeniable fact that, though a certain number rushes first into one's mind, one may reject it consciously and give another. In an experiment upon myself the first number that entered my mind was 473 , and I was able partly, though not fully, and certainly not conclusively, to discover the reasons for this by psycho-analysis. But

${ }^{2}$ C. F. Freud, Psychopathology of Every-day Life," and E. Jones, Papers on Psychoanalysis.

Ibid. 
at the same time I was perfectly conscious that I might have rejected this number, and said ro or 25 or 32 instead-or indeed anything else. Thus all the psychoanalysts manage to prove, as far as I can see, is that left to itself, without the checking action of consciousness, the brain and memory interact automatically and determinately. Many thanks to them for the information! I suspect most of us knew it before! We have already argued that the development of freedom, whether of mind or body, whether of intellect or purposive movement, was inconceivable except on a determined basis ${ }^{1}$. The determinist cause is not forwarded one millimetre by this work of the new psychologists. Determinists are still up against the irrefragable certainty of mankind that men can choose. All they have succeeded in proving is, that if a man deliberately abstains from choosing he does not choose. The moment I refuse to say 473 , and say some other number instead, I exercise my power of choice, and add one more to my evidences of freedom.

This kind of reasoning shows that we are exactly where we were before the theory of psycho-analysis dawned to irradiate the world. We have the incontrovertible fact that men believe themselves and other men to be free in some measure, and that the whole fabric of society rests on this belief. We have the incontrovertible fact of evolutionary progress. We have the incontrovertible fact that progress connotes increasing control over one's environment and one's destiny. We have, finally, the strong presumption that the progress of the race is made certain and even determined by the interplay of environment and vital impulse. All these matters I have discussed at length in my previous books. Frankly I cannot see that these new factors have any bearing on the general argument there adopted, and I see no reason whatever to modify it.

1 Evolution and Spiritual Life, ch. iii. 


\section{APPENDIX B}

\section{NOTE ON SOME CONCEPTIONS OF PRIMITIVE RELIGION, AND THEIR POSSIBLE RELATION WITH TRINITARIAN DOCTRINE}

Ar an early stage men apparently began to feel after something that could only be satisfied by assuming a dual nature in Godhead. It is difficult to trace this in detail, or even to be certain of the facts, for the essentials of early theology are not defined, and are besides overlaid with the dramatic necessities of myth, and with magic; while everything is confused, in the primitive pantheon, by a manifold repetition of persons who overlap each other. Even this fact is perhaps instructive. The need of divine sympathy and providence in every happening of life is reflected in numberless minor deities created to satisfy men's minds. Even to-day we see the same thing, prominent as when Erasmus wrote his Naufragium, in the appeal of the uneducated Roman Catholic to the most suitable Saint for help in some emergency.

In the polytheistic stage each God is looked upon as One; yet there is a great spirit who is also One. Pure unity leaves something unsatisfied, even in the primitive mind. Hence the persistence of a pantheon full of complex relationships, long after the idea of one great Causal God has dawned. We find this everywhere, in Egypt, Greece, Scandinavia, North America, India, Mexico, as well as Rome. Pure Unity does not, apparently, suffice. Again an attempt is made to satisfy the craving of the soul, itself not recognised, by postulating duality in the chief God of the moment; though this is done with but an elementary understanding of its meaning.

For two obvious reasons the means by which this is 
accomplished takes a characteristic form. The two aspects become male and female; and they are not truly fused, but represented by deities united in marriage. Men feel themselves allied to the gods, because they themselves can create life. Naturally, a simple anthropomorphism connects the mode of divine creation with human. But since like produces like in human experience, the marriage of the great gods gives issue to the lesser. Further, men and earthly things are generally regarded as the result of a divine fiat. Man knows that he can create at his will, even if only houses and weapons and offspring, and he argues that the gods do the same; but that, having more powers, they can create men and animals. Marriage thus typifies divine creative activity, and implicitly recognises the volitional and mediatorial aspects of all creation. Very dimly is the likeness of men and gods understood in its deeper significance. Crude anthropomorphism shows that it is there, none the less. More subtly is it implied in the similarity between the generative powers of gods and men; and the recognition that, besides like generating like, in both gods and men is the possibility of creating unlikes. Men can create unorganised tools; but the gods can create matter itself, and living animals, by virtue of their superior powers. Among men the best that even magicians can do is make a human marriage fertile or call up pre-existing spirits; but magicians are hampered by an earthly tenement. The marriage of the gods, then, typifies creative activity, but it does more. It indicates the close bond that exists between the nature of gods and men.

Our meaning may be illustrated by a few examples. Isis was the wife of Osiris. Osiris later became confused with $\mathrm{Ra}$, the sun-god; Isis with the Moon-goddess, according to Diodorus Siculus ${ }^{1}$. The great rite of Osiris

1 Diodorus, 1. quoted by Fraser. 
ended with the erection of the Tatu pillar; and his emblem was a tree, often stripped, of which facts more anon. Juno was the wife of Jupiter, who was originally worshipped as an oak-his sole image on the Capitol ${ }^{1}$. Hera was the wife of Zeus, who was represented by an oak at Dodona ${ }^{2}$. So too Freya was the wife of Thor, whose emblem is a hammer. The Asherah were symbols of a goddess; the male and female elements are here blended. Hindu mythology is so complex that to give a single instance that is characteristic is difficult, for no single deity in practice ${ }^{3}$ is regarded as supreme, but we may take the marriage between Lakshmi and Vishnu as an example. Vishnu is frequently worshipped in the guise of a pillar - the famous iron pillar at Delhi is a well-known example -or in the guise of a tree-as, for example, the sacred tree in the inner court of the great temple at Puris. Indeed Vishnu created the sacred linga which formed the centre of the world ${ }^{6}$. His very name, Vishnu, said in the Puranas to be derived from the root vis, to enter, is suggestive. For the pillar, the tree, the hammer, are ithyphallic symbols, representing the power of generation, while the ring represents the power of bringing forth. The one is causative, the other mediatorial.

We find traces of this perhaps in the very god-names themselves. It is sometimes said that the ' $I$ ' which

1 Fraser, Golden Bough, II. p. 29r, edn I8go.

Ibid. Ir. 29 r.

- Cf. Wilkins, Modern Hinduism, p. 39. "Another noticeable feature of Hindu worship is the way in which each deity is addressed as superior to the rest. Brahma, Vishnu, Siva, Krishna, Sakti, each, in turn, is regarded as the supreme, and the others are said to have sprung from, or are manifestations of, the one adored."

- Fergusson, History of Indian and Eastern Architechure, p. 50.

- Wilkins, op. cil. pp. I12, 117 .

- Ibid. p. 9 r. 
occurs in so many forms of the name of God is really the symbol for a god or king, representing the power of causing life. The god or king is the life-giver. It also represents the unity of the god.

But soon it becomes combined with the feminine symbol. IOVE, IOVAH, IOSHUA, IUNO, IUPITER, probably show the two aspects of the divine nature in the god-name IO. The two are combined in the orb of our regalia $\delta$, and in the ark of Isis $\downarrow$, which may represent the crescent moon, as perhaps does the open $\mathrm{O}$, or $\mathrm{U}$ in IUNO, IUPITER; and they may survive in the broad arrow, Neptune's trident, the fleur-de-lys, etc. This is at least suggested, I know not with what justification, in a letter from Mr H. A. Harris to the Numismatic Circular, Sept.-Oct. IgI6. For us, the interesting point lies in the combination of the two symbols in the name of, or to represent one god. We seem to find a similar significance in the planetary symbols for Jupiter and Venus, $\delta$ and $q$ commonly used by zoologists to denote male and female. The Logos-doctrine of Philo, and the Demiurge of Persian and Gnostic theology, show the existence of another aspect of the same mediatorial conception; though both implicitly affirm a certain degree of derivativeness, and so of inferiority, when they are pressed to their logical issue.

On the whole it is true to say that the causative and mediatorial functions are quickly recognised as activities of one being; men instinctively rebel against their separation in two gods, however closely united in the ties of wedlock.

But we can go still further. In very many religions at any rate there is a brooding deity behind, less definitely pictured and again liable to be blended-here is the interesting point - with the creator. Brahma lies behind the Hindu pantheon. The spirit of God broods over the waters. The Mana of savage religions is more than the 
magical rapport, to which Andrew Lang compares it ${ }^{1}$; it is a Spiritual Principle that lies behind everything ${ }^{2}$. I imagine there are few, if any, religions in which this Spirit cannot be traced, though it loses itself in the idea of the Great Spirit or Supreme God, or sometimes in the Demiurges. We thus find three Divine Activities vaguely resembling the three Persons of the Trinity early distinguished by an instinctive theology, one creative, another mediatorial, another all pervading. We also find a marked tendency to fuse these into one, as the need for unity grows upon man. Is it too much to say that even among the Hebrews, with their comparatively pure monotheism, the remains of the older thought are traceable in the sacred name of Iahweh? though it must be confessed that the Hebrew letters יהוה, with their omission of the vowel sounds, show no evidence of it-as indeed might be expected, when we remember the intense horror of the Hebrews for anything that suggested idolatrous symbolism. Finally, although among the great thinkers, whether Buddhist, Hindu, or Roman Catholic, the unity of the Godhead overshadows every other conception, yet among the less educated we have clear evidence of the more primitive stratum where the three aspects are visualised as isolated divinities. Nay, it is not a great overstatement to say that Protestant Christianity is quite definitely tritheistic in all but name, except among the deepest thinkers.

We find, then, that the sense of need for a godhead that is dual in function, however multiple in actual imagination, rests first upon a vague understanding

1 The Making of Religion, p. 199.

- Durkheim, The Elementary Forms of the Religious Life, passim.

- H. G. Wells' Veiled Being shows an instructive return to these more primitive conceptions (God the Invisible King)-and, metaphysically, to Kant's thing-in-itself. 
that creation has a causative and a mediatorial aspect. It is quite true that this notion is based on inadequate physiological conceptions, only partially sound. But the point is, that something in the human mind found a satisfaction in the idea of duality that it did not gain from the idea of pure unity, and fuller knowledge has not banished it. A unifying principle, too, hovers in the background, indicating clearly enough that the human mind demands unity as well as duality, though it tries to gain this queerly enough through the conception of an impersonal essence of some kind, in which the two creative aspects are sometimes unified, while sometimes it seems to provide but a third kind of spiritual reality, impersonal, and coexistent with the personal gods. It may be said that to argue thus is to import unjustified subtleties into a primitive conception that is, after all, very simple. Male and female are needed for human creation; well then, what more natural than to imagine male and female necessary for, or at least symbolic of, divine creation? Such a contention does not take account of the vital fact that the dual conception persists when man is no longer primitive. I believe that the true way to gain insight into primitive religion is to focus one's attention on the germ of truth, as it grows into a great stem; not on the fallen leaves of dead years. Leaves, as they fall, rid the tree of waste products; their loss is a mode of excretion. Fetishism has gone, or is going, but the truth of fetishism survives, and we may read it in the words imputed in the Logia to Christ, "Raise the stone, and thou shalt find Me; cleave the wood, and I am there." Animism is dead, but its truth remains in the doctrine of Immanence, and in the theory of the relation between body and mind ${ }^{1}$. Sacrifice is dead, but its truth lives on in sacrament and atonement. It is sounder to trace the development of a germ of truth 3 Cf. MacDougall, Body and Mind. 
that lies hidden in the humblest religion than to lecture on the outrageous externals that doomed a fossil belief. Evolutionary biology would not have gone far if students had merely had their attention directed to the pompous futility of the glyptodonts, the comic inadequacy of the dodo, or the irritating perversity of the vermiform appendix. In Comparative Religion and in Biology alike, it is the fact of progress that matters : the fact that each shows a process of unfolding. To lay stress on freakishness alone shows hopeless lack of grasp. So here. We have in Christianity a dual conception of the activity of God; we find a dual conception of all creative activity permeating earlier religions. Surely it is the part of a wise man to admit that there is a direct connection and sequence between the two, however freely we have to admit that the grounds on which primitive man postulated duality were inadequate and mistaken. The fact that in duality he found satisfaction of an instinct, however vague, is what really matters. I believe that a true instinct also underlies his search for a unifying principle in an all-pervading spiritual essence, even if he goes wrong in making the personality of the gods derivative and not primary. He feels the need of unity, of duality, and of personality in the Godhead, and in his simple way he offers the best solution he can. 


\section{BY THE SAME AUTHOR}

\section{EVOLUTION}

AND

\section{THE NEED OF ATONEMENT}

Second edition, revised and enlarged. Crown 8vo. 4 s $6 \mathrm{~d}$ net

"This little book is the work of one who combines the gifts of a thinker and a teacher. We can cordially recommend it to those-and they are many-who are keen to know more of the light which is corning from Science and Philosophy to aid us in our reconsideration of the deepest problems of our life....Mr McDowall has done much more than present a careful report of the labours of others; he has thought deeply for himself, and he gives us his results with freshness and courage." - The Guardian

"An essay which we recommend with confidence to thoughtful readers. ...It shows a frm grasp not only of scientific and philosophical principles, but also of spiritual facts, especially the fact of Sin, which it discusses in the light of evolutionary theory.... Incidentally many recent theories upon Sin and Atonement are discussed, and the criticisms are always penetrating." - The Spectalor

\section{EVOLUTION}

\section{AND \\ SPIRITUAL LIFE}

\section{Crown 8vo. 6s net}

"Mr McDowall has made a bold and clear-sighted attempt to bring within the scope of religion a number of the vital ideals of science to whose existence theology has been slow in awakening-an attempt which we hope will have the high success that it deserves."

\section{The Times Literary Supplement}

"A fascinating book for many theological students....Mr McDowall seeks in his own fashion to reconcile science and religion, and his book is a thoughtful, earnest, and very suggestive essay in that direction. It needs and will repay study." - The Meshodist Recorder

"A courageous attempt to build up a living faith upon a superstructure of things new and old, and we do not think the task has ever been attempted in quite this fashion before.... A most interesting and stimulating book, and one which the devont doctor and science stadent may profitably read."-The Cambridge Revirw

\section{Cambridge University Press}

Fetter Lane, London, E.C. 4 : C. F. Clay, Manager 


\section{CAMBRIDGE UNIVERSITY PRESS}

The Origin and Propagation of Sin. Being the Hulsean Lectures delivered before the University of Cambridge in rgor-2. By F. R. Tennant, D.D., B.Sc. Second edition. Crown 8 vo. $4^{\text {s net. }}$

"Mr Tennant is a frank, courageous thinker.... No Hulsean Lectures of recent years have approached them in real living thought."

The Spectator

"His four lectures are able, well-informed, and closely reasoned, and are written in an admirable style.... An able and honest attempt to face the problem in the light of modern knowledge."

The Glasgow Herald

\section{The Sources of the Doctrines of the Fall and Original Sin.}

By F. R. Tennant, D.D., B.Sc. Demy 8vo. ros net.

"The author of this genuinely learned work...has brought together into the compass of one handy volume pretty nearly all that ancient or modern learning has to say on this subject.... In short the book becomes at once the standard English authority." - The Daily Chronicle

The Concept of Sin. By F. R. Tennant, D.D., B.Sc. Crown 8vo. 4s $6 \mathrm{~d}$ net.

"To his previous works, The Origin and Propagution of Sin and The Soures of the Doctrines of the Fall and Original Sin, Dr Tennant has now added a third, which reveals the same high intellectual qualities, and constitutes with them a notable trilogy in prose on the great tragedy of human sin." - The Hibbert Journal

The Interregnum. Twelve Essays on Religious Doubt. By R. A. P. Hill, B.A., M.D. Crown 8 vo. 4 s 6 d net.

Forgiveness and Suffering. A Study of Christian Belief. By Douglas White, M.D., Trinity College, Cambridge. Crown 8vo. 3 net.

Grace and Personality. By John Oman, M.A., Author of The War and its Issues, etc. Large crown 8vo. 6s net.

The Divine Aspect of History. By JoHn Rickards MozLey. In 2 volumes. Royal 8 vo. $36 \mathrm{~s}$ net. An extensive survey of the working of the divine in history, covering the chief ancient religions, the history and theology of the Old Testament, the Life of Christ, and the birth and history of the Christian Church.

The Elements of $\mathrm{Pain}$ and Conflict in Human Life considered from a Christian Point of View. Being Lectures delivered at the Cambridge Summer Meeting 1916 by Members of the University. Crown 8vo. 4 s 6 d net.

\section{CAMbridge University Press}

Fetter Lane, London, E.C. 4: C. F. Clay, Manager 
University of California

SOUTHERN REGIONAL LIBRARY FACILITY

405 Hilgard Avenue, Los Angeles, CA 90024-1388

Return this material to the library from which it was borrowed.

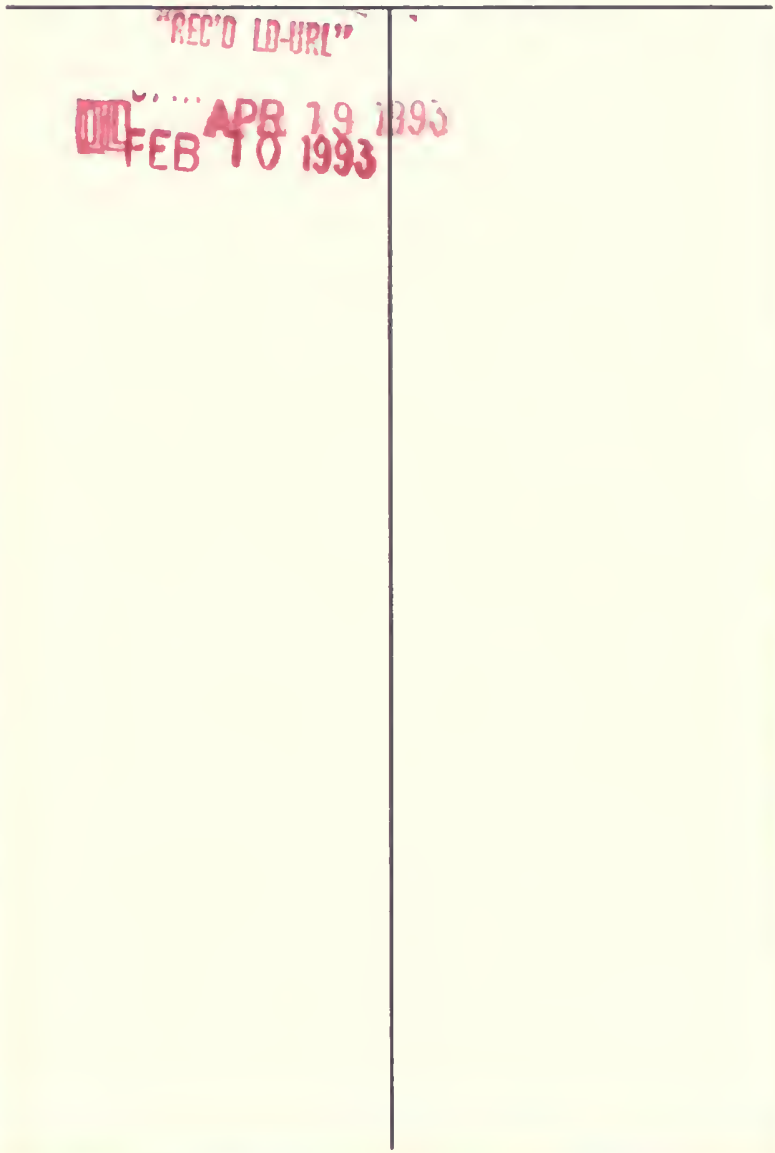


UC soutus an econk \& ewer rnatr

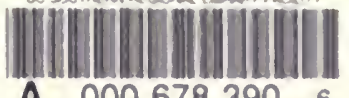

A 0006783906 
Univers

Sout

Lib 